\title{
Energy Conservation via Thioesters in a Non-Enzymatic Metabolism-like Reaction Network
}

\author{
Elodie Chevallot-Beroux, Jan Gorges, Joseph Moran
}

Submitted date: 09/07/2019 - Posted date: 09/07/2019

Licence: CC BY-NC-ND 4.0

Citation information: Chevallot-Beroux, Elodie; Gorges, Jan; Moran, Joseph (2019): Energy Conservation via Thioesters in a Non-Enzymatic Metabolism-like Reaction Network. ChemRxiv. Preprint.

Life's catabolic processes capture chemical energy from the oxidative breakdown of metabolites. In the catabolic pathways at the core of biochemistry, the oxidation of a-ketoacids or aldehydes is coupled to the synthesis of thioesters, whose energy-releasing hydrolysis is in turn coupled to the production of adenosine 5'-triphosphate (ATP). How these processes became linked before life emerged, and thus how the framework for modern bioenergetics was established, is a major problem for understanding the origins of biochemistry. The structure of biochemical networks suggests that the intermediary role of thioesters in biological energy flows, and their central role in biosynthesis, is a consequence of their entry into metabolism at the earliest stage of biochemical evolution. However, how thioesters could have become embedded within a metabolic network before the advent of enzymes remains unclear. Here we demonstrate non-enzymatic oxidant- or light-driven thioester synthesis from biological a-ketoacids and show it can be integrated within an iron-promoted metabolism-like reaction network. The thioesters obtained are those predicted to be pivotal in computational reconstructions of primitive biochemical networks (acetyl, malonyl, malyl and succinyl thioesters), demonstrating a rare convergence between top-down and bottom-up approaches to the origins of metabolism. The diversity and simplicity of conditions that form thioesters from core metabolites suggests the energetic link between thioester synthesis and catabolism was in place at the earliest stage of prebiotic chemistry, constraining the path for the later evolution of life's phosphorus-based energy currencies.

File list (2)

thioesters v14.pdf (220.89 KiB)

view on ChemRxiv - download file

Supporting Information V-14.pdf (6.31 MiB)

view on ChemRxiv • download file 


\section{Energy conservation via thioesters in a non-enzymatic}

2 metabolism-like reaction network

3

\section{Elodie Chevallot-Beroux, ${ }^{\ddagger}$ Jan Gorges, ${ }^{\ddagger}$ Joseph Moran*}

Université de Strasbourg, CNRS, ISIS, 8 allée Gaspard Monge, 67000 Strasbourg, France *moran@unistra.fr, "these authors contributed equally to this work

Life's catabolic processes capture chemical energy from the oxidative breakdown of metabolites. In the catabolic pathways at the core of biochemistry, the oxidation of $\alpha-$ ketoacids or aldehydes is coupled to the synthesis of thioesters, whose energy-releasing hydrolysis is in turn coupled to the production of adenosine 5'-triphosphate (ATP). How these processes became linked before life emerged, and thus how the framework for modern bioenergetics was established, is a major problem for understanding the origins of biochemistry. The structure of biochemical networks suggests that the intermediary role of thioesters in biological energy flows, and their central role in biosynthesis, is a consequence of their entry into metabolism at the earliest stage of biochemical evolution. However, how thioesters could have become embedded within a metabolic network before the advent of enzymes remains unclear. Here we demonstrate non-enzymatic oxidant- or light-driven thioester synthesis from biological a-ketoacids and show it can be integrated within an ironpromoted metabolism-like reaction network. The thioesters obtained are those predicted to be pivotal in computational reconstructions of primitive biochemical networks (acetyl, malonyl, malyl and succinyl thioesters), demonstrating a rare convergence between top-down and bottom-up approaches to the origins of metabolism. The diversity and simplicity of conditions that form thioesters from core metabolites suggests the energetic link between thioester synthesis and catabolism was in place at the earliest stage of prebiotic chemistry, constraining the path for the later evolution of life's phosphorus-based energy currencies.

A major goal of origins of life research is to understand how and why chemistry selforganized into today's biochemistry. ${ }^{1,2,3}$ The recent discovery of chemical reaction networks that break or form bonds in ways closely resembling biochemistry suggests that core metabolic pathways emerged from simpler non-enzymatic precursors, providing a straightforward explanation for why biochemistry came to be the way it is. ${ }^{4,5,67,8,9,10}$ However, non-enzymatic 
reaction networks that combine metabolite synthesis with life's ability to capture chemical energy from catabolic (breakdown) processes have yet to be demonstrated.

The hydrolysis of thioesters is highly exergonic, which allows them to occupy a central position in biosynthesis and to act as life's sulfur-based energy carriers. ${ }^{11}$ Accordingly, thioesters are thought to have played a dominant role in early biochemical evolution - a concept that De

37 Duve dubbed the "Thioester World". ${ }^{12,13,14}$ In biology, two of the main catabolic routes for thioester synthesis are the oxidative decarboxylation of $\alpha$-ketoacids and the oxidation of aldehydes, both of which employ the thiol cofactor $\mathrm{A}(\mathrm{CoA})$, and which constitute key steps in core metabolic pathways such as the Krebs cycle and glycolysis (Figure 1). Recent

41 computational predictions, based on the network structure and thermodynamics of all documented metabolic reactions, also support the existence of an early metabolic network hinging on thioesters. ${ }^{15,16}$ Specifically, acetyl, malonyl, malyl and succinyl thioesters were predicted to emerge within or from a reaction network resembling a primitive (reverse) Krebs cycle. ${ }^{16}$ Here we show that the same thioesters can be produced non-enzymatically from biological $\alpha$-ketoacids and integrated into a Krebs cycle-like chemical reaction network, in good agreement with computational predictions about the structure of primitive metabolism. ${ }^{15,16}$ 
A
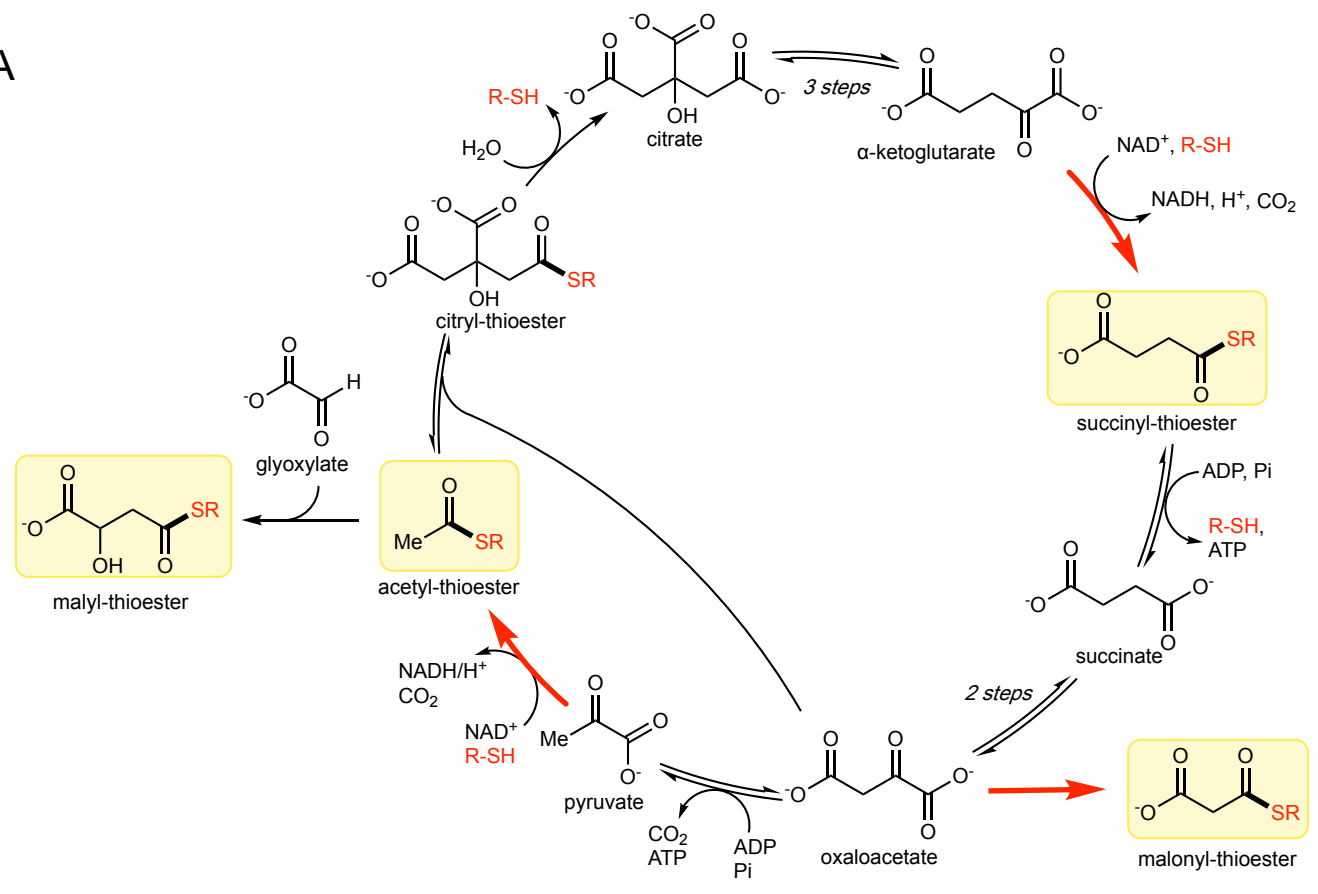

B

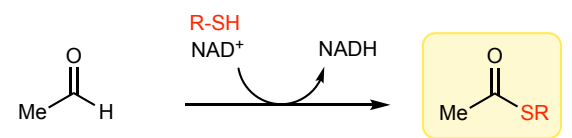

acetyl-thioester

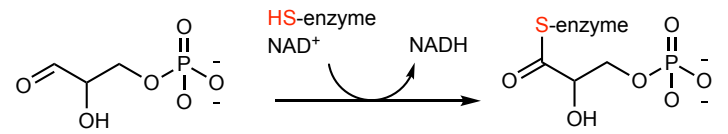

glyceraldehyde 3-phosphate

C

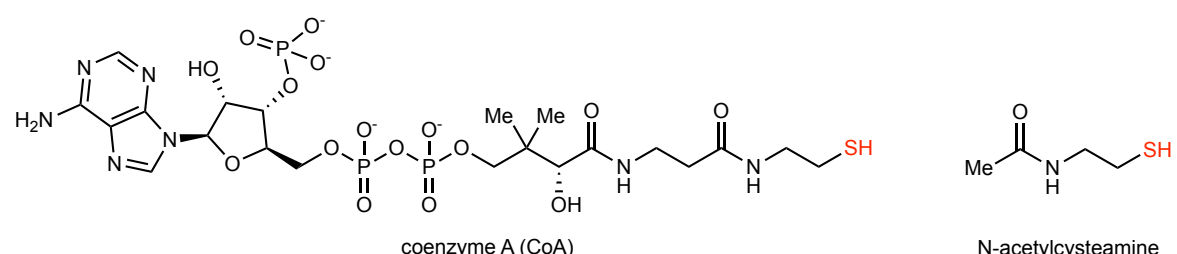

$$
\text { coenzyme A (CoA) }
$$

$\mathrm{N}$-acetylcysteamine

Figure 1 Energy conservation via thioesters in biosynthesis. A) Thioester synthesis in the Krebs cycle. Oxidative decarboxylations of $\alpha$-ketoacids are highlighted using red arrows. Additional biological reactions, such as the aldol reaction of acetyl thioester with glyoxylate to give malyl thioester, are also shown. A similar network was predicted to have been at the core of primitive metabolism, by starting from simple seed molecules and applying a thermodynamically constrained network expansion algorithm to grow the network using known biological reactions. ${ }^{16}$ B) Thioester synthesis via aldehyde oxidation in alcohol metabolism and glycolysis. C) Nature's most important thiol, coenzyme A (CoA) and a simpler analogue used in this study, $\mathrm{N}$-acetylcysteamine.

Experimental work on prebiotic thioester synthesis is limited, with the most important examples arising from aldehydes ${ }^{17,18,19,20}$ or acetyl thioester synthesis from carbon monoxide and methyl thiol in very low yields. ${ }^{21}$ Inspired by the synthetic organic chemistry literature, ${ }^{22,23}$ we searched for simple aqueous inorganic conditions that might enable thioester synthesis from $\alpha$ ketoacids and thiols. Our initial investigations focused on the reaction between pyruvate, the prebiotically plausible biological precursor to sugars and several amino acids, , ,5,6,24 and $\mathrm{N}$ - 
acetylcysteamine, a simpler, potentially ancestral, ${ }^{25}$ analogue of CoA. Optimization of oxidizing agent, catalyst, and temperature (see Table S-1) converged on sulfate radical-generating conditions identical to those reported to drive Krebs cycle-like breakdown of core metabolites ${ }^{5}$ $\left(\mathrm{S}_{2} \mathrm{O}_{8}{ }^{2-}\right.$ as oxidant, FeS as catalyst, $\left.70{ }^{\circ} \mathrm{C}\right)$, giving the corresponding acetyl thioester in $27 \%$ yield (Table 1, entry 1 , method A). The remaining material was found mostly to be unreacted pyruvate and a small amount of acetate, according to GC-MS and NMR analysis (Table S-2). Thioester synthesis could equally be carried out with another water-soluble thiol (Scheme S-3), or with a disulfide instead of a thiol (entry 2, method A). Two other key intermediates of the Krebs cycle, $\alpha$ ketoglutarate and oxaloacetate also underwent decarboxylative thioesterification to give the corresponding succinyl thioester, an analogue of the biosynthetic precursor to many co-factors, and malonyl thioester, an analogue of the precursor to biological fatty acid synthesis, respectively (entries 3-4, method A). Malonyl thioester formation is accompanied by decarboxylation to give acetyl thioester as a secondary product (entry 4). Malyl thioester was also formed under the same conditions starting from 4-hydroxyketoglutarate (entry 5, method A). UV-A light, thought to have constituted a significant portion of the solar spectrum on the early Earth, ${ }^{26}$ was equally able to generate sulfate radicals from $\mathrm{S}_{2} \mathrm{O}_{8}{ }^{2-}$, and therefore to deliver thioesters from $\alpha$-ketoacids at ambient temperature (entries 1-5, method B). Alternatively, UV-A light alone was found to trigger thioester formation under acidic conditions (entries 1-5, method C). In this case however, the reduced reactivity with disulfides suggests the mechanism is distinct from the light-triggered reaction in the presence of $\mathrm{S}_{2} \mathrm{O}_{8}{ }^{2-}$ (entry 2 , method $\left.\mathrm{C}\right)$. The direct photochemical reaction was found to be independent of the chemical nature of the acid (Table S-1), ruling out the involvement of photogenerated sulfate radicals from bisulfate. ${ }^{27}$ Acetaldehyde, a representative aldehyde, was also found to furnish acetyl thioester under thermal and photochemical sulfate radical-forming conditions (entry 6 , methods $A-B$ ), as well as under direct photochemical conditions similar to those previously reported by Weber (entry 6 , method C) ${ }^{17}$ Thus, all three 
Table 1. Thioester formation from biological $\alpha$-ketoacids or aldehydes and $\mathbf{N}$-acetylcysteamine.

\begin{tabular}{|c|c|c|c|c|c|}
\hline \multirow{2}{*}{ Entry } & \multirow{2}{*}{ Substrate } & \multirow{2}{*}{ Thioester Product(s) } & \multicolumn{3}{|c|}{ Product Yield $(\%) \pm \mathrm{SD}^{\ddagger}$} \\
\hline & & & Method $A^{a}$ & Method $\mathrm{B}^{\mathrm{b}}$ & Method $C^{c}$ \\
\hline 1 & pyruvate & acetyl thioester & $27 \pm 1$ & $31.2 \pm 0.4$ & $22.1 \pm 0.4$ \\
\hline $2^{d}$ & pyruvate & acetyl thioester & $34 \pm 1$ & $32 \pm 2$ & $4.9 \pm 0.2$ \\
\hline 3 & a-ketoglutarate & succinyl thioester & $10 \pm 2$ & $25 \pm 2$ & $13 \pm 1$ \\
\hline \multirow[t]{2}{*}{4} & oxaloacetate & malonyl thioester & $6.7 \pm 0.4$ & $24 \pm 2$ & $8 \pm 2$ \\
\hline & & acetyl thioester & $2.6 \pm 0.3$ & $2.4 \pm 0.3$ & $<0.5$ \\
\hline 5 & hydroxyketoglutarate $\mathrm{e}^{\mathrm{e}}$ & malyl thioester & $2.0 \pm 0.1$ & $10 \pm 1$ & $3.5 \pm 0.2$ \\
\hline 6 & acetaldehyde $^{f}$ & acetyl thioester & $15 \pm 1$ & $13 \pm 2$ & $20 \pm 2$ \\
\hline
\end{tabular}

\begin{abstract}
${ }^{\ddagger}$ Reported values were determined by GC-FID after an extraction procedure or by LCMS and represent the average of at least three runs. SD = standard deviation. See the Supplementary Information for additional control experiments. Unless otherwise

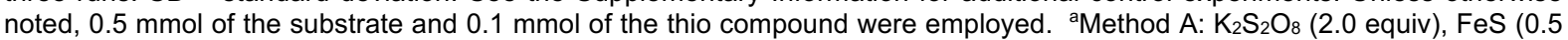
equiv) in $\mathrm{H}_{2} \mathrm{O}, 3 \mathrm{~h}, 70^{\circ} \mathrm{C}$. ${ }^{\mathrm{b}}$ Method $\mathrm{B}: \mathrm{K}_{2} \mathrm{~S}_{2} \mathrm{O}_{8}$ (2.0 equiv), $\mathrm{FeS}$ (0.5 equiv) in $\mathrm{H}_{2} \mathrm{O}, 6 \mathrm{~h}$, UV-A. ${ }^{\circ}$ Method $\mathrm{C}$ : $\mathrm{KHSO}_{4}(3 \mathrm{M})$ in $\mathrm{H}_{2} \mathrm{O}, 6$ h, UV-A. ${ }^{d} 0.05 \mathrm{mmol}$ of $\mathrm{N}$-acetyl cysteamine disulfide was used instead of $\mathrm{N}$-acetyl cysteamine. ${ }^{\text {eHydroxyketoglutarate was }}$ freshly prepared from glyoxylate and oxaloacetate without isolation. ${ }^{f} 1.0 \mathrm{mmol}$ of the substrate were used.
\end{abstract}

91

We recently reported an iron-promoted non-enzymatic reaction network in which most Krebs cycle metabolites are formed from pyruvate and glyoxylate, including other $\alpha$-ketoacids. ${ }^{8}$ To mimic the biological integration of $\alpha$-ketoacid synthesis, $\alpha$-ketoacid breakdown and thioester synthesis, we simulated non-equilibrium environments where material could cycle between neutral and oxidized regions, or between dark and light regions. In a first experiment, pyruvate, glyoxylate, ferrous iron and $\mathrm{N}$-acetylcysteamine were mixed in water at $70^{\circ} \mathrm{C}$ for $1 \mathrm{~h}$, after which time $\mathrm{K}_{2} \mathrm{~S}_{2} \mathrm{O}_{3}$ was added and the reaction continued without changing the temperature. At $4 \mathrm{~h}$, acetyl (1.4 mM), succinyl $(0.1 \mathrm{mM})$ and malyl $(3.6 \mathrm{mM})$ thioesters were detected, as well as 8 carboxylic acid metabolites (Table S-3). In a second experiment, pyruvate, glyoxylate and ferrous iron were mixed in water at $70{ }^{\circ} \mathrm{C}$ for $1 \mathrm{~h}$, after which time $\mathrm{N}$-acetylcysteamine and $\mathrm{KHSO}_{4}$ were added and the reaction was exposed to UV-A light at $22^{\circ} \mathrm{C}$. At $7 \mathrm{~h}$, acetyl $(0.1 \mathrm{mM})$, succinyl $(0.2 \mathrm{mM})$ and malyl $(0.06 \mathrm{mM})$ thioesters were detected, as well as 5 carboxylic acid metabolites (Table S-3). Thus, different types of non-equilibrium environments (neutral/oxidized or dark/light) can lead to a non-enzymatic reaction network in which $\alpha$-ketoacid and thioester synthesis are coupled, as in biochemistry (Figure 2). 


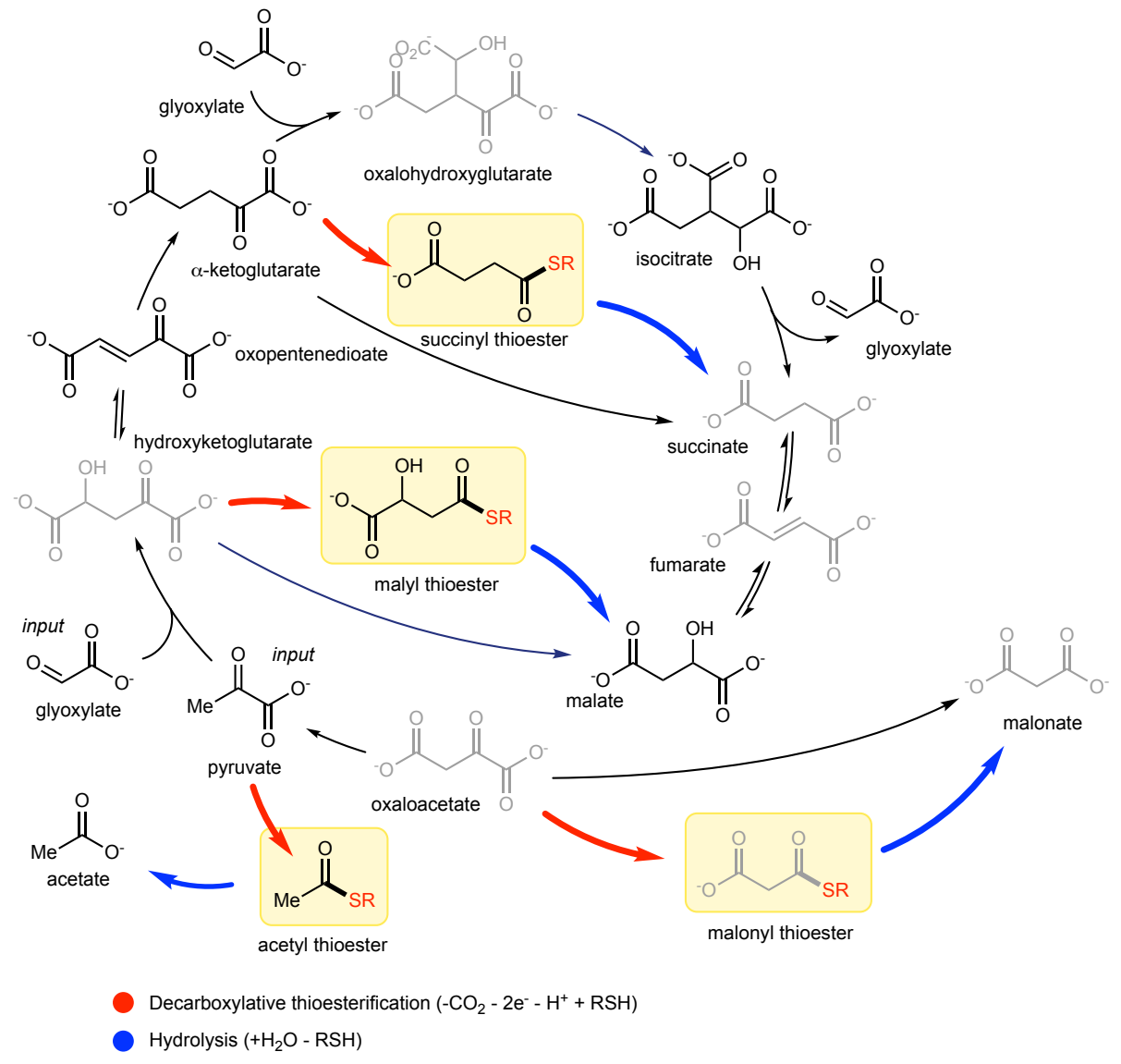

Figure 2 Thioester formation from an iron-catalysed reaction network generated from pyruvate, glyoxylate and $\mathrm{N}$-acetylcysteamine, achieved through redox or light cycling. Molecules in black represent those observed in the presence of $\mathrm{Fe}^{2+}$, thiol and oxidant. Molecules in grey represent those observed in the presence of $\mathrm{Fe}^{2+}$ only. Additional reactions and observed metabolites have been omitted for clarity.

In summary, inorganic oxidants or light enable non-enzymatic thioester synthesis from metabolites in a way that closely mimics energy conservation within biological catabolism, and that is integrated with metabolite-generating chemical networks. Synthesis and breakdown of metabolites could have been linked in an energy-conserving way from the outset of prebiotic chemistry, in accord with computational models of an "onion-like" growth of metabolism from one initially based on $\mathrm{C}, \mathrm{H}$, and $\mathrm{O}$ to one incorporating $\mathrm{S}, \mathrm{N}$, and then $\mathrm{P} .{ }^{12,13,15,16}$ The simplicity of the conditions observed here suggest thioester synthesis would have been difficult to avoid in any near-surface environment where light, $\alpha$-ketoacids or aldehydes and thiols were present. A primitive form of bioenergetics built around thioesters therefore may have emerged very early on, setting the stage for the complex life-like behaviours characteristic of thioester networks, ${ }^{28,29}$ and imposing constraints on later chemical energy currencies based on phosphorous. Finally, 
127 hydrogen-rich geochemical environments where reductive metabolite synthesis ${ }^{6}$ could occur

128 within proximity of oxidants or light, such as surface hydrothermal vents, warrant consideration

129 for the origin of life. ${ }^{30}$

130

131 Funding: This project has received funding from the European Research Council (ERC) under

132 the European Union's Horizon 2020 research and innovation programme (grant agreement $\mathrm{n}^{\circ}$

133 639170) and from ANR LabEx "Chemistry of Complex Systems" (ANR-10-LABX-0026 CSC).

134 Acknowledgements: J.-L. Schmitt and C. Antheaume are gratefully acknowledged for

135 assistance with LC-MS and GC experiments. We also thank M. Coppe for help with the NMR

136 experiments.

137 Author contributions: J.M. supervised the research and the other authors performed the

138 experiments. All authors contributed intellectually throughout the study. All authors wrote the

139 paper and E.C.-B. and J.G. assembled the Supplementary information.

140 Competing financial interests: Authors declare no competing financial interests.

141 Data and materials availability: All data is available in the main text or the supplementary

142 information file.

143 Supplementary Information:

144 Materials and Methods

145 Figures S-1 to S-9

146 Tables S-1 to S-3

147 Scheme S-1 to S-4

148 References

${ }^{1} \mathrm{G}$ Wächtershäuser, Evolution of the first metabolic cycles, Proceedings of the National Academy of Sciences 87, 200-204 (1990).

${ }^{2}$ E. Smith \& H. J. Morowitz, Universality in intermediary metabolism, Proceedings of the National Academy of Sciences of the United States of America 101, 13168-13173 (2004).

${ }^{3}$ W. F. Martin \& M. J. Russell, On the origin of biochemistry at an alkaline hydrothermal vent. Philosophical Transactions of the Royal Society B 362, 1887-1925 (2007). 
${ }^{4}$ S. J. Varma, K. B. Muchowska, P. Chatelain \& J. Moran, Native iron reduces $\mathrm{CO}_{2}$ to intermediates and end-products of the acetyl-CoA pathway, Nature Ecology \& Evolution 2, 10191024 (2018).

${ }^{5} \mathrm{~A}$ Roldan et al., Bio-inspired $\mathrm{CO}_{2}$ conversion by iron sulfide catalysts under sustainable conditions, Chemical Communications 51, 7501-7504 (2015).

${ }^{6} \mathrm{M}$. Preiner et al. A hydrogen dependent geochemical analogue of primordial carbon and energy metabolism. BioRxiv doi: 10.1101/682955 (2019).

${ }^{7}$ M. A. Keller, D. Kampjut, S. A. Harrison \& M. Ralser, Sulfate radicals enable a non-enzymatic Krebs cycle precursor, Nature Ecology \& Evolution 1, 0083 (2017).

${ }^{8}$ K. B Muchowska, S. J. Varma, \& J. Moran, Synthesis and breakdown of universal metabolic precursors promoted by iron, Nature 569, 104-107 (2019).

${ }^{9}$ K. B. Muchowska et al., Metals promote sequences of the reverse Krebs cycle, Nature Ecology \& Evolution 1, 1716-1721 (2017).

${ }^{10}$ M. Keller, A. Turchyn \& M. Ralser, Non-enzymatic glycolysis and pentose phosphate pathwaylike reactions in a plausible Archean ocean, Mol Syst Biol 10, 725-725 (2014).

${ }^{11}$ Biochemistry: The Chemical Reactions of Living Cells, David E. Metzler, Volume 1, Second Edition

12 De Duve, C. Blueprint for a cell: The nature and origin of life. (Neil Patterson Publishers, 1991).

${ }^{13} \mathrm{H}$. Hartman, Speculations on the origin and evolution of metabolism, Journal of Molecular Evolution 4, 359-370 (1975)

${ }^{14}$ D. Deamer, A. L. Weber, Bioenergetics and life's origin. Cold Spring Harb Perspect Biol 2, a004929 (2010).

15 J. E. Goldford, H. Hartman, T. F. Smith \& D. Segrè, Remnants of an Ancient Metabolism without Phosphate, Cell 168, 1126-1134 (2017).

${ }^{16}$ J. E. Goldford, H. Hartman, R. Marsland III \& D. Segrè, Boundary conditions for early life converge to an organo-sulfur metabolism, bioRxiv, doi: 10.1101/487660 
${ }^{17}$ A. L. Weber, Prebiotic formation of "energy-rich" thioesters from glyceraldehyde and $\mathrm{N}$ acetylcysteine. Orig. Life. Evol Biosph. 15, 17-27 (1984).

${ }^{18}$ M. Takagi, S. Goto, T. Matsuda, Photo-reaction of lipoic acid and related organic disulphides: reductive acylation of aldehydes, J. Chem. Soc. Chem. Commun. 92-93 (1976).

${ }^{19}$ A. L. Weber, Prebiotic amino acid thioester synthesis: thiol-dependent amino acid synthesis from formose substrates and ammonia. Orig. Life Evol. Biospheres 28, 259-270 (1998).

${ }^{20}$ A. L. Weber, Nonenzymatic formation of "energy-rich" lactoyl and glyceroyl thioesters from glyceraldehyde and a thiol. J. Mol. Evol. 20, 157-166 (1984).

${ }^{21}$ C. Huber, G. Wächtershäuser, Activated acetic acid by carbon fixation on (Fe,Ni)S under primordial conditions. Science 276, 245-247 (1997).

${ }^{22}$ G. Rong, J. Mao, D. Liu, H. Yan, Y. Zheng, J. Chen, Formation of C(sp2)-S bonds through decarboxylation of a-oxocarboxylic acids with disulfides or thiophenols, RSC Adv. 5, 2646126464 (2015).

${ }^{23}$ K. Yan, D. Yang, W. Wei, J. Zhao, Y. Shuai, L. Tian, H. Wang, Catalyst-free direct decarboxylative coupling of $\alpha$-keto acids with thiols: a facile access to thioesters, Org. Biomol. Chem. 13, 7323-7330 (2015).

${ }^{24}$ Coggins, A. \& Powner, M. Prebiotic synthesis of phosphoenol pyruvate by a-phosphorylationcontrolled triose glycolysis. Nat Chem 9, 310-317 (2016).

${ }^{25}$ Atomi, H., Tomita, H., Ishibara, T., Yokooji, Y., Imanaka, T. CoA biosynthesis in archea. Biochem. Soc. Trans. 41, 427-431 (2013).

${ }^{26}$ P. A. Karam, Inconstant sun: how solar evolution has affected cosmic and ultraviolet radiation exposure over the history of life on Earth, Health Phys. 84, 322-333 (2003).

${ }^{27}$ J. Barrett, M. F. Fox, A. L. Mansell, The photochemistry of aqueous sulfate ion, J. Phys. Chem. 69, 2996-3000 (1965).

${ }^{28} \mathrm{~S}$. N Semenov et al. Autocatalytic, bistable, oscillatory networks of biologically relevant organic reactions, Nature 537, 656-660 (2016).

${ }^{29} \mathrm{H}$. Jakubowski, Homocysteine Editing, Thioester Chemistry, Coenzyme A, and the Origin of Coded Peptide Synthesis, Life 7, 6 (2017). 
${ }^{30}$ P. B. Rimmer; O. Shorttle, Origin of life's building blocks in carbon- and nitrogen-rich surface hydrothermal vents, Life 9, 12 (2019). 
Supporting Information

\title{
Energy conservation via thioesters in a non-enzymatic metabolism-like reaction network
}

\author{
Elodie Chevallot-Beroux, Jan Gorges, ${ }^{\ddagger}$ Joseph Moran* \\ Université de Strasbourg, CNRS, ISIS UMR 7006, F-67000 Strasbourg, France \\ moran@unistra.fr, "these authors contributed equally to this work
}




\section{Content}

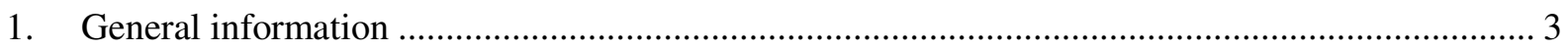

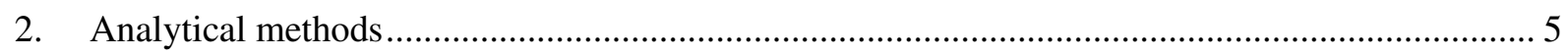

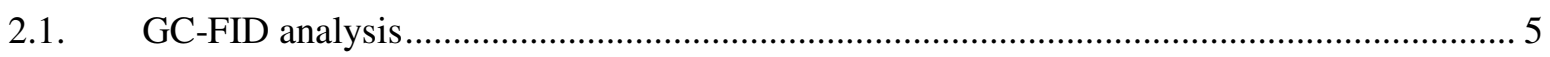

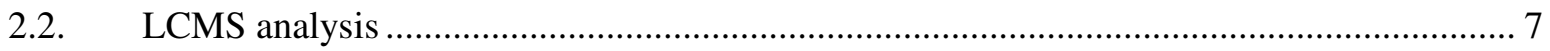

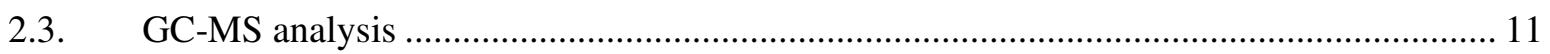

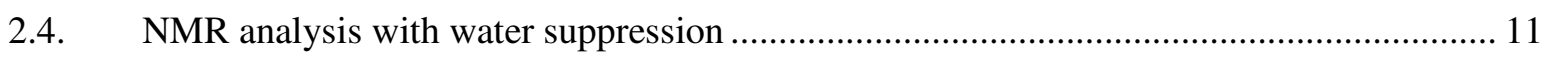

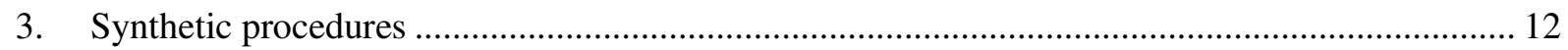

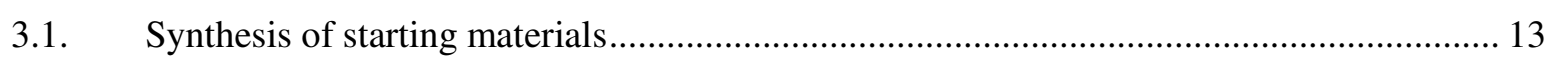

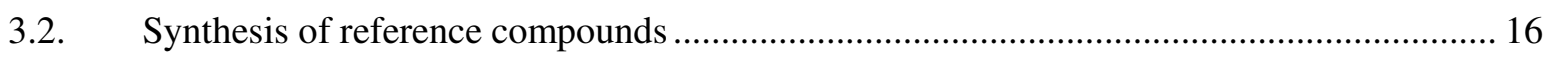

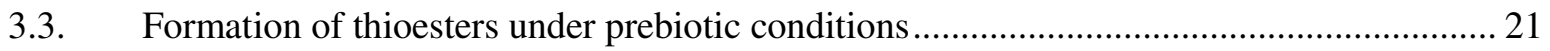

3.4 Thioester formation from a non-enzymatic reaction network ........................................ 27

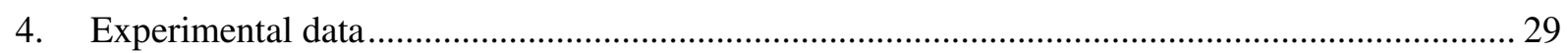

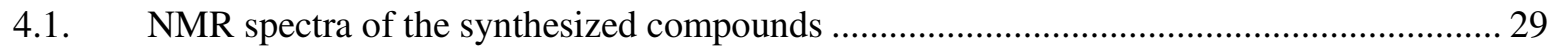

4.2. NMR spectra of reference compds. in $\mathrm{H}_{2} \mathrm{O} / \mathrm{D}_{2} \mathrm{O}$ with DSS as IS with water suppression.. 40

4.3. NMR spectra of selected reaction mixtures showing prebiotic thioester formations ........... 48

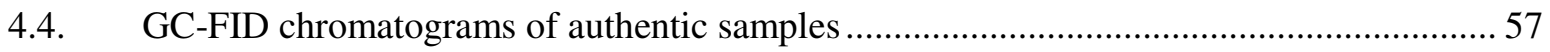

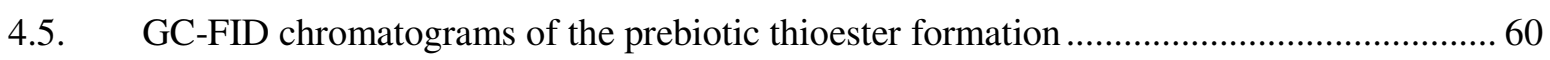

4.6. GC-FID chromatograms of the network combined with thioester formation ..................... 68

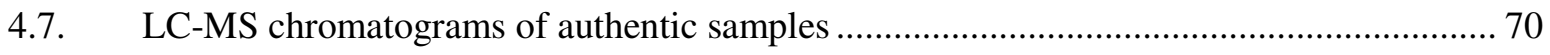

4.8. LC-MS chromatograms of thioester formation under prebiotic conditions ........................ 76

4.9. LC-MS chromatograms of the network combined with thioester formation ...................... 82

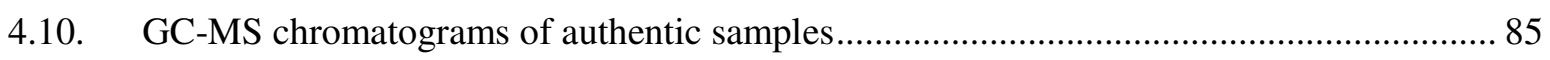

4.11. GC-MS chromatograms of the network after thioester formation ..................................... 86

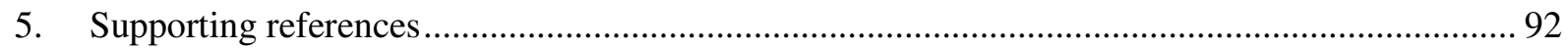




\section{General information}

All reactions were carried out in oven dried glassware under an atmosphere of argon. All glassware and stir bars were pre-washed with acid, followed by distilled water and acetone, and oven dried to prevent any cross-contamination by metal salts. Unless otherwise noted, all reagents and solvents were purchased from commercial suppliers and used without further purification. Water was obtained from a Milli-Q purification system (18 $\mathrm{M} \Omega \mathrm{cm})$ and was purged with argon before use.

For water suppression ${ }^{1} \mathrm{H}-\mathrm{NMR}$ spectra were recorded on a Bruker Avance300 (300 $\left.\mathrm{MHz}\right)$ spectrometer at ambient temperature in a $\mathrm{H}_{2} \mathrm{O}: \mathrm{D}_{2} \mathrm{O}$ mixture (6:1) as solvent, with sodium 3(trimethylsilyl)-1-propanesulfonate (DSS) as the internal standard (TMS peak at $0 \mathrm{ppm}$ ). Solvent suppression was achieved through excitation sculpting, using the Bruker ZGESGP pulse program adjusted for the water resonance. Integration was performed using ACD/NMR Processor Academic Version 12.00 software.

Regular ${ }^{1} \mathrm{H}$ - and ${ }^{13} \mathrm{C}-\mathrm{NMR}$ spectra were recorded on a Bruker Avance300 (300 MHz), Bruker UltraShield $400(400 \mathrm{MHz})$ or a Bruker Avance $500(500 \mathrm{MHz})$ spectrometer at ambient temperature and are reported in ppm using the solvent signal as internal reference $\left(\mathrm{CDCl}_{3}\right.$ at $7.26 \mathrm{ppm}\left({ }^{1} \mathrm{H}\right)$ or $77.00 \mathrm{ppm}\left({ }^{13} \mathrm{C}\right)$, DMSO- $\mathrm{d}_{6}$ at $2.50 \mathrm{ppm}\left({ }^{1} \mathrm{H}\right)$ or $\left.39.51 \mathrm{ppm}\left({ }^{13} \mathrm{C}\right)\right)$. Data are reported as: multiplicity (br. $\mathrm{s}=$ broad singlet, $\mathrm{s}=$ singlet, $\mathrm{d}=$ doublet, $\mathrm{t}=$ triplet, $\mathrm{q}=$ quartet, $\mathrm{m}=$ multiplet), coupling constants (in $\mathrm{Hz}$ ) and integration. Melting points were obtained on a Büchi Melting Point B-450 apparatus without correction. High resolution mass spectrometry (HRMS) analysis was performed on a Bruker MicroTOF-Q (ESI) instrument.

LC-MS analysis was performed on a ThermoFisher Scientific UltiMate 3000 UHPLC-system equipped with an $\mathrm{C}_{18}$ ThermoFisher Hypersil Gold $10 \mathrm{~mm}$ column using an Exactive Plus EMR Orbitrap detector. Acetonitrile (+ $0.1 \%$ formic acid) and water $(+0.1 \%$ formic acid) were used for the mobile phase. The column was maintained at $25{ }^{\circ} \mathrm{C}$ and the solvent gradient was used as following: $2 \% \mathrm{MeCN}$ for $1 \mathrm{~min}$, linear gradient to $15 \% \mathrm{MeCN}$ over $3.5 \mathrm{~min}$, linear gradient to $100 \%$ $\mathrm{MeCN}$ over $1 \mathrm{~min}, 100 \% \mathrm{MeCN}$ for $2.5 \mathrm{~min}$, linear gradient to $2 \% \mathrm{MeCN}$ over $0.5 \mathrm{~min}, 2 \% \mathrm{MeCN}$ for $1.5 \mathrm{~min}$. The analytes were quantified using a calibration of authentic samples by integration of the peak area of a specified $\mathrm{m} / \mathrm{z}$ range. Unless otherwise noted $0.1 \mu \mathrm{L}$ of the sample solutions were injected.

GC-MS analysis was performed on a GC System 7820A (G4320) using an Agilent High Resolution Gas Chromatography Column (PN 19091S - 433UI, HP - 5MS UI, $28 \mathrm{~m} \times 0.250$ mm, 0.25 Micron, SN USD 489634H). The system was connected to an MSD block 5977E (G7036A). Hydrogen (99.999 \% purity) was used as carrier gas at a constant flow rate of $1.5 \mathrm{~mL} / \mathrm{min}$. The analysis was carried out in a splitless mode with $1 \mu \mathrm{L}$ injection volume, at the injection port temperature of $250{ }^{\circ} \mathrm{C}$. The column was maintained at $60{ }^{\circ} \mathrm{C}$ for $1 \mathrm{~min}$, then ramped at $30^{\circ} \mathrm{C} / \mathrm{min}$ to $310{ }^{\circ} \mathrm{C}$ with $3 \mathrm{~min}$ hold, and the total 
running time was $12.33 \mathrm{~min}$. The mass spectrometer was turned on after a 2-min solvent delay, and was operated at the electron ionization (EI) mode with quadrupole temperature of $150{ }^{\circ} \mathrm{C}$. Data was acquired in the full-scan mode (50-500 amu).

GC-FID analysis was performed on a GC System GC7890B with an FID-detector using an Agilent High Resolution Gas Chromatography Column (PN 19091S - 433UI, HP - 5MS UI, $28 \mathrm{~m} \times 0.250 \mathrm{~mm}$, 0.25 Micron, SN USD 489634H). Hydrogen (99.999 \% purity) was used as carrier gas at a constant flow rate of $5.0 \mathrm{~mL} / \mathrm{min}$. The analysis was carried out in a splitless mode with $1 \mu \mathrm{L}$ injection volume, at the injection port temperature of $250{ }^{\circ} \mathrm{C}$. The column was maintained at $60{ }^{\circ} \mathrm{C}$ for $1 \mathrm{~min}$, then ramped at $30{ }^{\circ} \mathrm{C} / \mathrm{min}$ to $300{ }^{\circ} \mathrm{C}$ with $3 \mathrm{~min}$ hold, and the total running time was $12 \mathrm{~min}$. The FID detector was used with an airflow of $400 \mathrm{~mL} / \mathrm{min}$, a $\mathrm{H}_{2}$ fuel flow of $25 \mathrm{~mL} / \mathrm{min}$ and a $\mathrm{N}_{2}$ makeup flow of $10 \mathrm{~mL} / \mathrm{min}$. The software used was Agilent OpenLAB CDS ChemStation Edition Rev. C.01.09[144]. 


\section{Analytical methods}

\subsection{GC-FID analysis}

\section{Extraction procedure for GC-FID analysis}

A $0.5 \mathrm{~mL}$ aliquot of the reaction mixture was added to $0.5 \mathrm{~mL}$ of EA, followed by vortexing for $30 \mathrm{~s}$. The EA layer was separated and dried over anhydrous $\mathrm{Na}_{2} \mathrm{SO}_{4} .40 \mu \mathrm{L}$ of the dry EA layer was diluted with $960 \mu \mathrm{L}$ of EA and subjected to GC-FID analysis.

\section{Yield determination and error analysis for GC-FID analysis}

$1 \mathrm{~mL}$ standard aqueous solutions of thioesters at different concentrations $(1 \mathrm{mM}, 2 \mathrm{mM}, 5 \mathrm{mM}, 10$ $\mathrm{mM}, 20 \mathrm{mM}, 40 \mathrm{mM}$ ) were prepared by dilution $100 \mathrm{mM}$ stock solutions of these thioesters. $500 \mu \mathrm{L}$ of each standard solution were extracted using the above described extraction procedure for GC-FID analysis. For each thioester, a six-point graph was plotted, correlating the characteristic GC peak (as integrated automatically by the Agilent OpenLAB CDS ChemStation Edition Rev. C.01.09[144] software) with substrate concentration (Figure S-1 - S-2). Each data point was obtained from three independent measurements and the correlation line was obtained from the least-squares fitting (intercept $=0$ ). Error bars on graphs are shown as \pm standard deviation for each data point. Overall percentage error of the response factor corresponds to \pm standard deviation for each slope value.

The concentrations of the compounds were calculated by comparing the product peak area with the calibration curve. The yields of the products were calculated by multiplication of the determined concentration with the reaction volume, divided by the amount of limiting starting material (in most cases $0.1 \mathrm{mmol}$ of the thio compound). Each reaction was performed at least three times to ensure reproducibility and reported percentage yields are an average of these three runs, with an error corresponding to \pm standard deviation. 


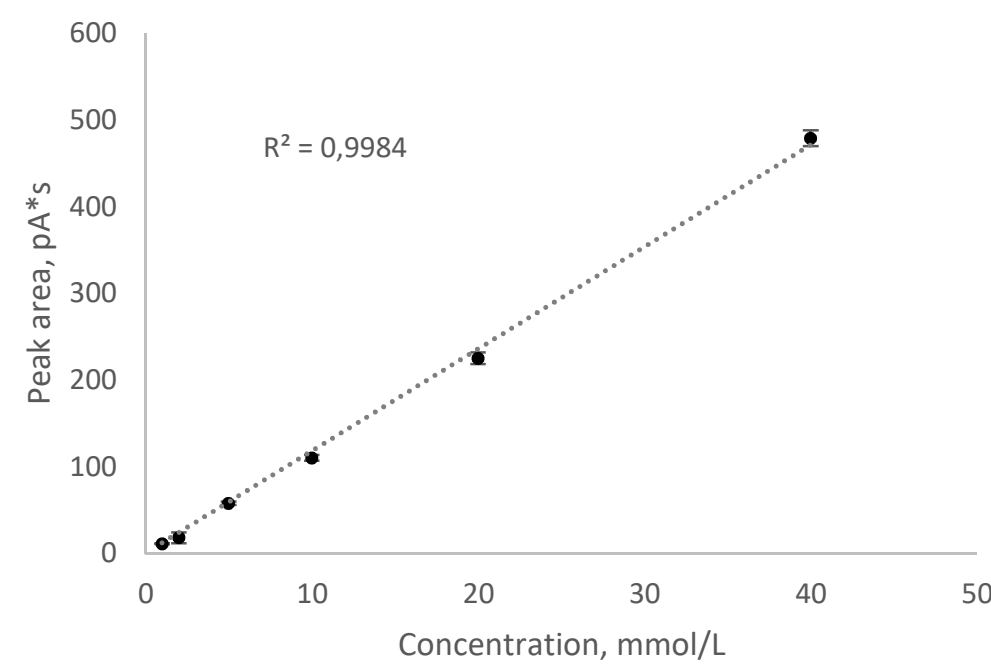

$N, S$-diacetyl cysteamine (3b)

Response factor: 11.773

Figure S-1: Correlation between the concentration of an aqueous solution of $\mathbf{3 b}$ and the measured gas chromatography FID peak area.

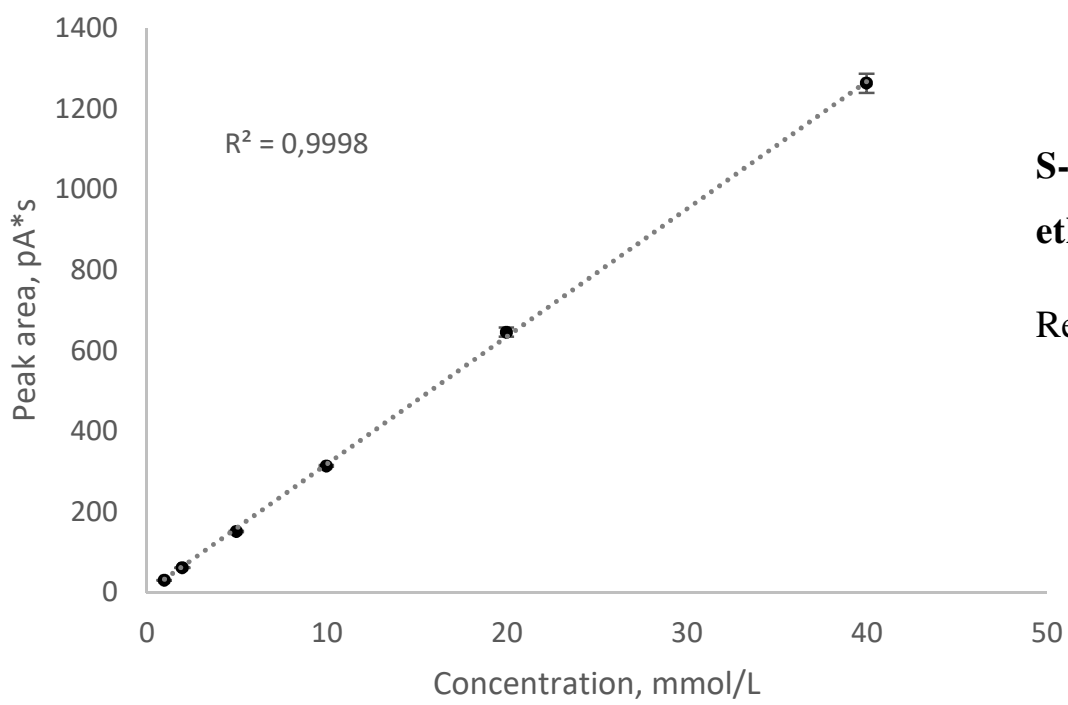

Figure S-2: Correlation between the concentration of an aqueous solution of $\mathbf{3 c}$ and the measured gas chromatography FID peak area. 


\subsection{LCMS analysis}

\section{Sample preparation of LCMS analysis}

After treatment of $1 \mathrm{~mL}$ of the reaction mixture with Chelex ${ }^{\circledR} 100$ resin followed by centrifugation 20 $\mu \mathrm{L}$ of the supernatant were diluted with $180 \mu \mathrm{L}$ of MilliQ-water and subjected to LCMS analysis (injection volume $=0.1 \mu \mathrm{L}$ unless otherwise noted).

\section{Yield determination and error analysis for LCMS analysis}

$1 \mathrm{~mL}$ standard aqueous solutions of authentic samples at different concentrations (selection of 0.5 $\mathrm{mM}, 1 \mathrm{mM}, 2 \mathrm{mM}, 4 \mathrm{mM}, 5 \mathrm{mM}, 10 \mathrm{mM}, 20 \mathrm{mM}, 40 \mathrm{mM}, 80 \mathrm{mM}$ ) were prepared by dilution of 100 $\mathrm{mM}$ stock solutions of these compounds. For each of these solutions $20 \mu \mathrm{L}$ were diluted with $180 \mu \mathrm{L}$ MilliQ-water and subjected to LCMS-analysis. For each compound, a six-point graph was plotted, correlating the characteristic LCMS-peak (as integrated by the Thermo Xcalibur 4.2.28.14 Qual Browser software) with substrate concentration (Figure S-3 - S-7). Each data point was obtained from three independent measurements and the correlation line was obtained from the least-squares fitting (intercept $=0$ ). Error bars on graphs are shown as \pm standard deviation for each data point. Overall percentage error of the response factor corresponds to \pm standard deviation for each slope value.

The concentrations of the compounds were calculated by comparing the product peak area with the calibration curve. The yields of the products were calculated by multiplication of the determined concentration with the reaction volume, divided by the amount of limiting starting material (in most cases $0.1 \mathrm{mmol}$ of the thio compound). Each reaction was performed at least three times to ensure reproducibility, and reported percentage yields are an average of these three runs, with an error corresponding to \pm standard deviation.

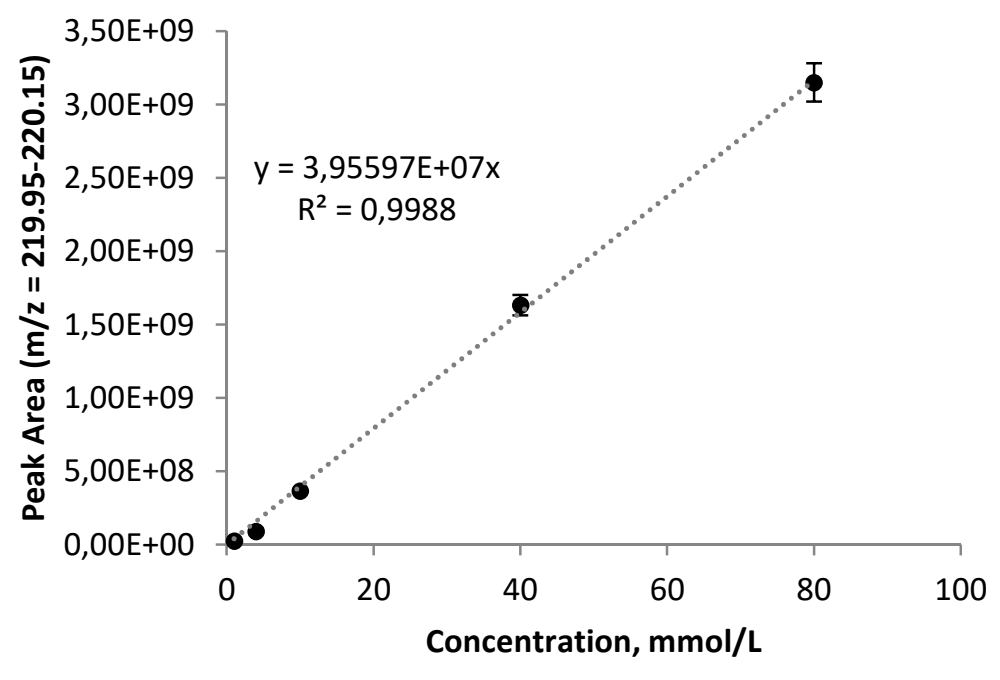

4-[[2-(Acetylamino)ethyl]thio]-4oxobutanoic acid (5b)

Response factor: $3.95597 * 10^{\wedge} 7$

Figure S-3: Correlation between the concentration of an aqueous solution of $\mathbf{5 b}$ and the measured LCMS peak area $(\mathrm{m} / \mathrm{z}=219.95-220.15)$. 


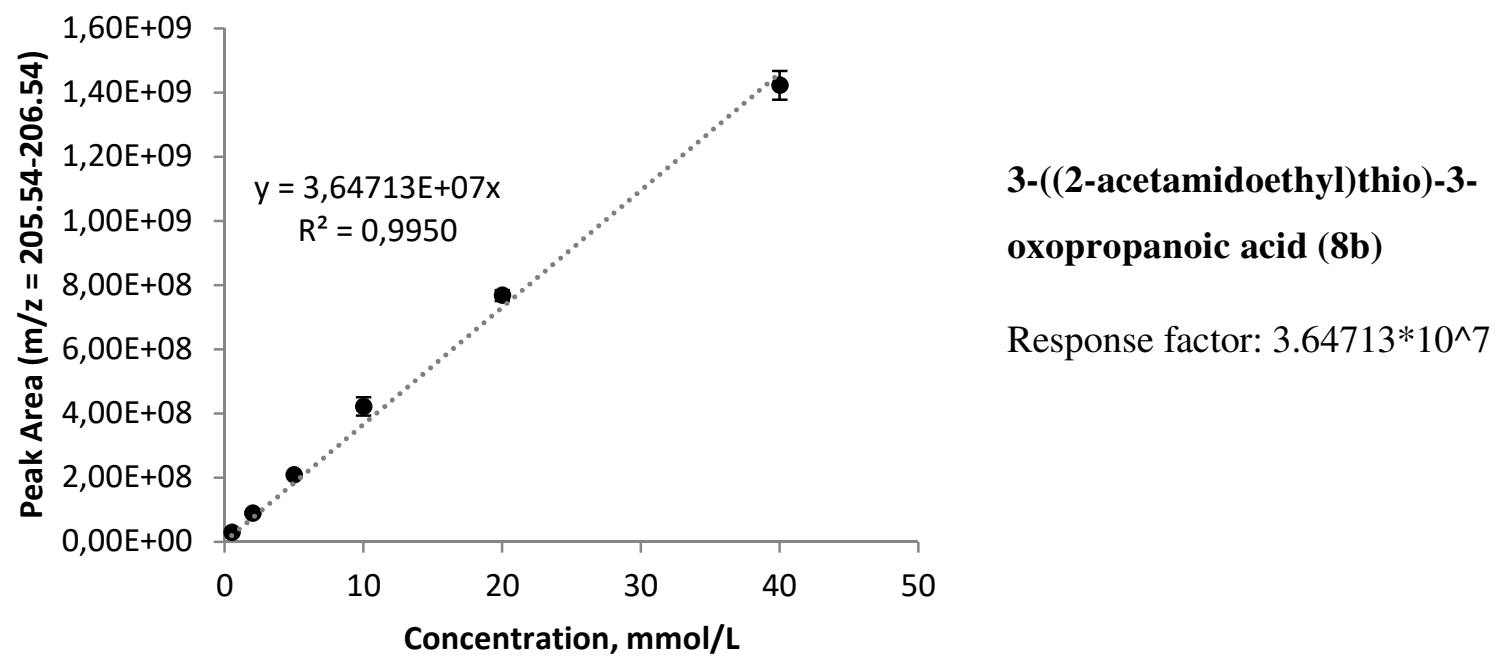

Figure S-4: Correlation between the concentration of an aqueous solution of $\mathbf{8 b}$ and the measured LCMS peak area $(\mathrm{m} / \mathrm{z}=205.54-206.54)$.

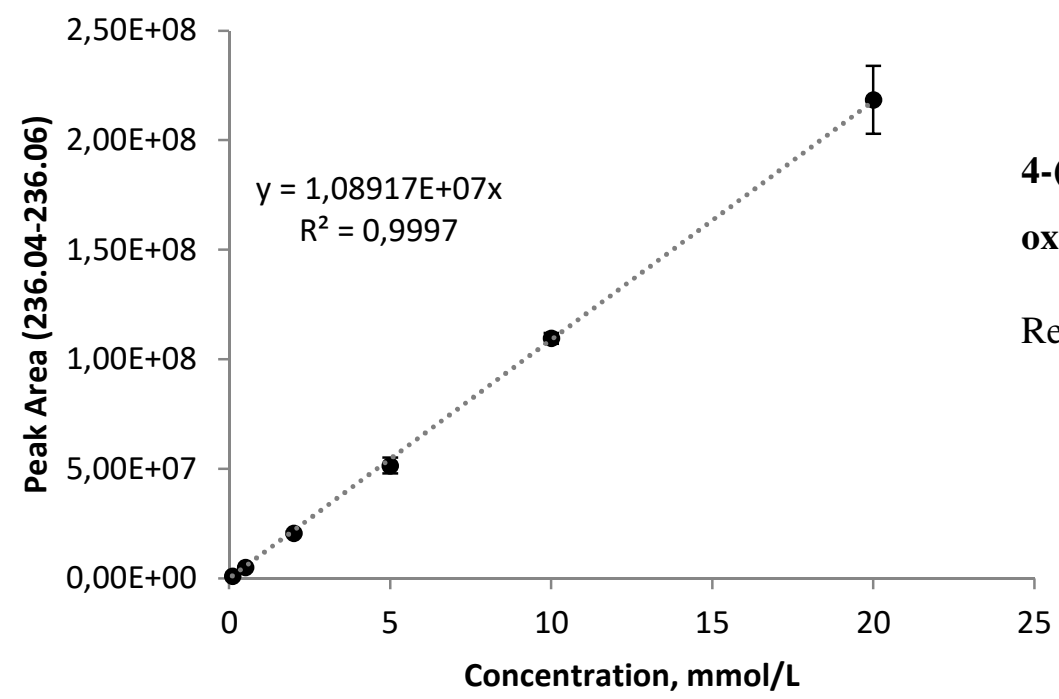

Figure S-5: Correlation between the concentration of an aqueous solution of $\mathbf{9 b}$ and the measured LCMS peak area $(\mathrm{m} / \mathrm{z}=236.04-236.06)$. 


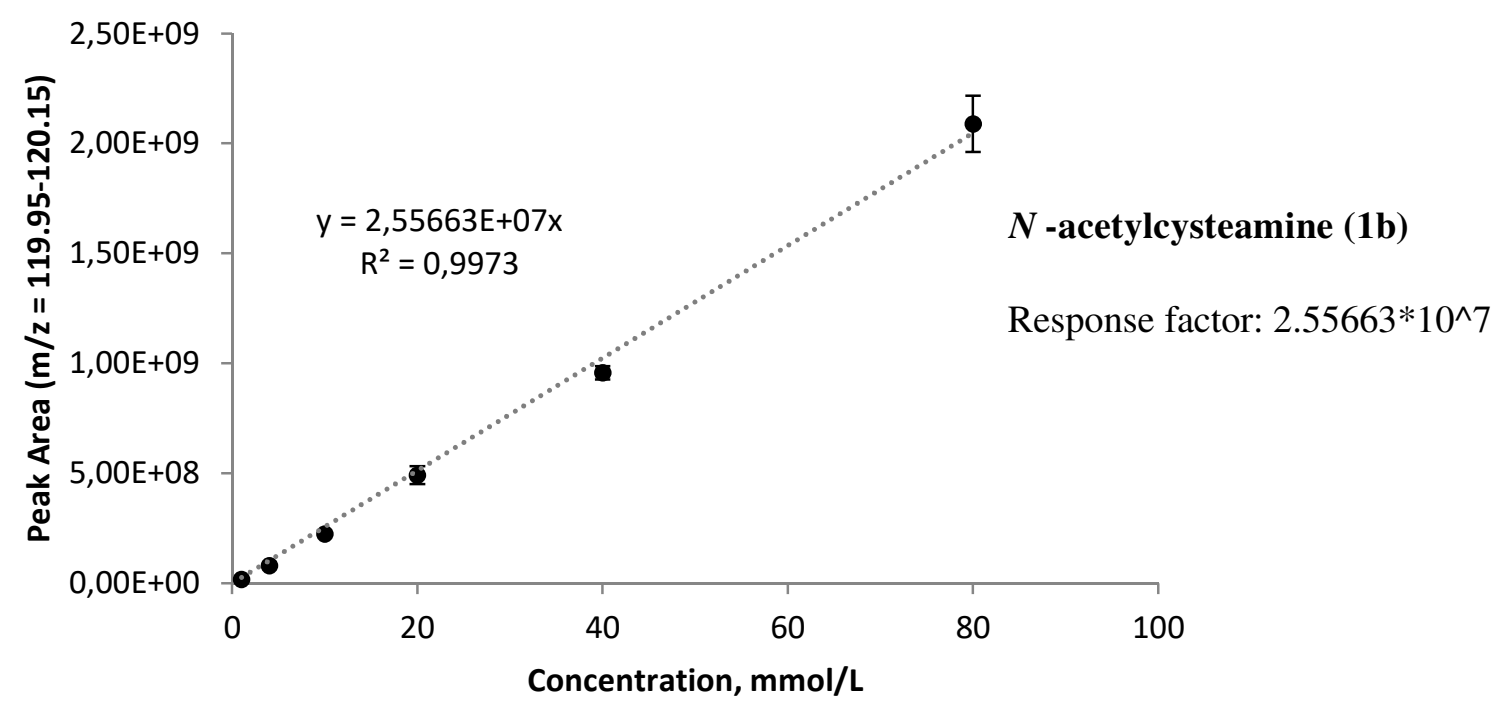

Figure S-6: Correlation between the concentration of an aqueous solution of $\mathbf{1 b}$ and the measured LCMS peak area $(\mathrm{m} / \mathrm{z}=119.95-120.15)$.

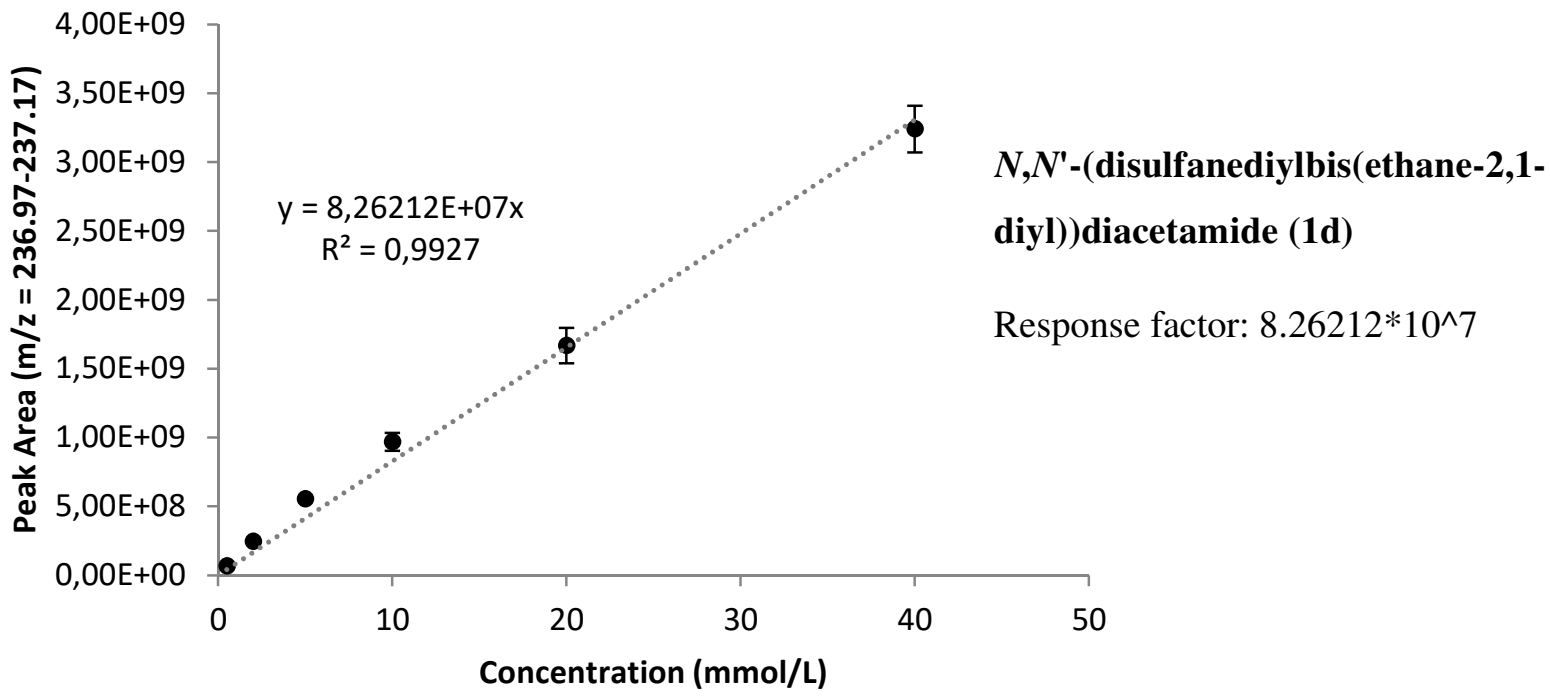

Figure S-7: Correlation between the concentration of an aqueous solution of $\mathbf{1 d}$ and the measured LCMS peak area $(\mathrm{m} / \mathrm{z}=236.97-237.17)$. 


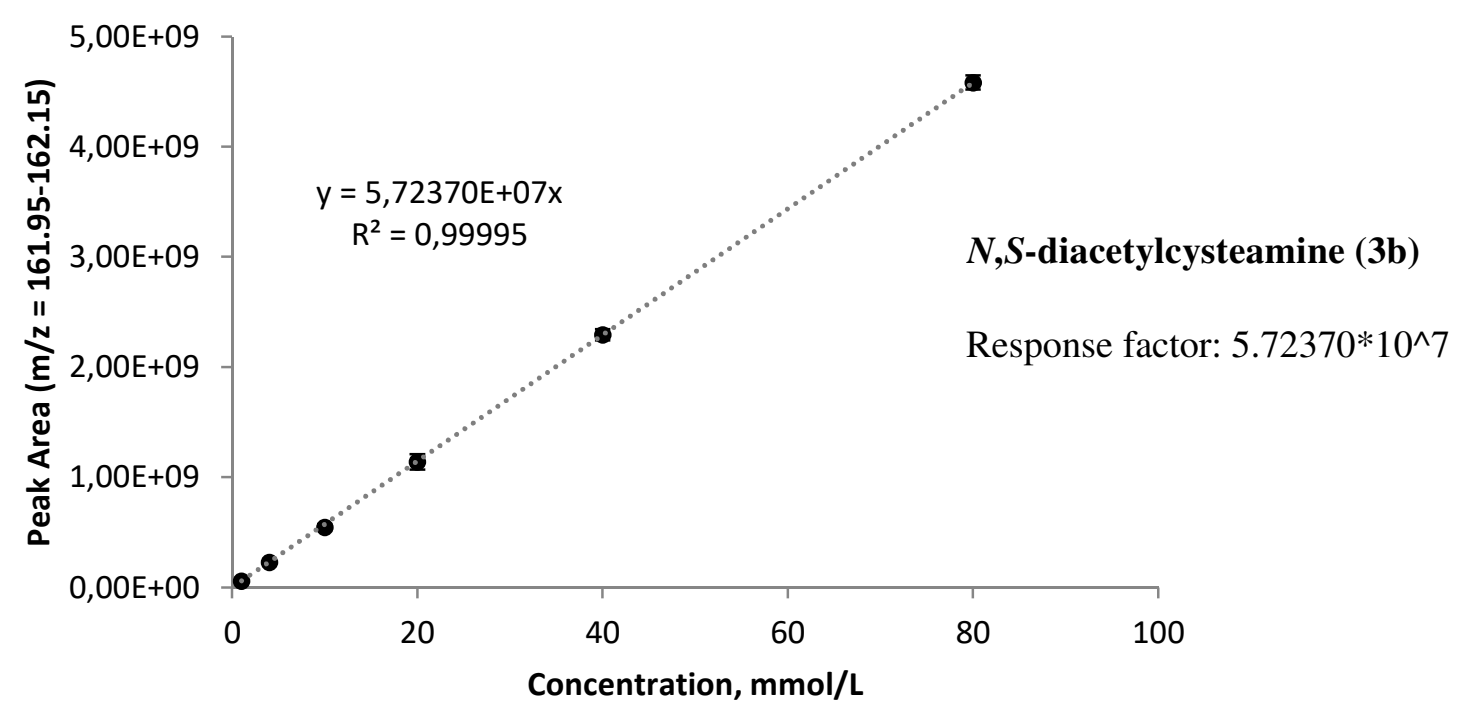

Figure S-8: Correlation between the concentration of an aqueous solution of $\mathbf{3 b}$ and the measured LCMS peak area $(\mathrm{m} / \mathrm{z}=161.95-161.15)$. 


\subsection{GC-MS analysis}

\section{Derivatisation procedure for GC-MS analysis}

To facilitate GC-MS analysis, a literature ECF-derivatization procedure ${ }^{1,2}$ was applied to the sample to convert carboxy groups to ethyl esters, hydroxy groups to ethyl carbonates, ketones to diethyl ketals, and aldehydes to diethyl acetals, using a mixture of ethanol/ethyl chloroformate (EtOH/ECF). For optimal gas chromatography resolution, heavy metal atoms were first removed using a resin (Chelex ${ }^{\circledR}$ 100 sodium form).

A $c a .1 \mathrm{~mL}$ aliquot of the reaction mixture was added to $50 \mathrm{mg}$ of Chelex ${ }^{\circledR}$, briefly shaken and then centrifuged (6000 rpm, $3 \mathrm{~min})$. To $600 \mu \mathrm{L}$ of the supernatant was added EtOH (300 $\mu \mathrm{L})$ and pyridine $(40 \mu \mathrm{L})$, followed by ethyl chloroformate (ECF, $40 \mu \mathrm{L}$ ). The mixture vortexed for $30 \mathrm{~s}$. A second 40 $\mu \mathrm{L}$ portion of ECF was added and the mixture was vortexed again for $30 \mathrm{~s}$. Next, $\mathrm{CHCl}_{3}(200 \mu \mathrm{L})$ was added, followed by vortexing $(10 \mathrm{~s})$. Finally, $\mathrm{NaHCO}_{3}(600 \mu \mathrm{L})$ was added and the mixture was vortexed again for $10 \mathrm{~s}$. The $\mathrm{CHCl}_{3}$ layer was separated and dried over anhydrous $\mathrm{Na}_{2} \mathrm{SO}_{4} .50 \mu \mathrm{L}$ of the dry $\mathrm{CHCl}_{3}$ layer were diluted with $150 \mu \mathrm{L}$ of ethyl acetate prior to GC-MS analysis.

\section{Product identification}

Reaction products derivatized were identified by comparing the mass spectra and retention times with analogously derivatized authentic samples, as described in a previous paper. ${ }^{3}$

\subsection{NMR analysis with water suppression}

For ${ }^{1} \mathrm{H}-\mathrm{NMR}$ analysis using water suppression the samples were first treated with Chelex ${ }^{\circledR} 100$ resin followed by centrifugation to remove heavy metal ions. $600 \mu \mathrm{L}$ from the supernatant were mixed with $100 \mu \mathrm{L}$ of DSS in $\mathrm{D}_{2} \mathrm{O}(0.05 \mathrm{M})$ and analyzed by NMR with water suppression. Water suppression was achieved using the Bruker ZGESGP pulse program. Relaxation delay D1 was set to $87 \mathrm{~s}$, with time domain size $\mathrm{TD}=32768$ and sweep width $\mathrm{SWH}=4789.27 \mathrm{~Hz}(11.963 \mathrm{ppm}) .32$ scans were acquired for each sample. 


\section{Synthetic procedures}

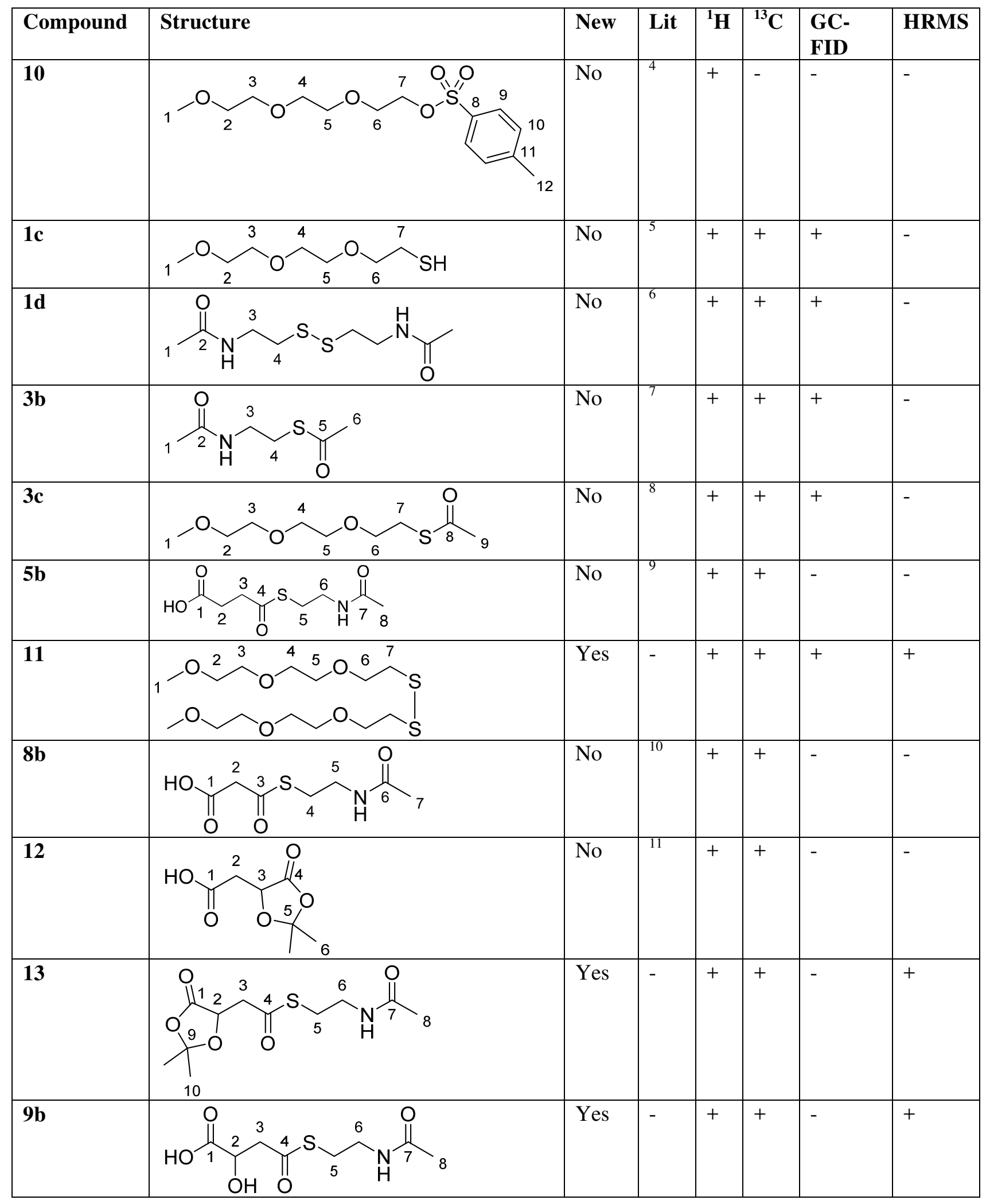




\subsection{Synthesis of starting materials}

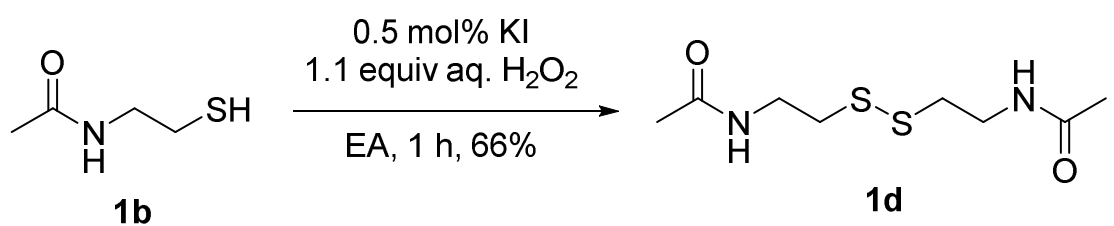

$1 \mathrm{~b}$

$1 d$

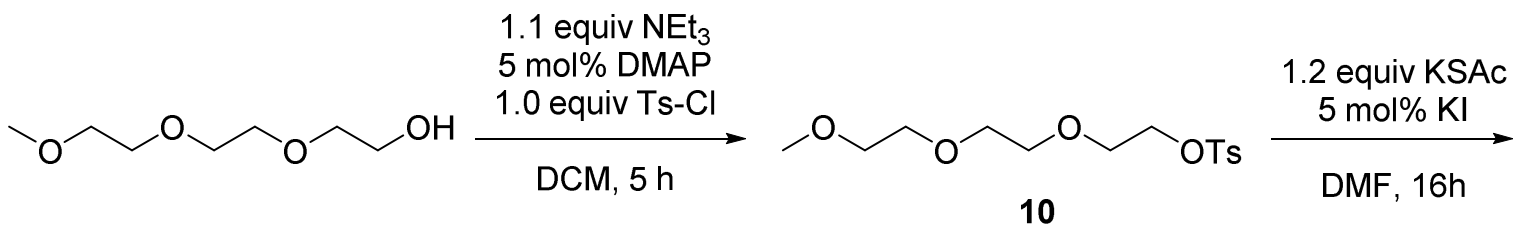

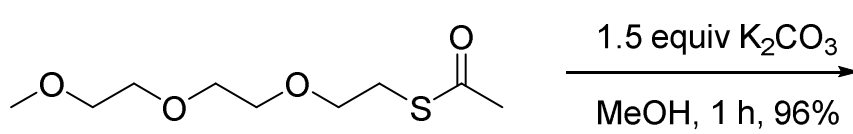

$3 c, 66 \%$ (2 steps)

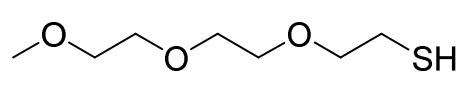

$1 \mathrm{c}$

Scheme S- 1: Synthesis routes toward 1d and 1c.

$N, N^{\prime}$-(disulfanediylbis(ethane-2,1-diyl))diacetamide (1d $)^{6}$<smiles>CC(=O)NCCSSCCNC(C)=O</smiles>

To a solution of $N$-acetylcysteamine $\mathbf{1 b}(1.00 \mathrm{~g}, 8.39 \mathrm{mmol}$, 1.0 equiv) in $9 \mathrm{~mL}$ of EA was added potassium iodide ( $7.0 \mathrm{mg}, 0.042 \mathrm{mmol}, 0.5 \mathrm{~mol} \%$ ) and aqueous hydrogen peroxide (33 wt.\%, $857 \mu \mathrm{L}, 9.23 \mathrm{mmol}, 1.1$ equiv) subsequently and the mixture was stirred at room temperature. After one hour the resulting brown solution was treated with $\mathrm{Na}_{2} \mathrm{~S}_{2} \mathrm{O}_{3}$-solution (5 wt. $\%, 10 \mathrm{~mL}$ ) followed by further stirring for 5 minutes. Then the layers were separated, and the aqueous layer was extracted two more times with EA $(2 \times 20 \mathrm{~mL})$. The combined organic layers were dried $\left(\mathrm{Na}_{2} \mathrm{SO}_{4}\right)$ and filtered. The solvent of the filtrate was removed in vacuo which gave access to $\mathbf{1 d}$ (653 $\mathrm{mg}, 2.76 \mathrm{mmol}, 66 \%)$ as a colorless white powder.

m.p. $87-88^{\circ} \mathrm{C}{ }^{1} \mathbf{H}-\mathbf{N M R}\left(500 \mathrm{MHz}, \mathrm{CDCl}_{3}\right): \delta=2.03(\mathrm{~s}, 6 \mathrm{H}, 1-\mathrm{H}), 2.83\left(\mathrm{t},{ }^{3} J_{4,3}=6.6 \mathrm{~Hz}, 4 \mathrm{H}, 4-\mathrm{H}\right)$, $3.56\left(\mathrm{dt},{ }^{3} J_{3,4} \approx{ }^{3} J_{3, \mathrm{NH}}=6.4 \mathrm{~Hz}, 4 \mathrm{H}, 3-\mathrm{H}\right), 6.68(\mathrm{bs}, 2 \mathrm{H}, \mathrm{N}-\mathrm{H}) .{ }^{13} \mathbf{C}-\mathbf{N M R}\left(125 \mathrm{MHz}, \mathrm{CDCl}_{3}\right): \delta=$ 23.1, 37.7, 38.6, 170.9 . 


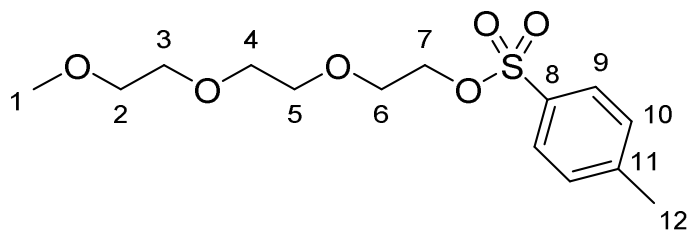

For the synthesis of the tosylate to a solution of triethylene glycol monomethyl ether $(12.3 \mathrm{~g}, 75 \mathrm{mmol}, 1.0$ equiv) in $150 \mathrm{~mL}$ DCM was added triethylamine ( $11.5 \mathrm{~mL}, 82 \mathrm{mmol}, 1.1$ equiv), 4-dimethylaminopyridine (0.46 g, $3.75 \mathrm{mmol}, 5 \mathrm{~mol} \%)$ and tosyl chloride (14.3 g, $75 \mathrm{mmol}, 1.0$ equiv). After stirring the reaction mixture for 5 hours at room temperature DCM (100 mL) was added and the organic layer was washed with $1 \mathrm{M} \mathrm{HCl}$ solution (150 $\mathrm{mL})$. The layers were separated, and the organic layer was dried $\left(\mathrm{Na}_{2} \mathrm{SO}_{4}\right)$ and filtered. After removal of the solvent in vacuo the crude tosylate $\mathbf{1 0}(21.9 \mathrm{~g})$ was isolated as a yellow oil and used in the next step without further purification.

${ }^{1}$ H-NMR $\left(400 \mathrm{MHz}, \mathrm{CDCl}_{3}\right): \delta=2.44(\mathrm{~s}, 3 \mathrm{H}, 12-\mathrm{H}), 3.36(\mathrm{~s}, 3 \mathrm{H}, 1-\mathrm{H}), 3.53(\mathrm{~m}, 2 \mathrm{H}, 2-\mathrm{H})$, 3.56-3.63 (m, $6 \mathrm{H}, 3-\mathrm{H}, 4-\mathrm{H}, 5-\mathrm{H}), 3.68\left(\mathrm{t},{ }^{3} J_{6,7}=4.8 \mathrm{~Hz}, 2 \mathrm{H}, 6-\mathrm{H}\right), 4.15\left(\mathrm{t},{ }^{3} J_{7,6}=4.8 \mathrm{~Hz}, 2\right.$ H, 7-H), $7.33\left(\mathrm{~d},{ }^{3} J_{10,9}=8.1 \mathrm{~Hz}, 2 \mathrm{H}, 10-\mathrm{H}\right), 7.79\left(\mathrm{~d},{ }^{3} J_{9,10}=8.2 \mathrm{~Hz}, 2 \mathrm{H}, 9-\mathrm{H}\right)$.

\section{S-(2-(2-(2-methoxyethoxy)ethoxy)ethyl) ethanethioate (3c) ${ }^{8}$}<smiles>COCCOCCOCCOCCOC</smiles>

To a solution of the tosylate $\mathbf{1 0}(21.9 \mathrm{~g}, 68.7 \mathrm{mmol}, 1.0$ equiv) in $100 \mathrm{~mL}$ DMF under $\mathrm{N}_{2}$-atmosphere was added potassium iodide $(0.57 \mathrm{~g}, 3.44 \mathrm{mmol}, 5 \mathrm{~mol} \%)$ and potassium thioacetate $(9.42 \mathrm{~g}, 82 \mathrm{mmol}, 1.2$ equiv). The mixture was stirred at room temperature overnight. After 16 hours $300 \mathrm{~mL}$ of EA were added followed by washing with water $(3 \mathrm{x} 150 \mathrm{~mL})$. The organic layer was dried $\left(\mathrm{Na}_{2} \mathrm{SO}_{4}\right)$ and filtered. After removal of the solvent in vacuo the thioester 3c (10.9 g, $49.2 \mathrm{mmol}, 66 \%$ over two steps) was isolated as a yellow oil. The compound was used for the synthesis of $\mathbf{1 c}$ and also as an authentic sample for the acetylation reaction.

${ }^{1} \mathbf{H}-\mathbf{N M R}\left(400 \mathrm{MHz}, \mathrm{CDCl}_{3}\right): \delta=2.32(\mathrm{~s}, 3 \mathrm{H}, 9-\mathrm{H}), 3.08\left(\mathrm{t},{ }^{3} J_{7,6}=6.5 \mathrm{~Hz}, 2 \mathrm{H}, 7-\mathrm{H}\right), 3.37(\mathrm{~s}, 3 \mathrm{H}, 1-$ H), 3.54 (m, 2 H, 2-H), 3.56-3.66 (m, 8 H, 3-H, 4-H, 5-H, 6-H). ${ }^{13}$-NMR (100 MHz, $\left.\mathrm{CDCl}_{3}\right): \delta=$ $28.8,30.5,59.0,69.7,70.3,70.5,70.5,71.9,195.5$. 
2-(2-(2-methoxyethoxy)ethoxy)ethane-1-thiol (1c) ${ }^{5}$

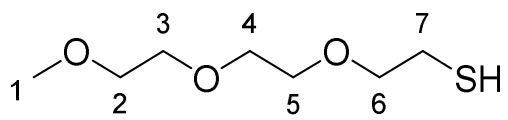

For the synthesis of the thiol to a slurry of potassium carbonate $(9.33 \mathrm{~g}, 67.5 \mathrm{mmol}, 1.5$ equiv) in $45 \mathrm{~mL}$ of methanol was added a solution of $\mathbf{3 c}(10.0 \mathrm{~g}, 45$ mmol, 1.0 equiv) dropwise over 30 seconds in the dark. After stirring at room temperature for one hour the reaction mixture was diluted with $\mathrm{DCM}(300 \mathrm{~mL})$ and washed with sat. $\mathrm{NH}_{4} \mathrm{Cl}$ solution. The aqueous layer was extracted with DCM $(100 \mathrm{~mL})$ and the combined organic layers were dried $\left(\mathrm{Na}_{2} \mathrm{SO}_{4}\right)$. After filtration the solvent was removed under reduced pressure giving access to $1 \mathrm{c}(7.75 \mathrm{~g}$, $43 \mathrm{mmol}, 96 \%$ ) as a pale yellow oil.

${ }^{1} \mathbf{H}$-NMR $\left(400 \mathrm{MHz}, \mathrm{CDCl}_{3}\right): \delta=1.57\left(\mathrm{t},{ }^{3} J_{\mathrm{SH}, 7}=8.3 \mathrm{~Hz}, 1 \mathrm{H}, \mathrm{S}-\mathrm{H}\right), 2.68\left(\mathrm{dt},{ }^{3} J_{7, \mathrm{SH}}=8.3 \mathrm{~Hz},{ }^{3} J_{7,6}=\right.$ $6.4 \mathrm{~Hz}, 2 \mathrm{H}, 7-\mathrm{H}), 3.37$ (s, 3 H, 1-H), 3.50-3.68 (m, 10 H, 2-H, 3-H, 4-H, 5-H, 6-H). ${ }^{13} \mathbf{C}-\mathbf{N M R}(100$ $\left.\mathrm{MHz}, \mathrm{CDCl}_{3}\right): \delta=24.3,59.0,70.2,70.6,70.6,71.9,72.9$. 


\subsection{Synthesis of reference compounds}

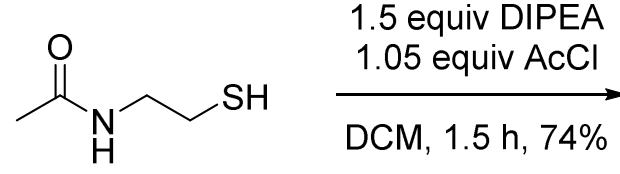

1b<smiles>CC(=O)NCCSC(C)=O</smiles>

$3 b$<smiles>CC(=O)NCC[SnH3]</smiles>

$1 \mathrm{~b}$

$5 b$

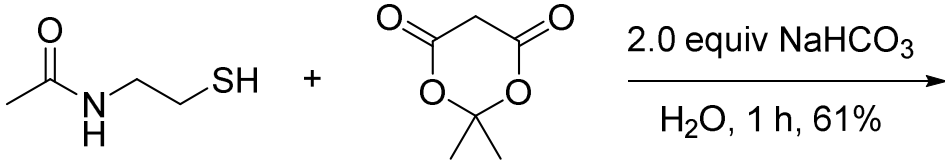

$1 \mathrm{~b}$<smiles>CC(=O)NCCSC(=O)CC(=O)O</smiles>

8b

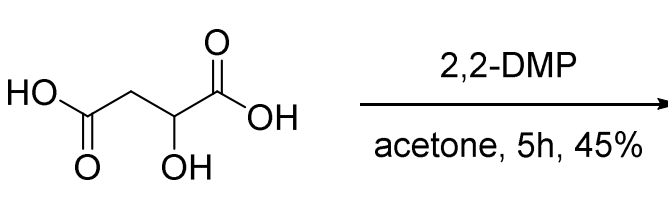<smiles>CC(=O)NCCSC(=O)CC1OC(C)(C)OC1=O</smiles>

13<smiles>CC1(C)OC(=O)C(CC(=O)O)O1</smiles>

12
1) 1.14 equiv DIPEA 0.95 equiv $\mathrm{ECF}$

2) 0.95 equiv $\mathbf{1 b}$ DCM, $82 \%$<smiles>[Mg][Mg][Mg]</smiles><smiles>CC(=O)NCCSC(=O)CC(O)C(=O)O</smiles>

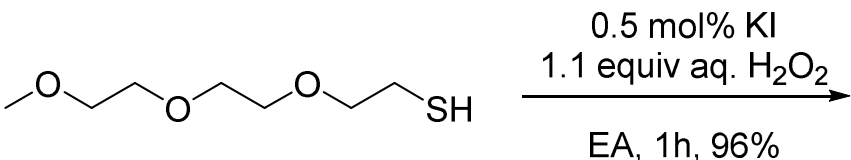<smiles>COCCOCCOCCOCCSSCCOCCOC</smiles>

11

Scheme S- 2: Synthesis routes toward several reference compounds. 


\section{$N, S$-diacetyl cysteamine $(3 \mathbf{b})^{7}$}<smiles>CC(=O)NCCSC(C)=O</smiles>

To a solution of $N$-acetyl cysteamine $\mathbf{1 b}(2.00 \mathrm{~g}, 16.8 \mathrm{mmol}, 1.0$ equiv) in 50 $\mathrm{mL}$ of DCM was added DIPEA (4.4 mL, $25.2 \mathrm{mmol}, 1.5$ equiv) followed by the dropwise addition of acetyl chloride $(1.2 \mathrm{~mL}, 17.6 \mathrm{mmol}, 1.05$ equiv). The reaction mixture was stirred at room temperature. After 1.5 hours the mixture was diluted with DCM $(50 \mathrm{~mL})$ and washed with $1 \mathrm{M} \mathrm{HCl}$ solution $(30 \mathrm{~mL})$ and sat. $\mathrm{NaHCO}_{3}$-solution $(10 \mathrm{~mL})$. The organic layer was dried $\left(\mathrm{Na}_{2} \mathrm{SO}_{4}\right)$ and filtered. Removal of the solvent under reduced pressure afforded $\mathbf{3 b}(2.00 \mathrm{~g}, 12.4 \mathrm{mmol}, 74 \%)$ as a pale yellow oil.

${ }^{1}$ H-NMR (300 MHz, $\left.\mathrm{CDCl}_{3}\right): \delta=1.95(\mathrm{~s}, 3 \mathrm{H}, 1-\mathrm{H}), 2.34(\mathrm{~s}, 3 \mathrm{H}, 6-\mathrm{H}), 3.00\left(\mathrm{t},{ }^{3} \mathrm{~J}_{4,3}=6.5 \mathrm{~Hz}, 2 \mathrm{H}, 4-\right.$ $\mathrm{H}), 3.40\left(\mathrm{dt},{ }^{3} J_{3,4} \approx{ }^{3} J_{3, \mathrm{NH}}=6.3 \mathrm{~Hz}, 2 \mathrm{H}, 3-\mathrm{H}\right), 6.03$ (br. s, $\left.1 \mathrm{H}, \mathrm{N}-\mathrm{H}\right) .{ }^{13} \mathbf{C}-\mathbf{N M R}\left(75 \mathrm{MHz}, \mathrm{CDCl}_{3}\right): \delta=$ 23.1, 28.7, 30.6, 39.5, 170.4, 196.3.

\section{4-[[2-(Acetylamino)ethyl]thio]-4-oxobutanoic acid (5b) ${ }^{9}$}<smiles>CC(=O)NCCSC(=O)CCC(=O)O</smiles>

To a solution of $N$-acetyl cysteamine $\mathbf{1 b}(99.2 \mathrm{mg}, 0.83 \mathrm{mmol}$, 1.0 equiv) in $3 \mathrm{~mL}$ of acetonitrile was added DMAP (10.2 mg, $0.083 \mathrm{mmol}, 0.1$ equiv), pyridine (197.4 mg, $2.50 \mathrm{mmol}, 3.0$ equiv) and succinic anhydride ( $83.26 \mathrm{mg}, 0.83 \mathrm{mmol}, 1.0$ equiv). The reaction mixture was stirred at room temperature. After 2 hours the mixture was diluted with sat. $\mathrm{NaHCO}_{3}$-solution $(3 \mathrm{~mL})$ and washed with $\mathrm{Et}_{2} \mathrm{O}(5 \mathrm{~mL})$. The organic layer was discarded. The aqueous layer was acidified with $1 \mathrm{M} \mathrm{HCl}$ solution to $\mathrm{pH} 1$ and was extracted with $\mathrm{EA}(4 \times 10 \mathrm{~mL})$. The combined organic layers were dried $\left(\mathrm{Na}_{2} \mathrm{SO}_{4}\right)$. After filtration the solvent was removed under reduced pressure giving access to $\mathbf{5 b}(88 \mathrm{mg}, 0.40 \mathrm{mmol}, 48 \%)$ as a colorless powder.

m.p. 78-80 ${ }^{\circ} \mathrm{C}{ }^{1} \mathbf{H}-N M R\left(500 \mathrm{MHz}, \mathrm{CDCl}_{3}\right): \delta=1.97(\mathrm{~s}, 3 \mathrm{H}, 8-\mathrm{H}), 2.73\left(\mathrm{t},{ }^{3} J_{3,2}=6.6 \mathrm{~Hz}, 2 \mathrm{H}, 3-\mathrm{H}\right)$, $2.90\left(\mathrm{t},{ }^{3} J_{2,3}=6.6 \mathrm{~Hz}, 2 \mathrm{H}, 2-\mathrm{H}\right), 3.06\left(\mathrm{t},{ }^{3} J_{5,6}=6.2 \mathrm{~Hz}, 2 \mathrm{H}, 5-\mathrm{H}\right), 3.45\left(\mathrm{dt},{ }^{3} J_{6,5}={ }^{3} J_{6, \mathrm{~N}-\mathrm{H}}=6.2 \mathrm{~Hz}, 2 \mathrm{H}\right.$, 6-H), 5.99 (s, $1 \mathrm{H}, \mathrm{N}-\mathrm{H}) .{ }^{13} \mathrm{C}-\mathrm{NMR}\left(125 \mathrm{MHz}, \mathrm{CDCl}_{3}\right): \delta=23.1,28.5,28.9,38.3,39.7,171.0,175.5$, 198.5 . 


\section{3-((2-acetamidoethyl)thio)-3-oxopropanoic acid (8b) $)^{10}$}<smiles>CC(=O)NCCSC(=O)CC(=O)O</smiles>

To a solution of malonyl monothiophenylester ${ }^{12}(125 \mathrm{mg}, 0.64 \mathrm{mmol}$, 1.0 equiv) and $\mathrm{NaHCO}_{3}(107 \mathrm{mg}, 1.27 \mathrm{mmol}, 2.0$ equiv) in $1 \mathrm{~mL}$ of MilliQ water was added $N$ acetylcysteamine $\mathbf{1 b}(85 \mathrm{mg}, 0.71 \mathrm{mmol}, 1.1$ equiv) dissolved in $1 \mathrm{~mL}$ of MilliQ water over 30 minutes. After stirring at room temperature for one hour, the mixture was acidified to $\mathrm{pH}=1$ with $1 \mathrm{M}$ $\mathrm{HCl}$. The aqueous layer was washed with chloroform $(3 \times 10 \mathrm{~mL})$ and DCM $(2 \times 10 \mathrm{~mL})$. The aqueous layer was lyophilizd. The resulting solid was suspended in acetonitrile $(20 \mathrm{~mL})$ and filtered to remove $\mathrm{NaCl}$. The filtrate was dried in vacuo giving access to the malonyl thioester $\mathbf{8 b}(80 \mathrm{mg}, 0.39$ mmol, $61 \%$ ) as a pale yellow oil.

${ }^{1} \mathbf{H}-\mathbf{N M R}\left(500 \mathrm{MHz}, \mathrm{CDCl}_{3}, \mathrm{DMSO}_{-}\right.$): $\delta=1.81(\mathrm{~s}, 3 \mathrm{H}, 7-\mathrm{H}), 2.95\left(\mathrm{t},{ }^{3} J_{4,5}=6.6 \mathrm{~Hz}, 2 \mathrm{H}, 4-\mathrm{H}\right), 3.27$ $\left(\mathrm{dt},{ }^{3} J_{5,4} \approx{ }^{3} J_{5, \mathrm{NH}}=6.4 \mathrm{~Hz}, 2 \mathrm{H}, 5-\mathrm{H}\right), 3.43$ (s, $\left.2 \mathrm{H}, 2-\mathrm{H}\right), 6.76$ (br. s, $\left.1 \mathrm{H}, \mathrm{N}-\mathrm{H}\right) .{ }^{13} \mathbf{C}-\mathrm{NMR}(125 \mathrm{MHz}$, $\left.\mathrm{CDCl}_{3}, \mathrm{DMSO}_{6}\right): \delta=22.7,28.7,38.6,49.3,167.6,170.3,191.5$.

\section{2-(2,2-dimethyl-5-oxo-1,3-dioxolan-4-yl)acetic acid (12) $)^{11}$}<smiles>CC1(C)OC(=O)C(CC(=O)O)O1</smiles>

A solution of racemic malic acid (3.00 g, $22.4 \mathrm{mmol}, 1.0$ equiv) and $p$-toluene sulfonic acid monohydrate ( $85 \mathrm{mg}, 0.45 \mathrm{mmol}, 2 \mathrm{~mol} \%$ ) in a mixture of $25 \mathrm{~mL}$ of 2,2dimethoxypropane and $25 \mathrm{~mL}$ acetone was stirred at room temperature for 5 hours. Then sodium bicarbonate ( $38 \mathrm{mg}, 0.45 \mathrm{mmol}, 2 \mathrm{~mol} \%$ ) and $50 \mathrm{~mL}$ of water were added. The mixture was extracted with DCM $(3 \times 100 \mathrm{~mL})$ and the combined organic layers were dried $\left(\mathrm{Na}_{2} \mathrm{SO}_{4}\right)$. After filtration and removal of the solvent in vacuo the crude product was recrystallized from $\mathrm{PE} / \mathrm{Et}_{2} \mathrm{O}$ (97:3). The protected malic acid 12 (1.74 g, $10.0 \mathrm{mmol}, 45 \%)$ was isolated as a white solid.

m.p. $74-77^{\circ} \mathrm{C}^{1} \mathrm{H}-\mathrm{NMR}\left(400 \mathrm{MHz}, \mathrm{CDCl}_{3}\right): \delta=1.56$ (s, $\left.3 \mathrm{H}, 6-\mathrm{H}\right), 1.61$ (s, $\left.3 \mathrm{H}, 6-\mathrm{H}^{\prime}\right), 2.85$ (dd, $\left.{ }^{2} J_{2 \mathrm{a}, 2 \mathrm{~b}}=17.2 \mathrm{~Hz},{ }^{3} J_{2 \mathrm{a}, 3}=6.6 \mathrm{~Hz}, 1 \mathrm{H}, 2-\mathrm{H}_{\mathrm{a}}\right), 2.99\left(\mathrm{dd},{ }^{2} J_{2 \mathrm{~b}, 2 \mathrm{a}}=17.2 \mathrm{~Hz},{ }^{3} J_{2 \mathrm{~b}, 3}=3.8 \mathrm{~Hz}, 1 \mathrm{H}, 2-\right.$ $\mathrm{H}_{\mathrm{b}}$ ), $4.71\left(\mathrm{dd},{ }^{3} J_{3,2 \mathrm{a}}=6.6 \mathrm{~Hz},{ }^{3} J_{3,2 \mathrm{~b}}=3.8 \mathrm{~Hz}, 1 \mathrm{H}, 3-\mathrm{H}\right), 10.23$ (br. s, $\left.1 \mathrm{H}, \mathrm{COO}-\mathrm{H}\right) .{ }^{13} \mathbf{C}-\mathbf{N M R}$ $\left(100 \mathrm{MHz}, \mathrm{CDCl}_{3}\right): \delta=25.8,26.7,36.0,70.4,111.4,171.8,175.1$. 


\section{S-(2-acetamidoethyl) 2-(2,2-dimethyl-5-oxo-1,3-dioxolan-4-yl)ethanethioate (13)}<smiles>CC(=O)NCCSC(=O)CC1OC(C)(C)OC1=O</smiles>

To a mixture of the protected malic acid $12(300 \mathrm{mg}, 1.72 \mathrm{mmol}, 1.05$ equiv) and DIPEA (344 $\mu \mathrm{L}, 1.97 \mathrm{mmol}, 1.2$ equiv) in $17 \mathrm{~mL}$ of DCM was added ethyl chloroformate $\left(158 \mu \mathrm{L}, 1.64 \mathrm{mmol}, 1.0\right.$ equiv) dropwise at $0{ }^{\circ} \mathrm{C}$. After 5 minutes, $N$-acetylcysteamine $\mathbf{1 b}(196 \mathrm{mg}$, $1.64 \mathrm{mmol}, 1.0$ equiv) was added and the mixture was allowed to warm to room temperature. After 3 hours the reaction mixture was diluted with DCM $(30 \mathrm{~mL})$ and washed once with $1 \mathrm{M}$ HCl-solution $(10 \mathrm{~mL})$ and sat. $\mathrm{NaHCO}_{3}$-solution $(10 \mathrm{~mL})$. The organic layer was dried $\left(\mathrm{Na}_{2} \mathrm{SO}_{4}\right)$ and filtered. After removal of the solvent in vacuo the thioester $\mathbf{1 3}(369 \mathrm{mg}, 1.34 \mathrm{mmol}, 82 \%)$ was isolated as a colorless liquid.

${ }^{1}$ H-NMR (500 MHz, CDCl $): \delta=1.57(\mathrm{~s}, 3 \mathrm{H}, 10-\mathrm{H}), 1.62\left(\mathrm{~s}, 3 \mathrm{H}, 10-\mathrm{H}^{\prime}\right), 2.00(\mathrm{~s}, 3 \mathrm{H}, 8-\mathrm{H})$, $3.06\left(\mathrm{dd},{ }^{2} J_{3 \mathrm{a}, 3 \mathrm{~b}}=16.5 \mathrm{~Hz},{ }^{3} J_{3 \mathrm{a}, 2}=6.7 \mathrm{~Hz}, 1 \mathrm{H}, 3-\mathrm{H}_{\mathrm{a}}\right), 3.11\left(\mathrm{td},{ }^{3} J_{5,6}=6.4 \mathrm{~Hz},{ }^{4} J_{5, \mathrm{NH}}=2.1 \mathrm{~Hz}\right.$, $2 \mathrm{H}, 5-\mathrm{H}), 3.19\left(\mathrm{dd},{ }^{2} J_{3 \mathrm{~b}, 3 \mathrm{a}}=16.5 \mathrm{~Hz},{ }^{3} J_{3 \mathrm{~b}, 2}=4.0 \mathrm{~Hz}, 1 \mathrm{H}, 3-\mathrm{H}_{\mathrm{b}}\right), 3.46(\mathrm{~m}, 2 \mathrm{H}, 6-\mathrm{H}), 4.76(\mathrm{dd}$, $\left.{ }^{3} J_{2,3 \mathrm{a}}=6.7 \mathrm{~Hz},{ }^{3} J_{2,3 \mathrm{~b}}=4.3 \mathrm{~Hz}, 1 \mathrm{H}, 2-\mathrm{H}\right), 6.29$ (br. s, $\left.1 \mathrm{H}, \mathrm{N}-\mathrm{H}\right) \cdot{ }^{13} \mathbf{C}-\mathbf{N M R}\left(100 \mathrm{MHz}, \mathrm{CDCl}_{3}\right): \delta$ $=23.0,25.8,26.8,28.8,39.3,44.8,70.5,111.4,170.7,171.8,195.0$. HRMS: $\left[\mathrm{C}_{11} \mathrm{H}_{17} \mathrm{NO}_{5} \mathrm{~S}+\mathrm{K}\right]^{*}$ calculated 314.0450 found: $314.0459, \mathbf{R}_{\mathbf{f}}($ silica, EA) $=0.40$.

\section{4-((2-acetamidoethyl)thio)-2-hydroxy-4-oxobutanoic acid (9b)}<smiles>CC(=O)NCCSC(=O)CC(O)C(=O)O</smiles>

A solution of the thioester 13 ( $87 \mathrm{mg}, 0.317 \mathrm{mmol}, 1.0$ equiv) in a mixture of $2.5 \mathrm{~mL}$ THF and $1 \mathrm{~mL}$ of $1 \mathrm{M} \mathrm{HCl}$ solution was heated to $50{ }^{\circ} \mathrm{C}$. After one hour, TLCanalysis showed complete conversion of the starting material. The reaction was cooled to room temperature and extracted with EA $(5 \mathrm{~mL})$. The organic layer was again extracted with $2 \mathrm{~mL}$ of $1 \mathrm{M}$ $\mathrm{HCl}$-solution and the combined aqueous layers were dried in vacuo giving access to the malyl thioester $9 \mathrm{~b}$ (51.4 $\mathrm{mg}, 0.218 \mathrm{mmol}, 69 \%)$ as a colorless resin. 
${ }^{1} \mathbf{H}-\mathbf{N M R}\left(500 \mathrm{MHz}, \mathrm{D}_{2} \mathrm{O}\right): \delta=1.89(\mathrm{~s}, 3 \mathrm{H}, 8-\mathrm{H}), 3.01(\mathrm{~m}, 2 \mathrm{H}, 5-\mathrm{H}), 3.07\left(\mathrm{dd},{ }^{2} J_{3 \mathrm{a}, 3 \mathrm{~b}}=16.2 \mathrm{~Hz},{ }^{3} J_{3 \mathrm{a}, 2}\right.$ $\left.=6.7 \mathrm{~Hz}, 1 \mathrm{H}, 3-\mathrm{H}_{\mathrm{a}}\right), 3.13\left(\mathrm{dd},{ }^{2} J_{3 \mathrm{~b}, 3 \mathrm{a}}=15.9 \mathrm{~Hz},{ }^{3} J_{3 \mathrm{~b}, 2}=4.6 \mathrm{~Hz}, 1 \mathrm{H}, 3-\mathrm{H}_{\mathrm{b}}\right), 3.32\left(\mathrm{t},{ }^{3} J_{6,5}=6.3 \mathrm{~Hz}, 2 \mathrm{H}\right.$, 6-H), $4.57\left(\mathrm{dd},{ }^{3} \mathrm{~J}_{2,3 \mathrm{a}}=6.9 \mathrm{~Hz},{ }^{3} \mathrm{~J}_{2,3 \mathrm{~b}}=4.1 \mathrm{~Hz}, 1 \mathrm{H}, 2-\mathrm{H}\right) .{ }^{13} \mathbf{C}-\mathbf{N M R}(125 \mathrm{MHz}$, DMSO-d 6 ): $\delta=25.2$, 30.8, 40.8, 50.6, 69.6, 172.0, 176.8, 198.4. HRMS: $\left[\mathrm{C}_{8} \mathrm{H}_{13} \mathrm{NO}_{5} \mathrm{~S}+\mathrm{H}\right]^{*}$ calculated 236.0587 found: 236.0583 .

\section{2,5,8,15,18,21-hexaoxa-11,12-dithiadocosane (11)}<smiles>[2H]CCOCCOCCOCCOCCOCCOCCOCCOC</smiles>

A solution of the thiol 1c $(300 \mathrm{mg}$, $1.66 \mathrm{mmol}, 1.0$ equiv) in $2 \mathrm{~mL}$ of EA was treated with sodium iodide ( $1 \mathrm{mg}, 8 \mu \mathrm{mol}, 0.5 \mathrm{~mol} \%)$ and aqueous hydrogen peroxide solution (33 wt.\%, $160 \mu \mathrm{L}, 1.83 \mathrm{mmol}, 1.1$ equiv) and stirred at room temperature. After one hour the resulting brown solution was treated with $\mathrm{Na}_{2} \mathrm{~S}_{2} \mathrm{O}_{3}$ solution ( $5 \mathrm{wt} . \%, 2$ $\mathrm{mL}$ ), followed by further stirring for 5 minutes. Then the layers were separated, and the aqueous layer was extracted two more times with EA $(2 \times 5 \mathrm{~mL})$. The combined organic layers were dried $\left(\mathrm{Na}_{2} \mathrm{SO}_{4}\right)$ and filtered. The solvent of the filtrate was removed in vacuo which gave access to $\mathbf{1 1}(287 \mathrm{mg}, 0.80$ mmol, $96 \%$ ) as a pale yellow oil.

${ }^{1} \mathbf{H}-\mathbf{N M R}\left(400 \mathrm{MHz}, \mathrm{CDCl}_{3}\right): \delta=2.88\left(\mathrm{t},{ }^{3} \boldsymbol{J}_{7,6}=6.7 \mathrm{~Hz}, 4 \mathrm{H}, 7-\mathrm{H}\right), 3.37(\mathrm{~s}, 6 \mathrm{H}, 1-\mathrm{H}), 3.55(\mathrm{~m}, 4 \mathrm{H}, 2-$ H), 3.62-3.72 (m, $12 \mathrm{H}, 3-\mathrm{H}, 4-\mathrm{H}, 5-\mathrm{H}), 3.72\left(\mathrm{t},{ }^{3} J_{6,7}=6.7 \mathrm{~Hz}, 4 \mathrm{H}, 6-\mathrm{H}\right) .{ }^{13} \mathbf{C}-\mathbf{N M R}(125 \mathrm{MHz}$, $\left.\mathrm{CDCl}_{3}\right): \delta=38.3,59.0,69.6,70.3,70.51,71.52,71.9$. HRMS: $\left[\mathrm{C}_{14} \mathrm{H}_{30} \mathrm{O}_{6} \mathrm{~S}_{2}+\mathrm{Na}\right]^{+}$calculated: 381.1376 found: 381.1384 . 


\subsection{Formation of thioesters under prebiotic conditions}

\section{General procedures for thioester formation:}

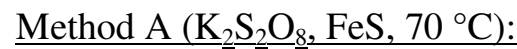

To a solution of the thiol $(0.1 \mathrm{mmol})$ in $3 \mathrm{~mL}$ of MilliQ water in a Pyrex pressure tube with a stirring bar was added the corresponding $\alpha$-keto acid $(0.50 \mathrm{mmol}$; $0.42 \mathrm{mmol}$ for hydroxyketoglutarate $)$ or acetaldehyde $(1.0 \mathrm{mmol})$ under a constant argon flow. Iron(II) sulfide $(0.05 \mathrm{mmol})$ and potassium persulfate $(0.2 \mathrm{mmol})$ were added. The reaction vessel was closed and heated to $70{ }^{\circ} \mathrm{C}$ for 3 hours. After cooling to room temperature, the amount of thioester formed was determined by GC-FID analysis or LCMS analysis (see section 2.1 and 2.2). Additionally selected samples were analyzed by NMR using water suppression (see section 2.4).

\section{Method B ( $\left.\mathrm{K}_{2} \underline{\mathrm{S}}_{2} \underline{\mathrm{O}}_{8}, \mathrm{FeS}, \mathrm{UV}-\mathrm{A}\right)$ :}

To a solution of the thiol $(0.1 \mathrm{mmol})$ in $3 \mathrm{~mL}$ of MilliQ water in a quartz tube with a stirring bar was added the corresponding $\alpha$-keto acid $(0.50 \mathrm{mmol} ; 0.42 \mathrm{mmol}$ for hydroxyketoglutarate) or acetaldehyde $(1.0 \mathrm{mmol})$ under a constant argon flow. Iron(II) sulfide $(0.05 \mathrm{mmol})$ and potassium persulfate $(0.2 \mathrm{mmol})$ were added. The tube was closed with a septum and irradiated in a Luzchem LZC-ORG photoreactor equipped with 10 LZC-UVA lamps for 6 hours. The amount of thioester formed was determined by GC-FID analysis or LCMS analysis (see section 2.1 and 2.2). Additionally selected samples were analyzed by NMR using water suppression (see section 2.4).

\section{Method C ( $\left.\mathrm{KHSO}_{4}, \mathrm{UV}-\mathrm{A}\right)$ :}

To a solution of the thiol $(0.1 \mathrm{mmol})$ in $3 \mathrm{~mL}$ of a $\mathrm{KHSO}_{4}$-solution ( $3 \mathrm{M}$ in MilliQ water) in a quartz tube with a stirring bar was added the corresponding $\alpha$-keto acid $(0.50 \mathrm{mmol} ; 0.42 \mathrm{mmol}$ for hydroxyketoglutarate) or acetaldehyde $(1.0 \mathrm{mmol})$ under a constant argon flow. The tube was closed with a septum and irradiated in a Luzchem LZC-ORG photoreactor equipped with 10 LZC-UVA lamps for 6 hours. The amount of thioester formed was determined by GC-FID analysis or LCMS analysis (see section 2.1 and 2.2). Additionally selected samples were analyzed by NMR using water suppression (see section 2.4). 
Hydroxyketoglutarate was synthesized by adapting a literature procedure without isolation of the product. ${ }^{3}$ To a solution of glyoxylic acid hydrate $(506 \mathrm{mg}, 5.50 \mathrm{mmol}, 1.1$ equiv) in $30 \mathrm{~mL}$ of MilliQ water was added oxaloacetic acid (660 mg, $5.00 \mathrm{mmol}, 1.0$ equiv) and $\mathrm{NaHCO}_{3}(840 \mathrm{mg}, 10.0 \mathrm{mmol}$, 2.0 equiv) under argon. The resulting mixture was stirred at room temperature for two hours. A concentration of $139 \mathrm{mM}$ for the resulting hydroxyketoglutarate was determined by NMR analysis with water suppression using DSS as an internal standard. 
Table S-1: Optimization of the oxidative decarboxylation of sodium pyruvate with $1 \mathrm{~b}$.

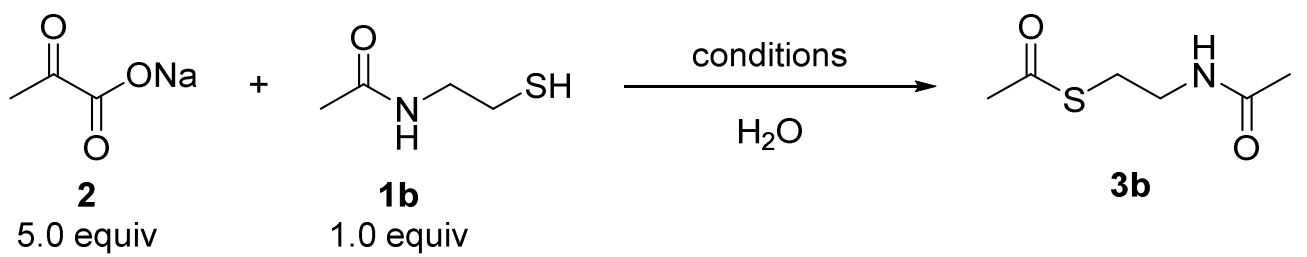

\begin{tabular}{|c|c|c|c|c|}
\hline Entry & Additive (equiv/conc) & Light source/T & $\mathbf{t}[\mathbf{h}]$ & Yield $(3 b)[\%]$ \\
\hline 1 & none & $\mathrm{UVA} /-\mathrm{B} /-\mathrm{C} / \mathrm{CW}$ & 3 & $0.6 \pm 0.2$ \\
\hline 2 & none & $70^{\circ} \mathrm{C}$ & 3 & $0.0 \pm 0.0$ \\
\hline 3 & $\mathrm{~K}_{2} \mathrm{~S}_{2} \mathrm{O}_{8}$ (2 equiv) & $\mathrm{rt}$ & 3 & $1.5 \pm 0.7$ \\
\hline 4 & $\mathrm{~K}_{2} \mathrm{~S}_{2} \mathrm{O}_{8}$ (2 equiv) & $50^{\circ} \mathrm{C}$ & 3 & $9.0 \pm 0.9$ \\
\hline 5 & $\mathrm{~K}_{2} \mathrm{~S}_{2} \mathrm{O}_{8}$ (2 equiv) & $70^{\circ} \mathrm{C}$ & 3 & $14.8 \pm 0.7$ \\
\hline 6 & $\mathrm{~K}_{2} \mathrm{~S}_{2} \mathrm{O}_{8}$ (2 equiv) & $100{ }^{\circ} \mathrm{C}$ & 3 & $8.6 \pm 0.8$ \\
\hline 7 & $\mathrm{~K}_{2} \mathrm{~S}_{2} \mathrm{O}_{8}$ (2 equiv) & $\mathrm{UVA} /-\mathrm{B} /-\mathrm{C} / \mathrm{CW}$ & 3 & $6.4 \pm 1.8$ \\
\hline 8 & $\mathrm{~K}_{2} \mathrm{~S}_{2} \mathrm{O}_{8}$ (2 equiv) $+\mathrm{FeS}$ ( 0.5 equiv) & $\mathrm{UVA} /-\mathrm{B} /-\mathrm{C} / \mathrm{CW}$ & 3 & $23.1 \pm 2.7$ \\
\hline 9 & $\mathrm{~K}_{2} \mathrm{~S}_{2} \mathrm{O}_{8}$ (2 equiv) $+\mathrm{FeS}$ ( 0.5 equiv) & $70^{\circ} \mathrm{C}$ & 3 & $21.2 \pm 0.5$ \\
\hline 10 & $\mathrm{KHSO}_{4}(3 \mathrm{M})$ & UVA & 6 & $22.1 \pm 0.4$ \\
\hline 11 & $\mathrm{Fe}\left(\mathrm{ClO}_{4}\right)_{3}(1.0$ equiv $)$ & UVA & 6 & $4.8 \pm 0.4$ \\
\hline 12 & $\mathrm{~K}_{2} \mathrm{~S}_{2} \mathrm{O}_{8}$ (2 equiv) $+\mathrm{FeS}$ ( 0.5 equiv) & UVA & 6 & $31.2 \pm 0.4$ \\
\hline 13 & $\mathrm{~K}_{2} \mathrm{~S}_{2} \mathrm{O}_{8}$ (2 equiv) $+\mathrm{FeS}$ ( 0.5 equiv) & $70{ }^{\circ} \mathrm{C}$ & 3 & $26.6 \pm 0.7$ \\
\hline 14 & $\mathrm{KHSO}_{4}(1 \mathrm{M})$ & $\mathrm{UVA} /-\mathrm{B} /-\mathrm{C} / \mathrm{CW}$ & 3 & $6.2 \pm 0.2$ \\
\hline 15 & $\mathrm{KHSO}_{4}(3 \mathrm{M})$ & $\mathrm{UVA} /-\mathrm{B} / \mathrm{-C} / \mathrm{CW}$ & 3 & $8.4 \pm 1.9$ \\
\hline 16 & $\mathrm{NaHSO}_{4}(1 \mathrm{M})$ & $\mathrm{UVA} /-\mathrm{B} /-\mathrm{C} / \mathrm{CW}$ & 3 & $4.4 \pm 0.9$ \\
\hline 17 & $\mathrm{H}_{2} \mathrm{SO}_{4}(1 \mathrm{M})$ & $\mathrm{UVA} /-\mathrm{B} /-\mathrm{C} / \mathrm{CW}$ & 3 & $6.8 \pm 0.3$ \\
\hline 18 & $\mathrm{H}_{3} \mathrm{PO}_{4}(3 \mathrm{M})$ & $\mathrm{UVA} /-\mathrm{B} /-\mathrm{C} / \mathrm{CW}$ & 3 & $6.1 \pm 0.3$ \\
\hline 19 & $\mathrm{HCl}(0.5 \mathrm{M})$ & $\mathrm{UVA} /-\mathrm{B} /-\mathrm{C} / \mathrm{CW}$ & 3 & $2.5 \pm 0.2$ \\
\hline 20 & $\begin{array}{c}\mathrm{H}_{2} \mathrm{SO}_{4}(1 \mathrm{M}) \text { or } \mathrm{H}_{3} \mathrm{PO}_{4}(3 \mathrm{M}) \text { or } \mathrm{HCl} \\
(0.5 \mathrm{M}) \text { or } \mathrm{KHSO}_{4}(3 \mathrm{M})\end{array}$ & $70{ }^{\circ} \mathrm{C}$ & 3 & $0 \pm 0$ \\
\hline 21 & none $^{\mathrm{a}}$ & $\mathrm{UVA} /-\mathrm{B} /-\mathrm{C} / \mathrm{CW}$ & 3 & $1.8 \pm 0.0$ \\
\hline 22 & $\mathrm{KHSO}_{4}(1 \mathrm{M})$ & none & 3 & $0.5 \pm 0.1$ \\
\hline 23 & $\mathrm{KHSO}_{4}(1 \mathrm{M})$ & UVA & 3 & $14.2 \pm 0.7$ \\
\hline 24 & $\mathrm{KHSO}_{4}(1 \mathrm{M})$ & UVB & 3 & $9.5 \pm 1.0$ \\
\hline 25 & $\mathrm{KHSO}_{4}(1 \mathrm{M})$ & UVC & 3 & $0.8 \pm 0.0$ \\
\hline 26 & $\mathrm{KHSO}_{4}(1 \mathrm{M})$ & $\mathrm{CW}$ & 3 & $0.6 \pm 0.1$ \\
\hline 27 & $\mathrm{KHSO}_{4}(3 \mathrm{M})^{\mathrm{b}}$ & UVA & 6 & $4.9 \pm 0.2$ \\
\hline 28 & $\mathrm{Fe}\left(\mathrm{ClO}_{4}\right)_{3}(1.0 \text { equiv })^{\mathrm{b}}$ & UVA & 6 & $0.5 \pm 0.1$ \\
\hline 29 & $\mathrm{~K}_{2} \mathrm{~S}_{2} \mathrm{O}_{8}(2$ equiv $)+\mathrm{FeS}(0.5$ equiv $){ }^{\mathrm{b}}$ & UVA & 6 & $31.9 \pm 0.7$ \\
\hline
\end{tabular}




\begin{tabular}{|c|c|c|c|c|}
\hline Entry & Additive (equiv/conc) & Light source/T & $\mathbf{t}[\mathbf{h}]$ & Yield $(3 b)[\%]$ \\
\hline 30 & $\mathrm{~K}_{2} \mathrm{~S}_{2} \mathrm{O}_{8}$ (2 equiv) $+\mathrm{FeS}\left(0.5\right.$ equiv) ${ }^{\mathrm{b}}$ & $70{ }^{\circ} \mathrm{C}$ & 3 & $32.9 \pm 0.8$ \\
\hline 31 & $\mathrm{KHSO}_{4}(0.5 \mathrm{M})$ & UVA & 3 & $7.2 \pm 0.5$ \\
\hline 32 & $\mathrm{KHSO}_{4}(0.41 \mathrm{M})+\mathrm{K}_{2} \mathrm{SO}_{4}(0.09 \mathrm{M})$ & UVA & 3 & $6.6 \pm 0.3$ \\
\hline 33 & $\mathrm{KHSO}_{4}(0.33 \mathrm{M})+\mathrm{K}_{2} \mathrm{SO}_{4}(0.17 \mathrm{M})$ & UVA & 3 & $5.5 \pm 0.3$ \\
\hline 34 & $\mathrm{KHSO}_{4}(0.25 \mathrm{M})+\mathrm{K}_{2} \mathrm{SO}_{4}(0.25 \mathrm{M})$ & UVA & 3 & $4.4 \pm 0.7$ \\
\hline 35 & $\mathrm{KHSO}_{4}(0.17 \mathrm{M})+\mathrm{K}_{2} \mathrm{SO}_{4}(0.33 \mathrm{M})$ & UVA & 3 & $3.0 \pm 0.1$ \\
\hline 36 & $\mathrm{KHSO}_{4}(0.09 \mathrm{M})+\mathrm{K}_{2} \mathrm{SO}_{4}(0.41 \mathrm{M})$ & UVA & 3 & $1.4 \pm 0.1$ \\
\hline 37 & $\mathrm{KHSO}_{4}(0.46 \mathrm{M})+\mathrm{K}_{2} \mathrm{SO}_{4}(0.04 \mathrm{M})$ & UVA & 3 & $0.8 \pm 0.1$ \\
\hline 38 & $\mathrm{~K}_{2} \mathrm{SO}_{4}(0.5 \mathrm{M})$ & UVA & 3 & $0.5 \pm 0.0$ \\
\hline 39 & $\mathrm{Fe}\left(\mathrm{ClO}_{4}\right)_{3}$ (2 equiv) & $\mathrm{UVA} /-\mathrm{B} /-\mathrm{C} / \mathrm{CW}$ & 3 & $4.4 \pm 0.3$ \\
\hline 40 & $\mathrm{FeCl}_{2}$ (2 equiv) & $\mathrm{UVA} /-\mathrm{B} /-\mathrm{C} / \mathrm{CW}$ & 3 & $2.8 \pm 0.1$ \\
\hline 41 & $\mathrm{FeCl}_{3}$ (2 equiv) & $\mathrm{UVA} /-\mathrm{B} /-\mathrm{C} / \mathrm{CW}$ & 3 & $3.1 \pm 0.1$ \\
\hline 42 & $\mathrm{FeS}$ (2 equiv) & $\mathrm{UVA} /-\mathrm{B} /-\mathrm{C} / \mathrm{CW}$ & 3 & $1.1 \pm 0.2$ \\
\hline 43 & $\mathrm{KHSO}_{4}(3 \mathrm{M})^{\mathrm{c}}$ & UVA & 6 & $0.0 \pm 0.0$ \\
\hline 44 & $\mathrm{~K}_{2} \mathrm{~S}_{2} \mathrm{O}_{8}(2$ equiv $)+\mathrm{FeS}(0.5 \text { equiv })^{\mathrm{c}}$ & UVA & 6 & $0.0 \pm 0.0$ \\
\hline 45 & $\mathrm{~K}_{2} \mathrm{~S}_{2} \mathrm{O}_{8}(2$ equiv $)+\mathrm{FeS}(0.5 \text { equiv })^{\mathrm{c}}$ & $70{ }^{\circ} \mathrm{C}$ & 3 & $0.0 \pm 0.0$ \\
\hline 46 & $\mathrm{KHSO}_{4}(3 \mathrm{M})^{\mathrm{d}}$ & UVA & 6 & $0.0 \pm 0.0$ \\
\hline 47 & $\mathrm{~K}_{2} \mathrm{~S}_{2} \mathrm{O}_{8}(2$ equiv $)+\mathrm{FeS}(0.5 \text { equiv })^{\mathrm{d}}$ & UVA & 6 & $0.0 \pm 0.0$ \\
\hline 48 & $\mathrm{~K}_{2} \mathrm{~S}_{2} \mathrm{O}_{8}(2$ equiv $)+\mathrm{FeS}(0.5 \text { equiv })^{\mathrm{d}}$ & $70^{\circ} \mathrm{C}$ & 3 & $0.0 \pm 0.0$ \\
\hline
\end{tabular}

${ }^{\mathrm{a}}$ pyruvic acid was used instead of sodium pyruvate ${ }^{\mathrm{b}} 0.5$ equiv disulfide $\mathbf{1 d}$ instead of thiol $\mathbf{1 b}$. ${ }^{c}$ control experiment without sodium pyruvate ${ }^{\mathrm{d}}$ control experiment without thiol $\mathbf{1 b}$

To show that the described method can also be applied to other thiols, the formation of the acetyl thioester $3 \mathbf{c}$ starting from pyruvate and the thiol $\mathbf{1} \mathbf{c}$ has been investigated.

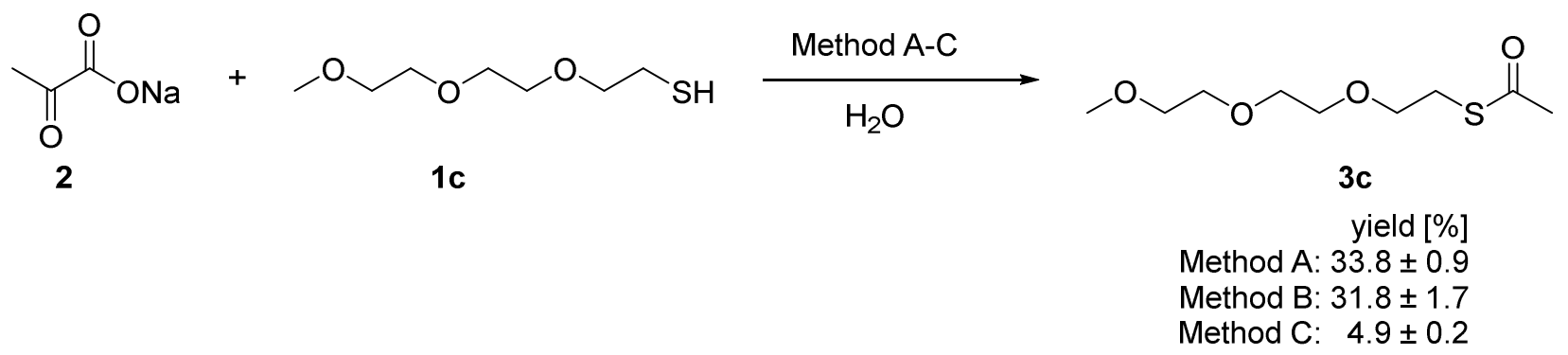

Scheme S-3: Thioester formation with an alternative thiol 1c analyzed by GC-FID. 
Additionally, the use of $\alpha$-hydroxy acids instead of $\alpha$-keto acids has been investigated.<smiles>CC(O)C(=O)O</smiles>

lactic acid<smiles>CC(=O)NCCS</smiles>

$1 \mathrm{~b}$

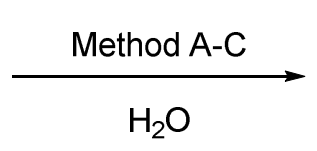

$\mathrm{H}_{2} \mathrm{O}$<smiles>CC(=O)NCCSC(C)=O</smiles>

3b

Method A: $3.6 \pm 0.1$

Method B: $3.5 \pm 0.2$

Method C: $0.0 \pm 0.0$

Scheme S-4: Thioester formation using lactic acid analyzed by GC-FID.<smiles>CC(=O)C(=O)O</smiles>

2

5.0 equiv

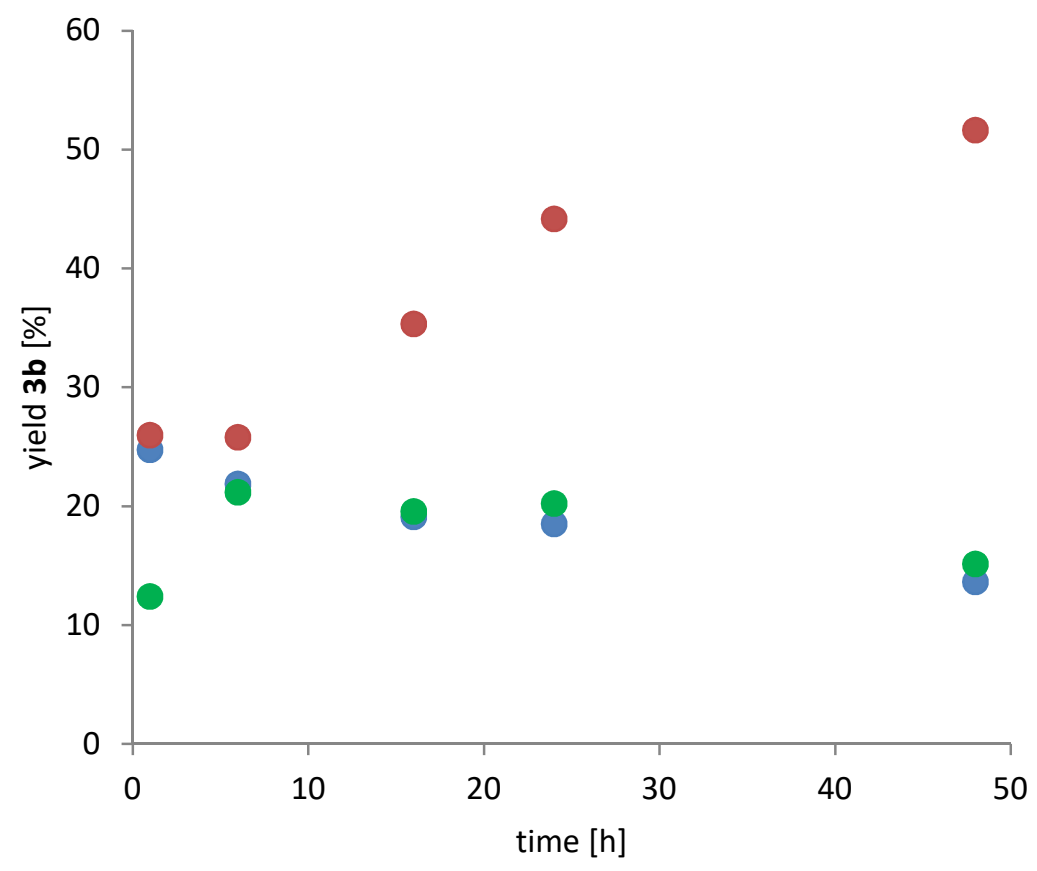

$\underset{\mathrm{H}_{2} \mathrm{O}}{\stackrel{\text { conditions }}{\longrightarrow}}$

$1 \mathrm{~b}$

1.0 equiv<smiles>CC(=O)NCCSC(C)=O</smiles>

3b
$\mathrm{K} 2 \mathrm{~S} 2 \mathrm{O} 8+\mathrm{FeS}, 70^{\circ} \mathrm{C}$

K2S2O8 + FeS, UVA

- KHSO4, UVA

Figure S-9: Time dependence of the thioester formation under optimized conditions 
Table S-2: Stability and decomposition products of different keto acids using methods A-C<smiles>CC(=O)C(=O)[O-]</smiles>

pyruvate (2)<smiles>CC(CC(C)C(=O)O)C(=O)[O-]</smiles>

oxaloacetate $6(\mathrm{n}=1)$ $\alpha$-ketoglutarate $4(n=2)$
$\mathrm{RSH}(1 \mathrm{~b} / 1 \mathrm{c})$ or RSSR (1d)

$\mathrm{H}_{2} \mathrm{O}$<smiles>[R]SC(C)=O</smiles>

acetyl thioester $(3 b / 3 c)$<smiles>[R]SC(=O)C(C)C(=O)O</smiles>

malonyl thioester $8 b(n=1)$ succinyl thioester $5 b(n=2)$

\begin{tabular}{|c|c|c|c|c|}
\hline Ketoacid & Thio-cmpd. & Method & Remaining Ketoacid $^{\mathrm{a}}$ & Decomposition $^{\mathrm{a}}$ \\
\hline pyruvate & $1 \mathrm{~b}$ & $\mathrm{~A}$ & $48 \%^{\mathrm{b}}$ & acetate $(7 \%)$ \\
\hline pyruvate & $1 \mathrm{~b}$ & $\mathrm{~B}$ & $48 \%^{b}$ & acetate $(10 \%)$ \\
\hline pyruvate & $1 \mathrm{~b}$ & $\mathrm{C}$ & $64 \%{ }^{b}$ & acetate $(2 \%)$ \\
\hline pyruvate & $1 \mathrm{c}$ & $\mathrm{A}$ & $63 \%{ }^{b}$ & acetate $(4 \%)$ \\
\hline pyruvate & 1c & B & $48 \%{ }^{b}$ & acetate $(9 \%)$ \\
\hline pyruvate & $1 \mathrm{c}$ & $\mathrm{C}$ & $63 \%^{\mathrm{b}}$ & acetate $(4 \%)$ \\
\hline pyruvate & 1d & A & $54 \%^{\mathrm{b}}$ & acetate $(4 \%)$ \\
\hline pyruvate & 1d & B & $56 \%{ }^{\mathrm{b}}$ & acetate $(13 \%)$ \\
\hline pyruvate & 1d & $\mathrm{C}$ & $80 \%^{\mathrm{b}}$ & acetate $(1 \%)$ \\
\hline$\alpha$-ketoglutarate & $1 b$ & $\mathrm{~A}$ & $66 \%{ }^{b}$ & succinate $(5 \%)$ \\
\hline$\alpha$-ketoglutarate & $1 b$ & B & $82 \%^{b}$ & succinate $(7 \%)$ \\
\hline$\alpha$-ketoglutarate & $1 \mathrm{~b}$ & $\mathrm{C}$ & $57 \%^{b}$ & succinate $(1 \%)$ \\
\hline oxaloacetate & 1b & $\mathrm{A}$ & $0 \%$ & pyruvate $\left(52 \%^{\mathrm{b}}\right)$ \\
\hline oxaloacetate & $1 \mathrm{~b}$ & B & $0 \%$ & pyruvate $\left(32 \%^{b}\right)$ \\
\hline oxaloacetate & $1 \mathrm{~b}$ & $\mathrm{C}$ & $44 \%{ }^{b}$ & pyruvate $\left(4 \%^{\mathrm{b}}\right)$ \\
\hline
\end{tabular}

${ }^{a}$ determined by NMR with DSS as internal standard using water suppression ${ }^{\mathrm{b}}$ the shown value is the sum of the ketoacid and its hydrate form 


\subsection{Thioester formation from a non-enzymatic reaction network}

A solution of sodium pyruvate $2(110 \mathrm{mg}, 1.0 \mathrm{mmol}, 2.0$ equiv), glyoxylic acid monohydrate (46 mg, $0.5 \mathrm{mmol}, 1.0$ equiv) and $\mathrm{FeCl}_{2} \cdot 4 \mathrm{H}_{2} \mathrm{O}$ (200 mg, $1.0 \mathrm{mmol}, 2.0$ equiv) in $3 \mathrm{~mL}$ of MilliQ water was prepared in a Pyrex pressure tube equipped with a stirring bar under a constant argon flow. For oxidation procedure A $N$-acetylcysteamine $1 \mathbf{b}(59 \mathrm{mg}, 0.5 \mathrm{mmol}, 1.0$ equiv) was added. The reaction vessel was closed and heated to $70{ }^{\circ} \mathrm{C}$ for $1 \mathrm{~h}$ or $3 \mathrm{~h}$, followed by an oxidation procedure.

\section{Oxidation procedure A:}

To the solution prepared as described above, potassium persulfate ( $270 \mathrm{mg}, 1.0 \mathrm{mmol}, 1.0$ equiv) was added under a constant argon flow. The reaction vessel was closed and heated to $70{ }^{\circ} \mathrm{C}$ for 3 hours. After cooling to room temperature, the amount of thioesters formed was determined by GC-FID analysis or LCMS analysis (see section 2.1 and 2.2), the different intermediates of the network were determined by GC-MS analysis (see section 2.3).

Oxidation procedure B: (in this case, $N$-acetylcysteamine was added at a later stage)

To the solution prepared as described above, $\mathrm{KHSO}_{4}(1.2 \mathrm{~g}, 9.0 \mathrm{mmol}$, to form a $\sim 3 \mathrm{M}$ solution) and $\mathrm{N}$-acetylcysteamine (59 mg, $0.50 \mathrm{mmol} 1.0$ equiv) were added, the mixture was transferred in a quartz tube under a constant argon flow. The tube was closed with a septum and irradiated in a Luzchem LZC-ORG photoreactor equipped with 10 LZC-UVA lamps for 3 hours. The amount of thioesters formed was determined by GC-FID analysis or LCMS analysis (see section 2.1 and 2.2), the different intermediates of the network were determined by GC-MS analysis (see section 2.3). 
Table S-3: Thioester formation from a non-enzymatic reaction network

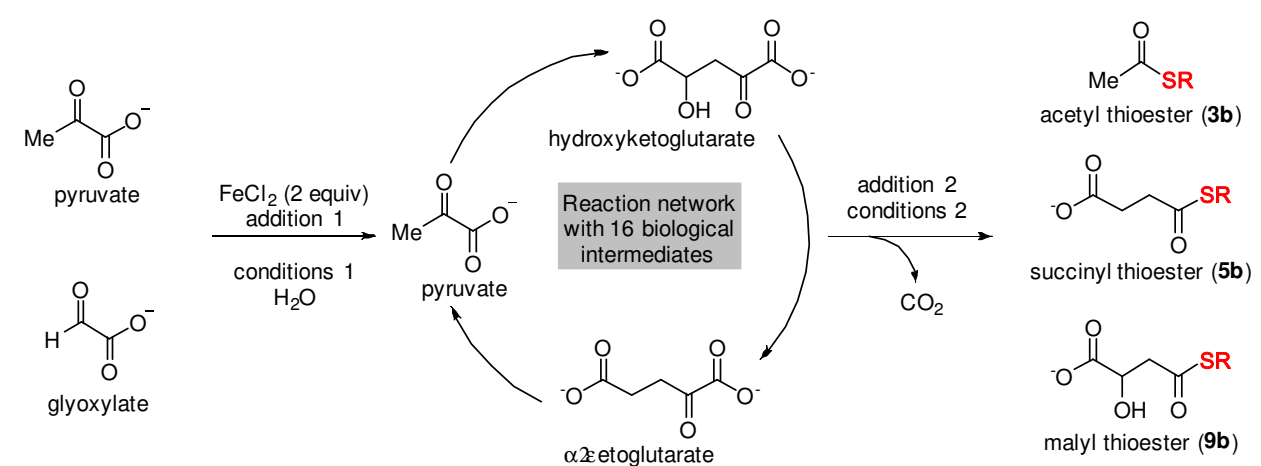

\begin{tabular}{|c|c|c|c|c|c|c|c|c|}
\hline Entry & equiv pyruvate & addition 1 (equiv) & conditions 1 & addition 2 (equiv) & conditions 2 & $\mathbf{c}(3 \mathrm{~b})^{\mathrm{a}}[\mathrm{mM}]$ & $\mathbf{c}(5 \mathbf{b})^{\mathrm{b}}[\mathrm{mM}]$ & $\mathbf{c}(9 \mathbf{b})^{\mathrm{b}}[\mathrm{mM}]$ \\
\hline 1 & 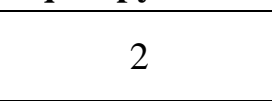 & & $70{ }^{\circ} \mathrm{C}, 1 \mathrm{~h}$ & $\begin{array}{c}\text { Thiol (1) } \\
\mathrm{KHSO}_{4}(3 \mathrm{M}) \\
\end{array}$ & UVA, $3 \mathrm{~h}$ & $0.11 \pm 0.01$ & $0.19 \pm 0.04$ & $0.06 \pm 0.00$ \\
\hline 2 & 2 & Thiol (1) & $70^{\circ} \mathrm{C}, 1 \mathrm{~h}$ & $\mathrm{~K}_{2} \mathrm{~S}_{2} \mathrm{O}_{8}(2)$ & $70^{\circ} \mathrm{C}, 3 \mathrm{~h}$ & $1.41 \pm 0.11$ & $0.11 \pm 0.01$ & $3.60 \pm 0.30$ \\
\hline 3 & 2 & Thiol (1) & $70{ }^{\circ} \mathrm{C}, 3 \mathrm{~h}$ & $\mathrm{~K}_{2} \mathrm{~S}_{2} \mathrm{O}_{8}(2)$ & $70{ }^{\circ} \mathrm{C}, 3 \mathrm{~h}$ & $1.11 \pm 0.14$ & $0.11 \pm 0.02$ & $3.63 \pm 0.28$ \\
\hline 4 & 1 & $\begin{array}{c}\text { Thiol (1) } \\
\mathrm{KHSO}_{4}(3 \mathrm{M})\end{array}$ & UVA, $3 \mathrm{~h}$ & - & - & $0.06 \pm 0.05$ & - & - \\
\hline 5 & 2 & $\begin{array}{c}\text { Thiol (1) } \\
\mathrm{KHSO}_{4}(3 \mathrm{M})\end{array}$ & UVA, $6 \mathrm{~h}$ & - & - & $0.16 \pm 0.02$ & - & - \\
\hline 6 & 1 & $\begin{array}{c}\text { Thiol (1) } \\
\mathrm{KHSO}_{4}(3 \mathrm{M})\end{array}$ & UVA, $3 \mathrm{~h}$ & - & - & $0.11 \pm 0.05$ & - & - \\
\hline 7 & 2 & $\begin{array}{c}\text { Thiol (1) } \\
\mathrm{KHSO}_{4}(3 \mathrm{M})\end{array}$ & UVA, $6 \mathrm{~h}$ & - & - & $0.31 \pm 0.05$ & - & - \\
\hline 8 & 2 & Thiol (1) & $70^{\circ} \mathrm{C}, 1 \mathrm{~h}$ & $\mathrm{KHSO}_{4}(3 \mathrm{M})$ & UVA, $3 \mathrm{~h}$ & $0.12 \pm 0.01$ & - & - \\
\hline 9 & 2 & Thiol (1) & $70^{\circ} \mathrm{C}, 1 \mathrm{~h}$ & $\mathrm{KHSO}_{4}(3 \mathrm{M})$ & UVA, $6 \mathrm{~h}$ & $0.15 \pm 0.01$ & - & - \\
\hline 10 & 2 & Thiol (1) & UVA, $1 \mathrm{~h}$ & $\mathrm{KHSO}_{4}(3 \mathrm{M})$ & UVA, $3 \mathrm{~h}$ & $0.22 \pm 0.02$ & & \\
\hline
\end{tabular}

${ }^{\mathrm{a}}$ Determined by GC-FID analysis after extraction with ethyl acetate ${ }^{\mathrm{b}}$ Determined by LCMS-analysis. For the network experiments $0.5 \mu \mathrm{L}$ instead of $0.1 \mu \mathrm{L}$ were injected, the resulting value calculated using the calibration curves was divided by 5 afterwards. See section 4.10 for GCMS-chromatograms of the network products. 


\section{Experimental data}

\subsection{NMR spectra of the synthesized compounds}

$N, N^{\prime}$-(disulfanediylbis(ethane-2,1-diyl))diacetamide (1d)
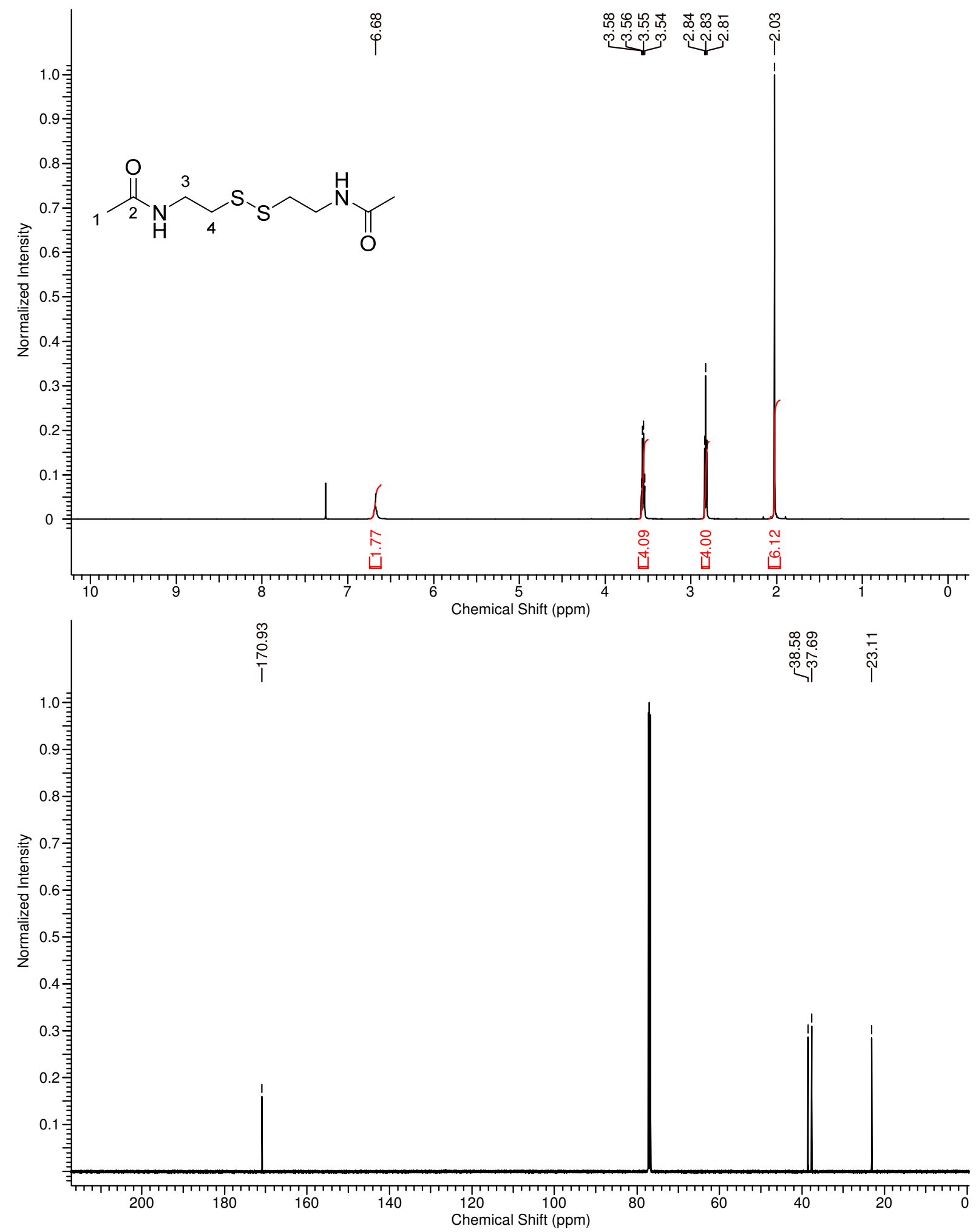
2-(2-(2-methoxyethoxy)ethoxy)ethyl 4-methylbenzenesulfonate (10)

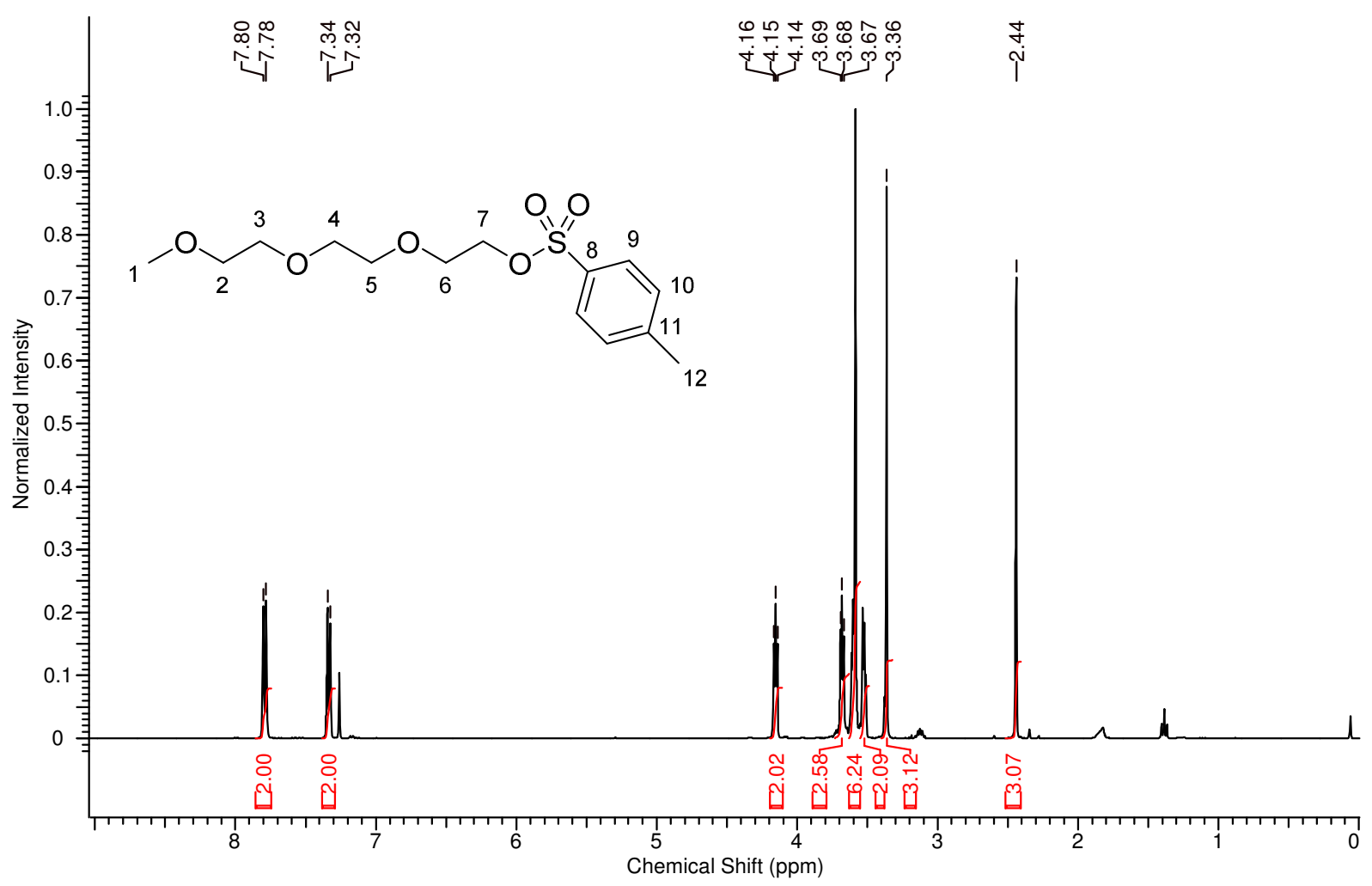


S-(2-(2-(2-methoxyethoxy)ethoxy)ethyl) ethanethioate (3c)

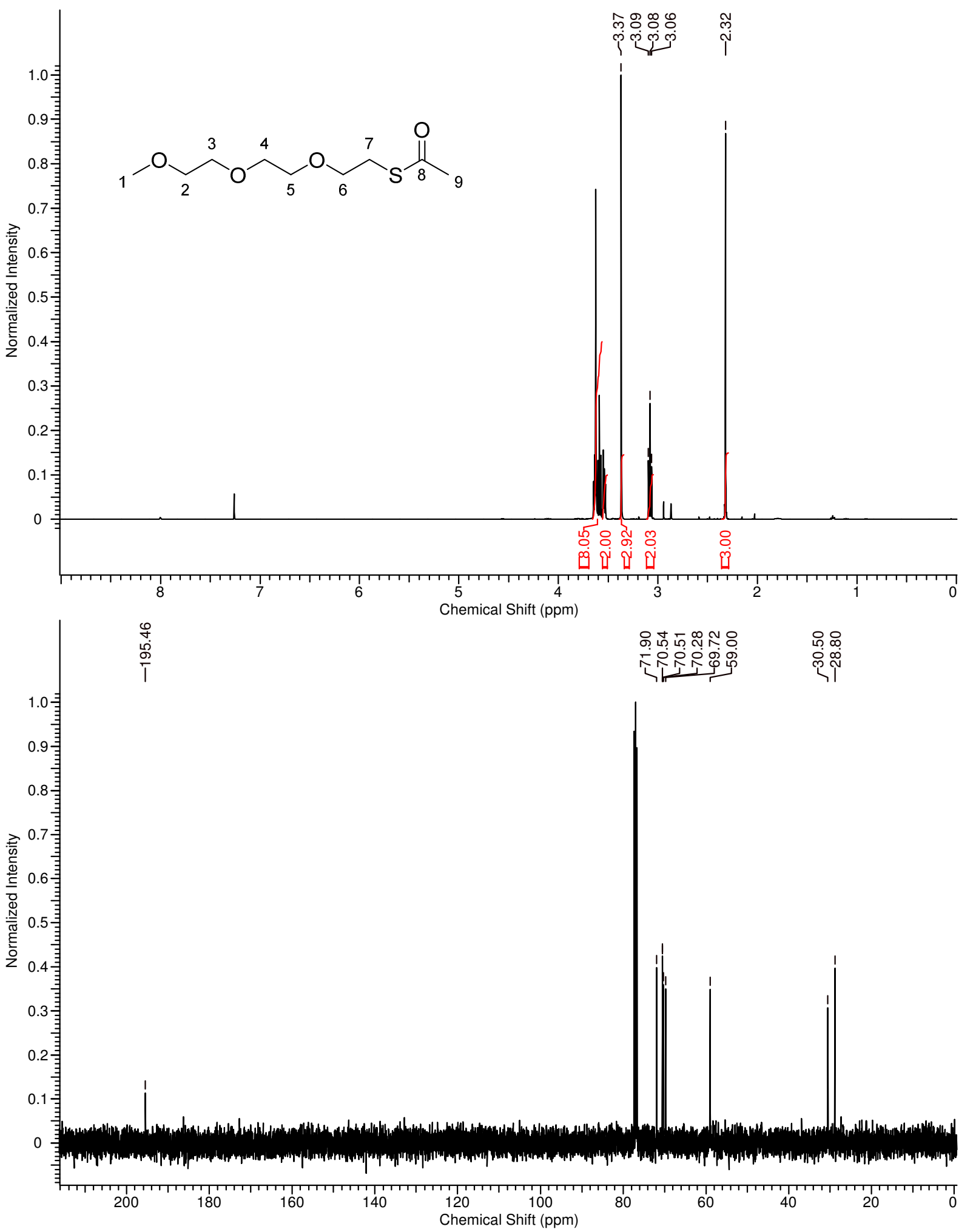


2-(2-(2-methoxyethoxy)ethoxy)ethane-1-thiol (1c)
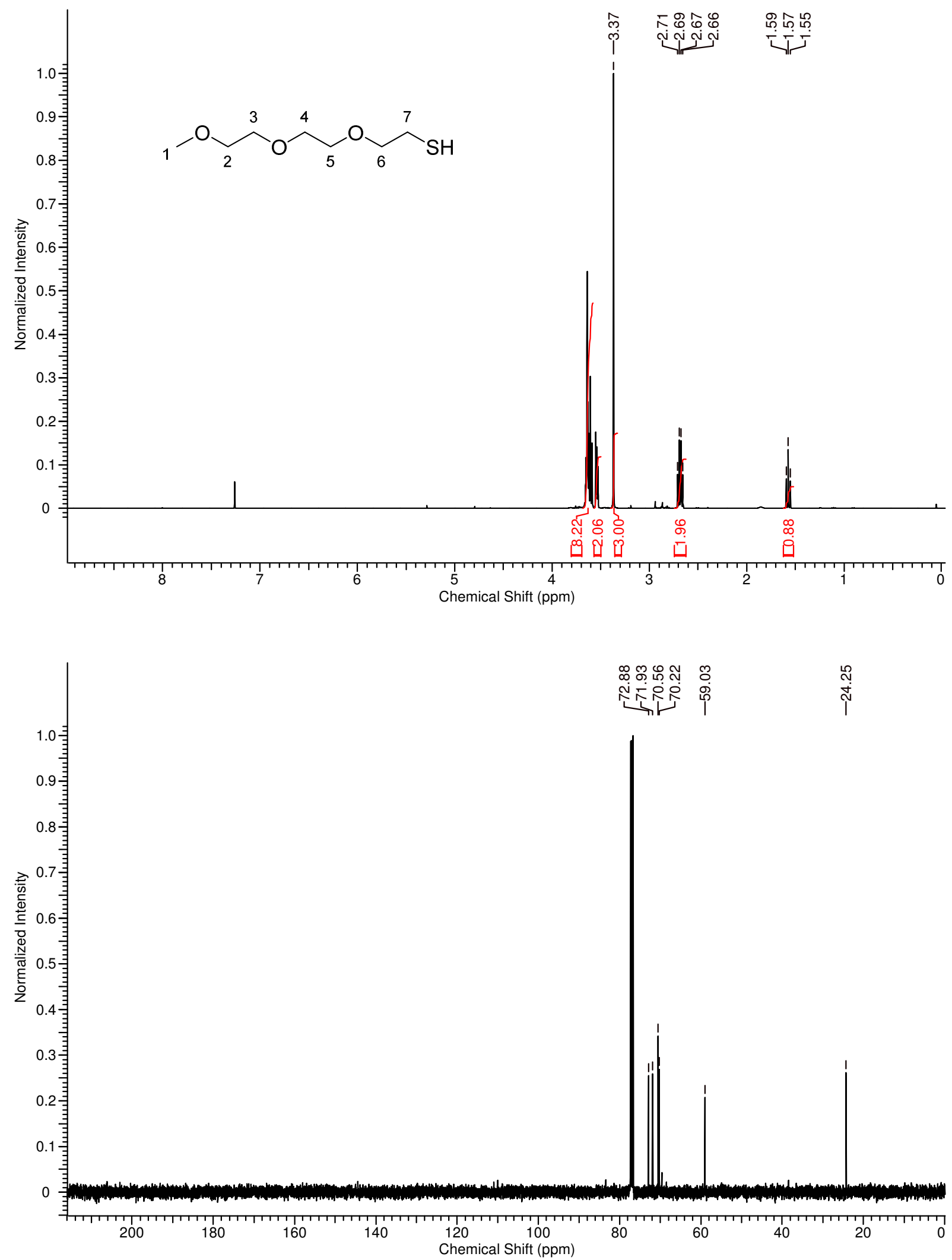
$N, S$-diacetyl cysteamine (3b)
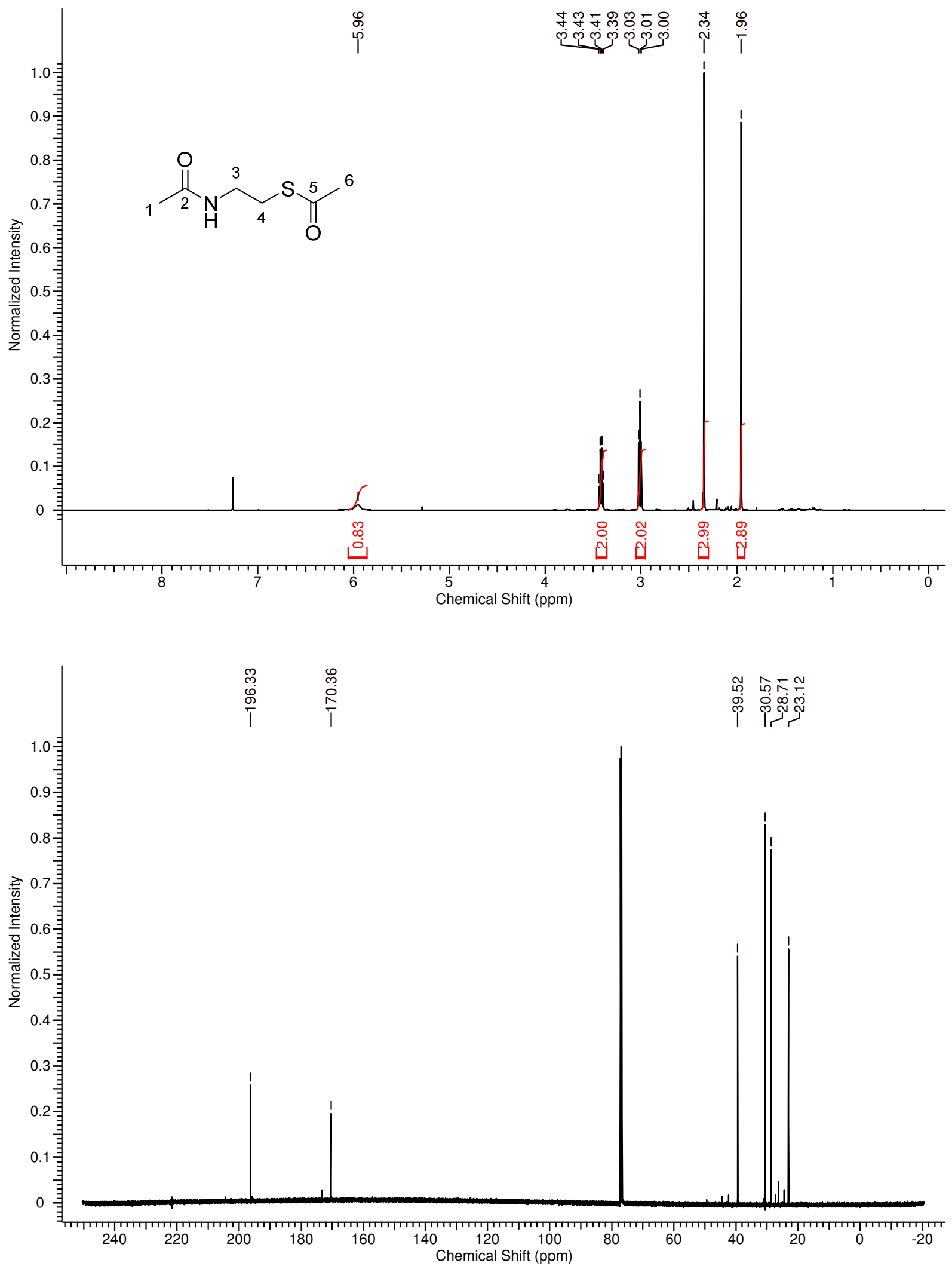


\section{2,5,8,15,18,21-hexaoxa-11,12-dithiadocosane (11)}
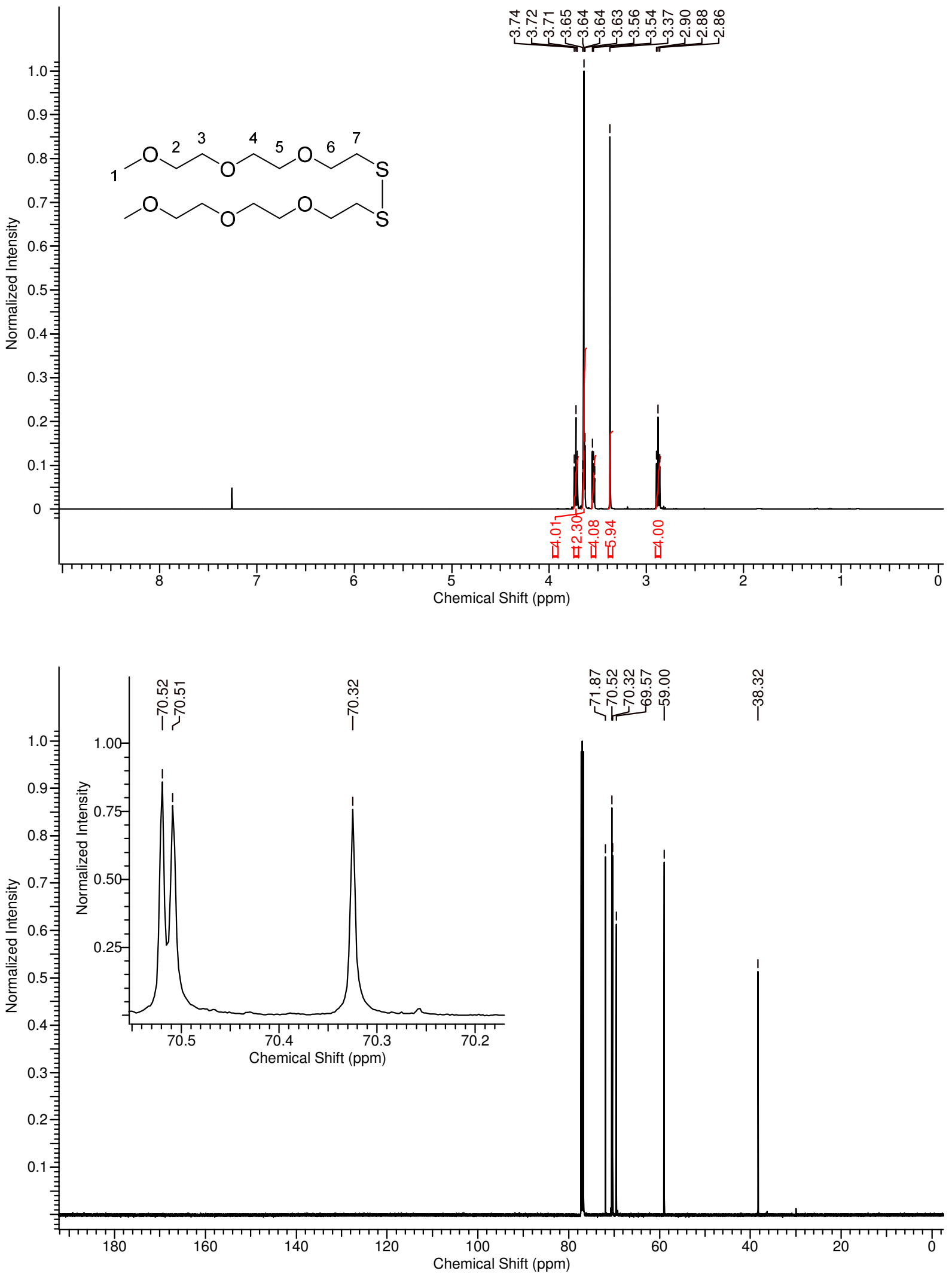
4-[[2-(Acetylamino)ethyl]thio]-4-oxobutanoic acid (5b)
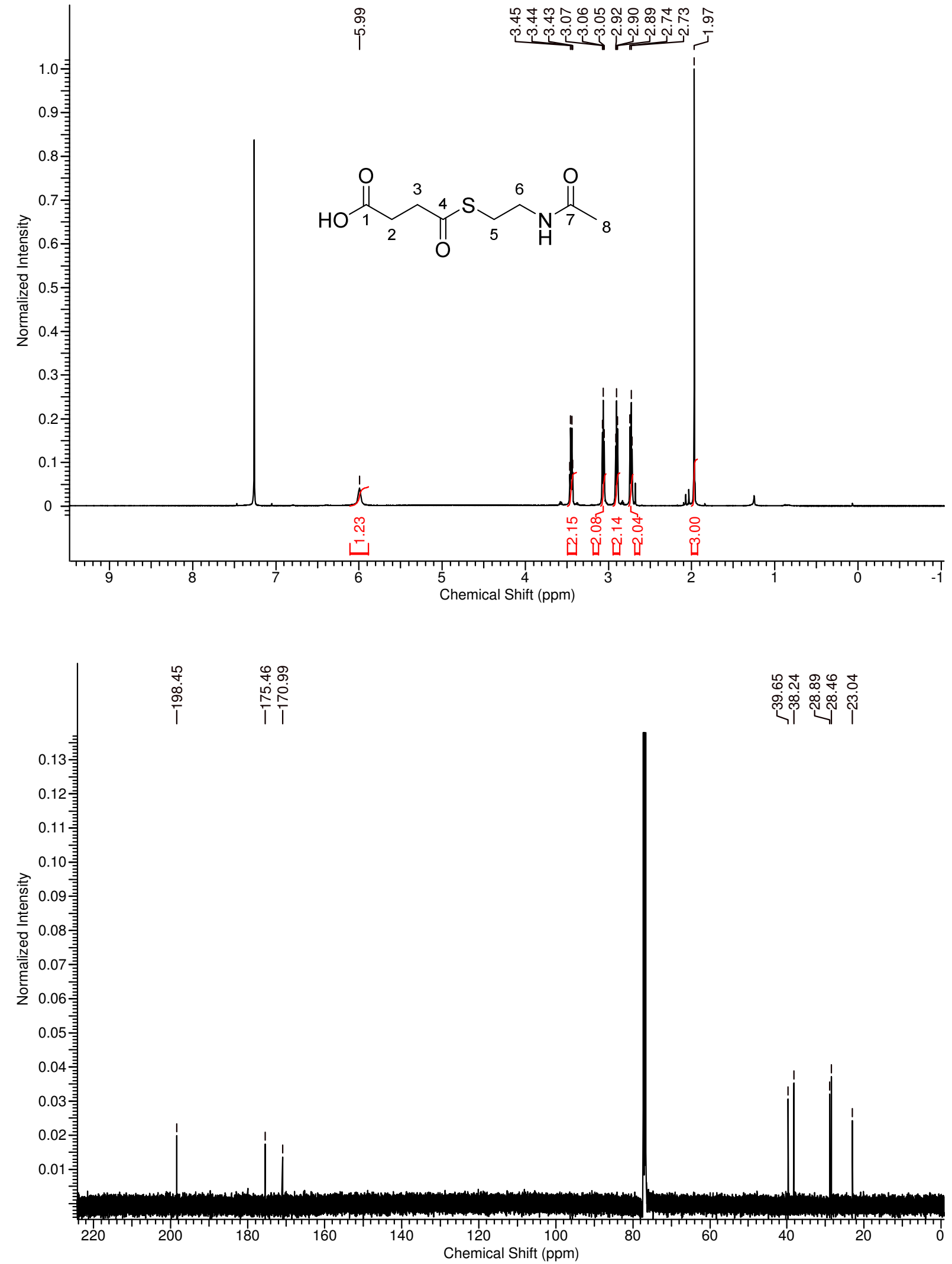


\section{3-((2-acetamidoethyl)thio)-3-oxopropanoic acid (8b)}
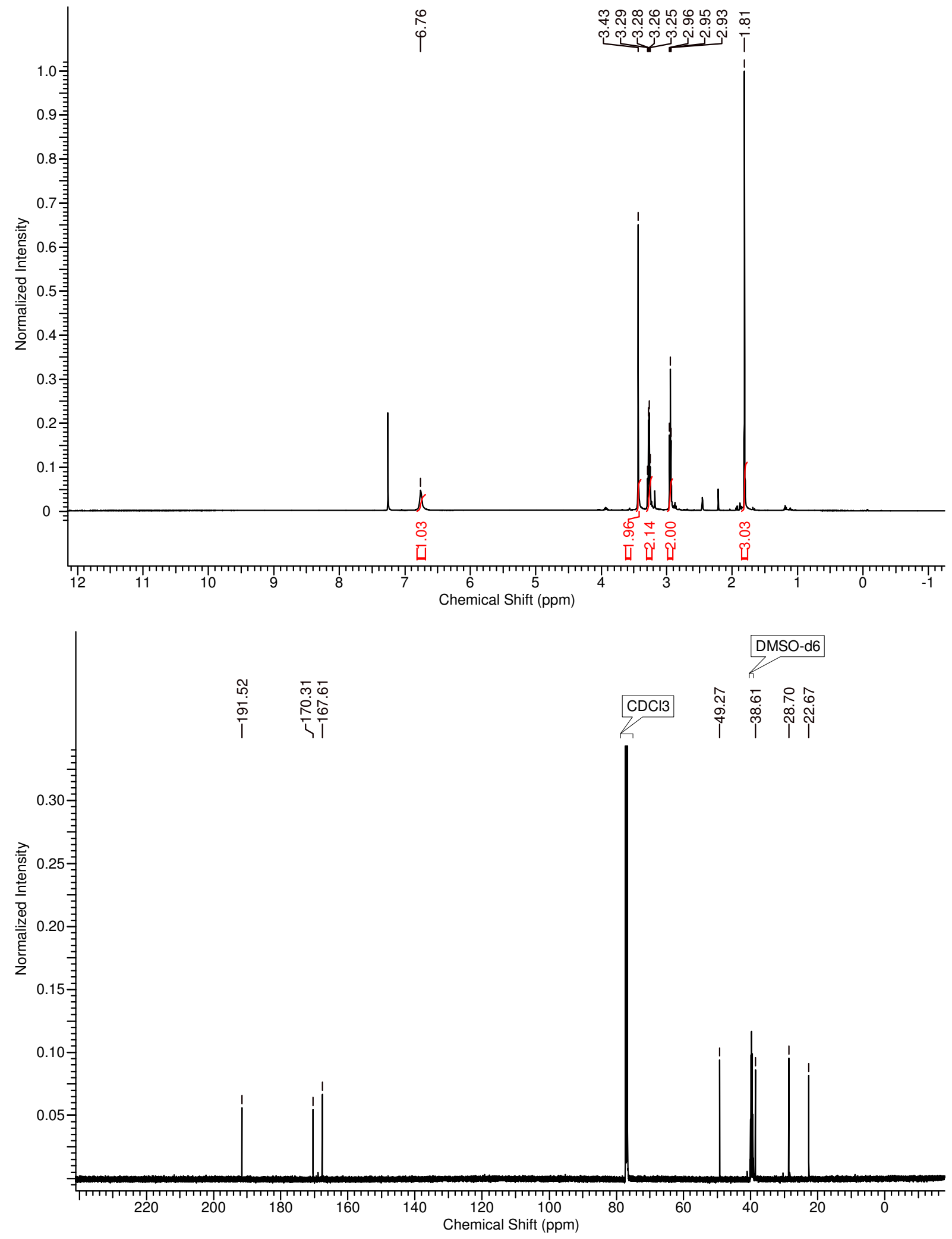
2-(2,2-dimethyl-5-oxo-1,3-dioxolan-4-yl)acetic acid (12)
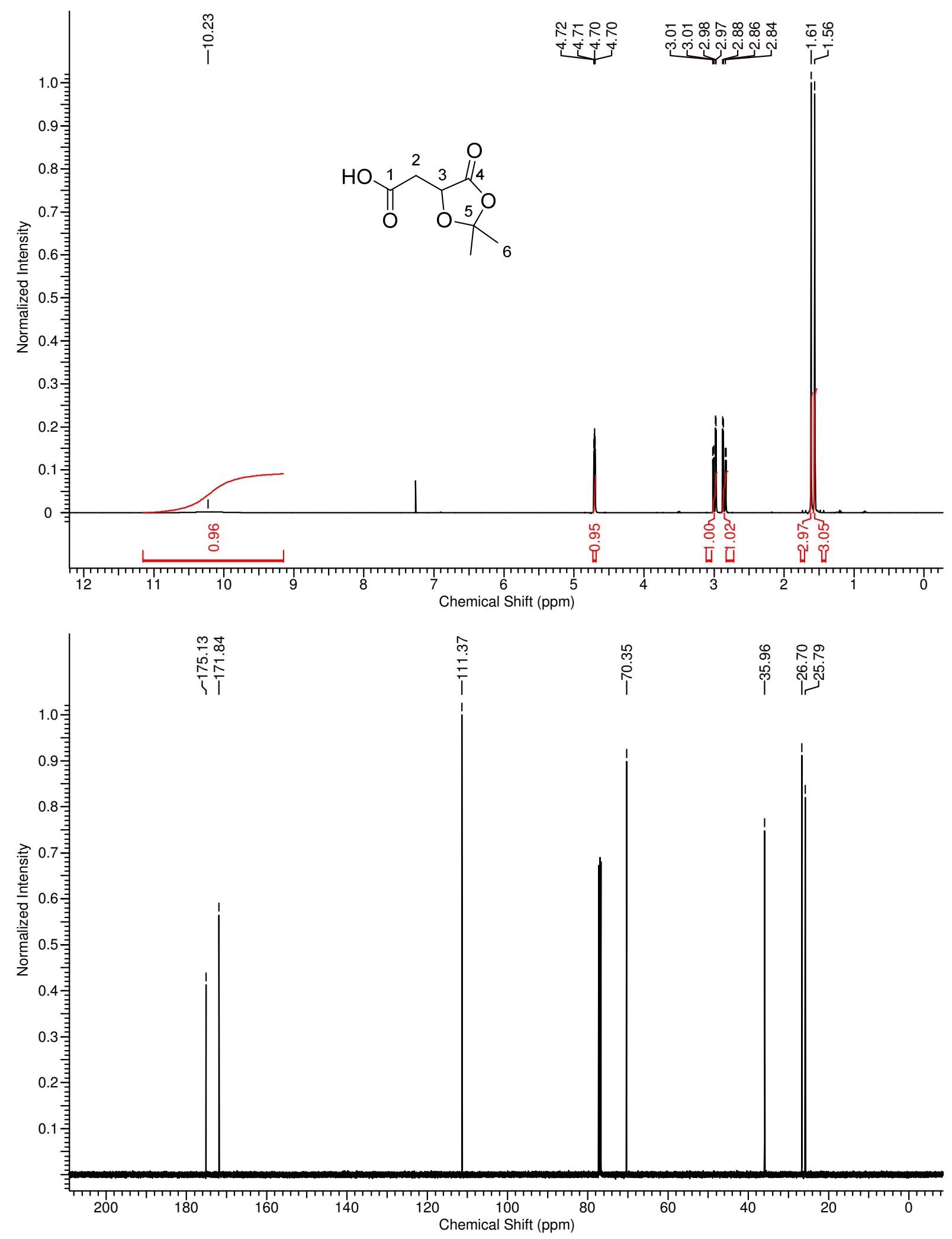
$S$-(2-acetamidoethyl) 2-(2,2-dimethyl-5-oxo-1,3-dioxolan-4-yl)ethanethioate (13)
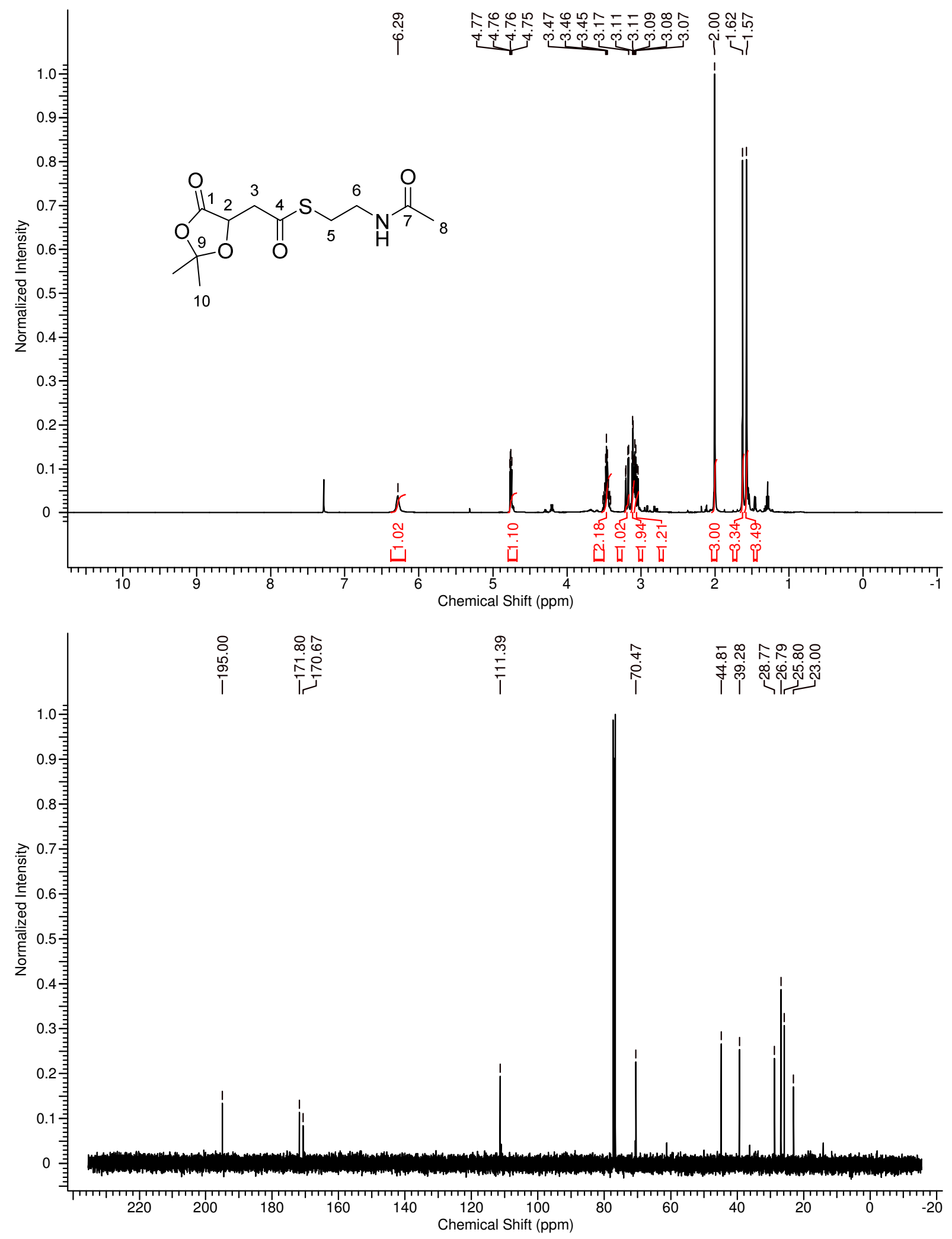
4-((2-acetamidoethyl)thio)-2-hydroxy-4-oxobutanoic acid (9b)
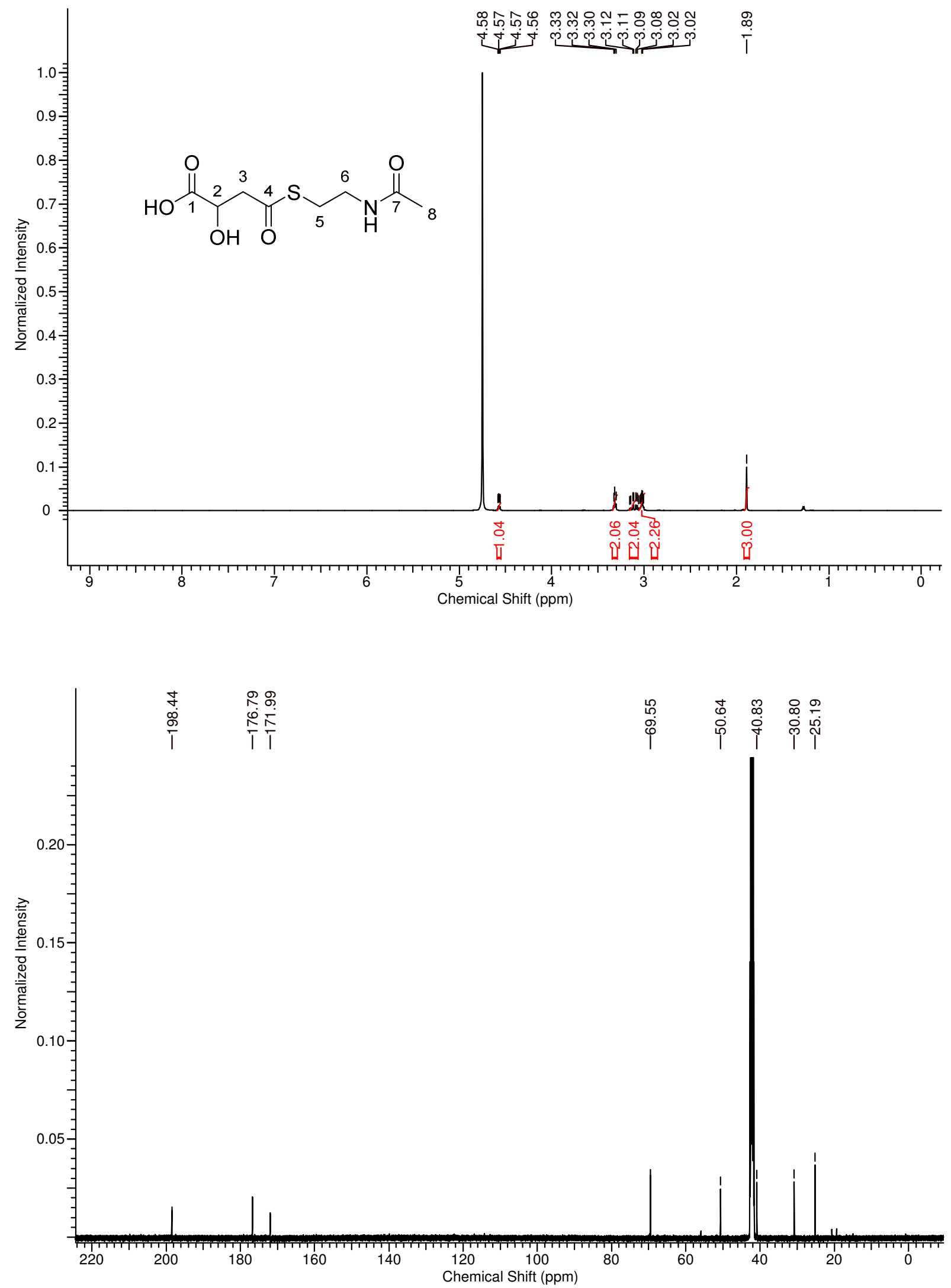
4.2. NMR spectra of reference compds. in $\mathrm{H}_{2} \mathrm{O} / \mathrm{D}_{2} \mathrm{O}$ with DSS as IS with water suppression $\mathrm{N}$-acetyl cysteamine (1b) in $\mathrm{H}_{2} \mathrm{O} / \mathrm{D}_{2} \mathrm{O}+\mathrm{DSS}$

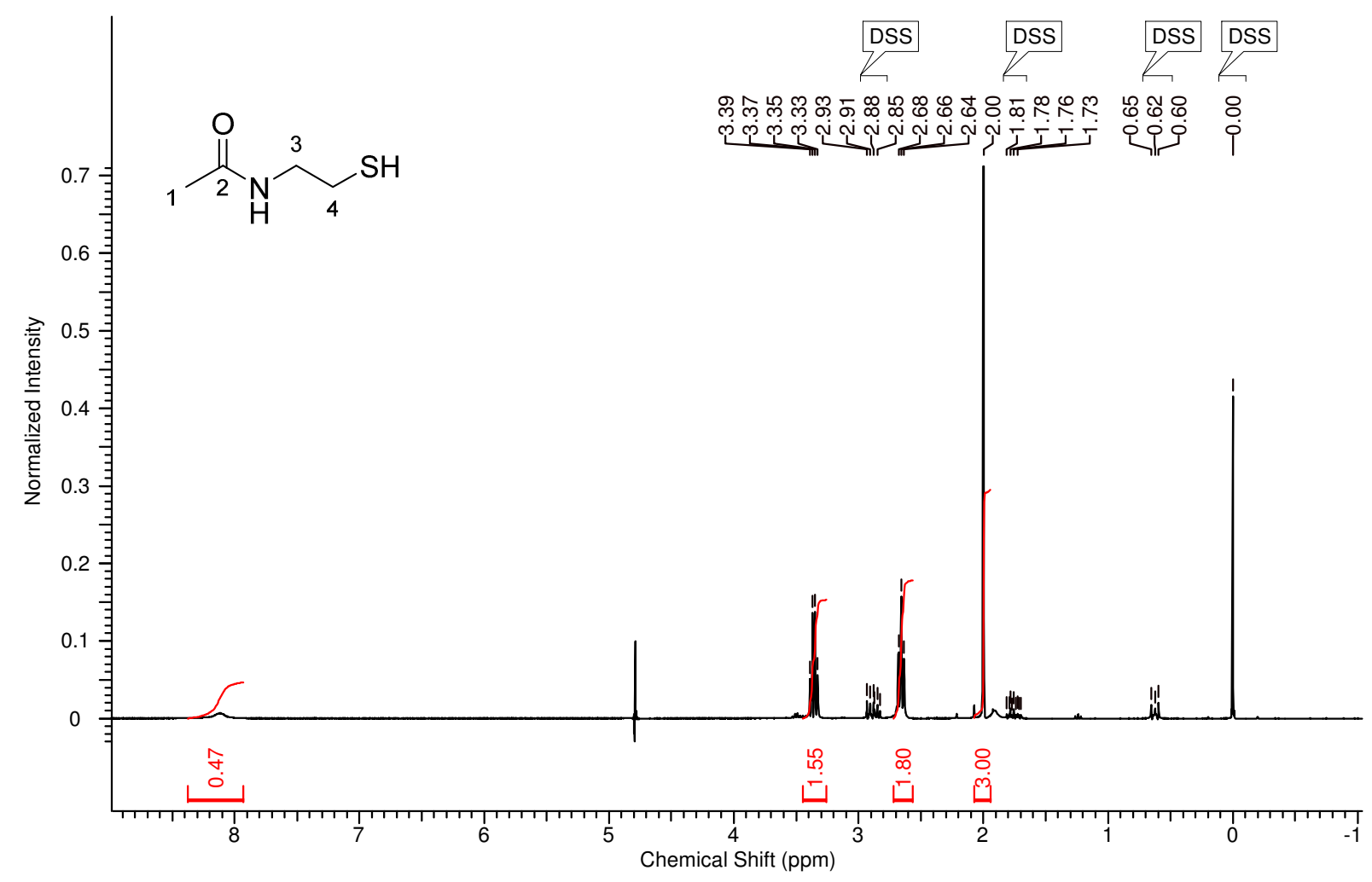

2-(2-(2-methoxyethoxy)ethoxy)ethane-1-thiol (1c) in $\mathrm{H}_{2} \mathrm{O} / \mathrm{D}_{2} \mathrm{O}+\mathrm{DSS}$

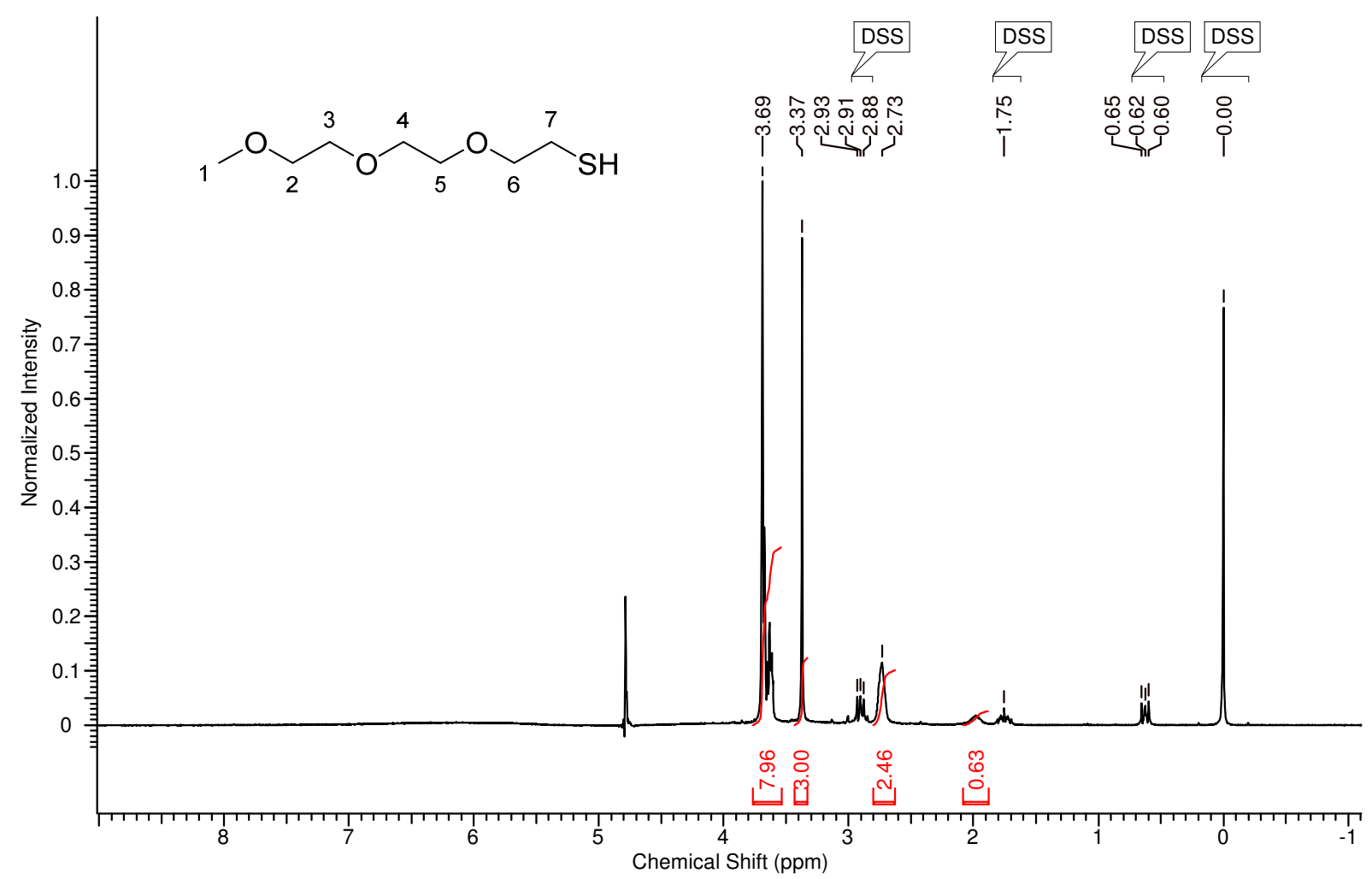


$N, N^{\prime}$-(disulfanediylbis(ethane-2,1-diyl))diacetamide (1d) in $\mathrm{H}_{2} \mathrm{O} / \mathrm{D}_{2} \mathrm{O}+\mathrm{DSS}$

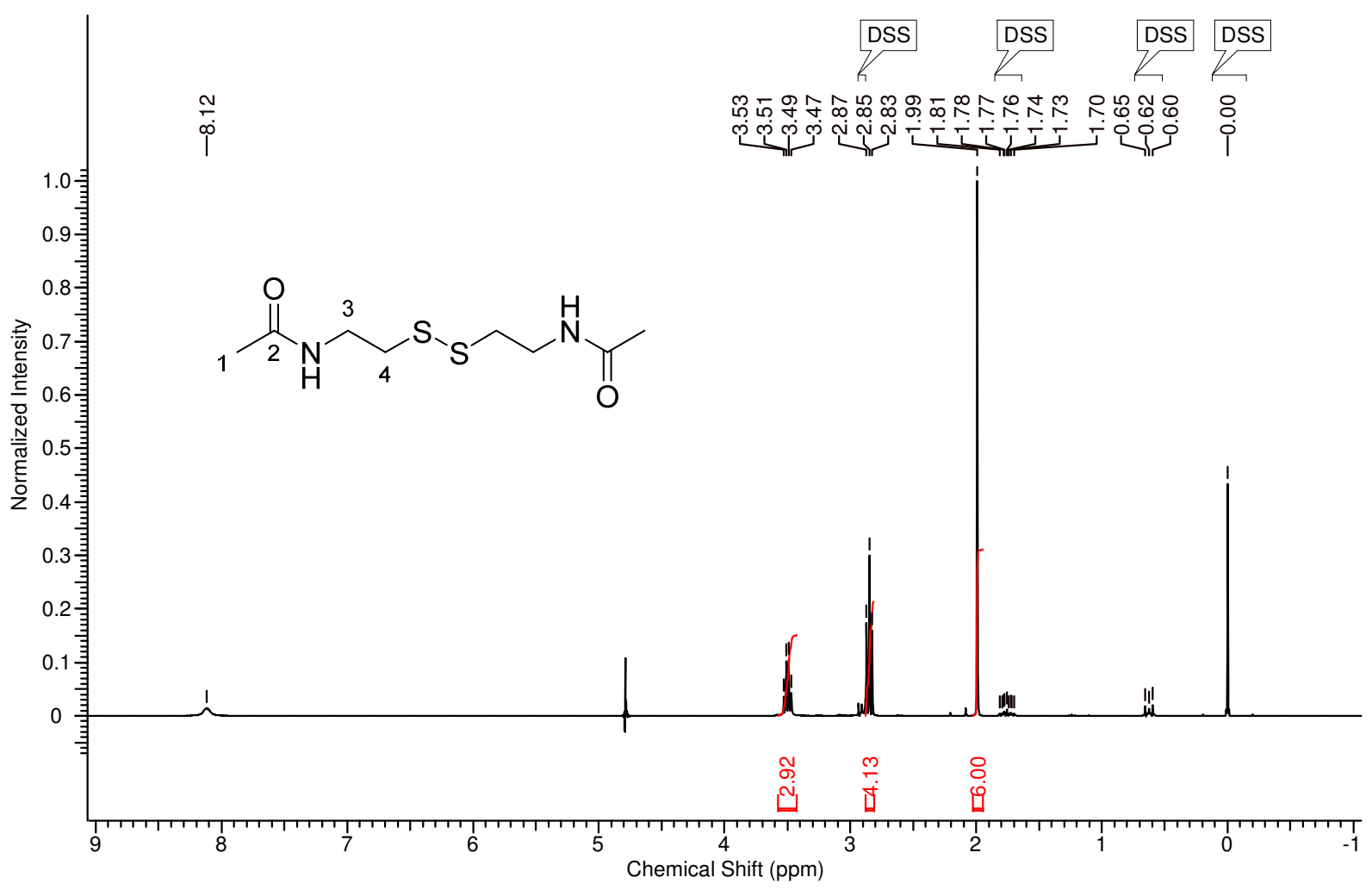

$N, S$-diacetyl cysteamine (3b) in $\mathrm{H}_{2} \mathrm{O} / \mathrm{D}_{2} \mathrm{O}+\mathrm{DSS}$

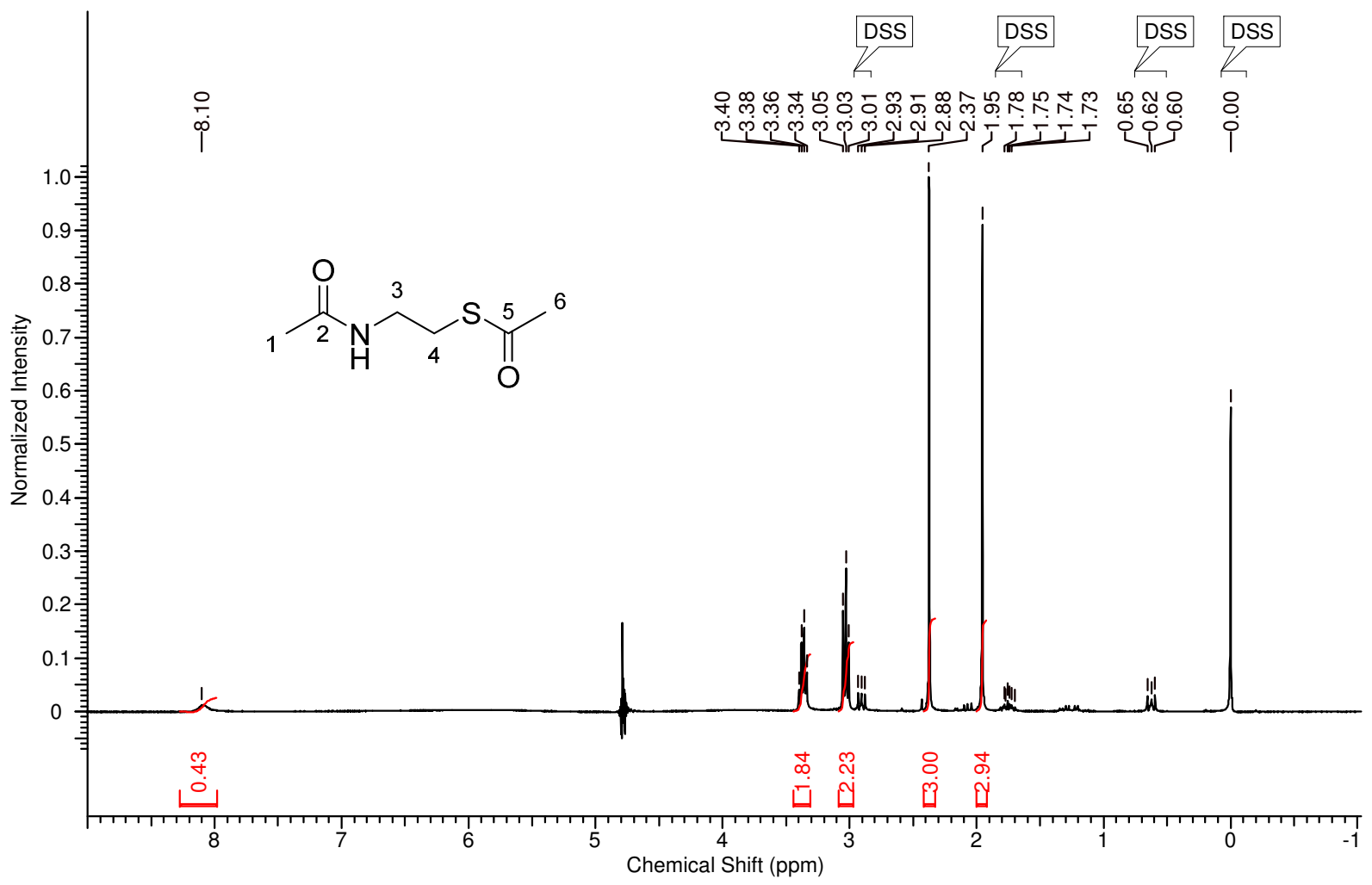


S-(2-(2-(2-methoxyethoxy)ethoxy)ethyl) ethanethioate (3c) in $\mathrm{H}_{2} \mathrm{O} / \mathrm{D}_{2} \mathrm{O}+\mathrm{DSS}$

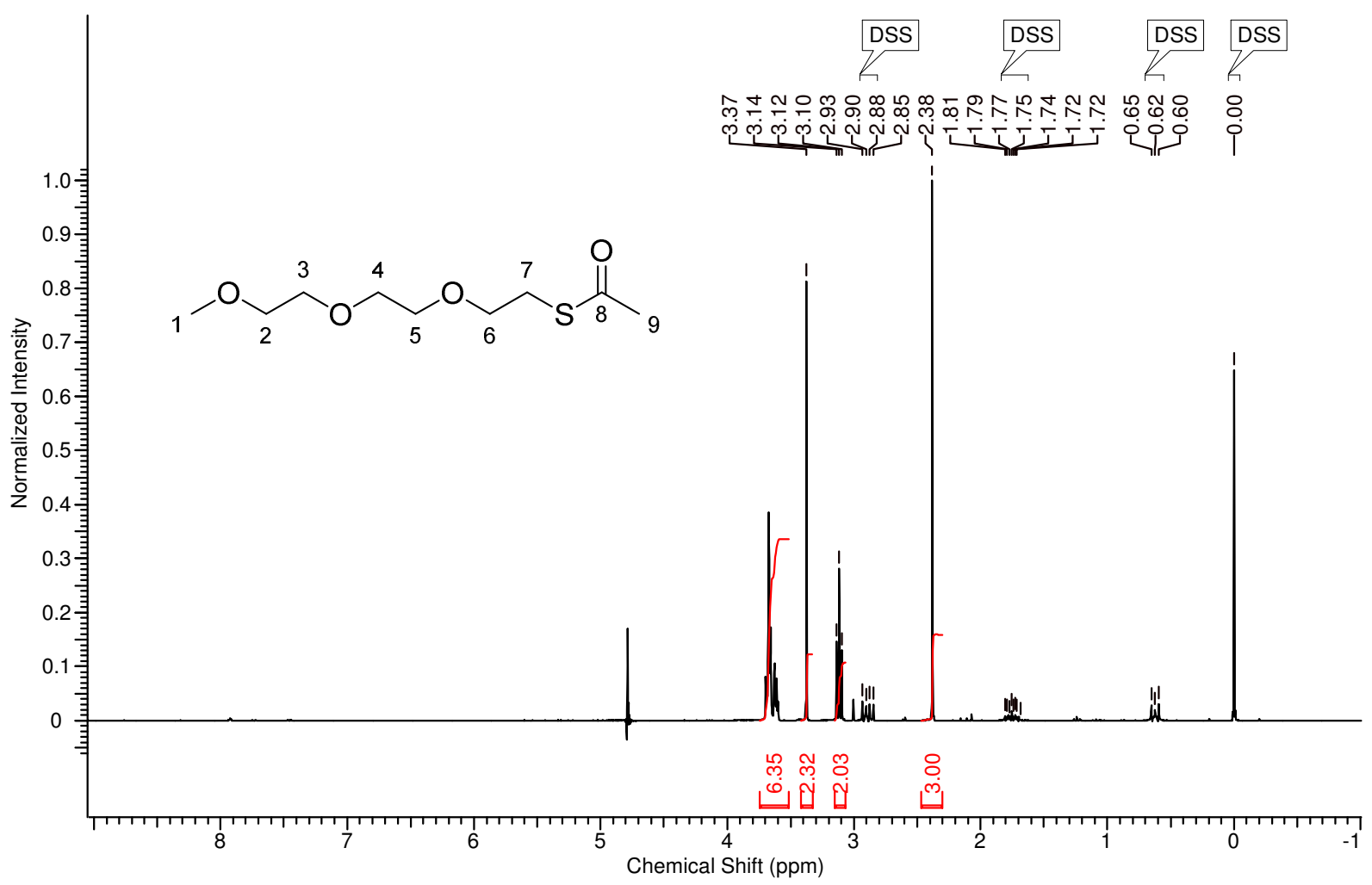

4-[[2-(Acetylamino)ethyl]thio]-4-oxobutanoic acid (5b) in $\mathrm{H}_{2} \mathrm{O} / \mathrm{D}_{2} \mathrm{O}+\mathrm{DSS}$

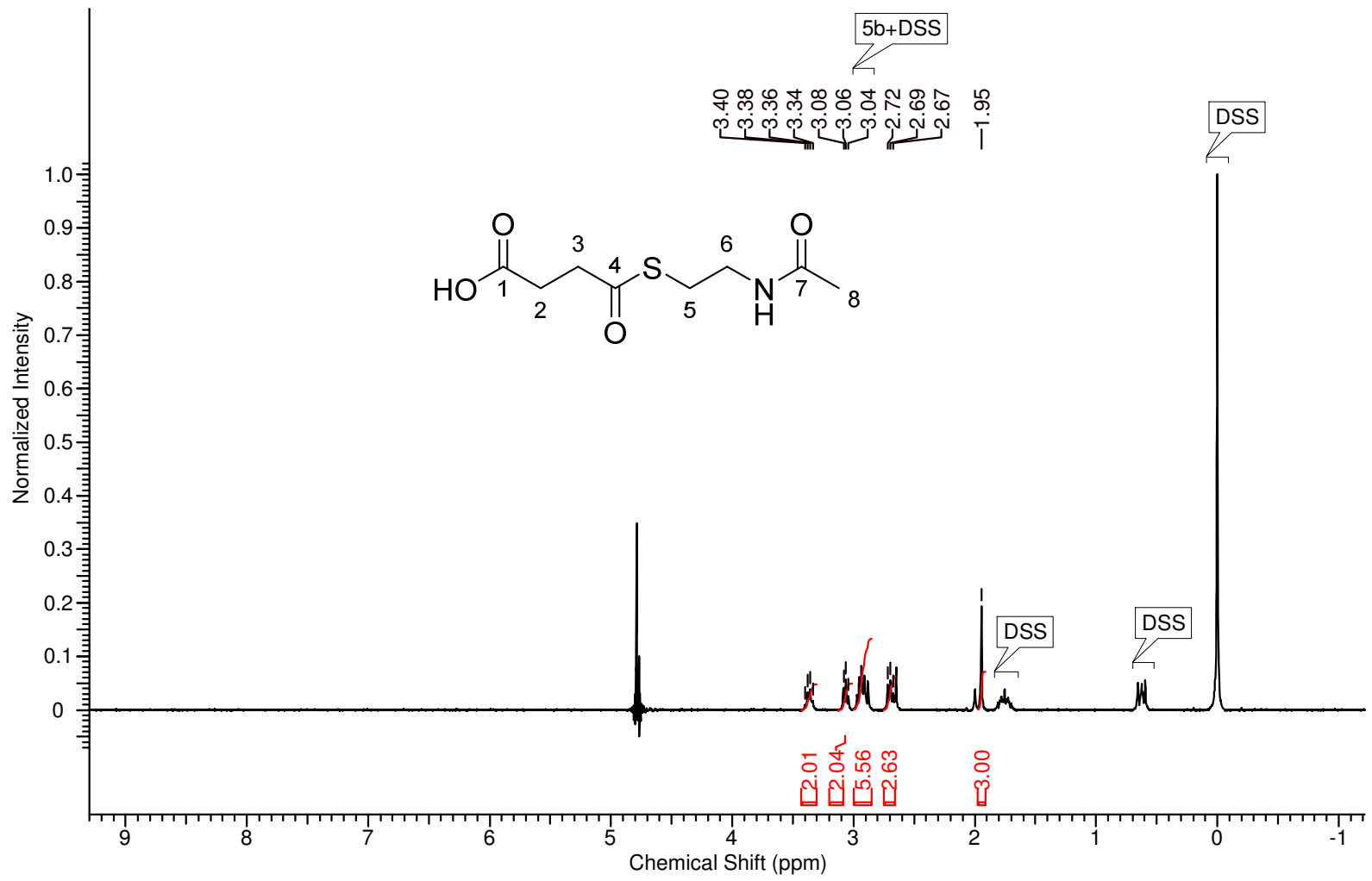




\section{2,5,8,15,18,21-hexaoxa-11,12-dithiadocosane (11) in $\mathrm{H}_{2} \mathrm{O} / \mathrm{D}_{2} \mathrm{O}+\mathrm{DSS}$}

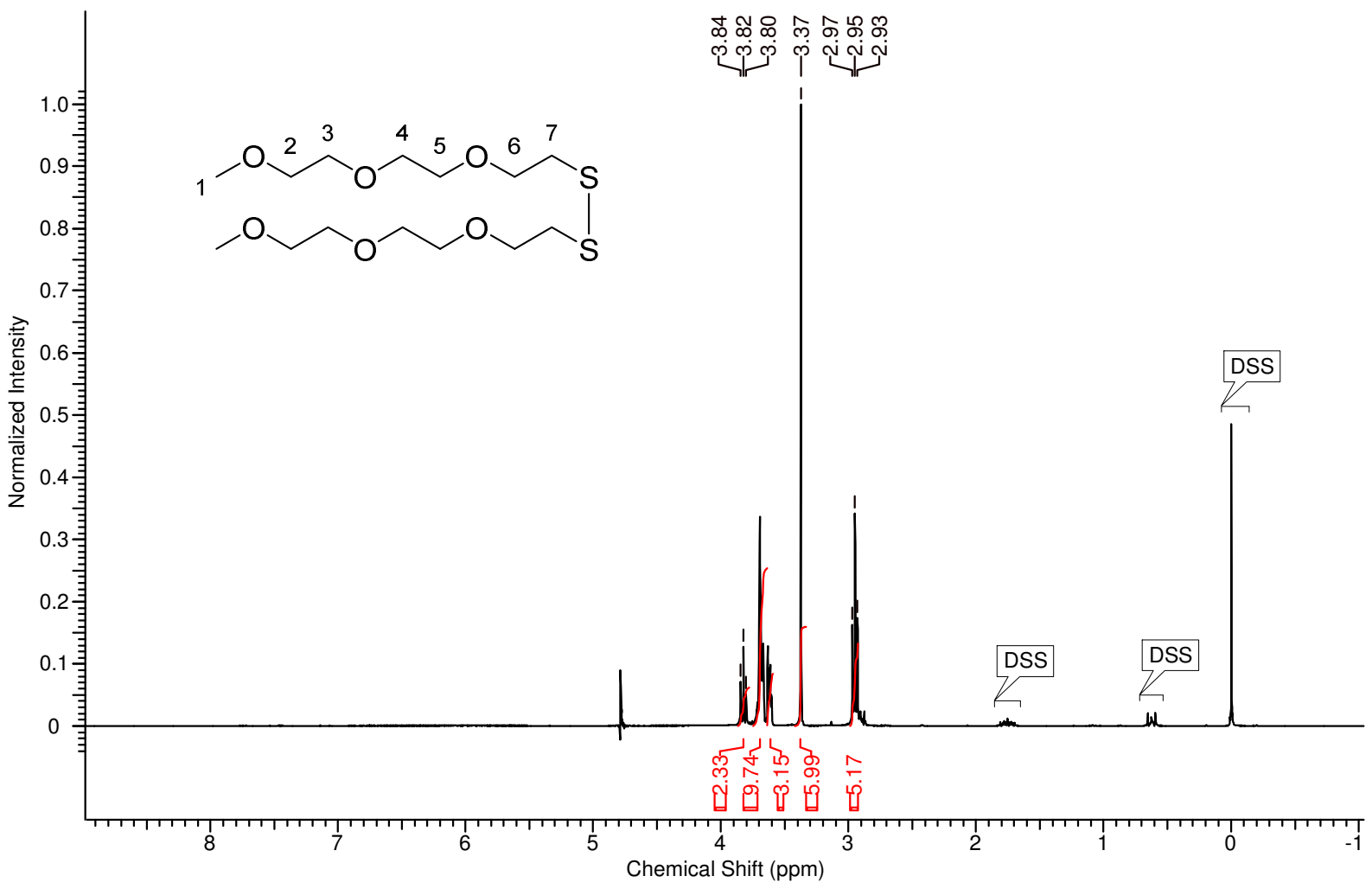

3-((2-acetamidoethyl)thio)-3-oxopropanoic acid (8b) in $\mathrm{H}_{2} \mathrm{O} / \mathrm{D}_{2} \mathrm{O}+\mathrm{DSS}$

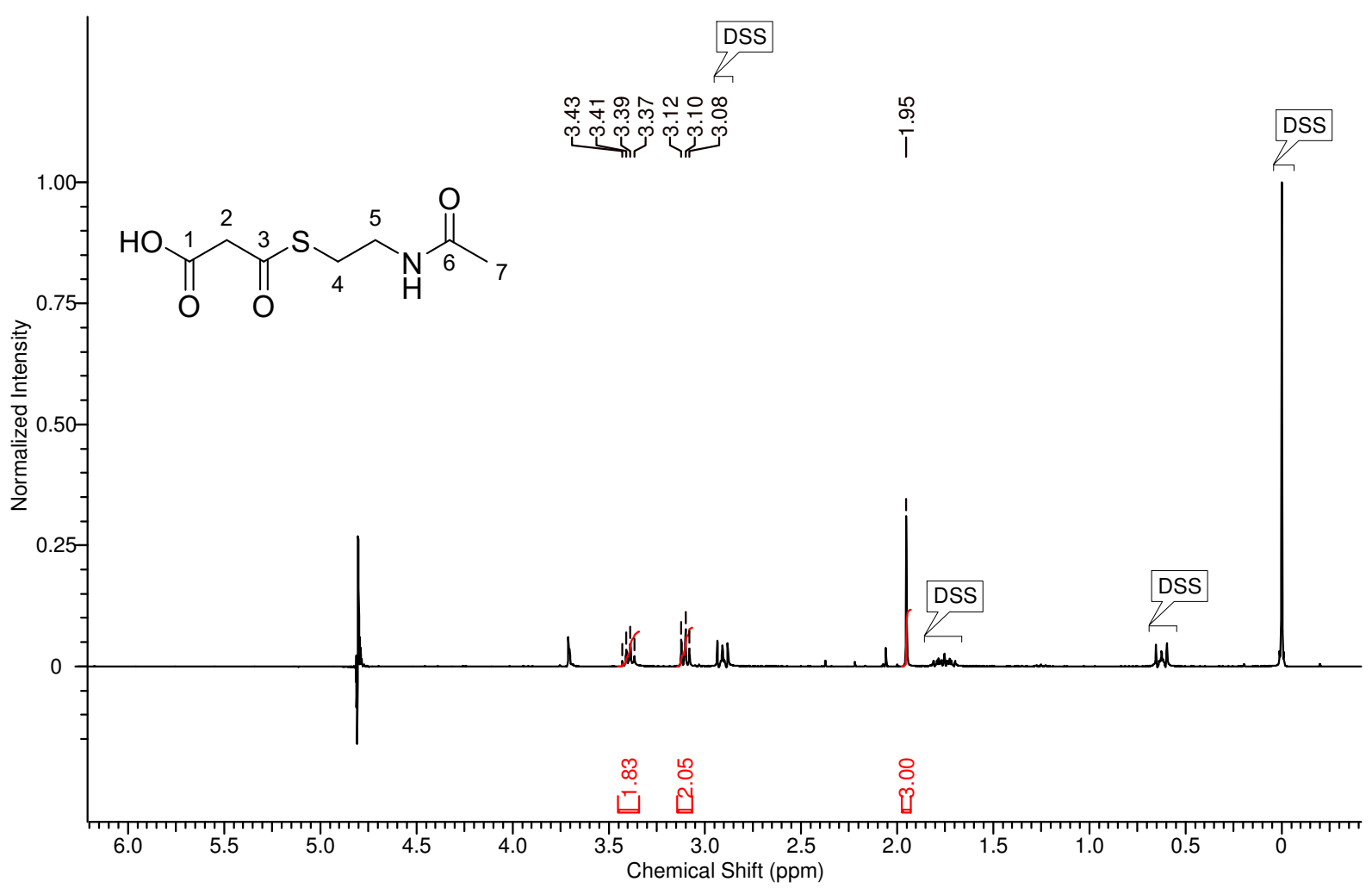


sodium pyruvate (1)
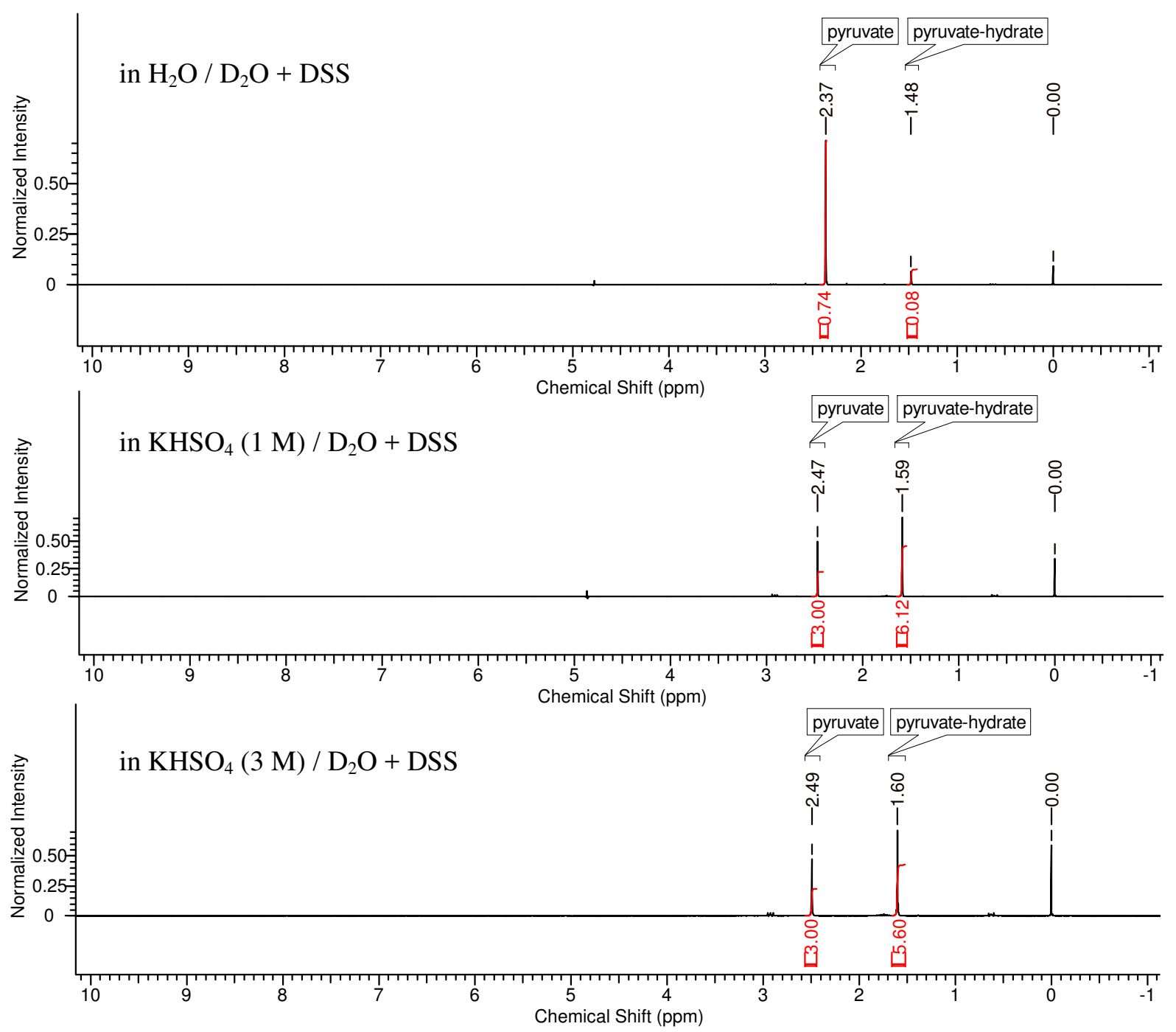
oxaloacetic acid (6)
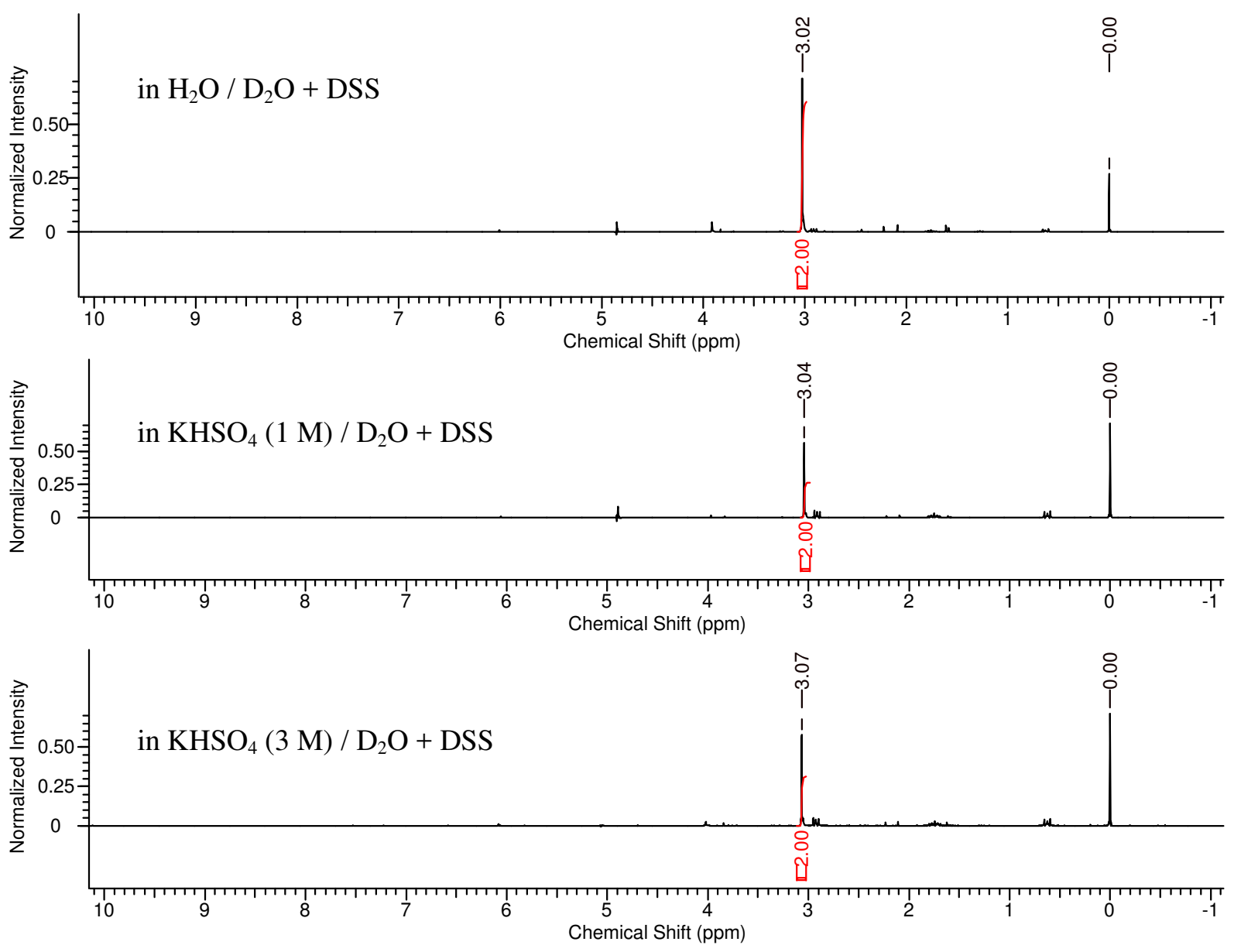
$\alpha$-ketoglutaric acid (4) in $\mathrm{H}_{2} \mathrm{O} / \mathrm{D}_{2} \mathrm{O}+\mathrm{DSS}$

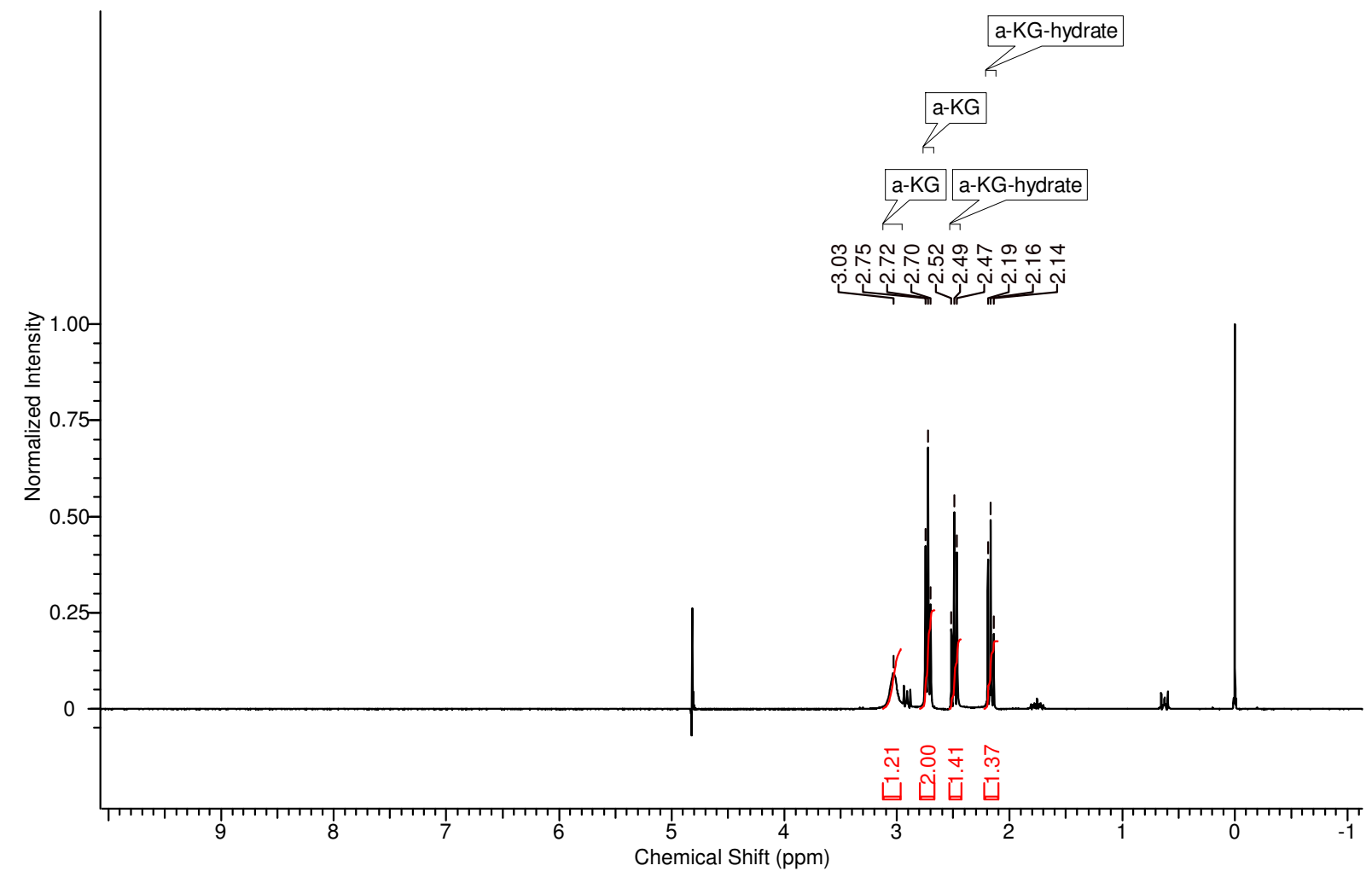

succinic acid in $\mathrm{H}_{2} \mathrm{O} / \mathrm{D}_{2} \mathrm{O}+\mathrm{DSS}$

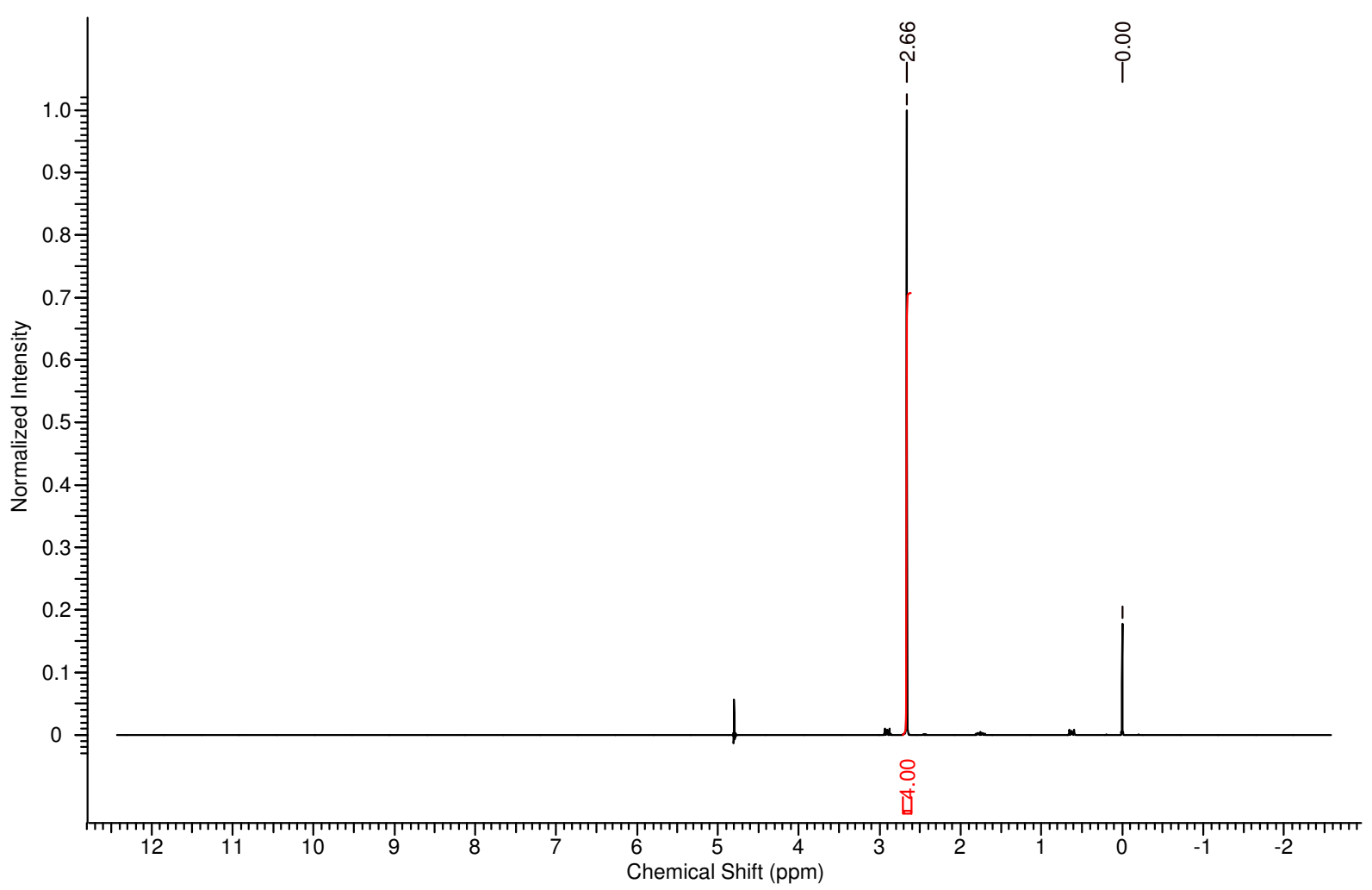


malonic acid in $\mathrm{H}_{2} \mathrm{O} / \mathrm{D}_{2} \mathrm{O}+\mathrm{DSS}$

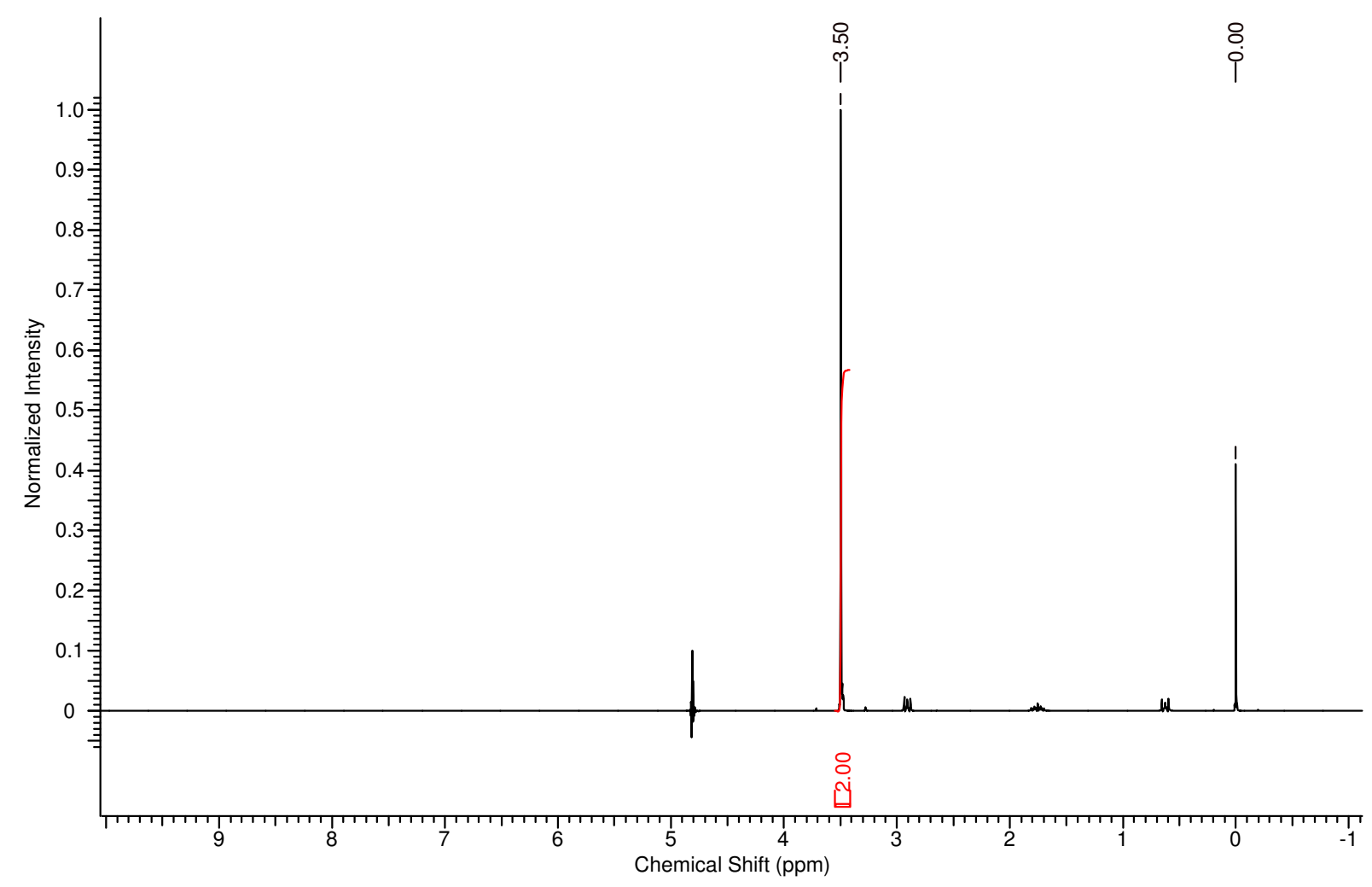




\subsection{NMR spectra of selected reaction mixtures showing prebiotic thioester formations}

Table 1, Entry 1, Method A

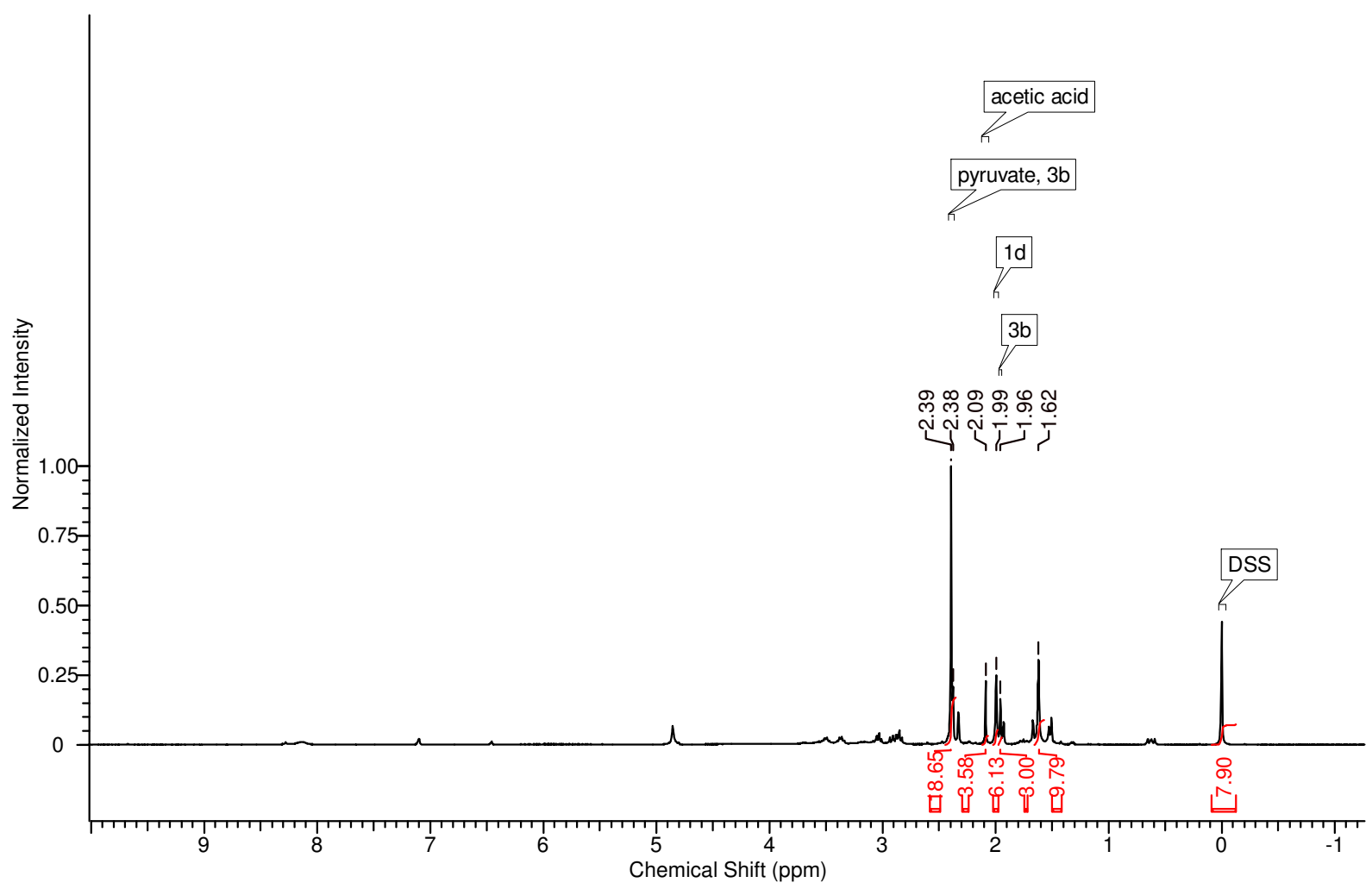

Table 1, Entry 1, Method B

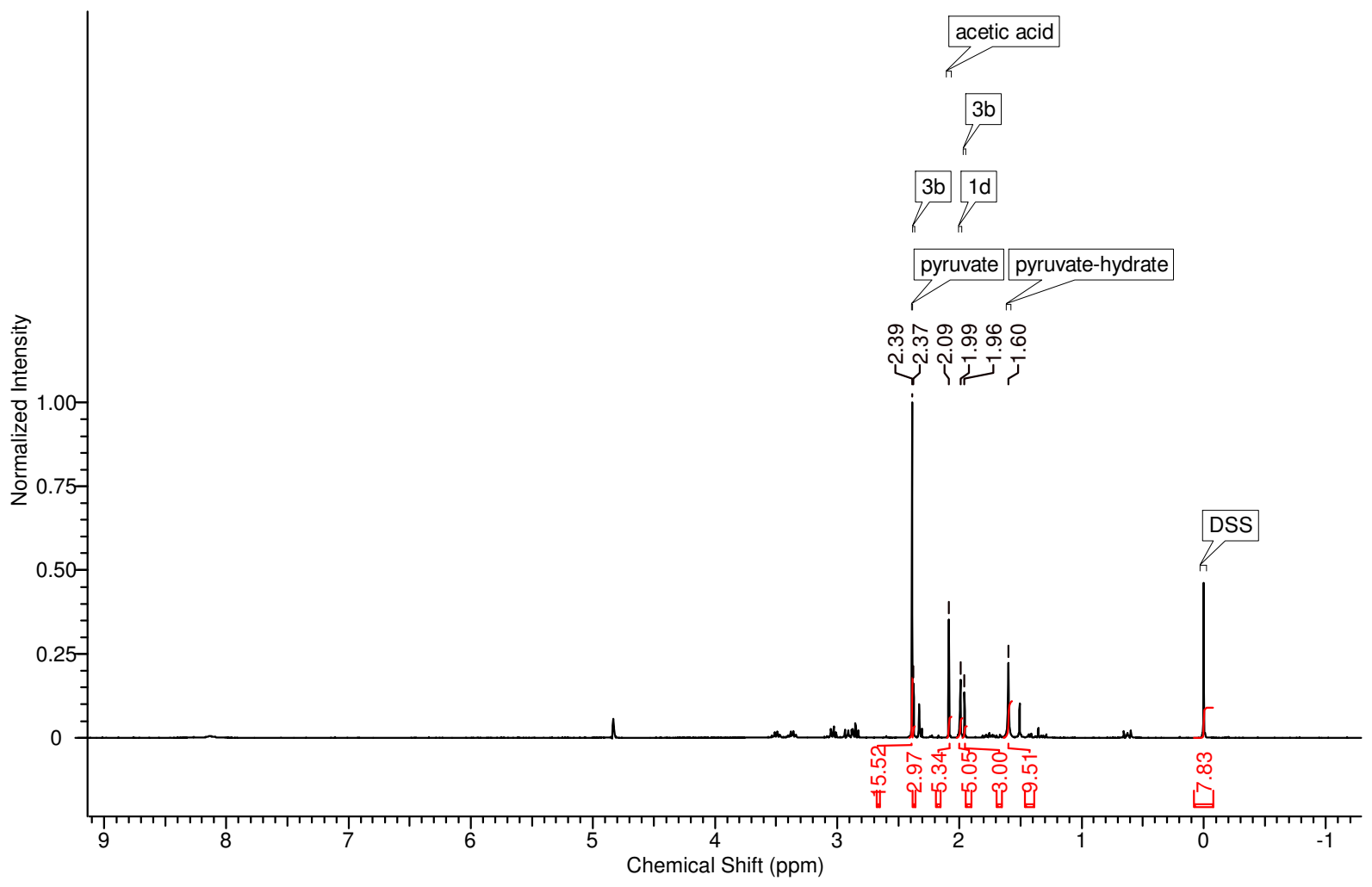


Table 1, Entry 1, Method C

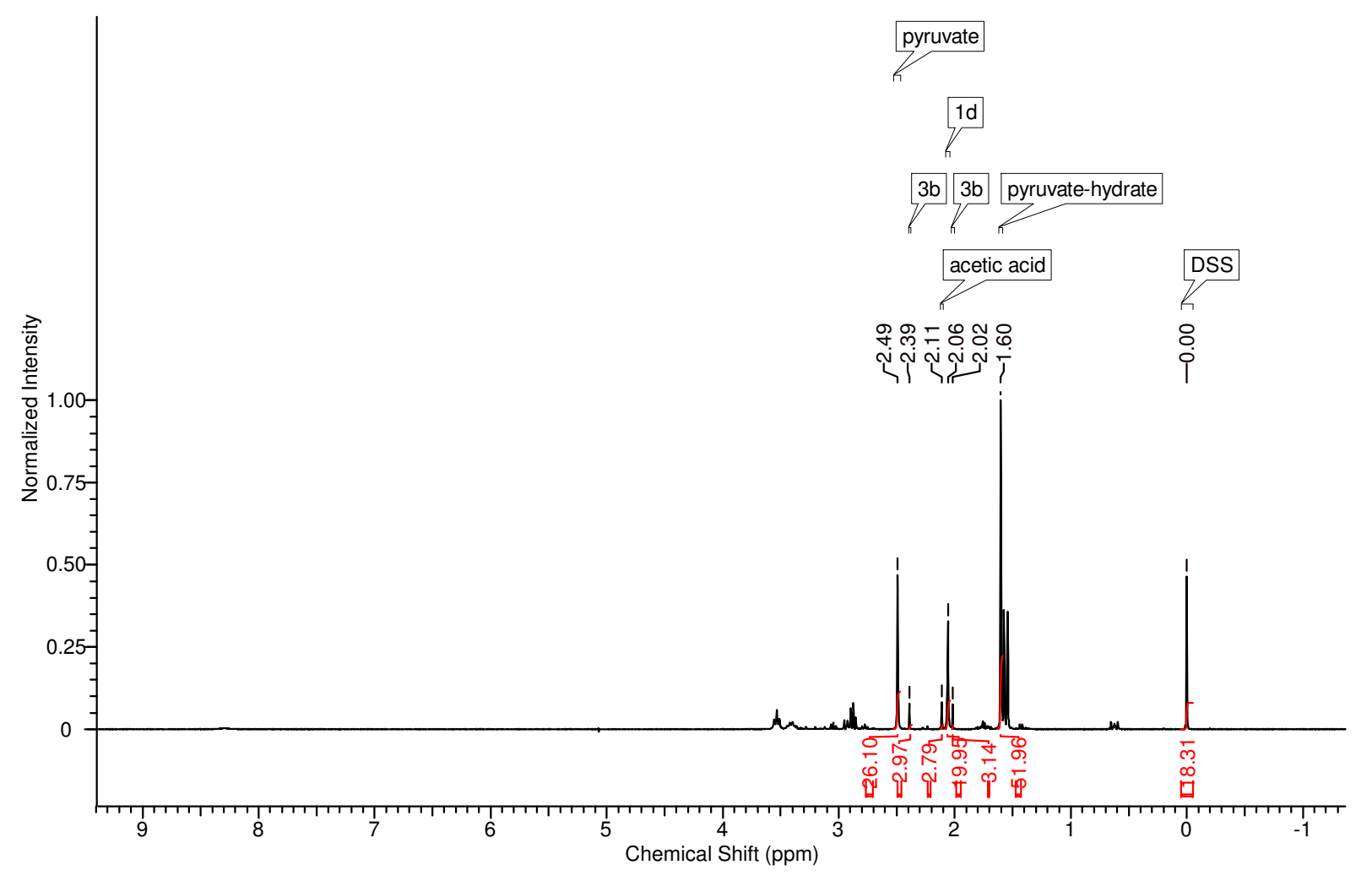

Table 1, Entry 2, Method A

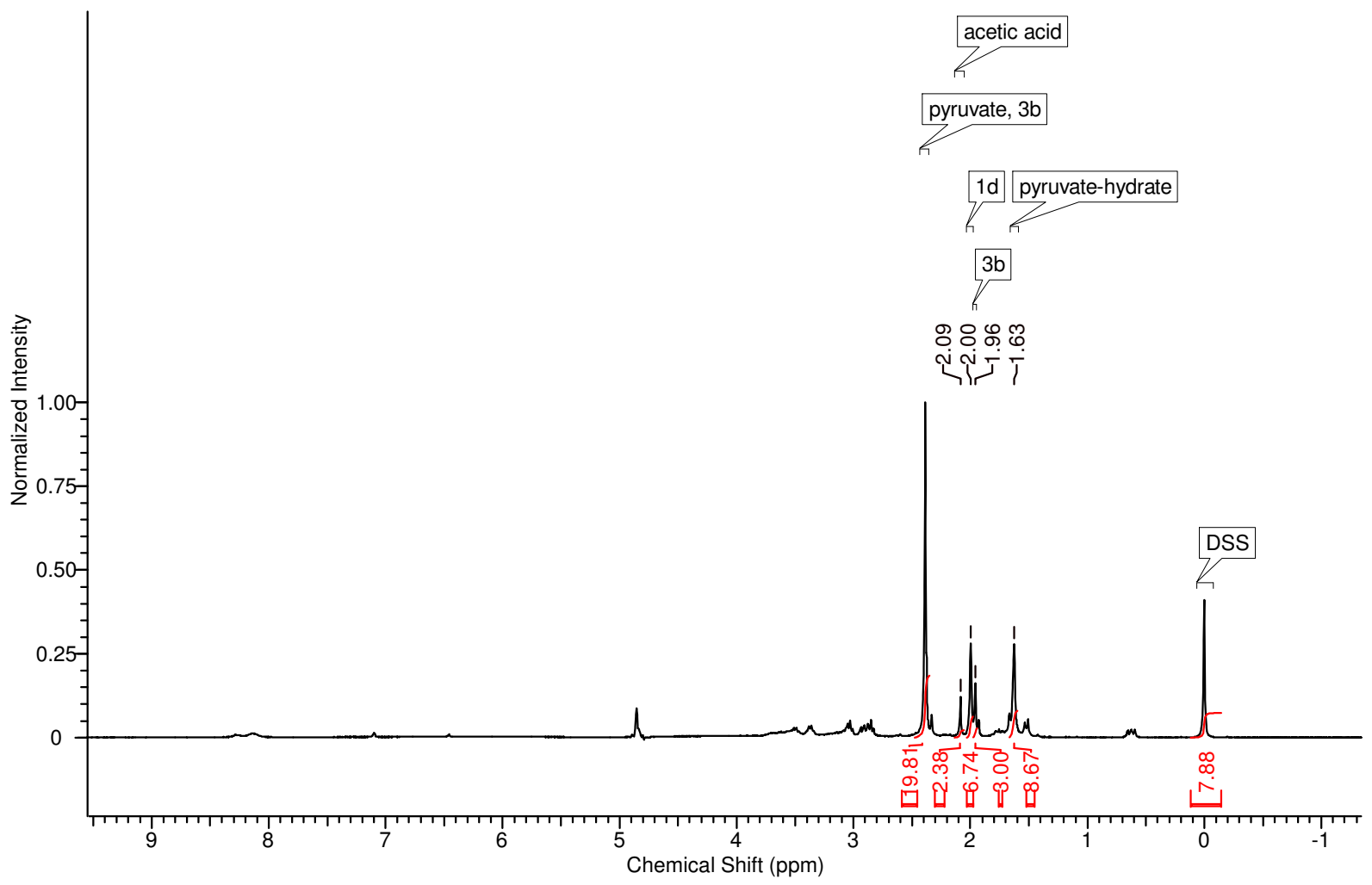


Table 1, Entry 2, Method B

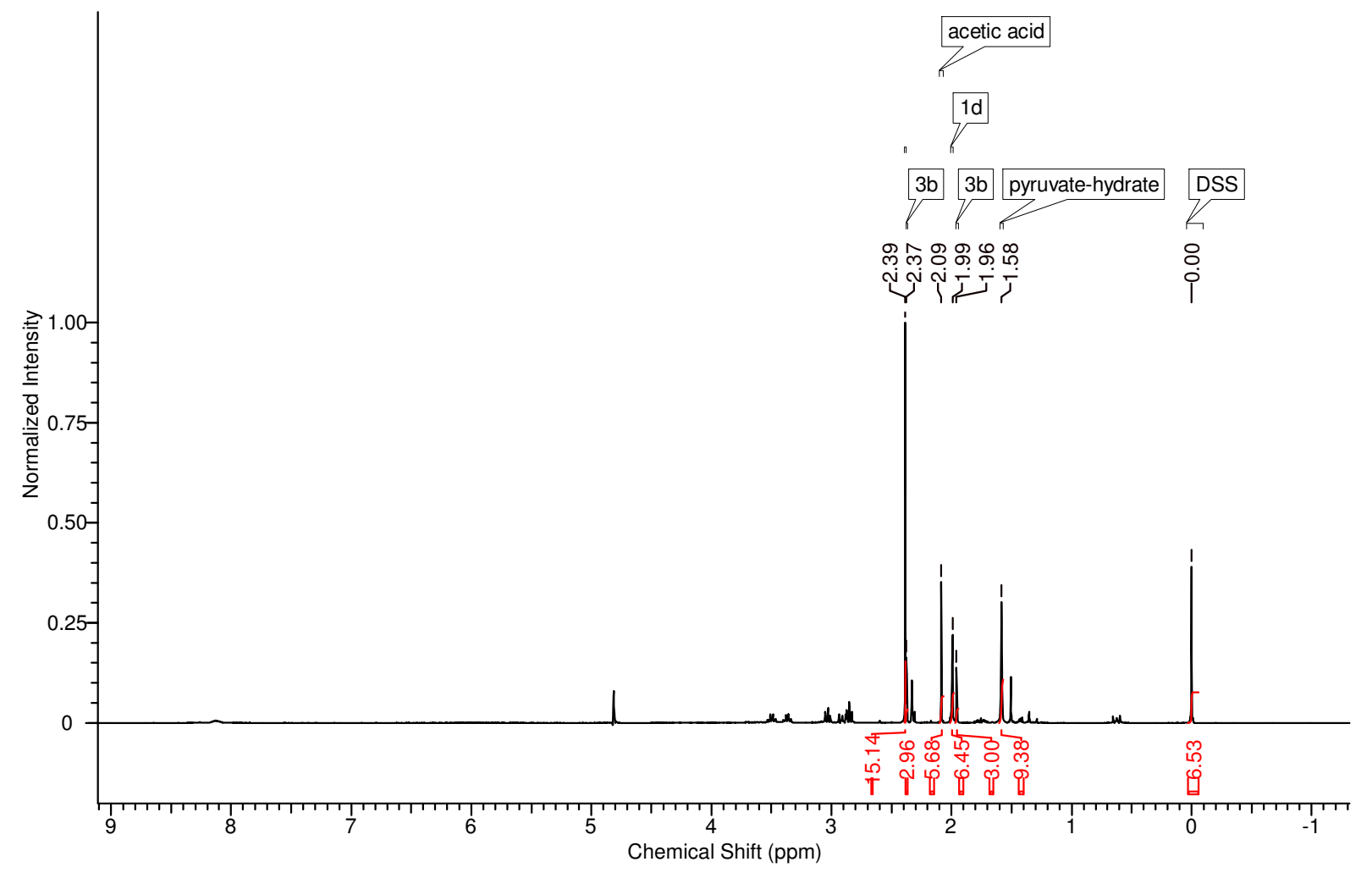

Table 1, Entry 2, Method C

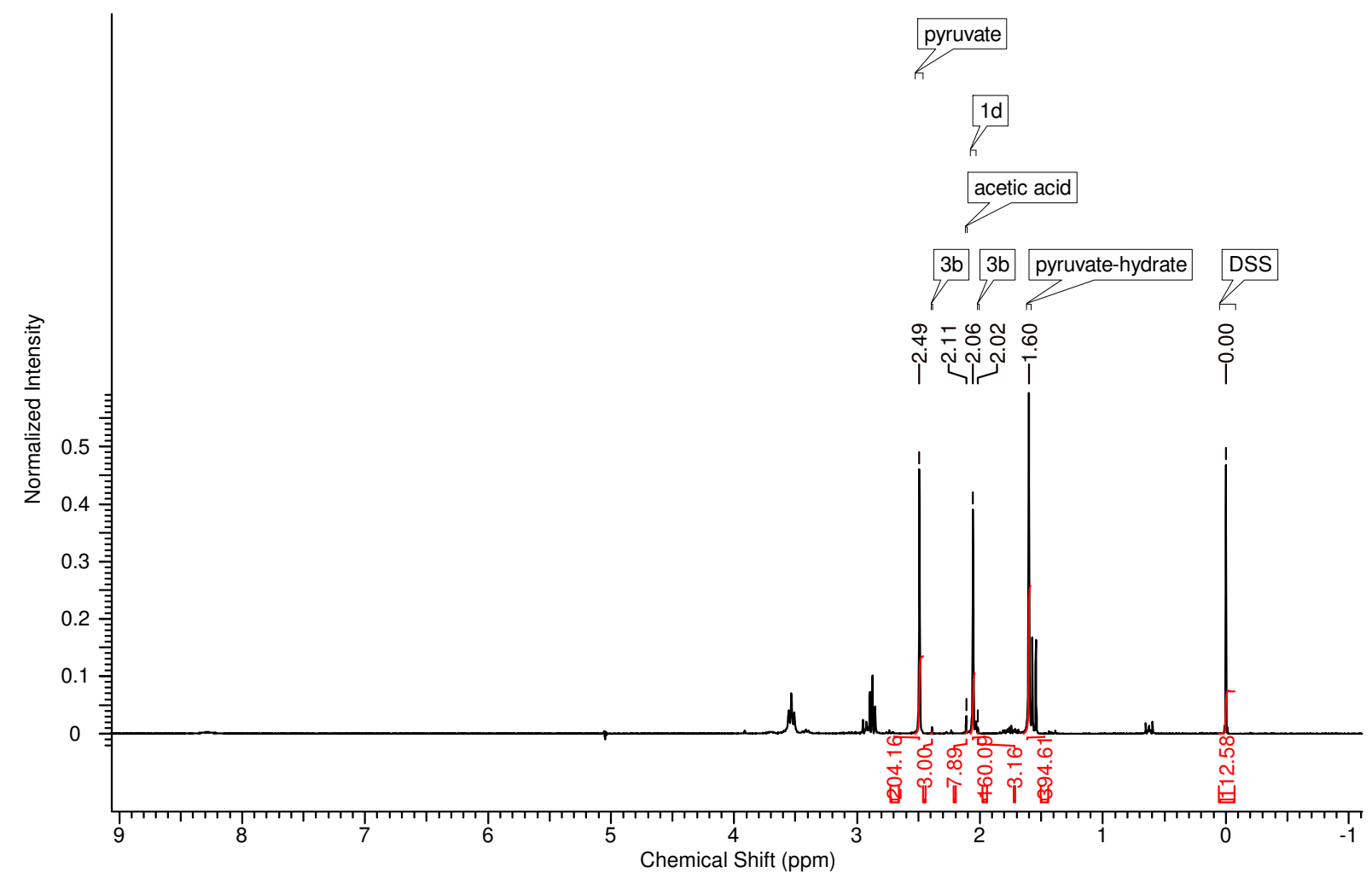


Table 1, Entry 3, Method A

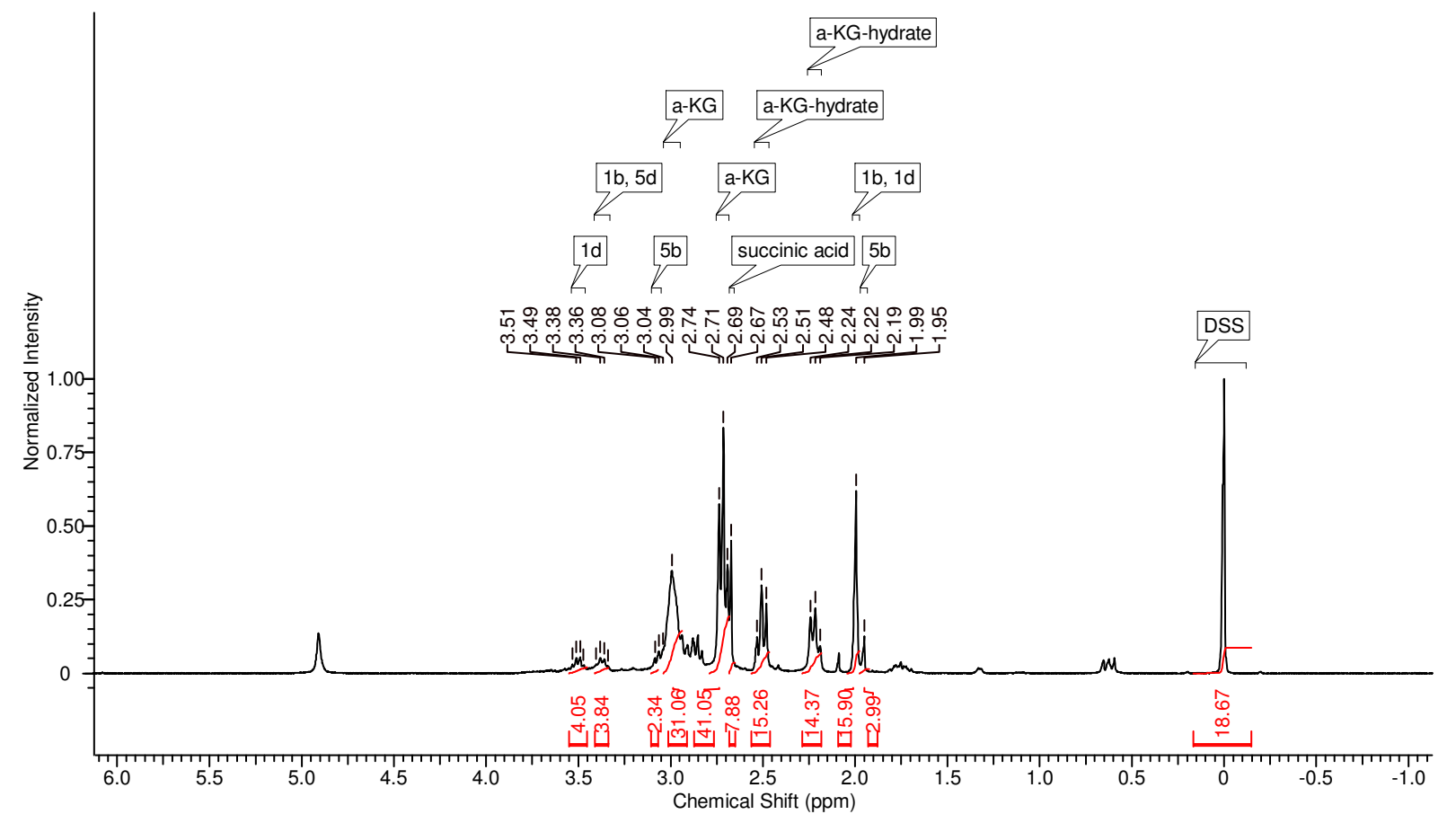

Table 1, Entry 3, Method B

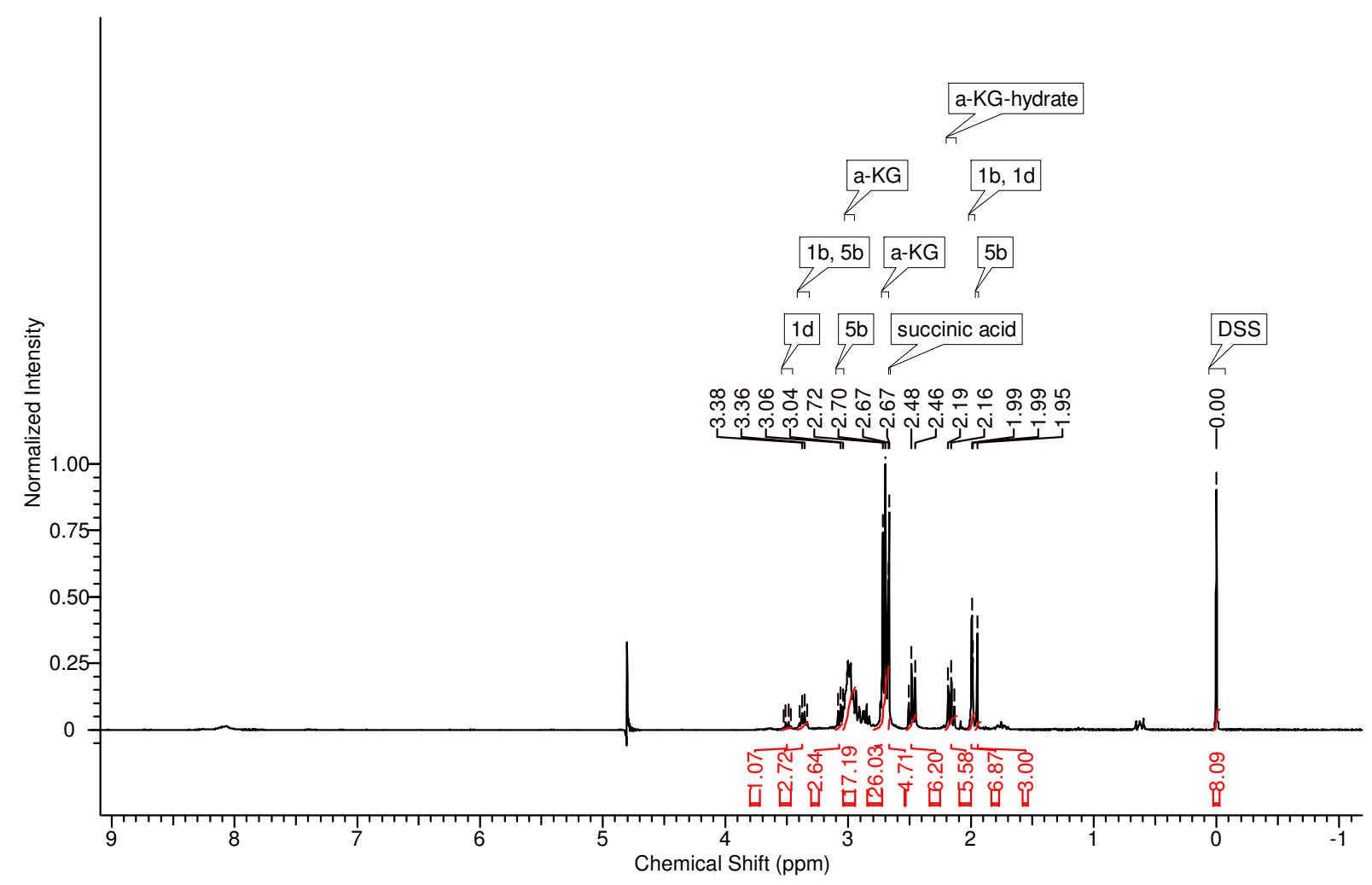


Table 1, Entry 3, Method C

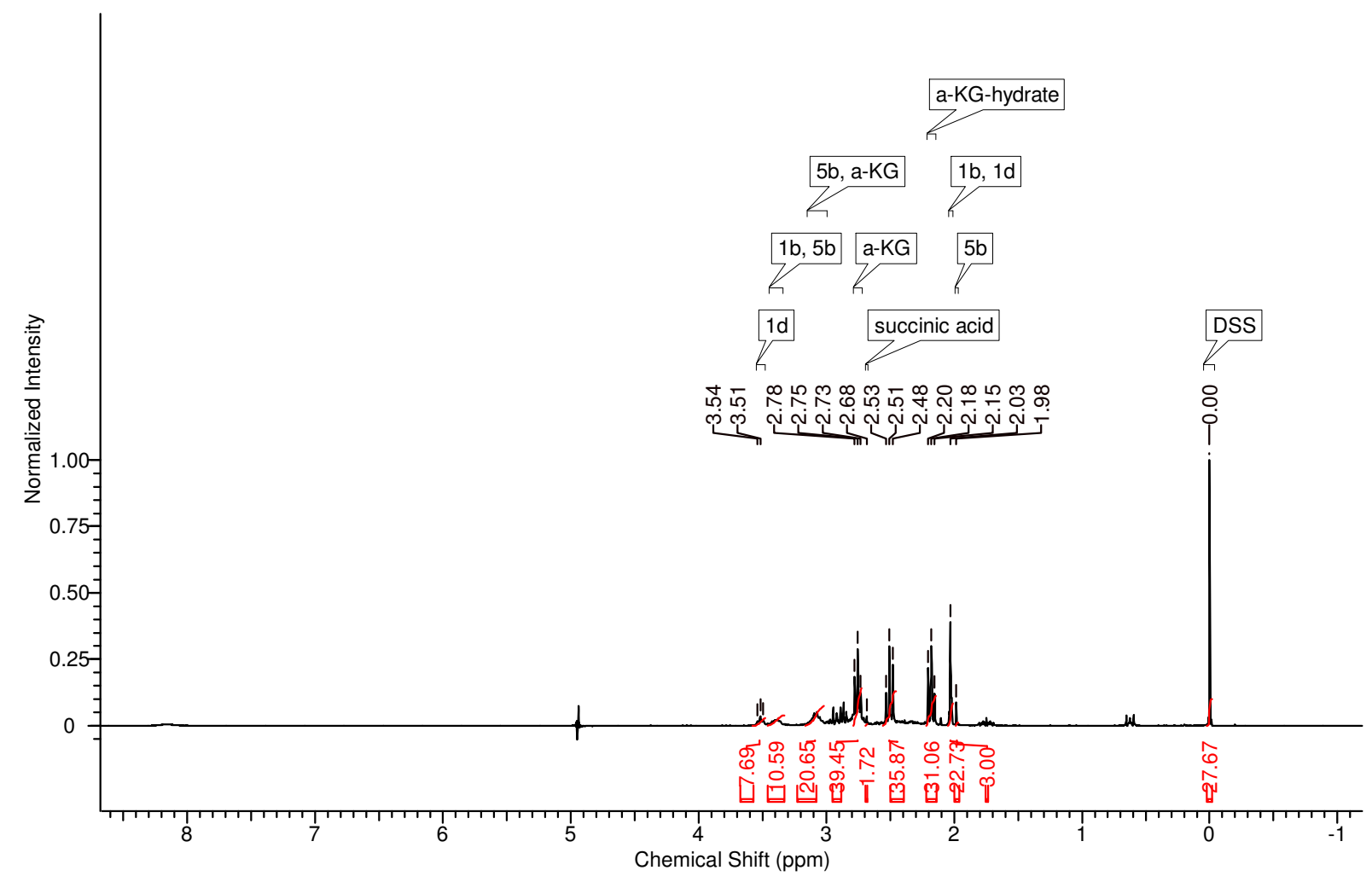

Table 1, Entry 4, Method A

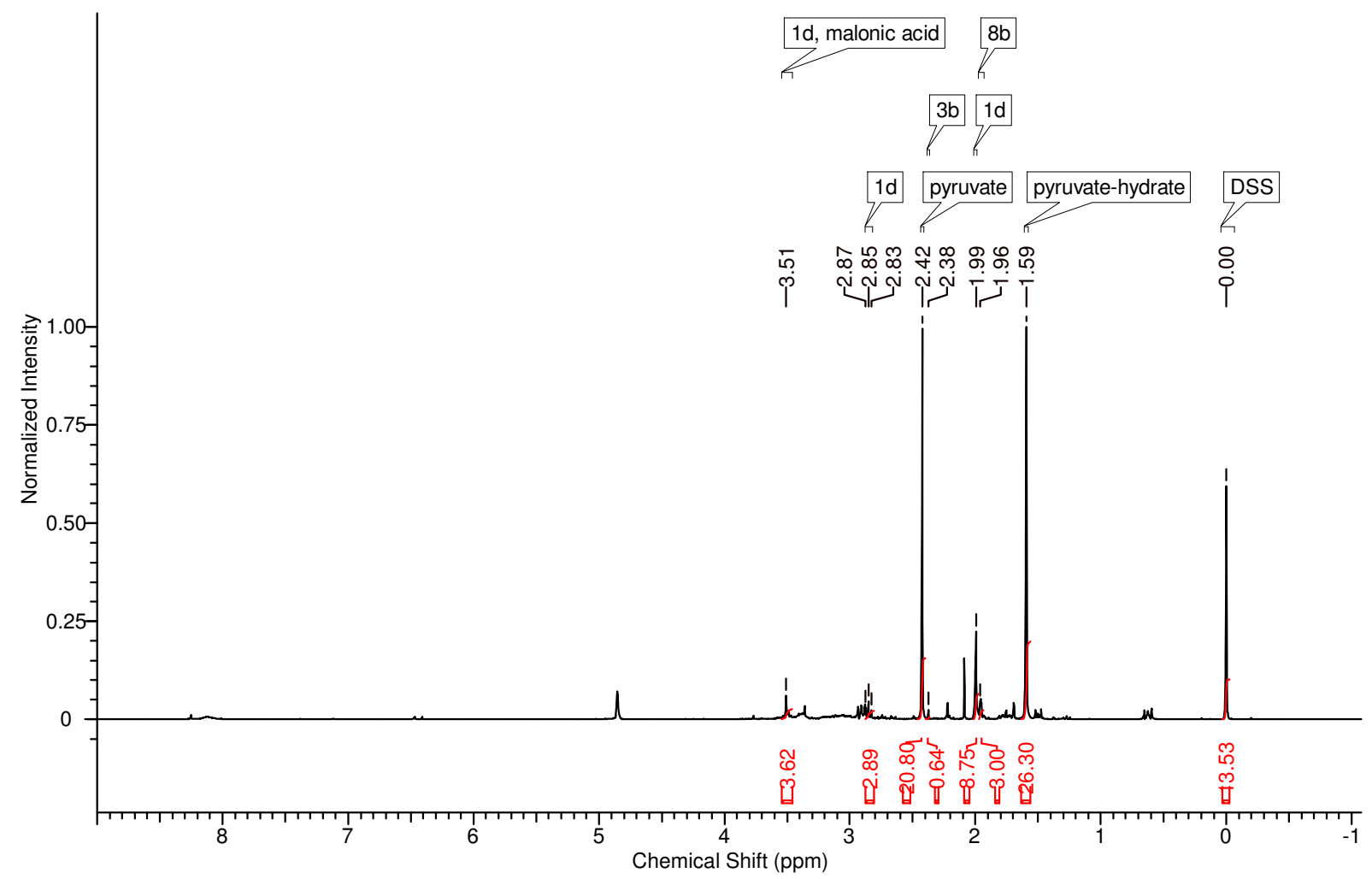


Table 1, Entry 4, Method B

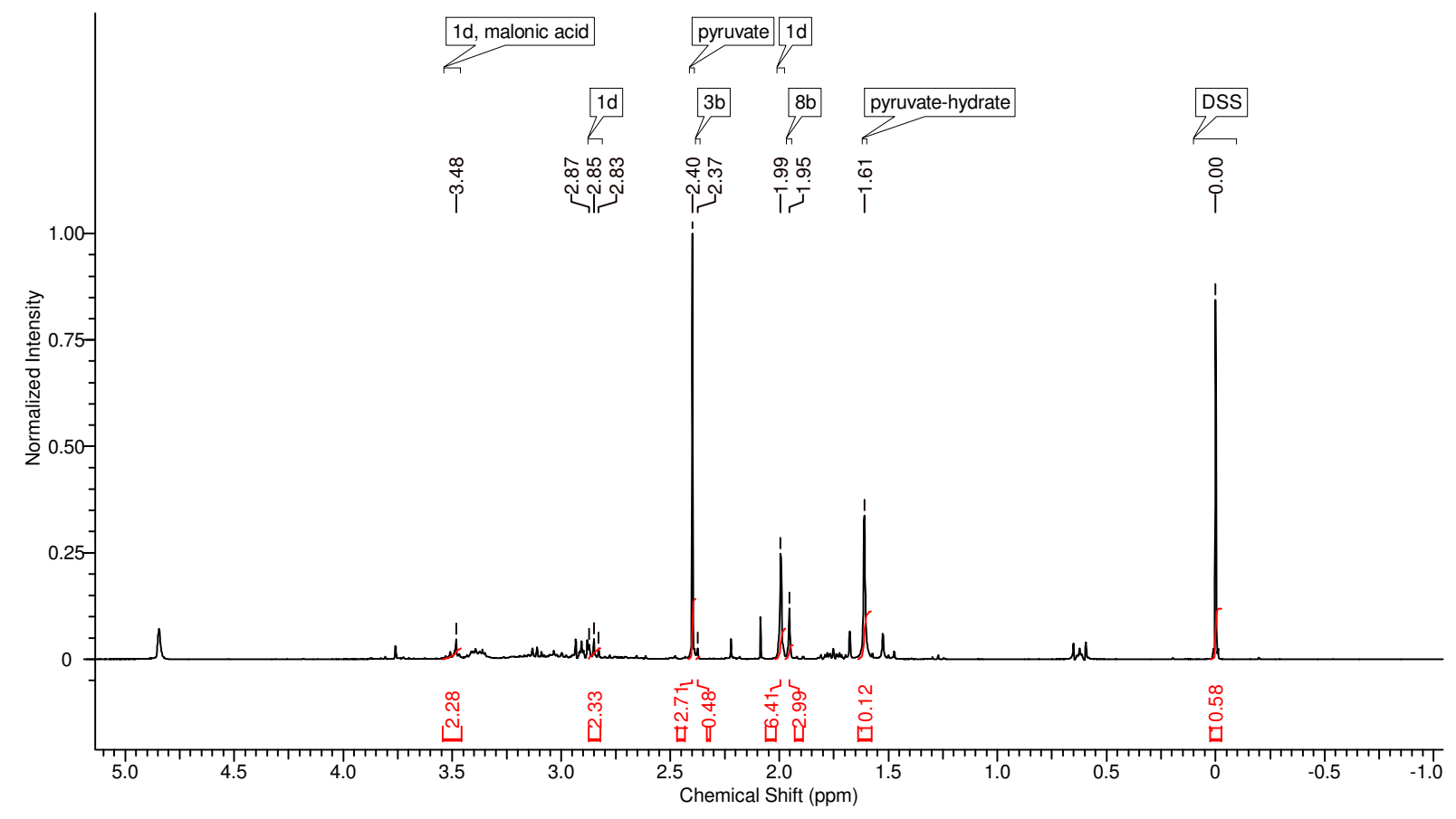

Table 1, Entry 4, Method C

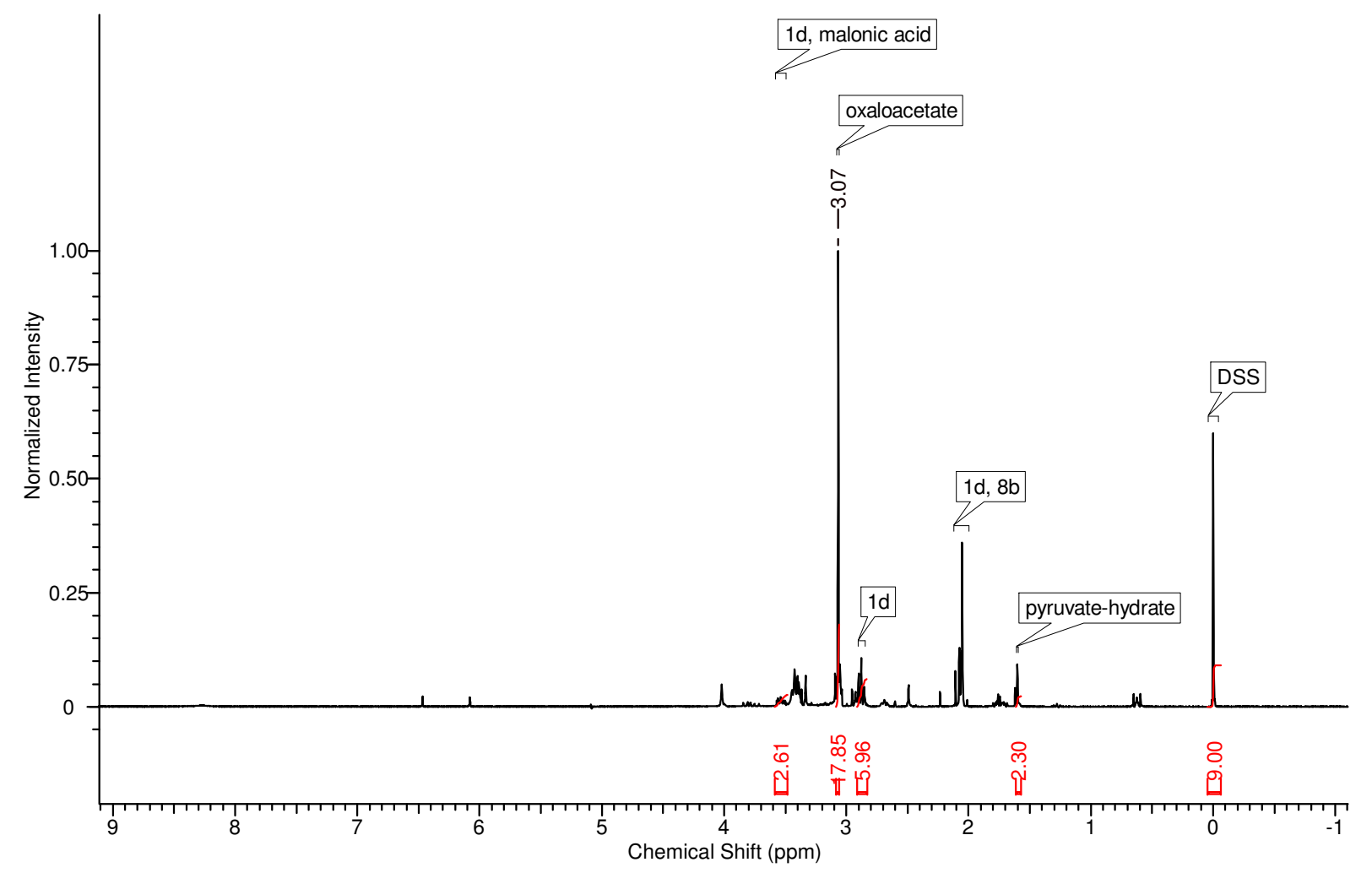


Table 1, Entry 6, Method A

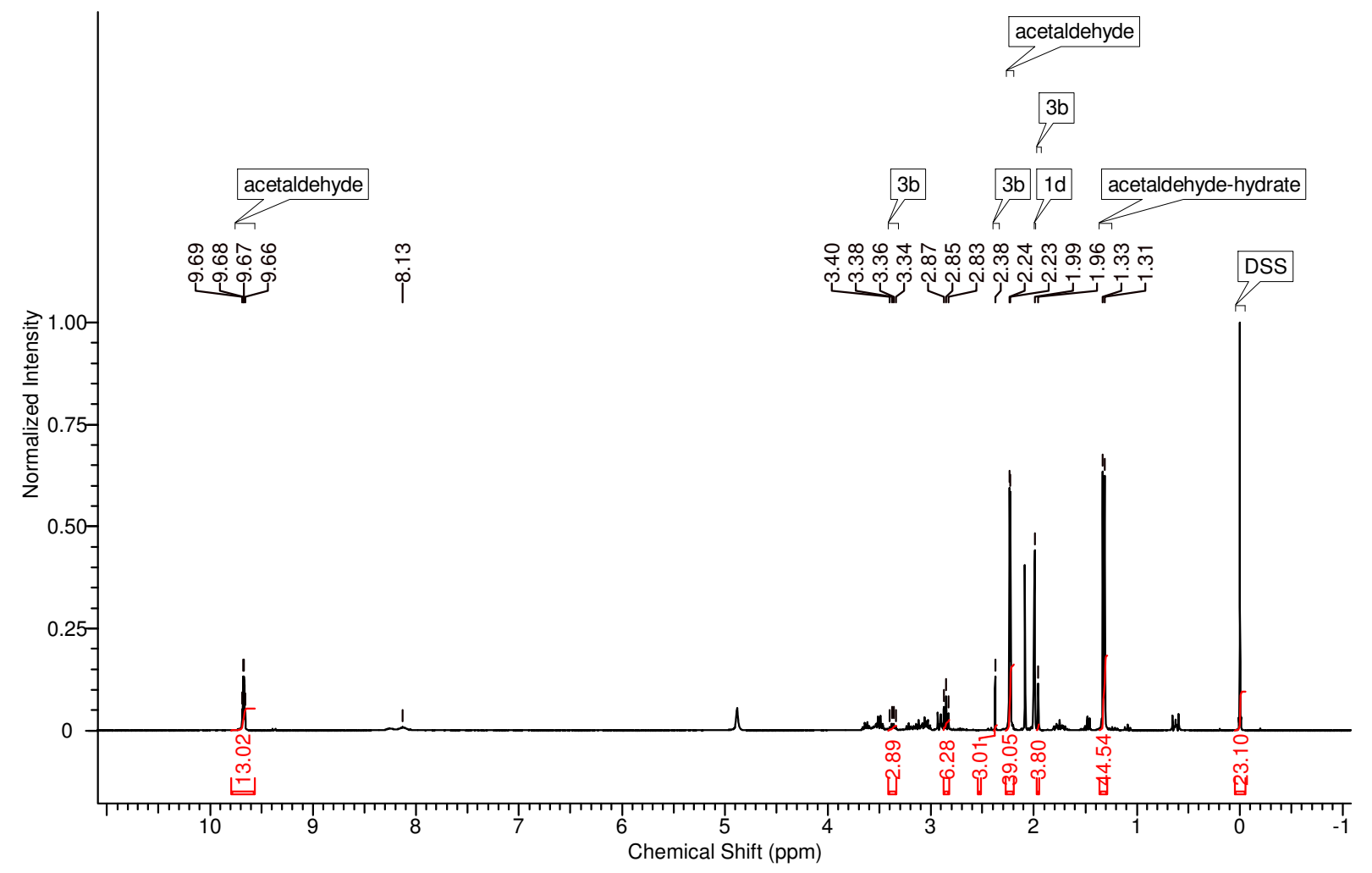

Table 1, Entry 6, Method B

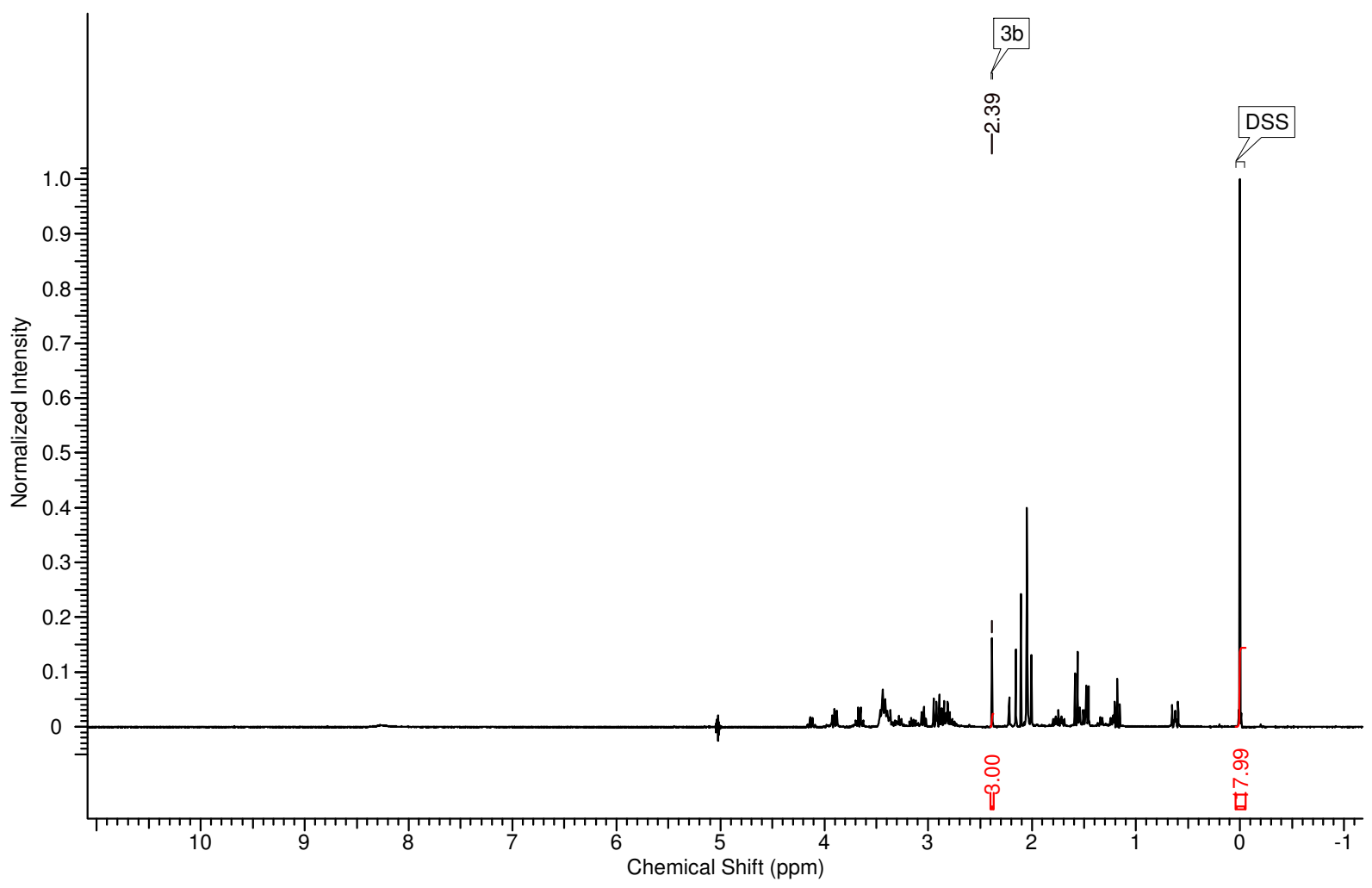


Table 1, Entry 6, Method C

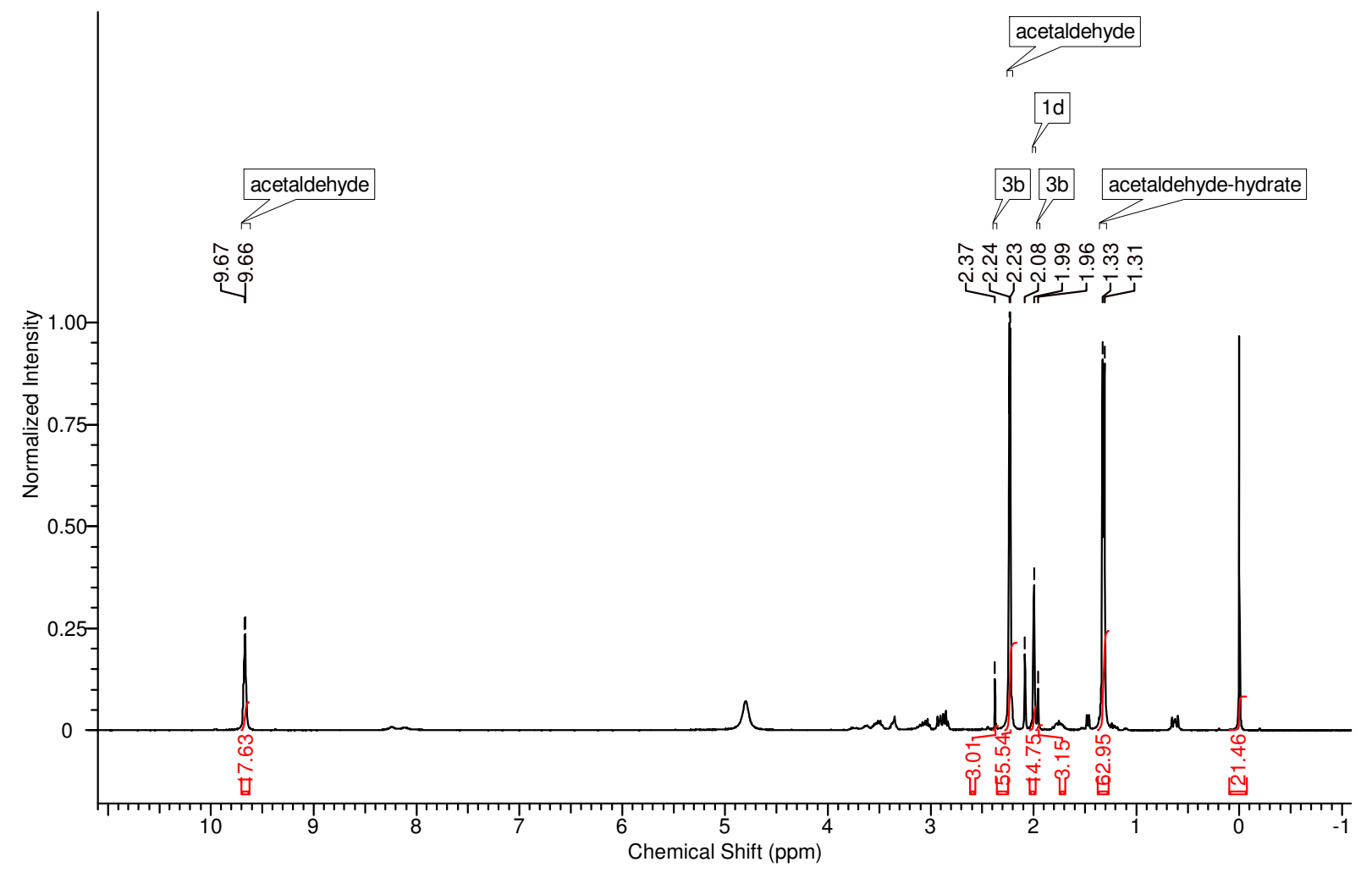

Scheme S-3 Method A

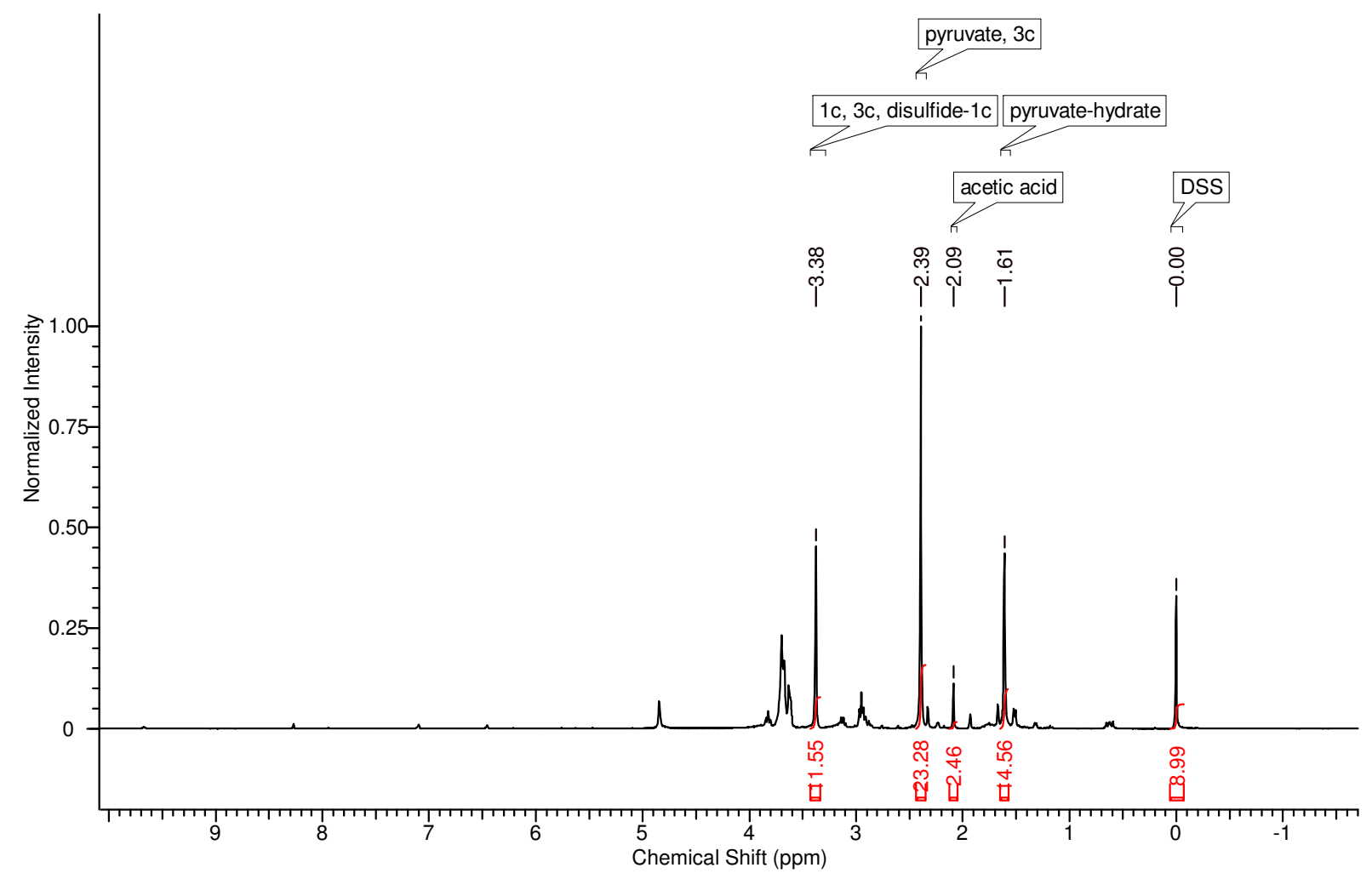


Scheme S-3 Method B

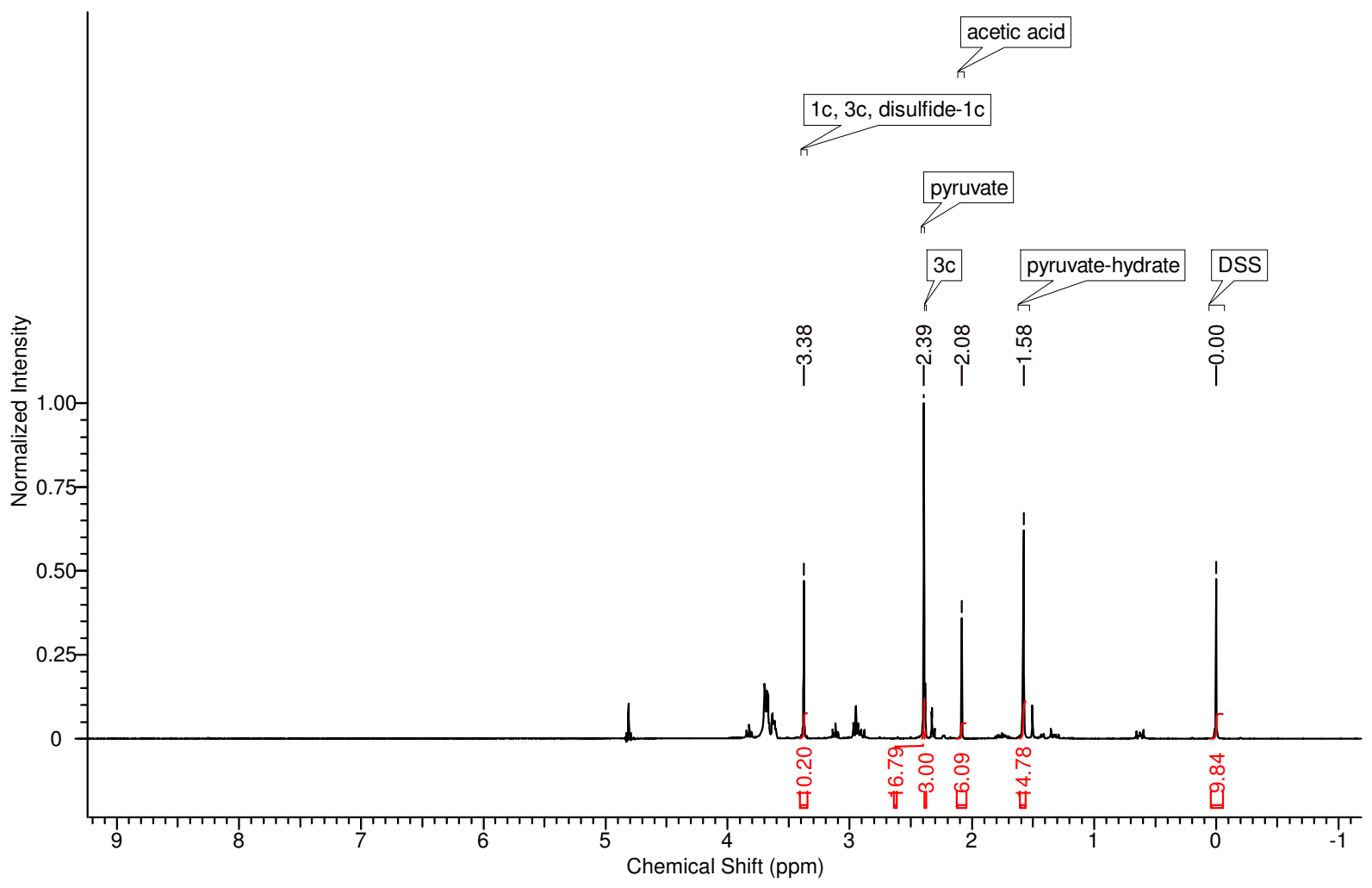

Scheme S-3 Method C

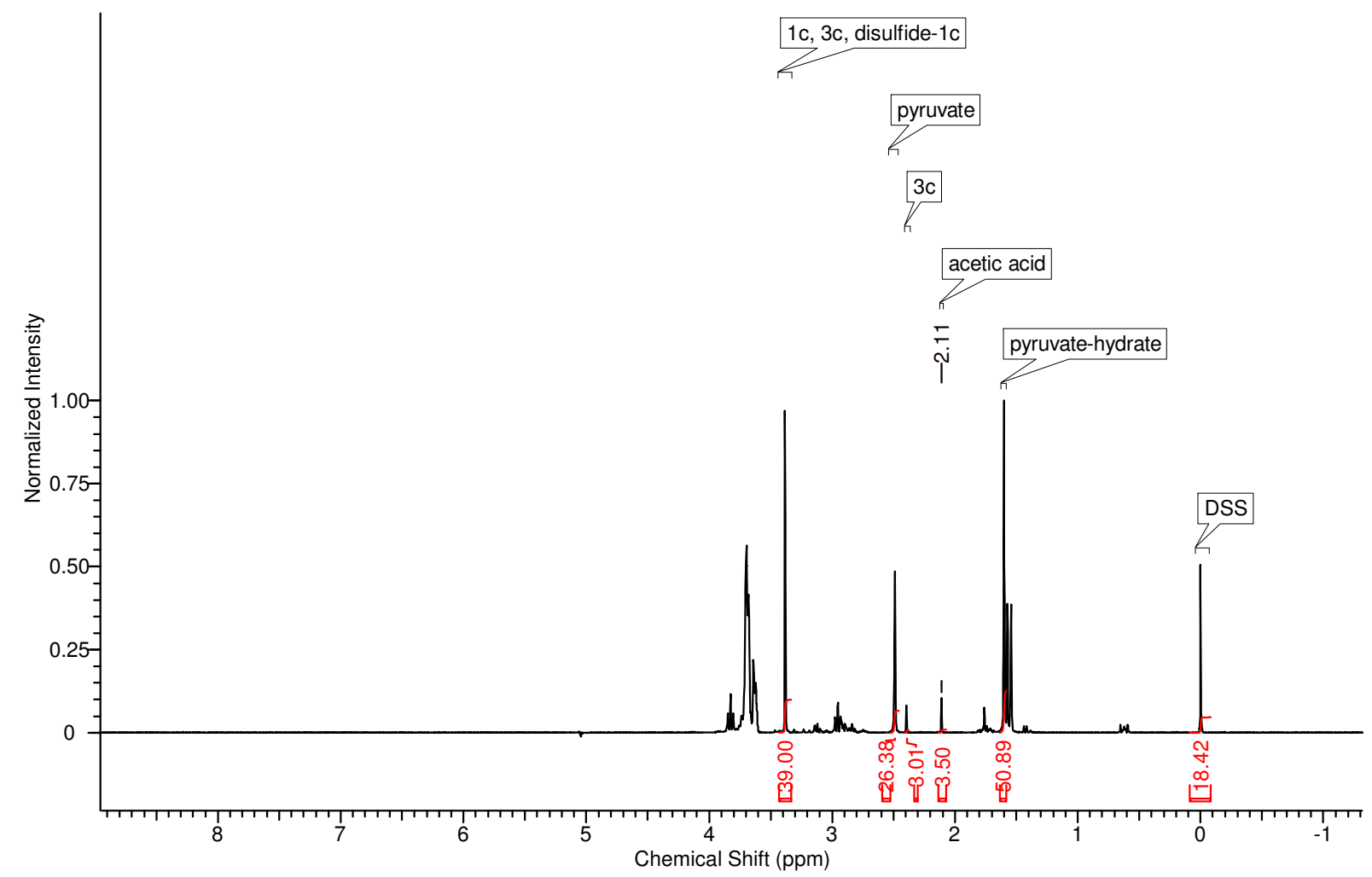


4.4. GC-FID chromatograms of authentic samples

$N$-acetylcysteamine (1b)

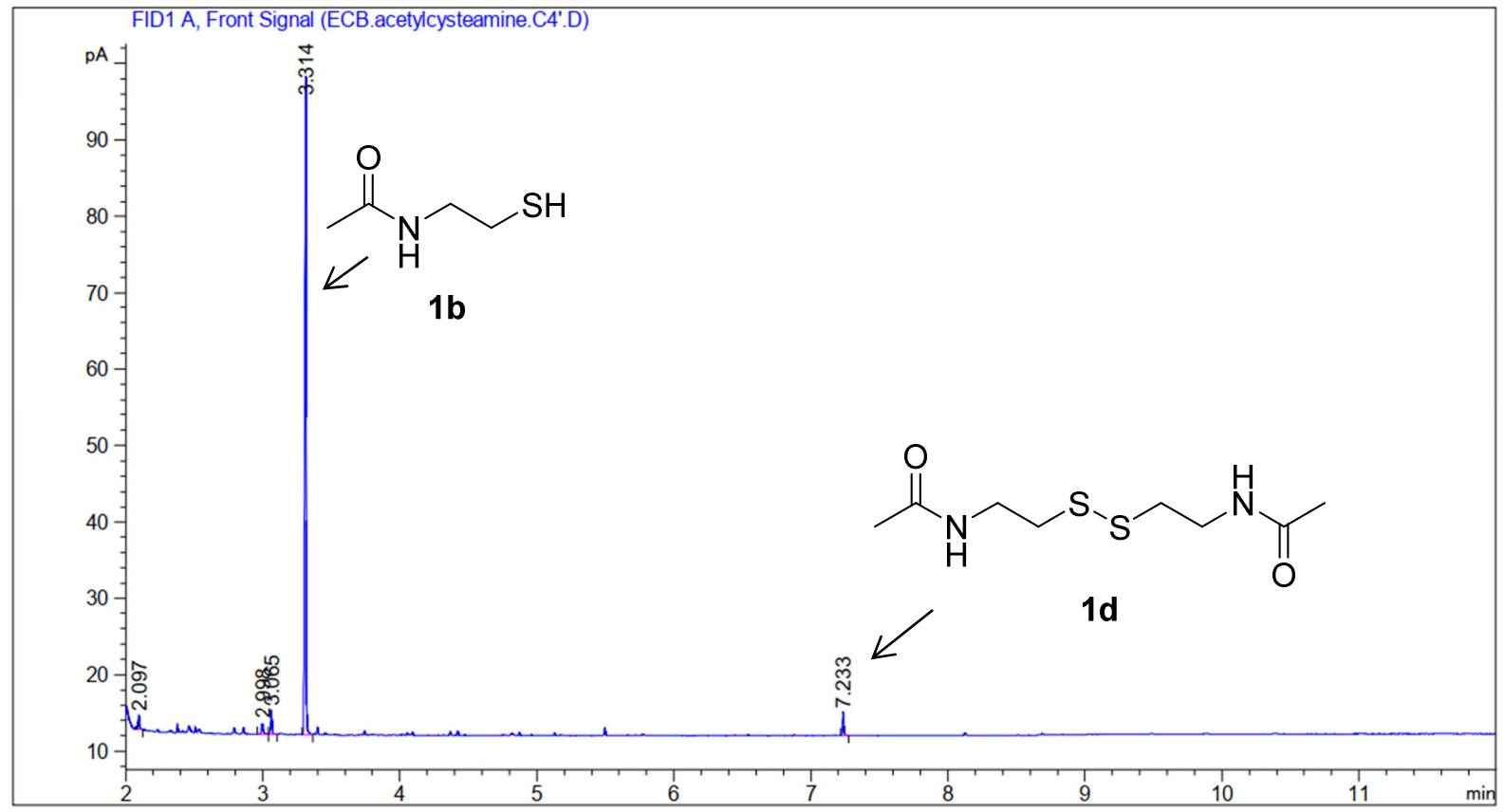

2-(2-(2-methoxyethoxy)ethoxy)ethane-1-thiol (1c)

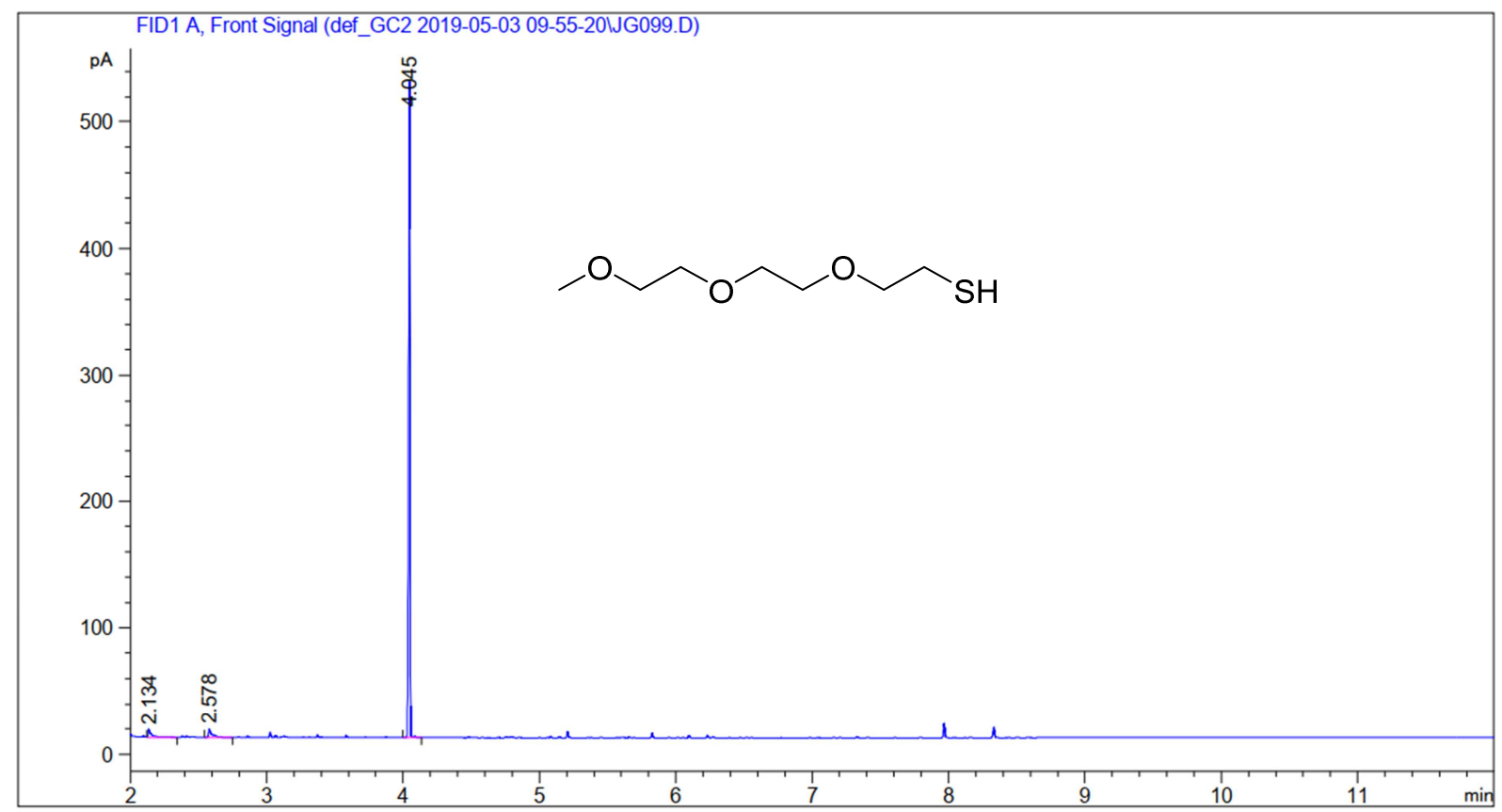


$N, N^{\prime}$-(disulfanediylbis(ethane-2,1-diyl))diacetamide (1d)

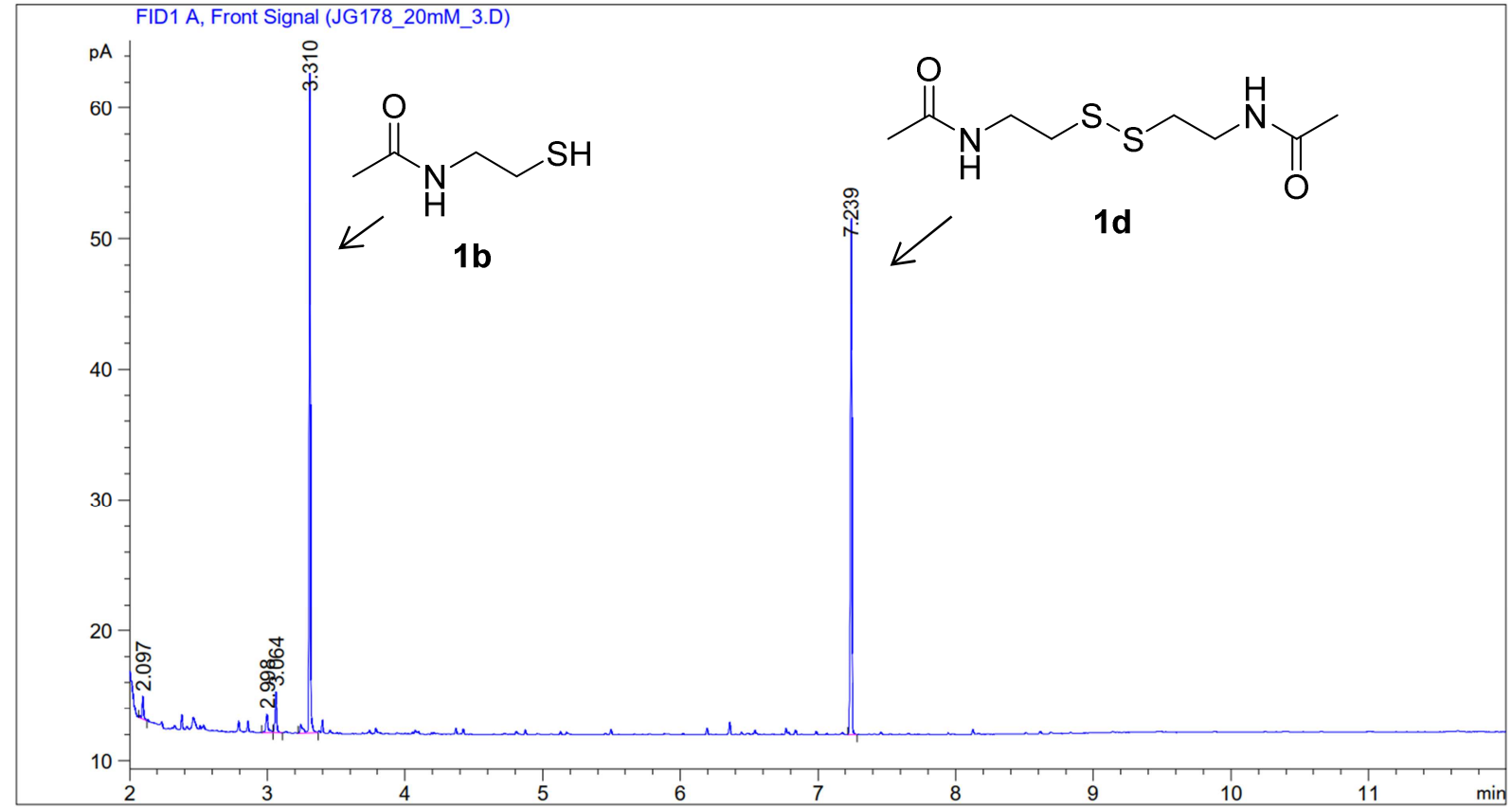

$N, S$-diacetyl cysteamine (3b)

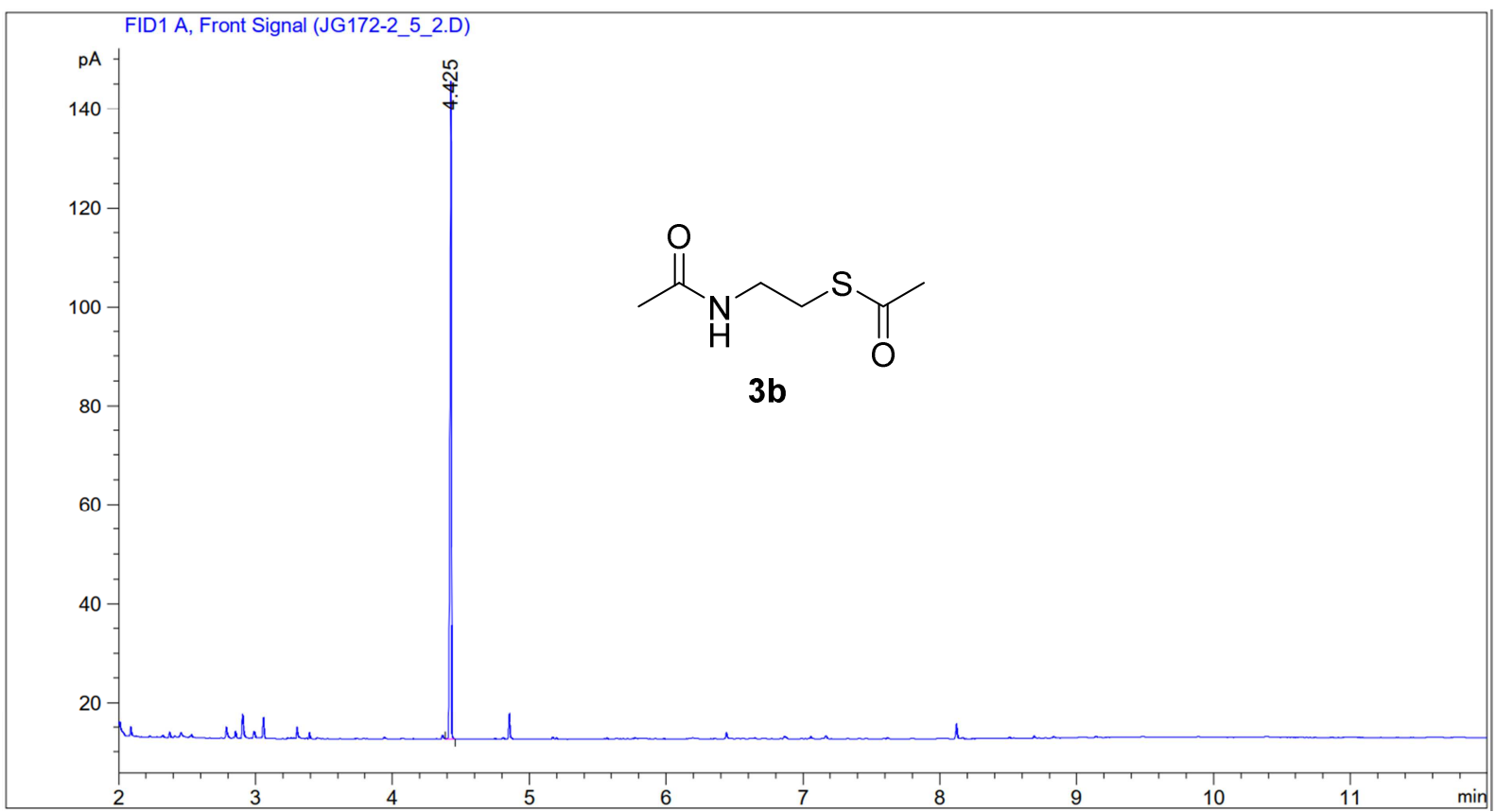


S-(2-(2-(2-methoxyethoxy)ethoxy)ethyl) ethanethioate (3c)

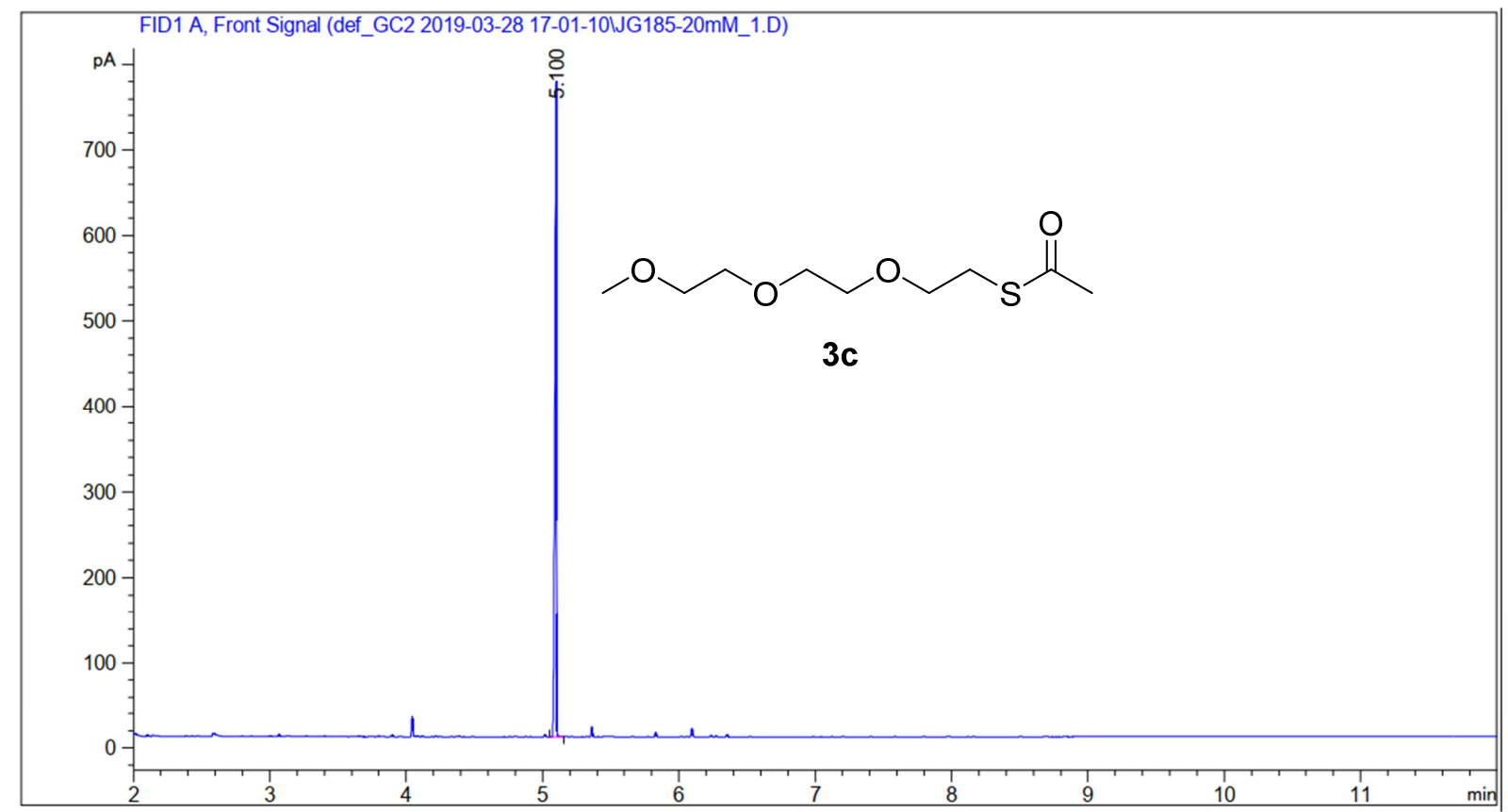

\section{2,5,8,15,18,21-hexaoxa-11,12-dithiadocosane (11)}

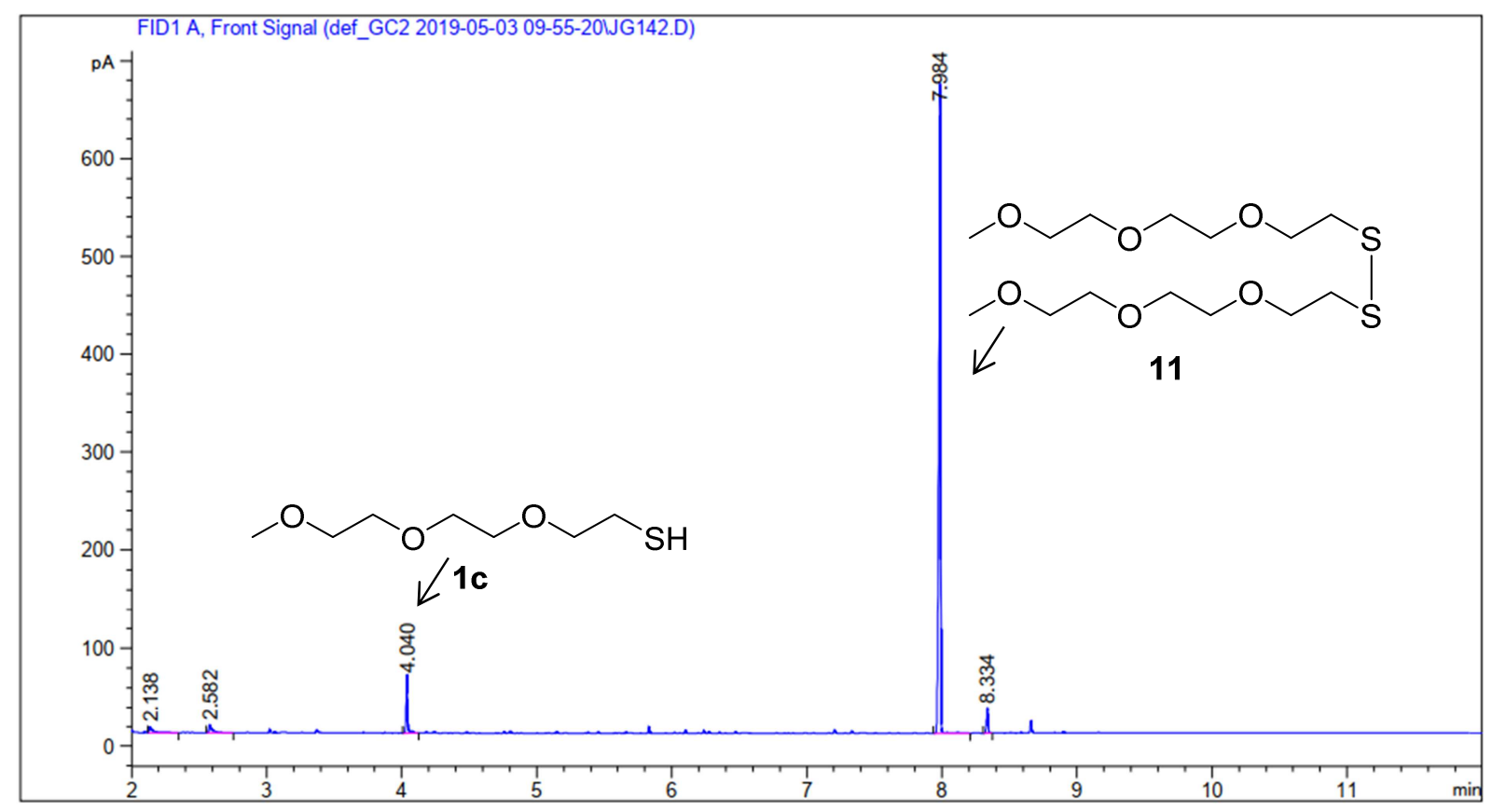




\subsection{GC-FID chromatograms of the prebiotic thioester formation}

Table 1, Entry 1, Method A

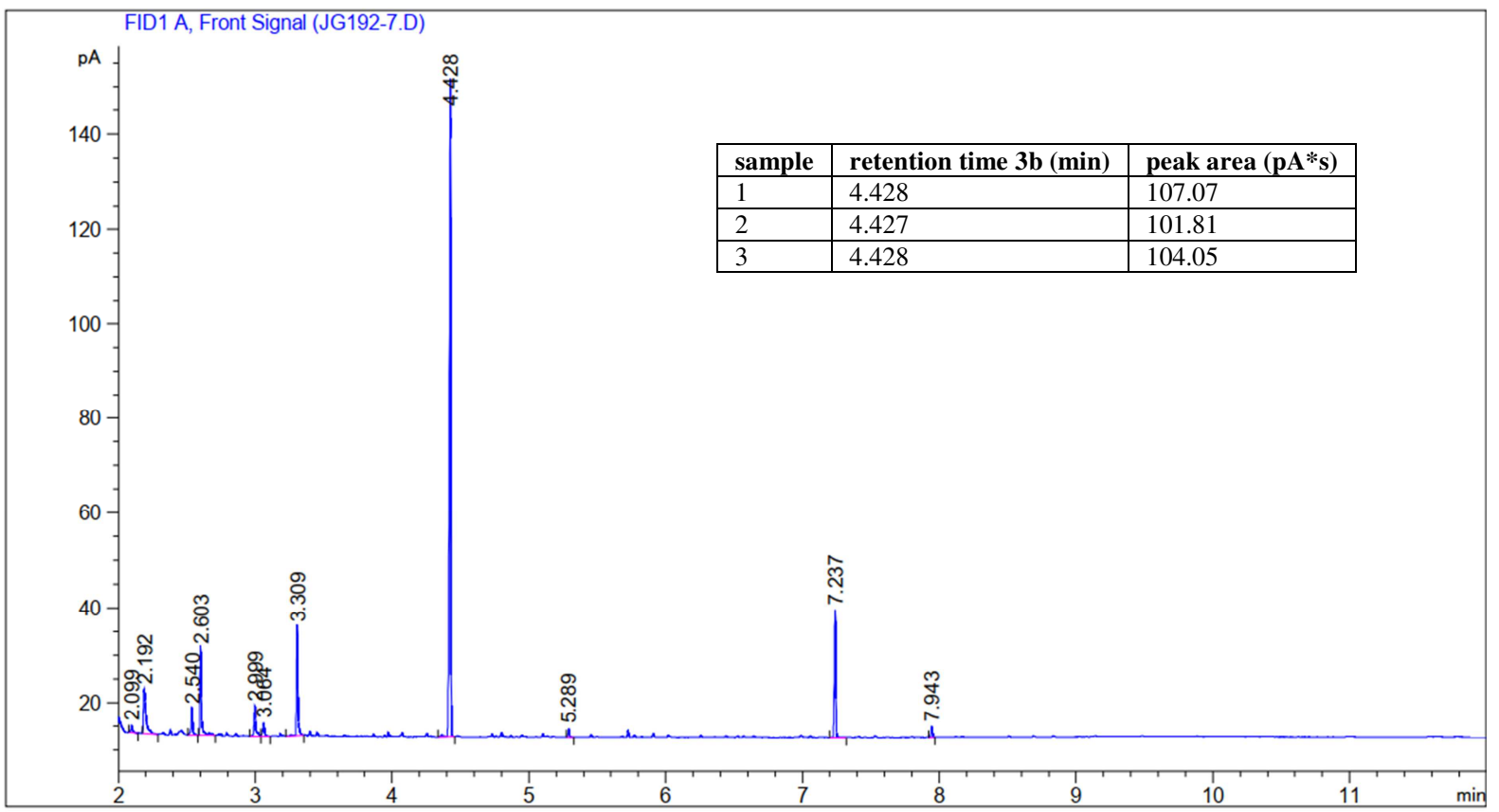

Table 1, Entry 1, Method B

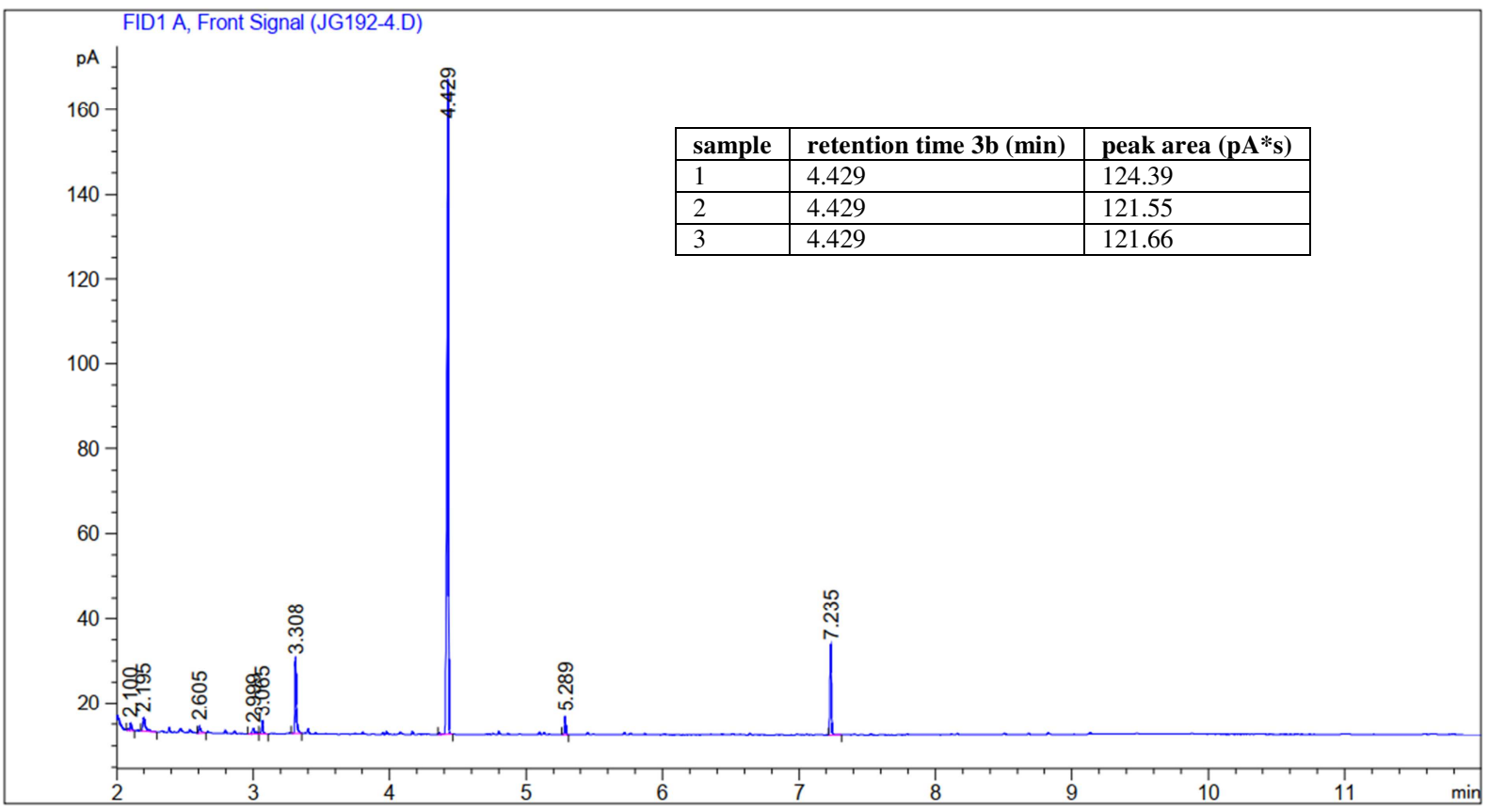


Table 1, Entry 1, Method C

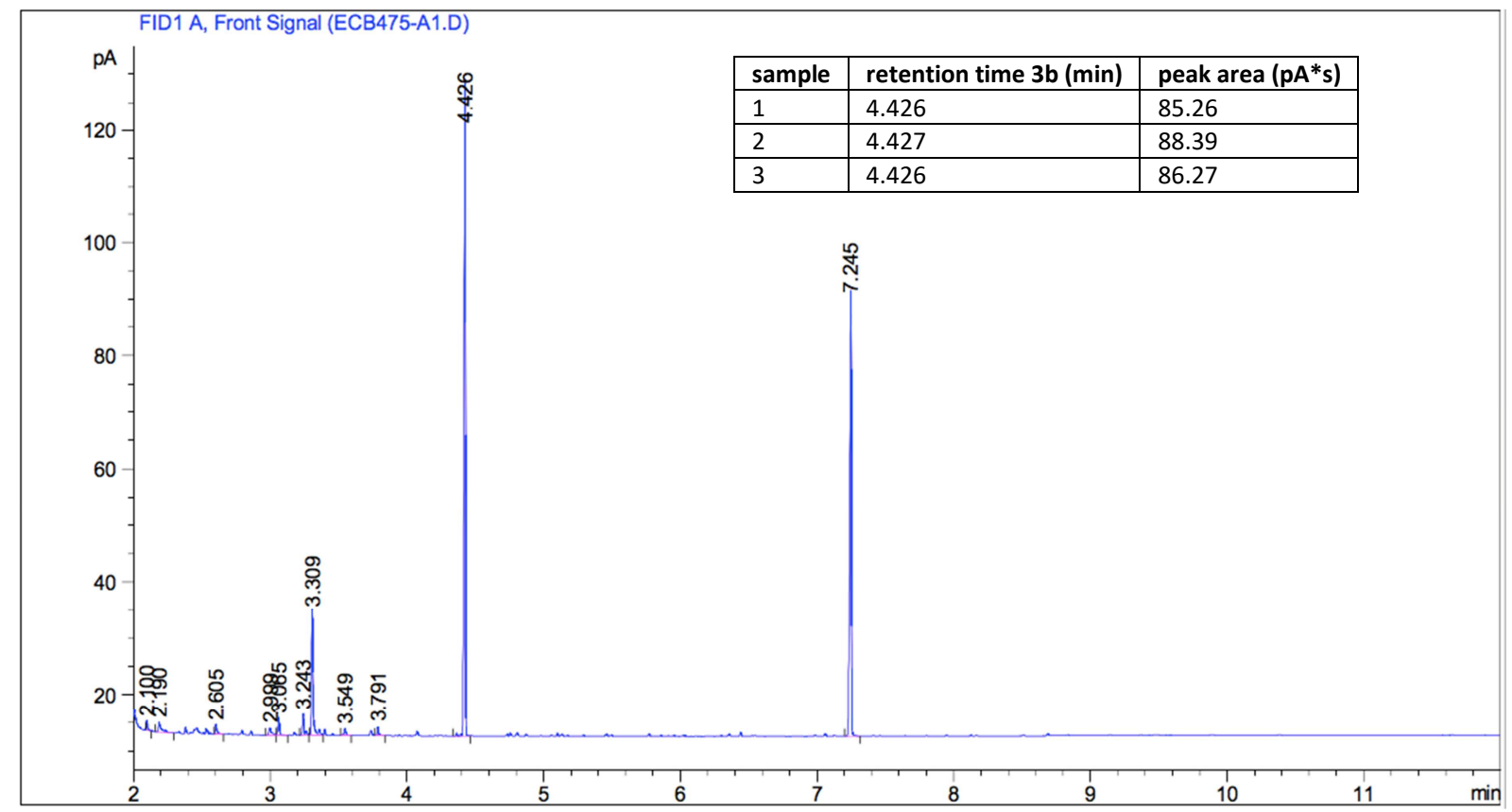

Table 1, Entry 2, Method A

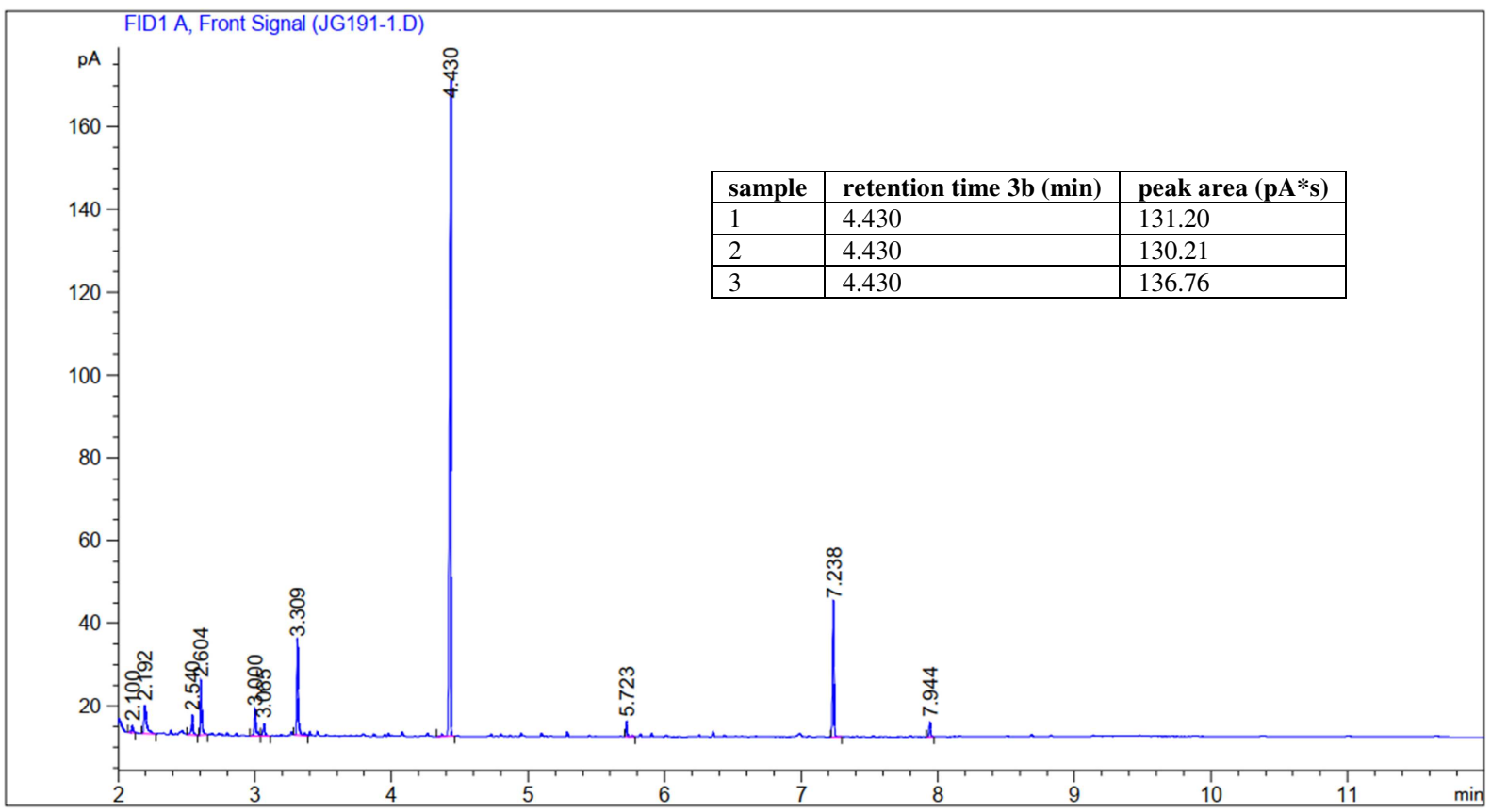


Table 1, Entry 2, Method B

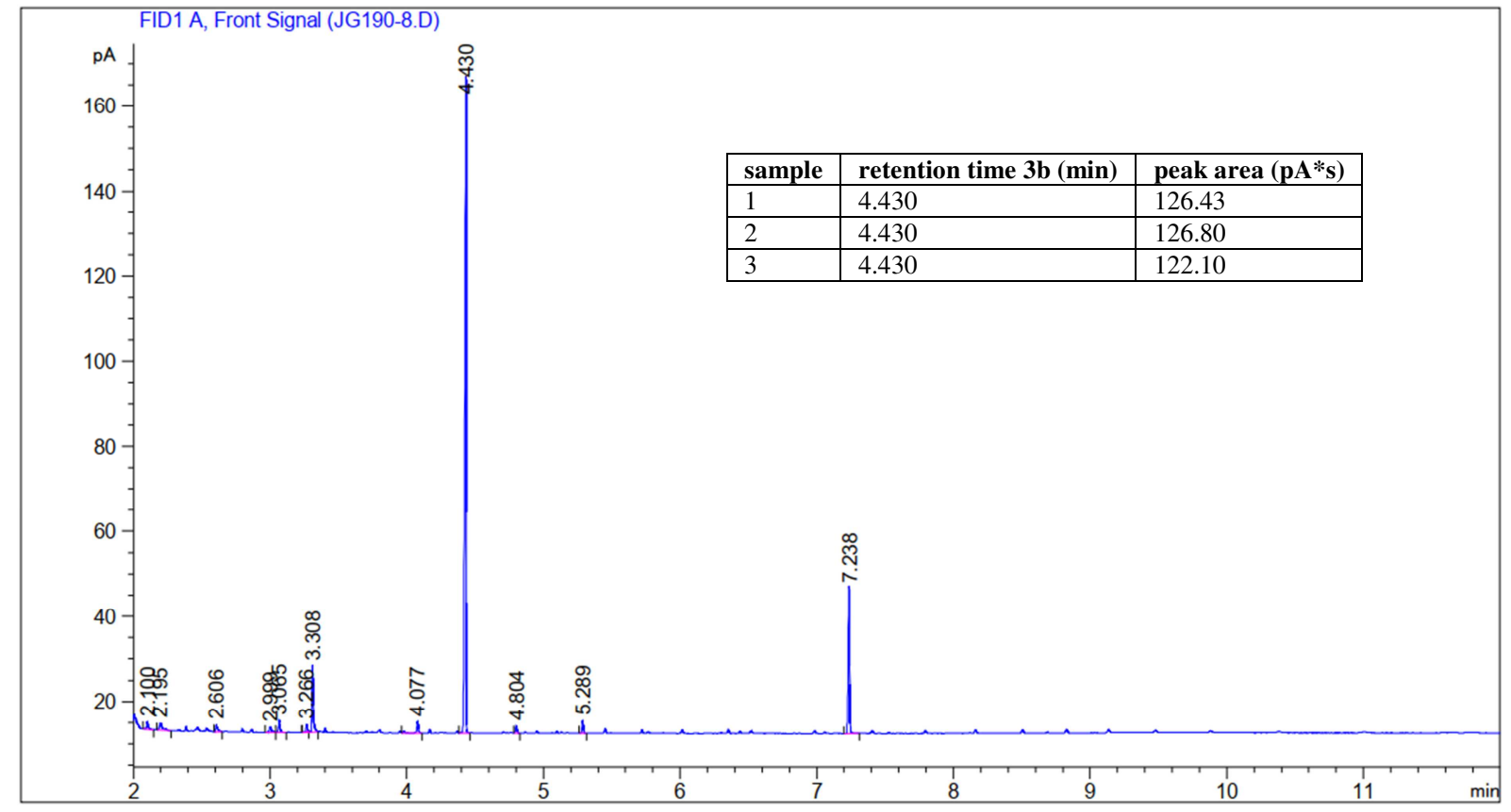

Table 1, Entry 2, Method C

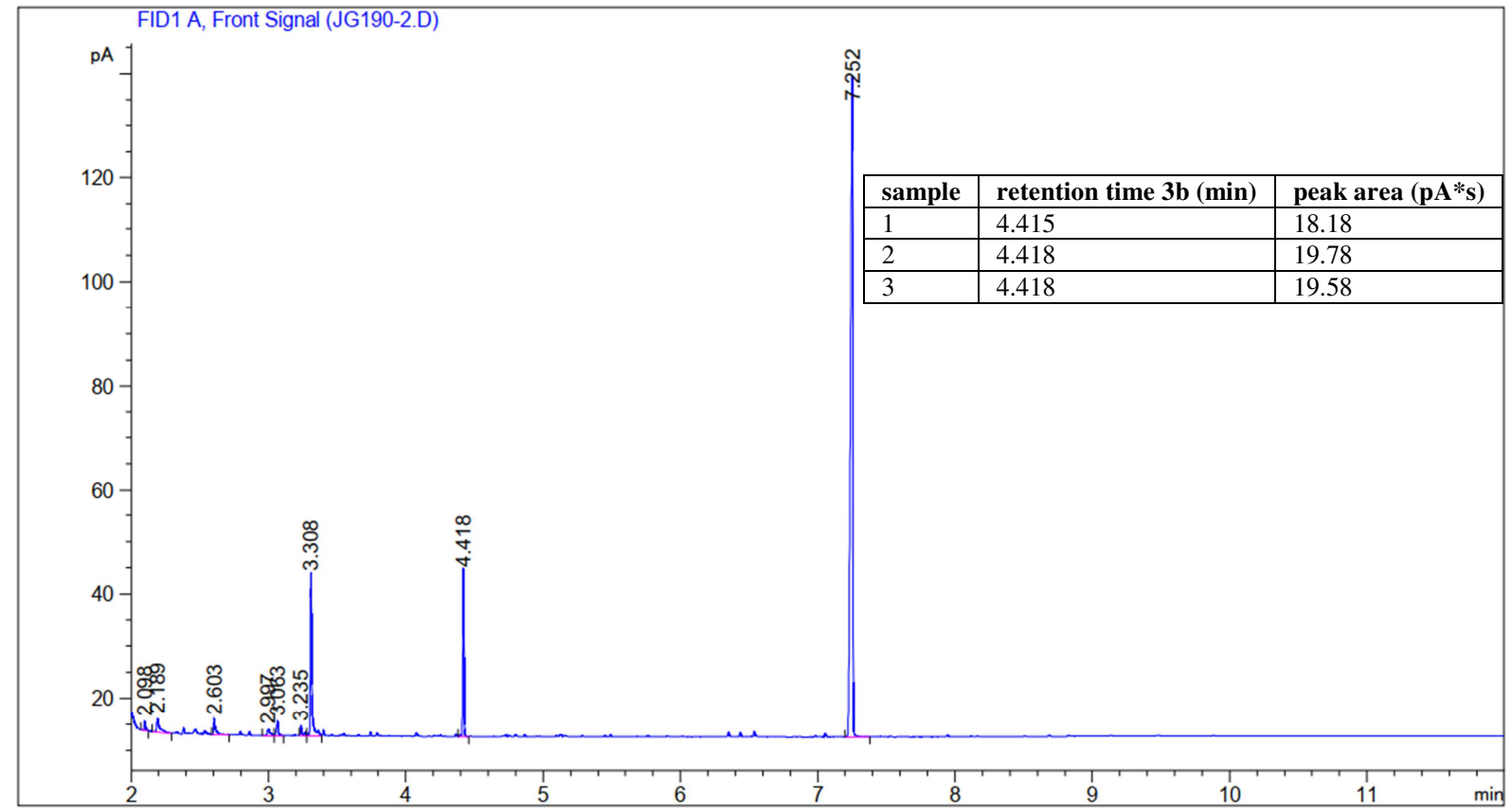


Table 1, Entry 6, Method A

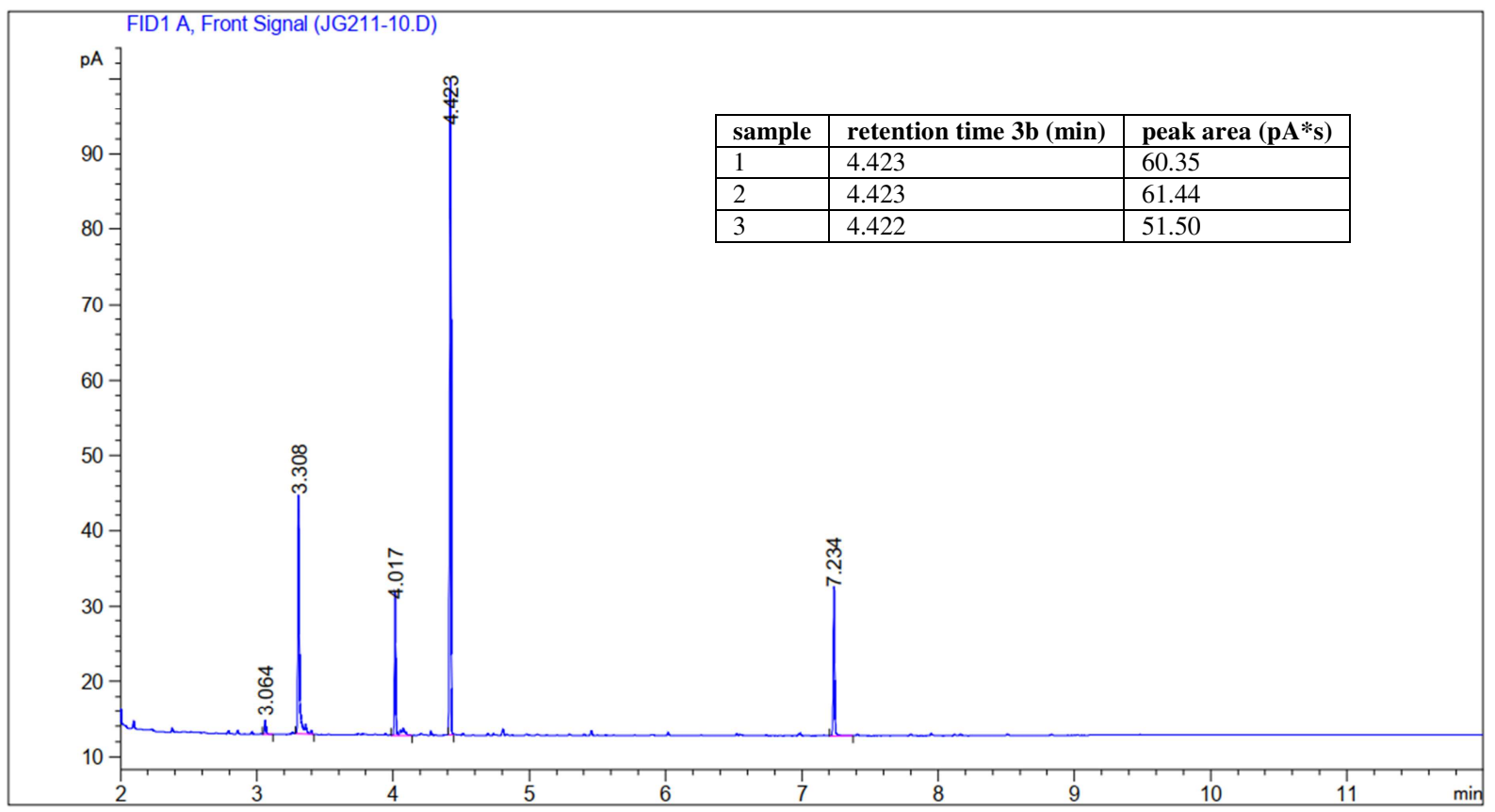

Table 1, Entry 6, Method B

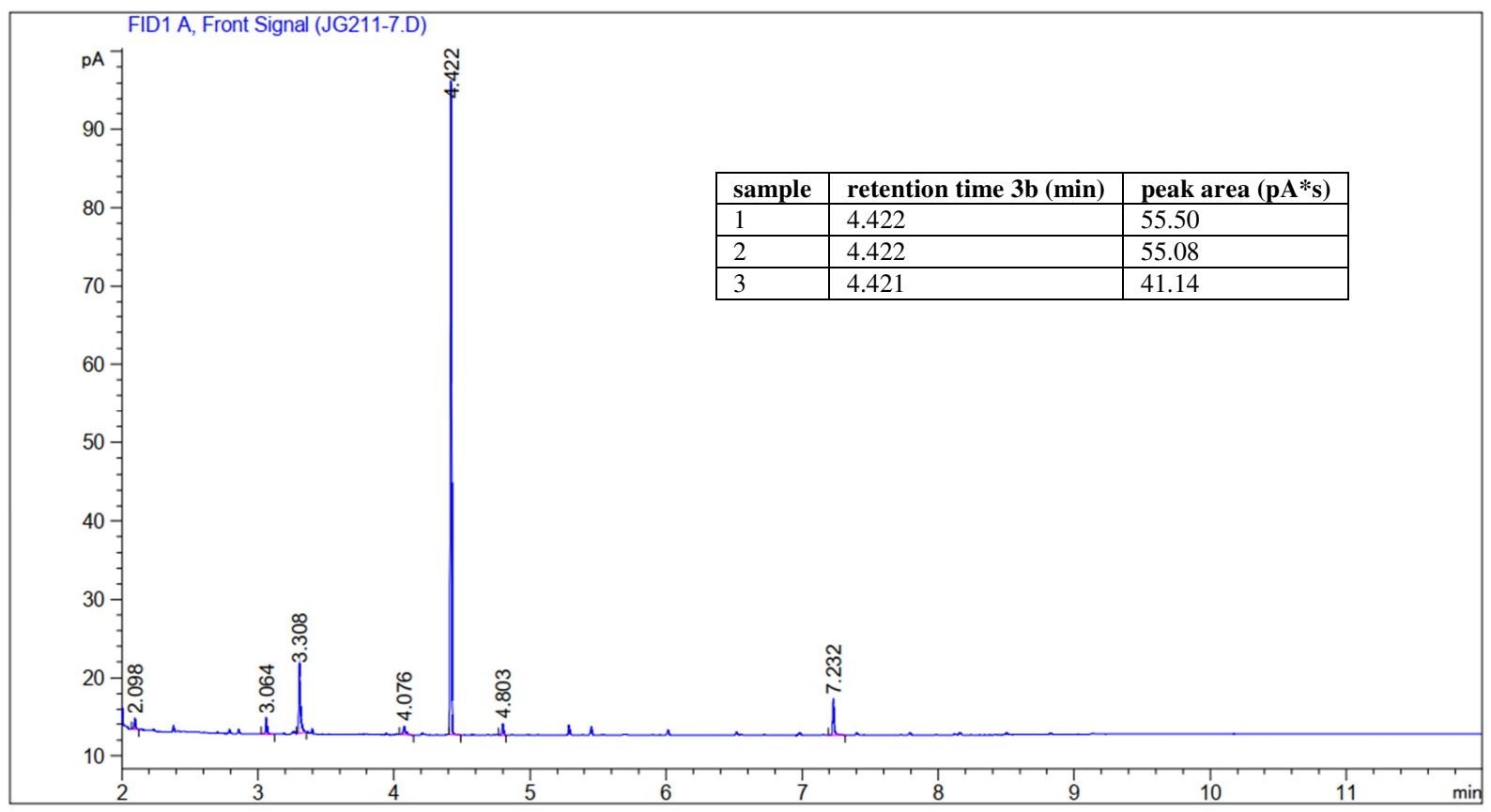


Table 1, Entry 6, Method C

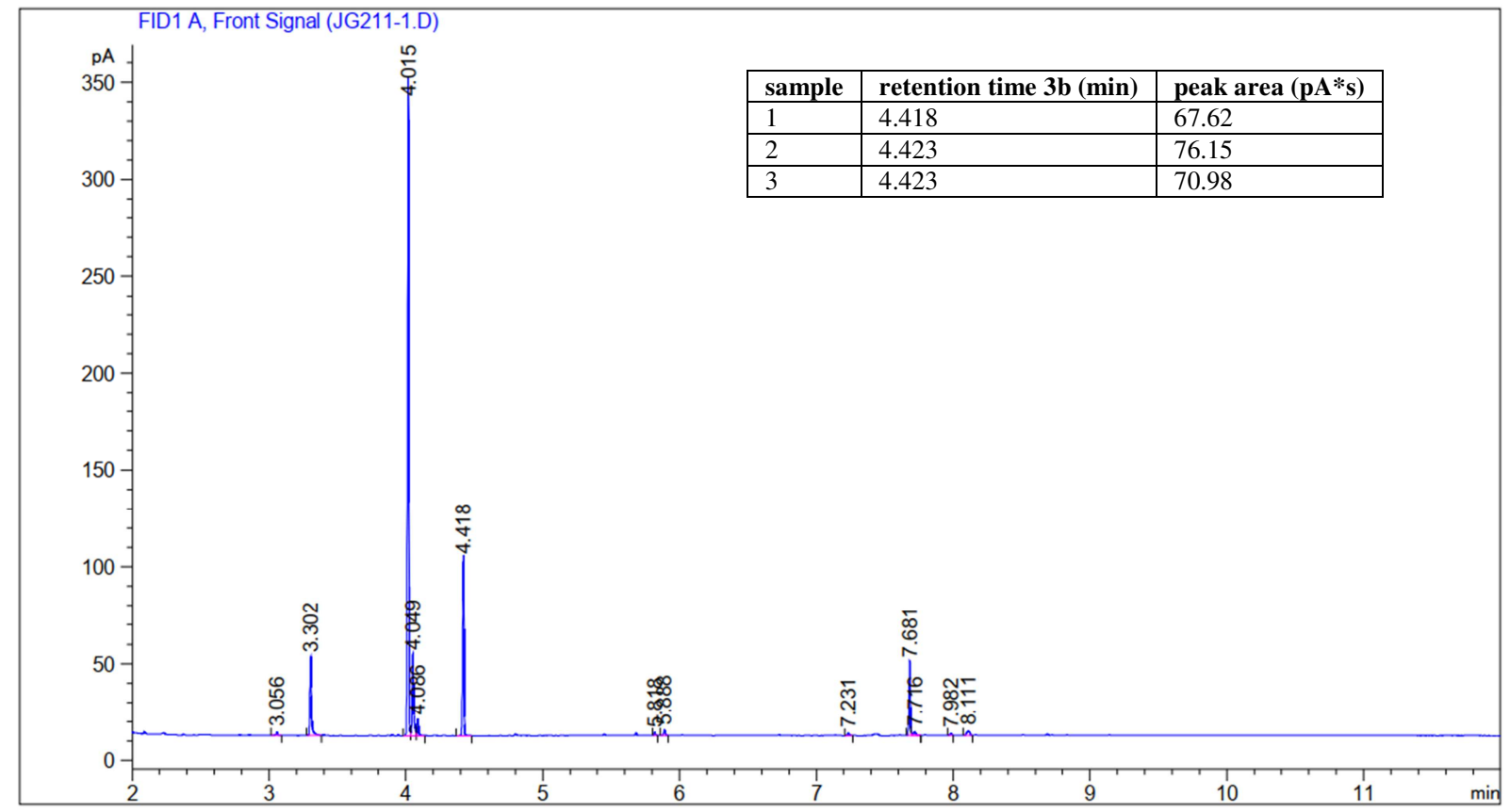


Scheme S-4, Method A

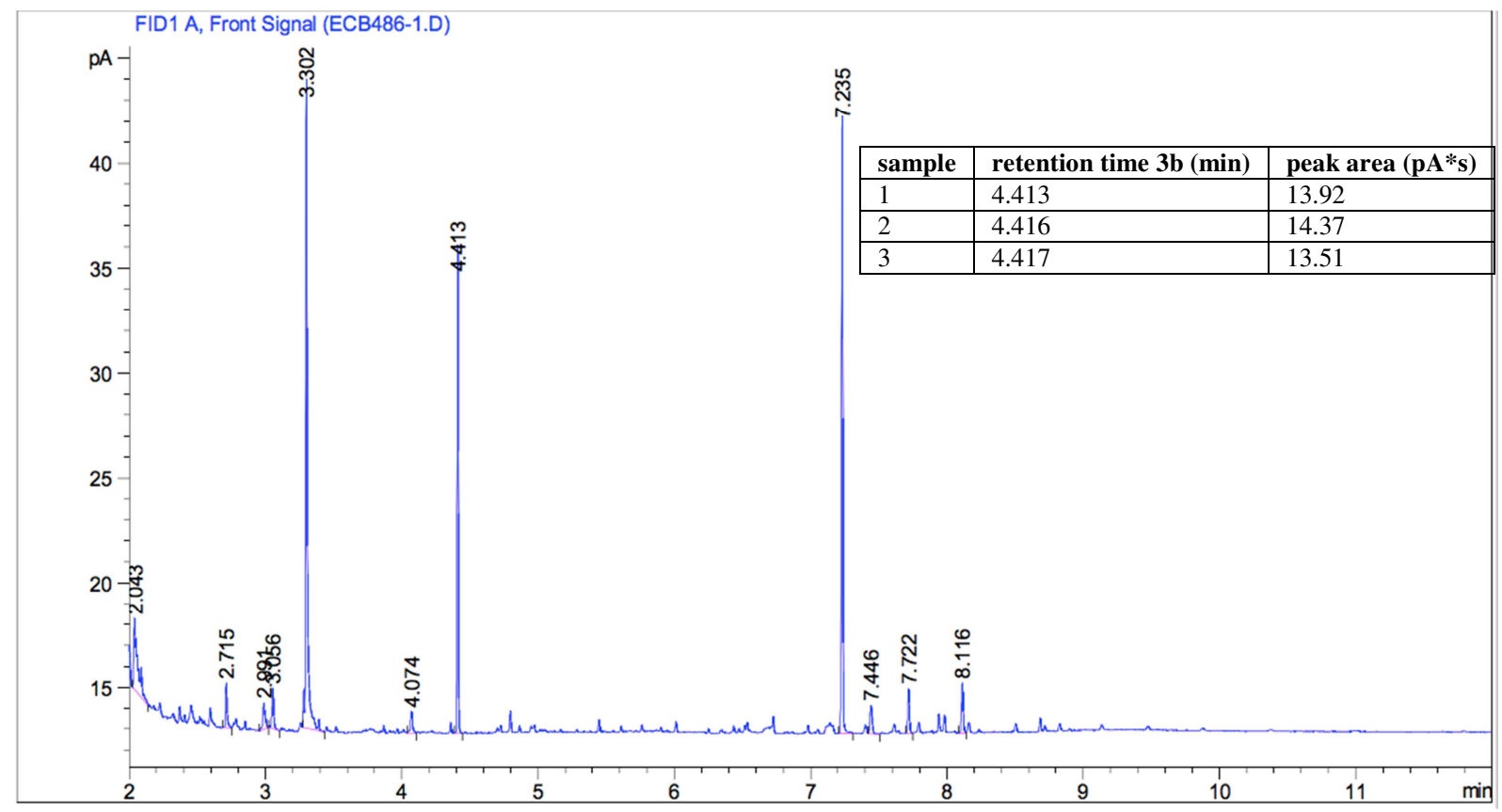

Scheme S-4, Method B

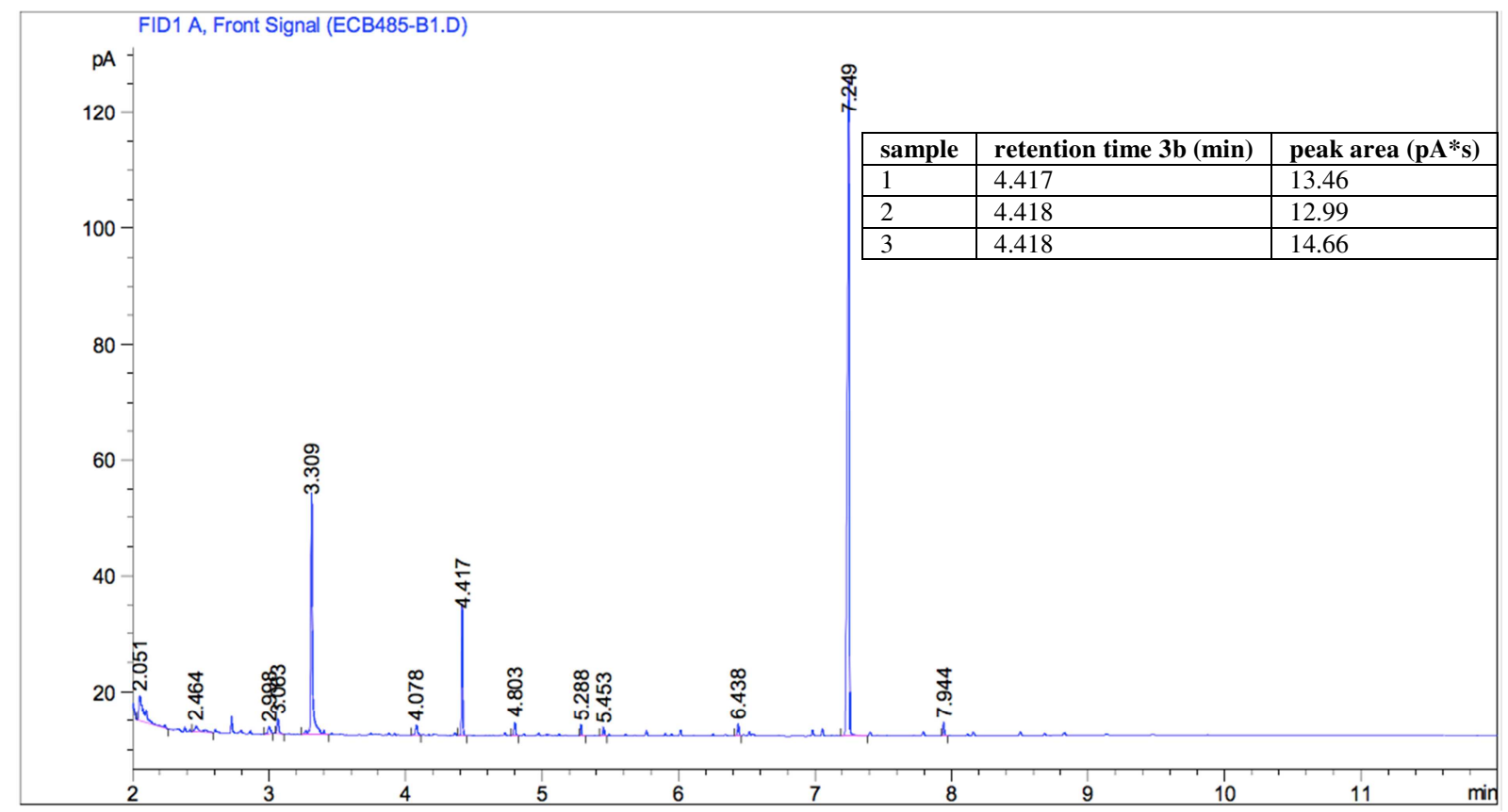


Scheme S-4, Method C

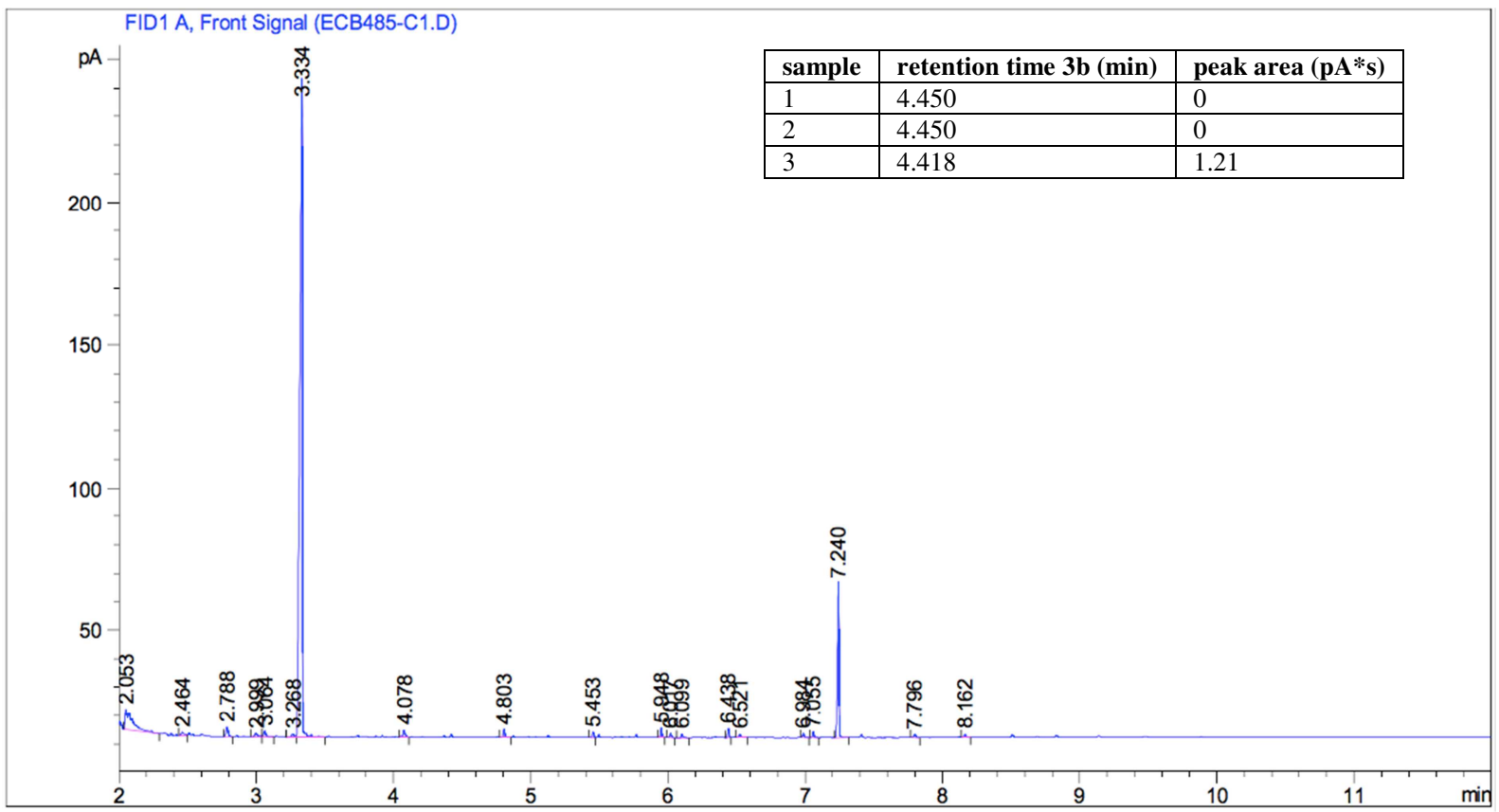

Scheme S-3, Method A

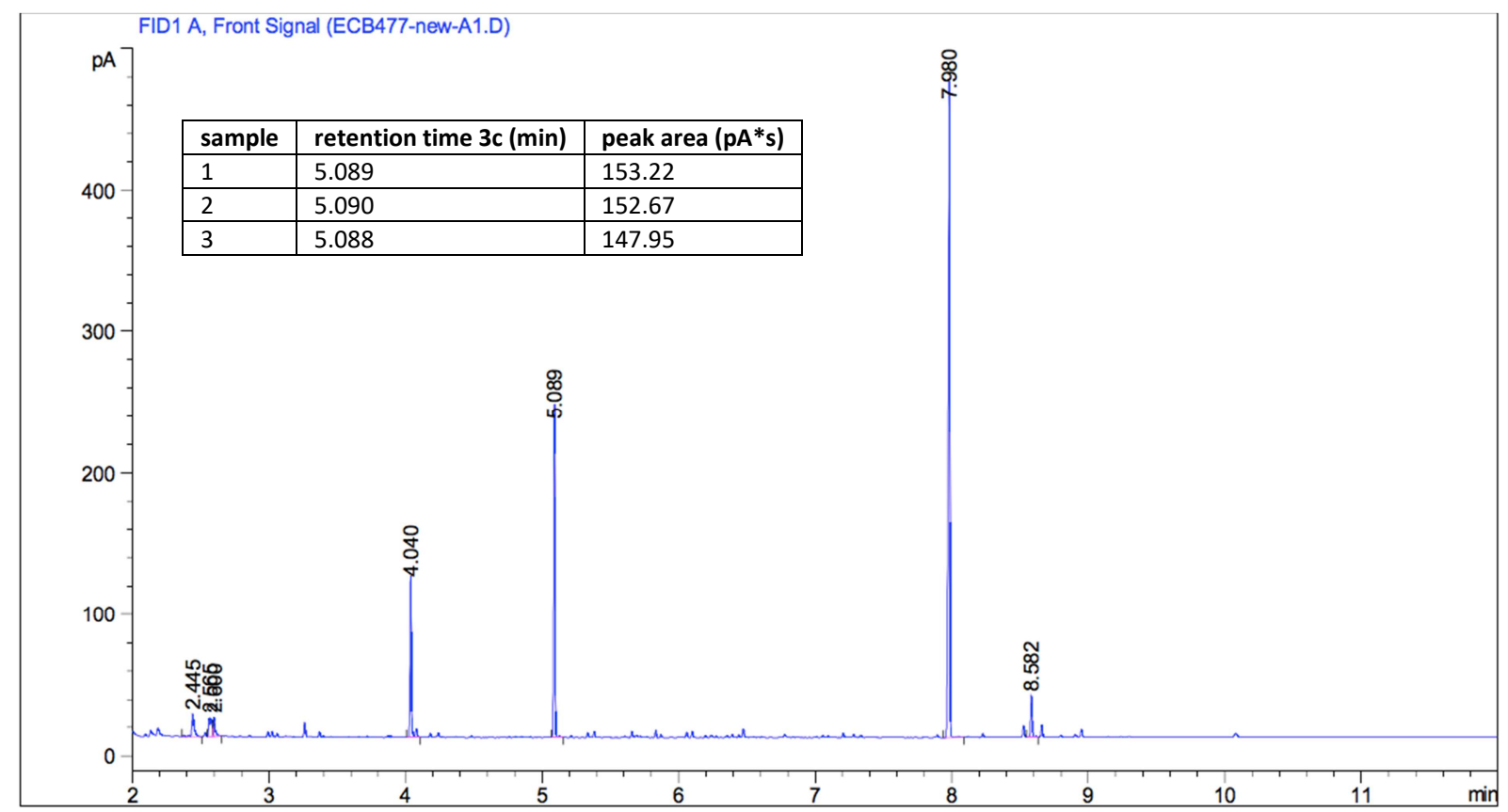


Scheme S-3, Method B

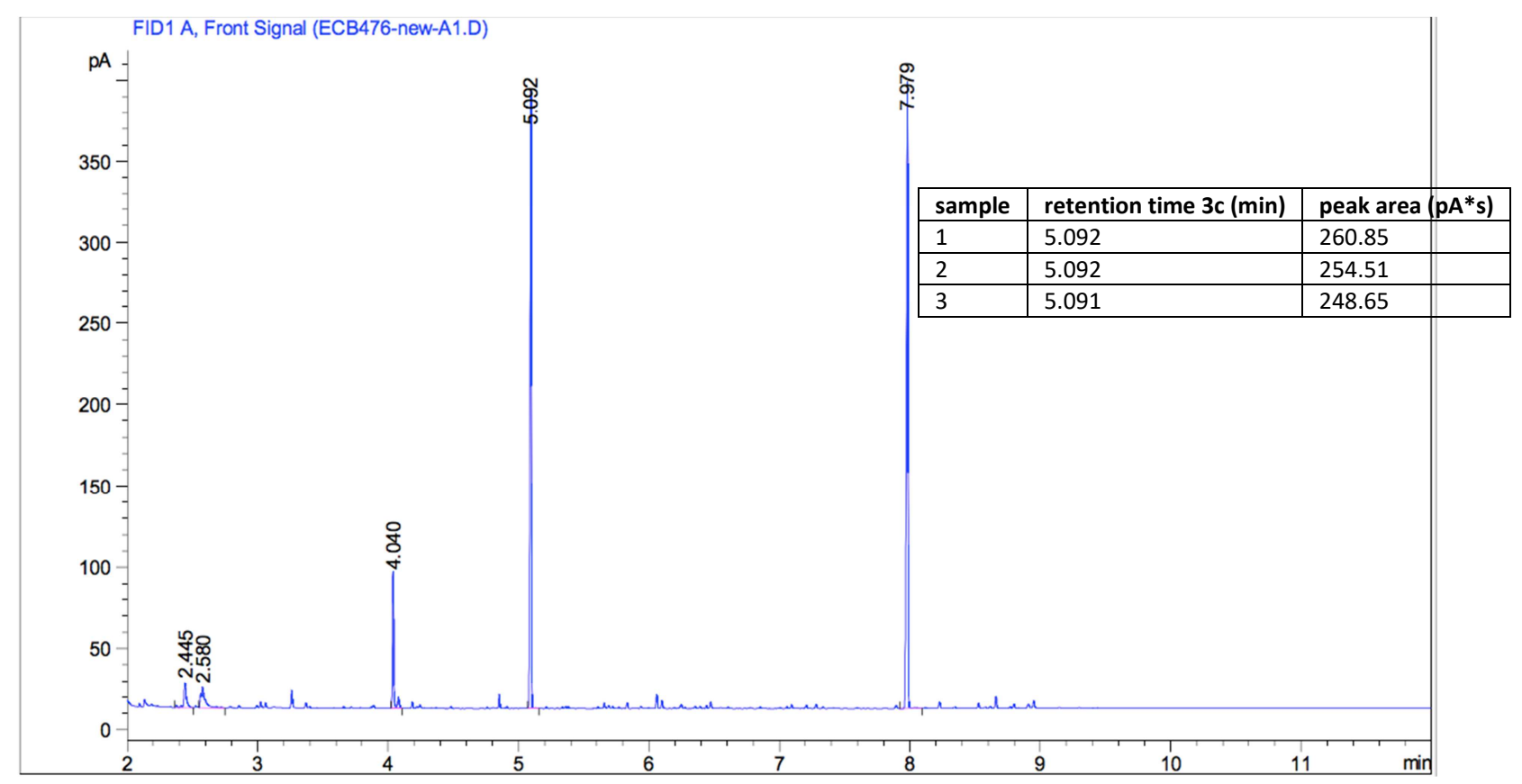

Scheme S-3, Method C

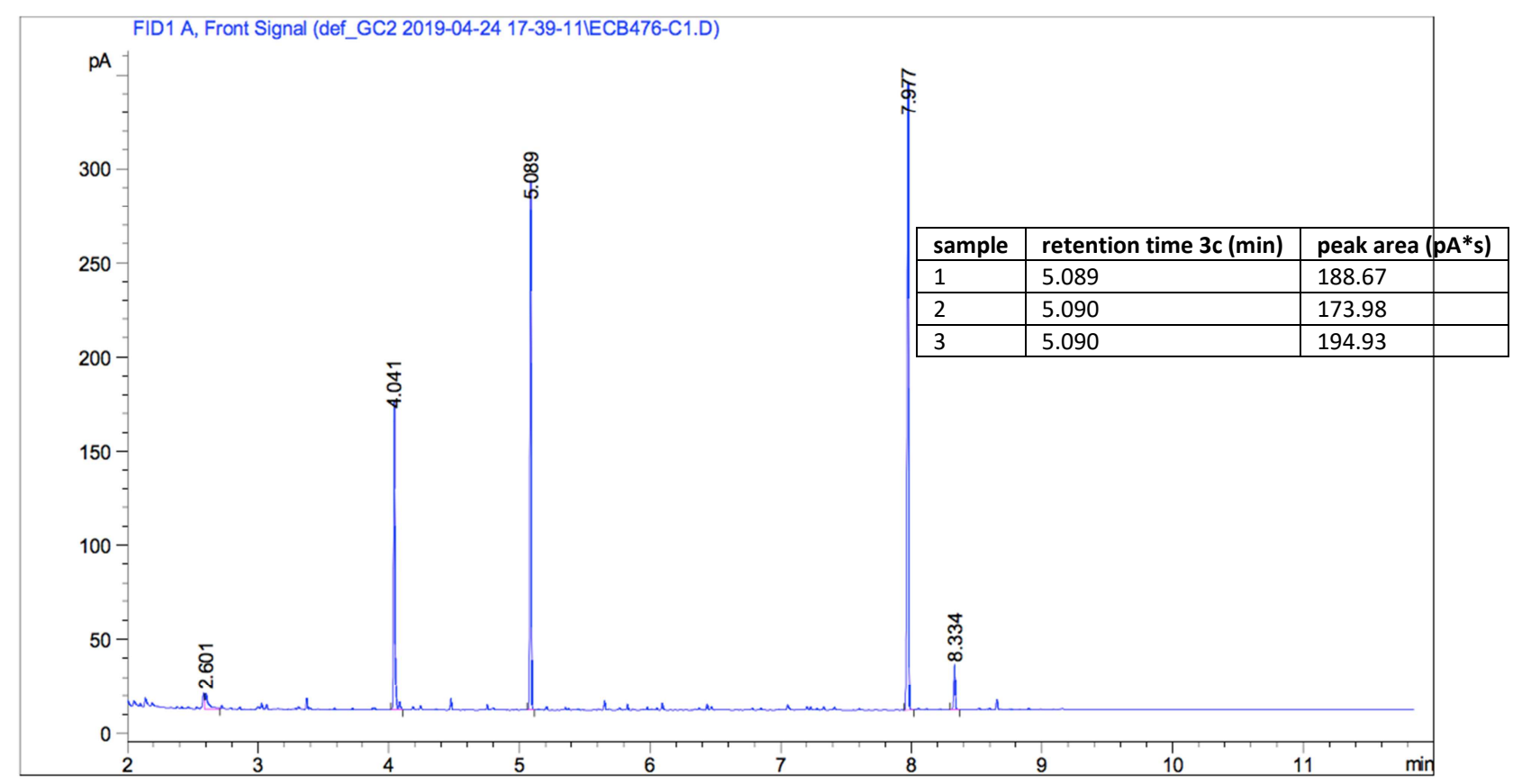




\subsection{GC-FID chromatograms of the network combined with thioester formation}

Table S-3, Entry 1

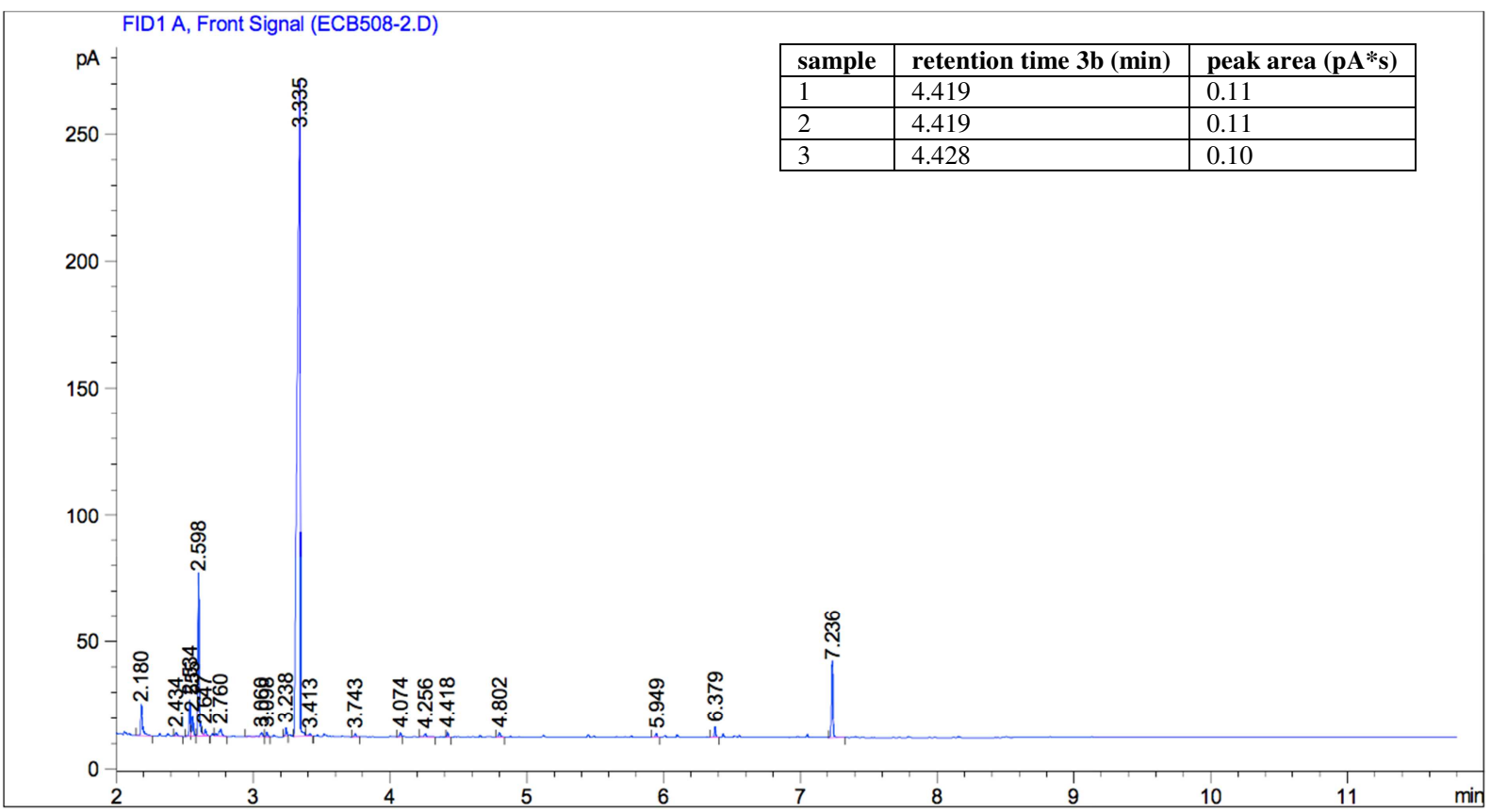

Table S-3, Entry 2

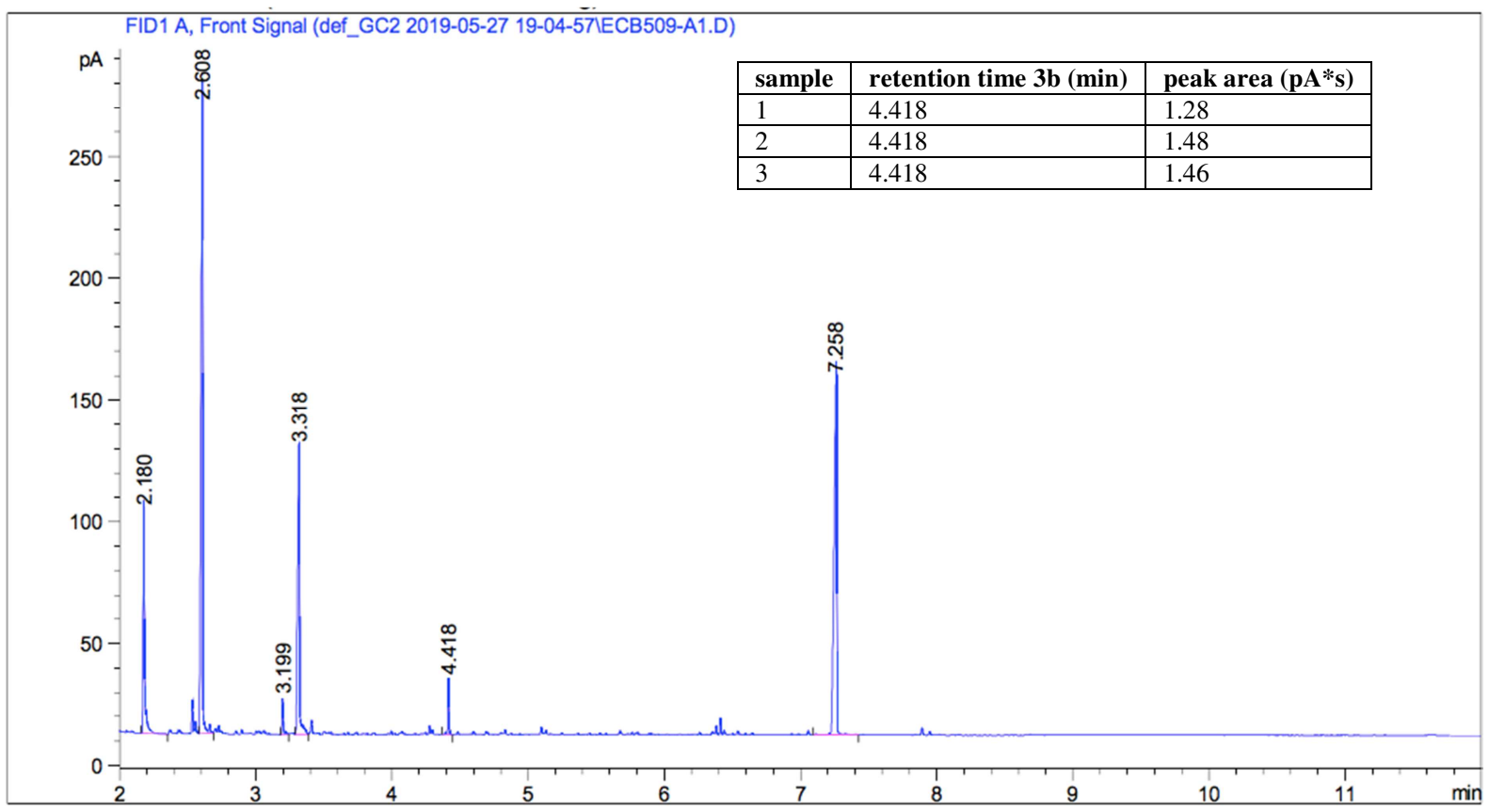


Table S-3, Entry 3

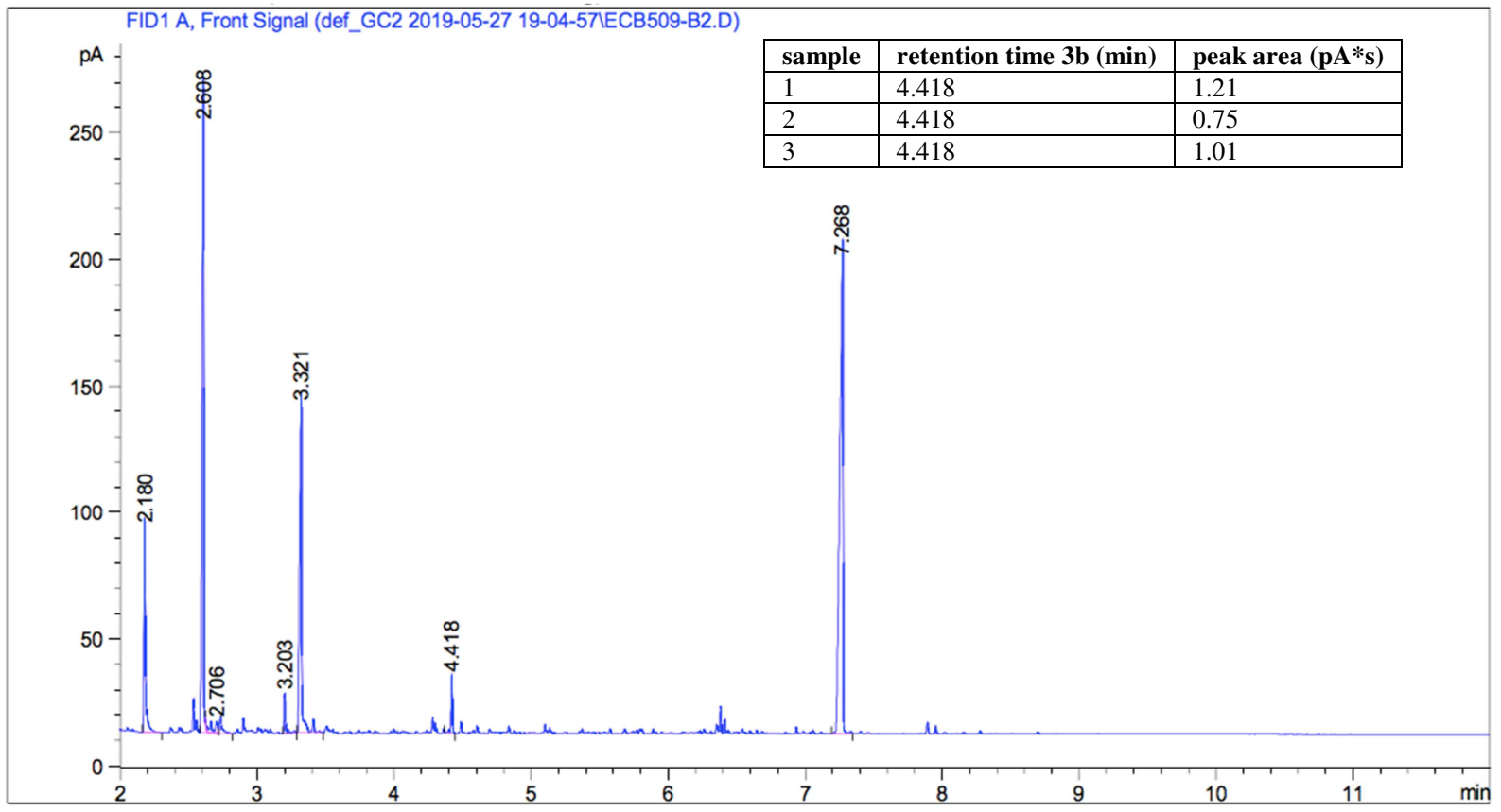




\subsection{LC-MS chromatograms of authentic samples}

$N$-acetyl cysteamine (1b) $\mathrm{m} / \mathrm{z}=119.95-120.15$
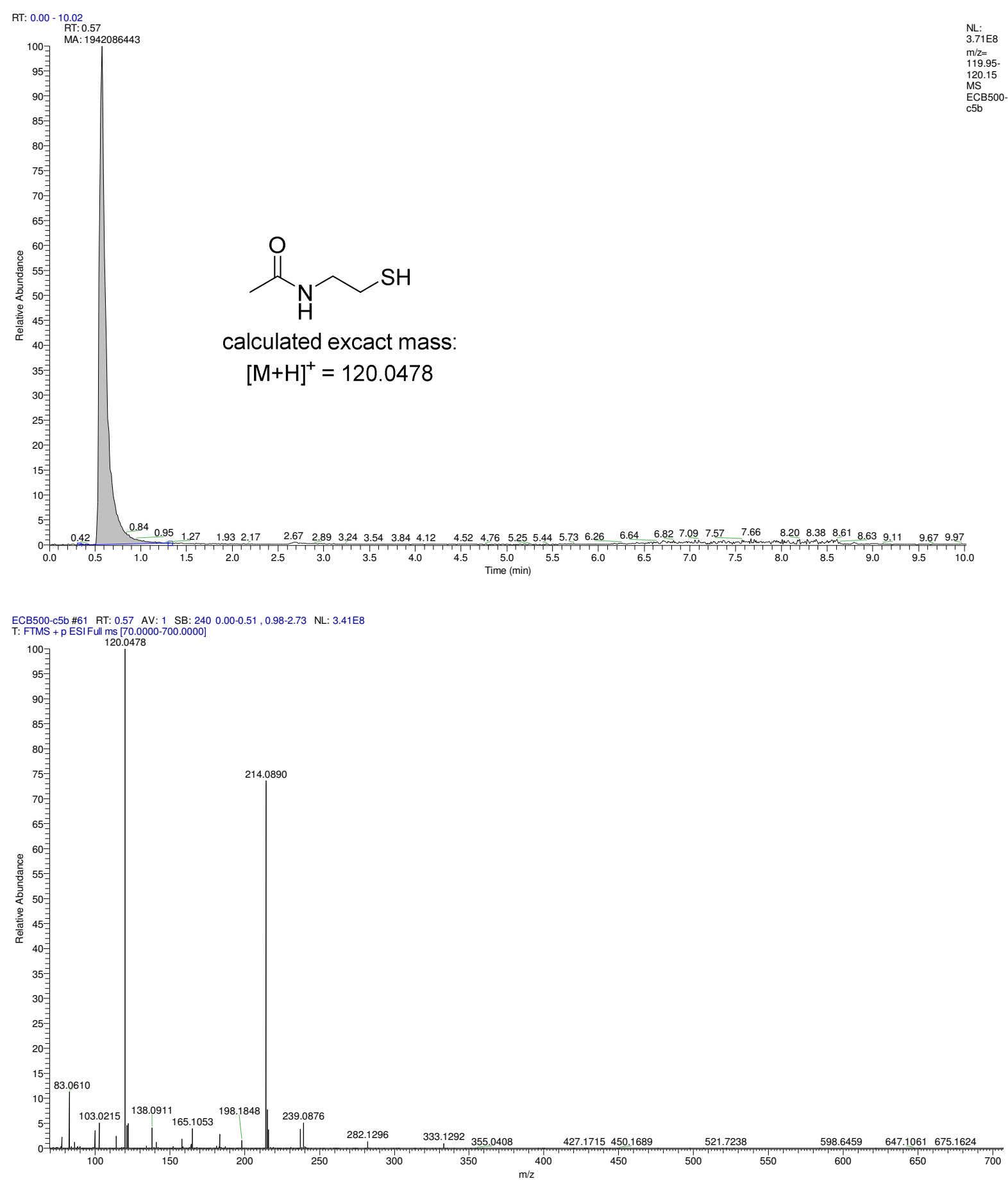
$\boldsymbol{N}, \boldsymbol{N}^{\prime}$-(disulfanediylbis(ethane-2,1-diyl))diacetamide (1d) m/z = 236.97-237.17
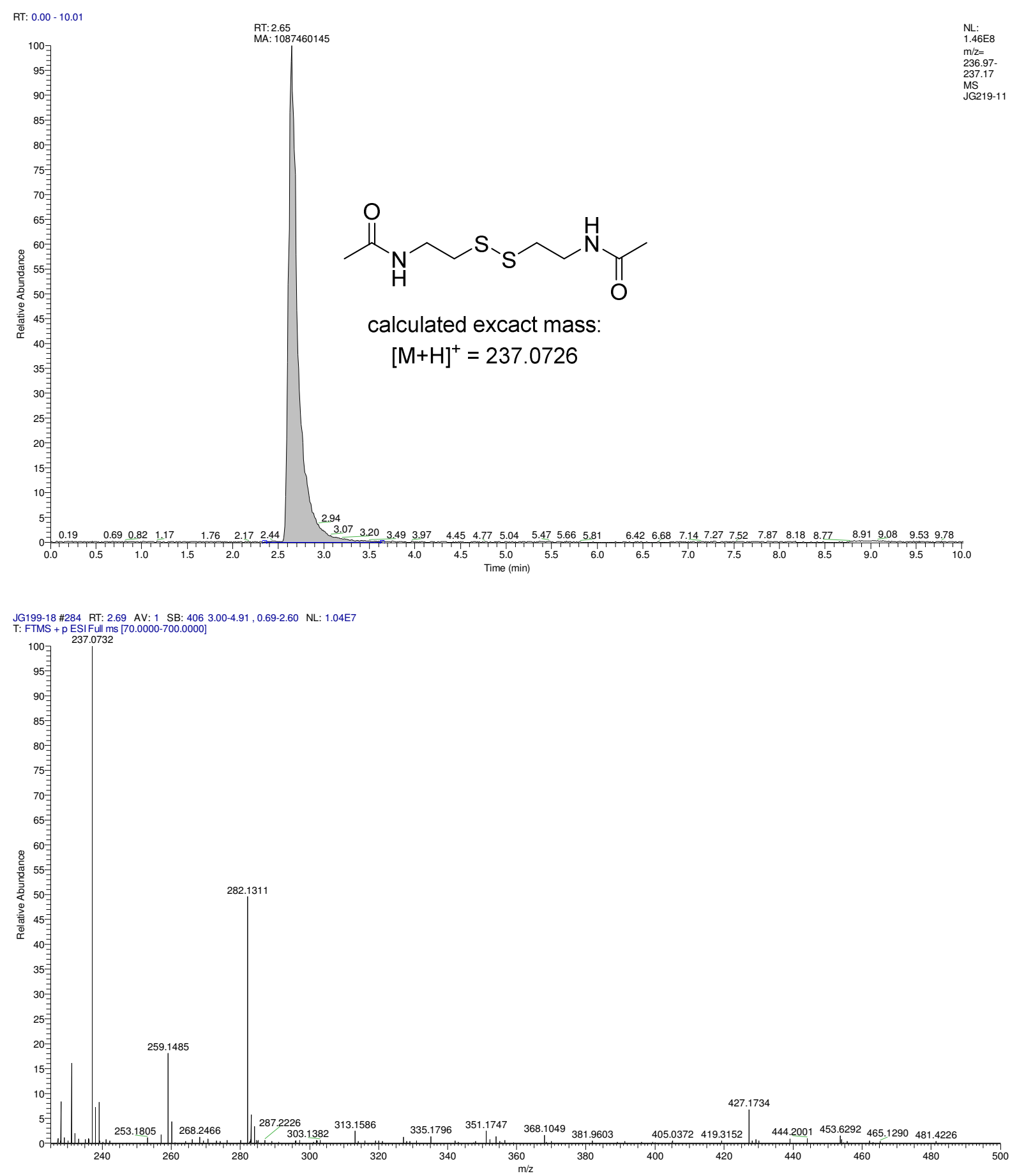
$N, S$-diacetyl cysteamine (3b) $\mathrm{m} / \mathrm{z}=161.95-162.15$

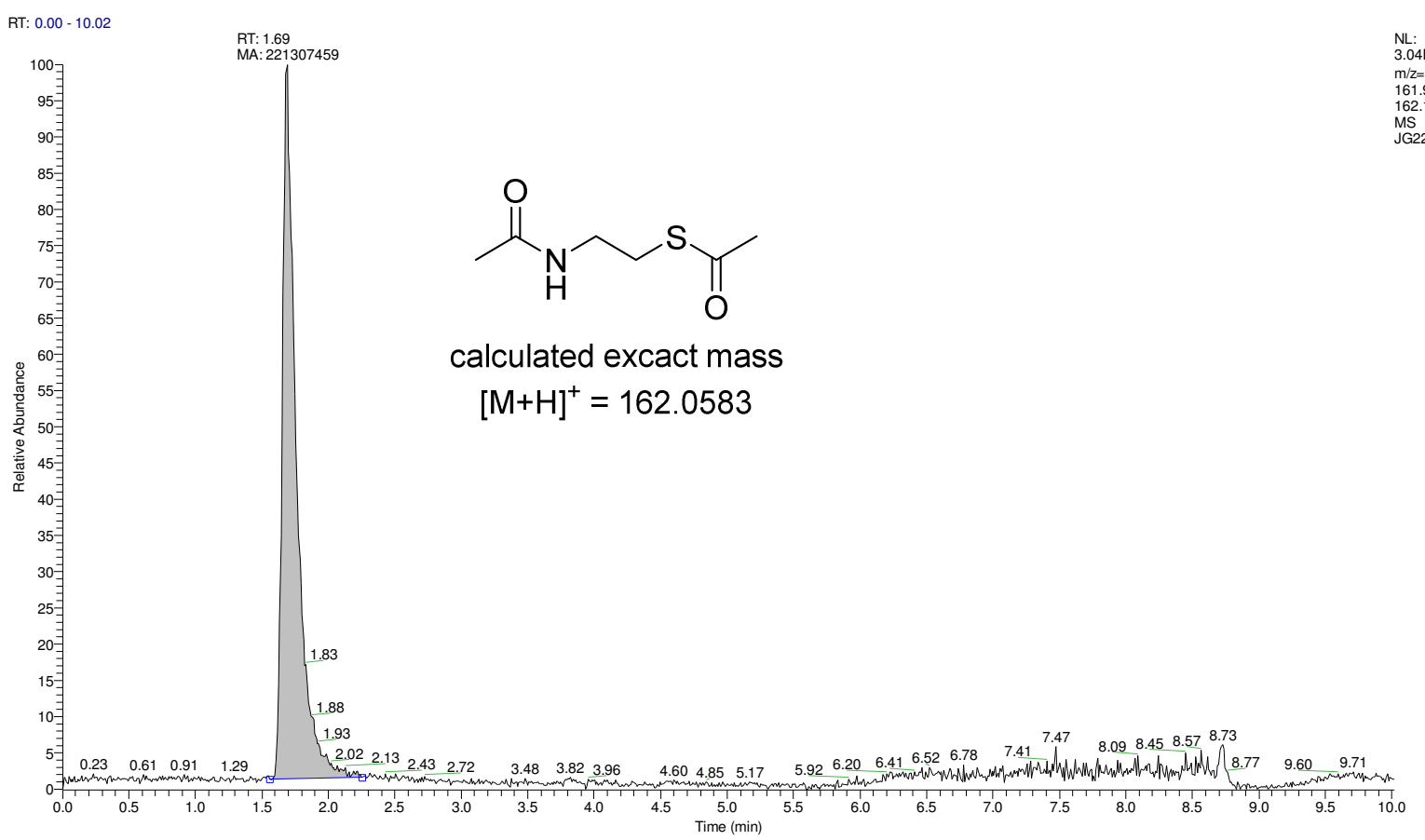

JG220-4\#179 RT: 1.69 AV: 1 SB: 1003 0.00-1.50, 2.02-10.02 NL: 5.44E7

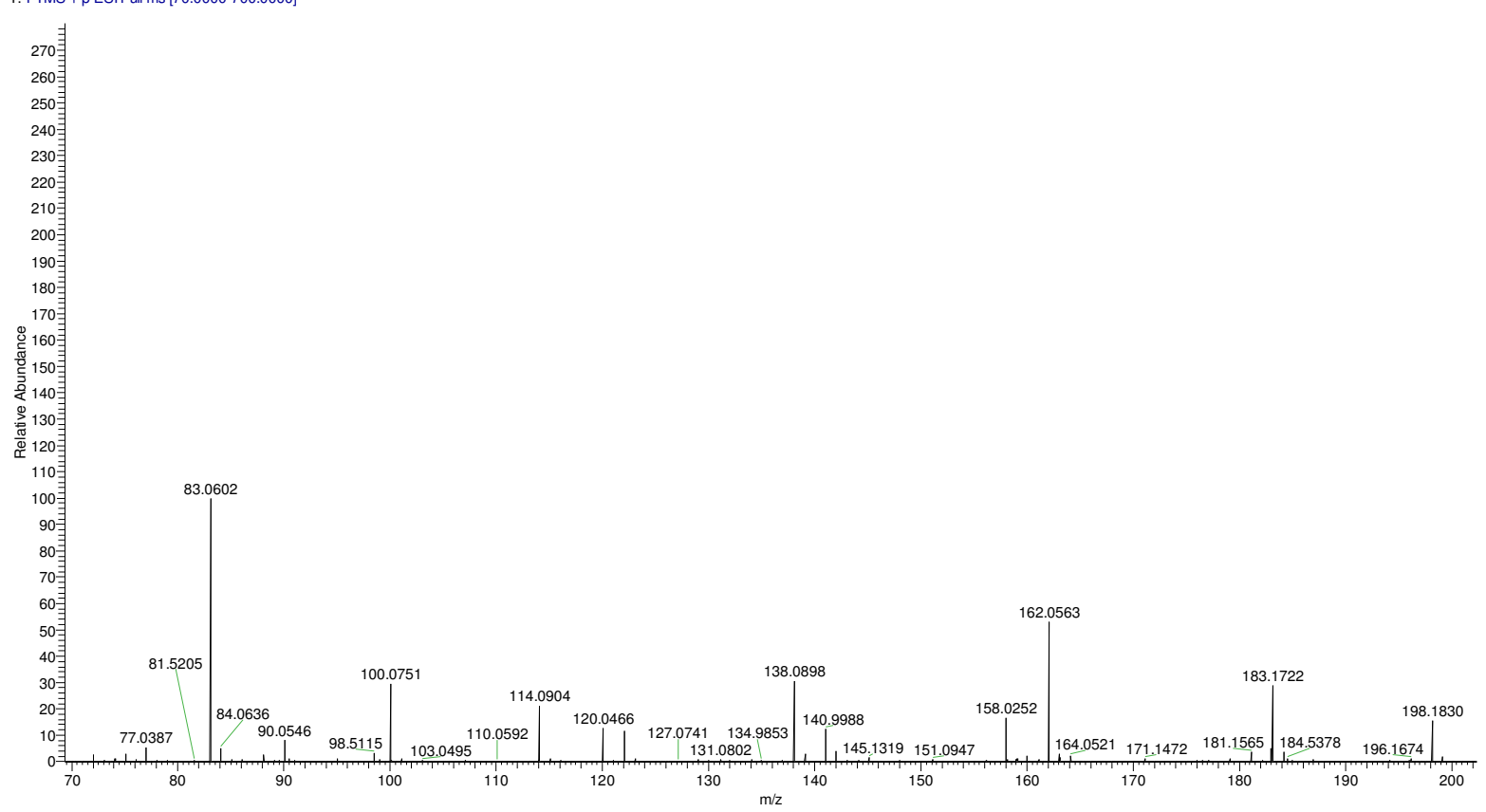


4-[[2-(Acetylamino)ethyl]thio]-4-oxobutanoic acid (5b) $\mathrm{m} / \mathrm{z}=219.95-220.15$
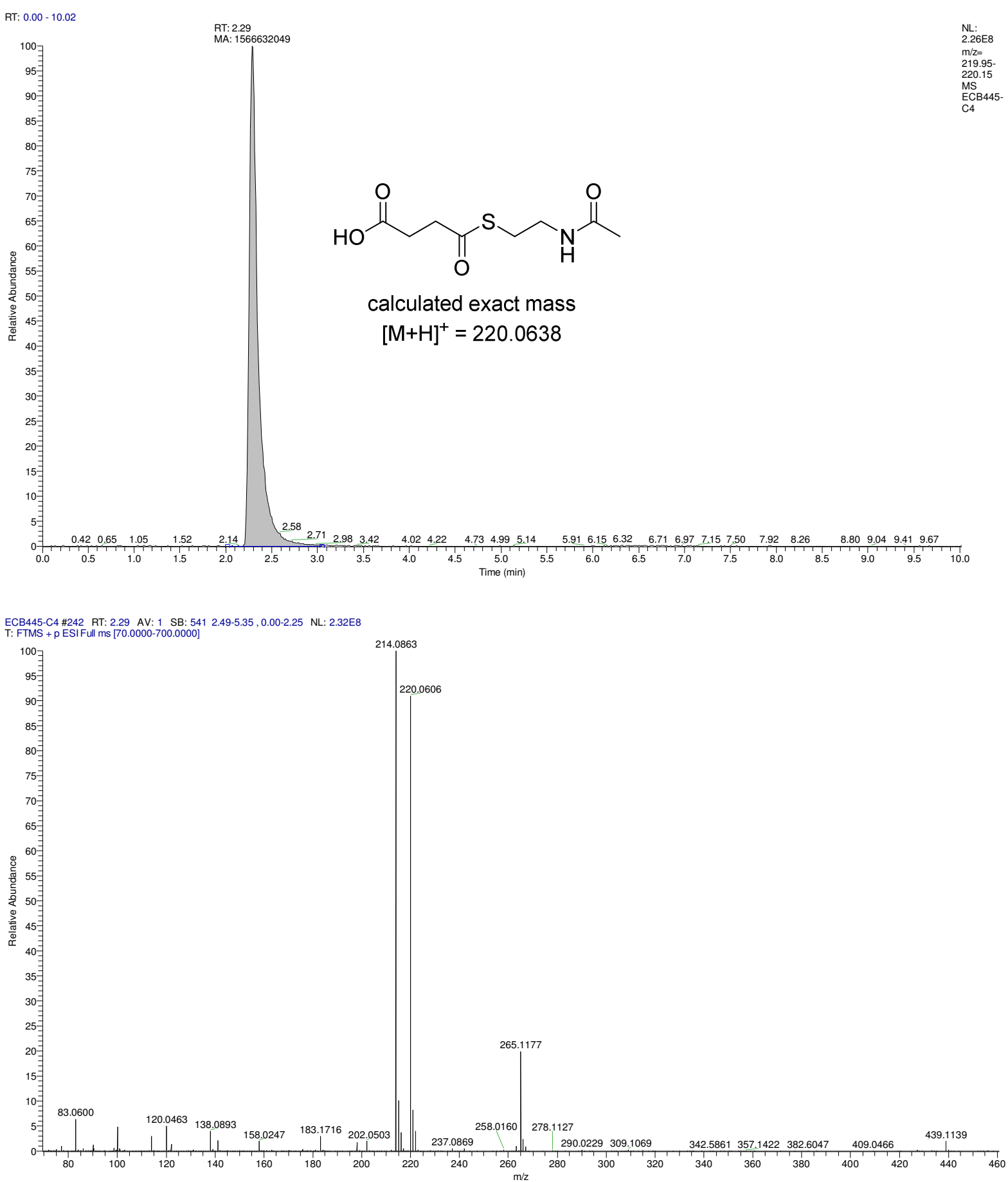
3-((2-acetamidoethyl)thio)-3-oxopropanoic acid (8b) m/z = 205.54-206.54

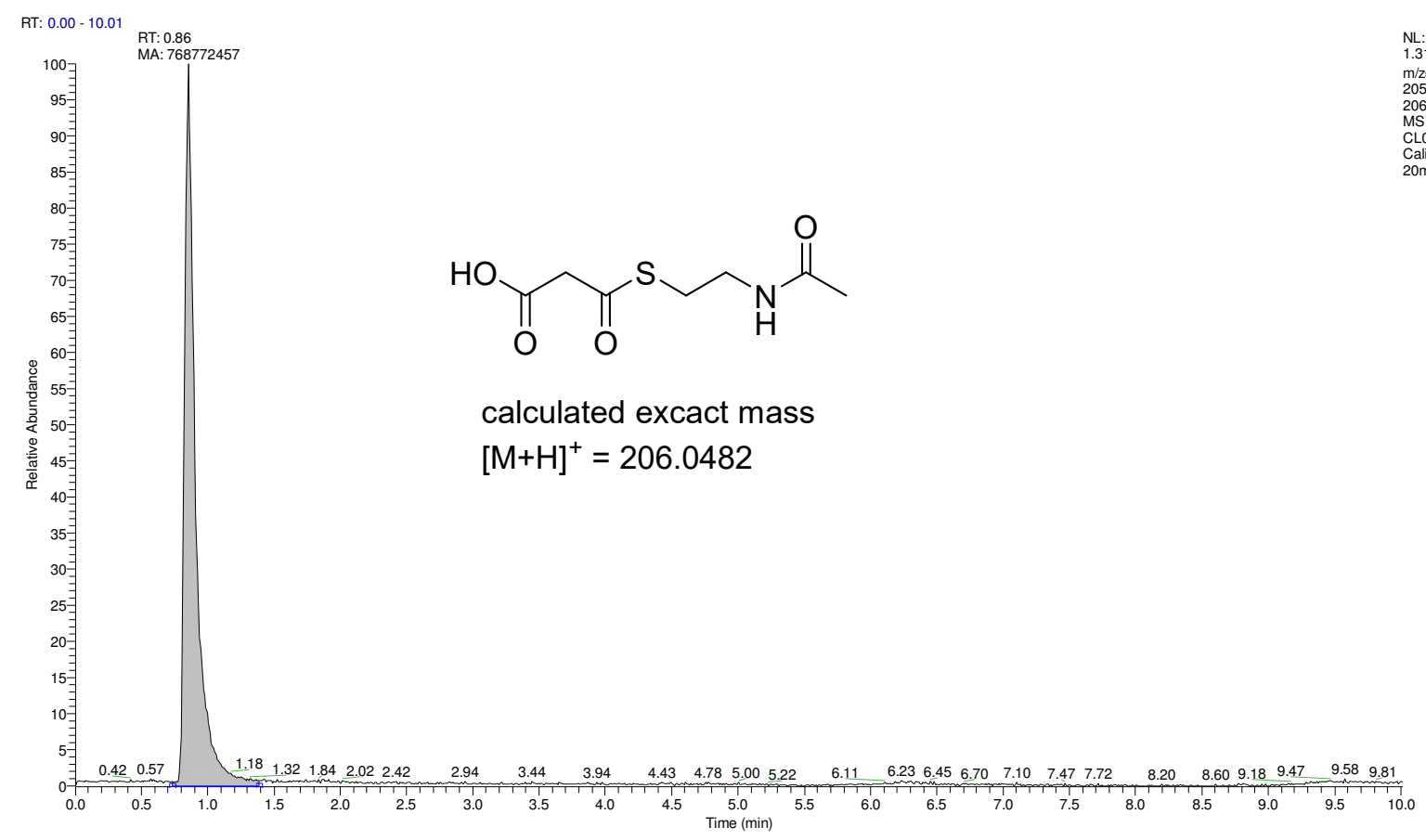

CL030-Calib-20mM-1 \#89 RT: 0.84 AV: 1 SB: 1037 0.99-10.01, 0.00-0.80 NL: 1.01E8
T: FTMS + p ESIFull ms [70.0000-700.0000]

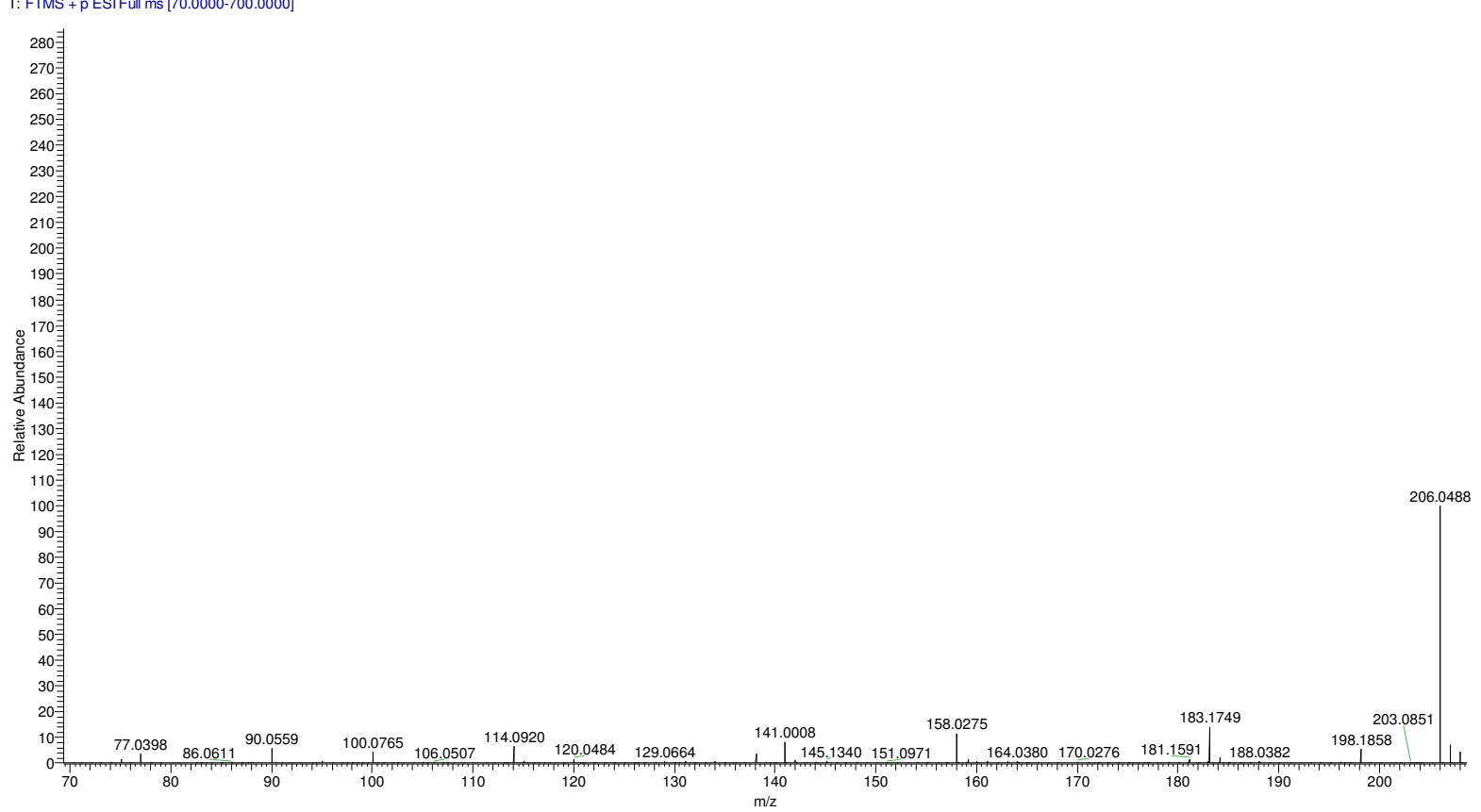


4-((2-acetamidoethyl)thio)-2-hydroxy-4-oxobutanoic acid (9b) $\mathrm{m} / \mathrm{z}=236.04-236.06$
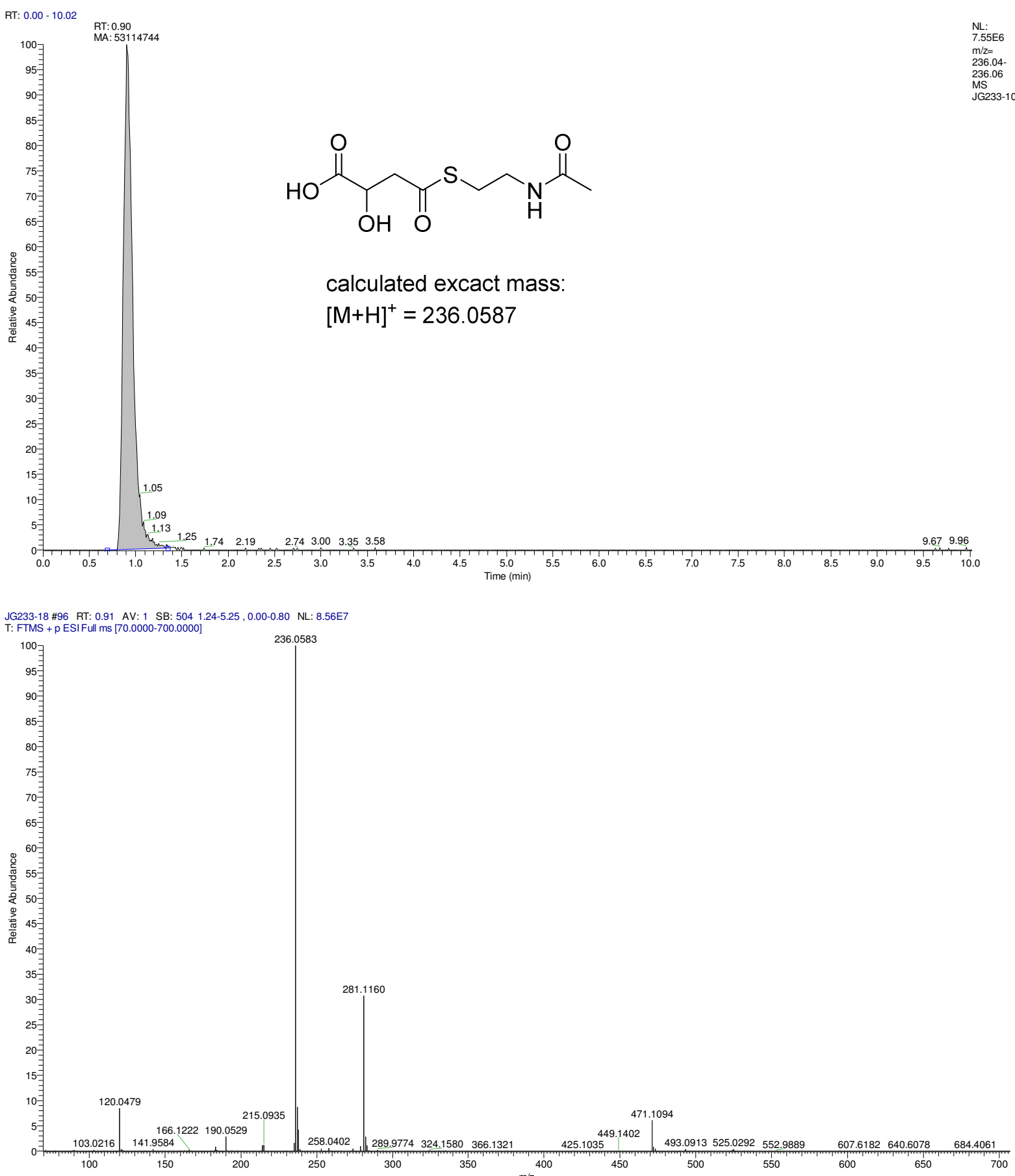


\subsection{LC-MS chromatograms of thioester formation under prebiotic conditions}

Table 1, Entry 3, Method A

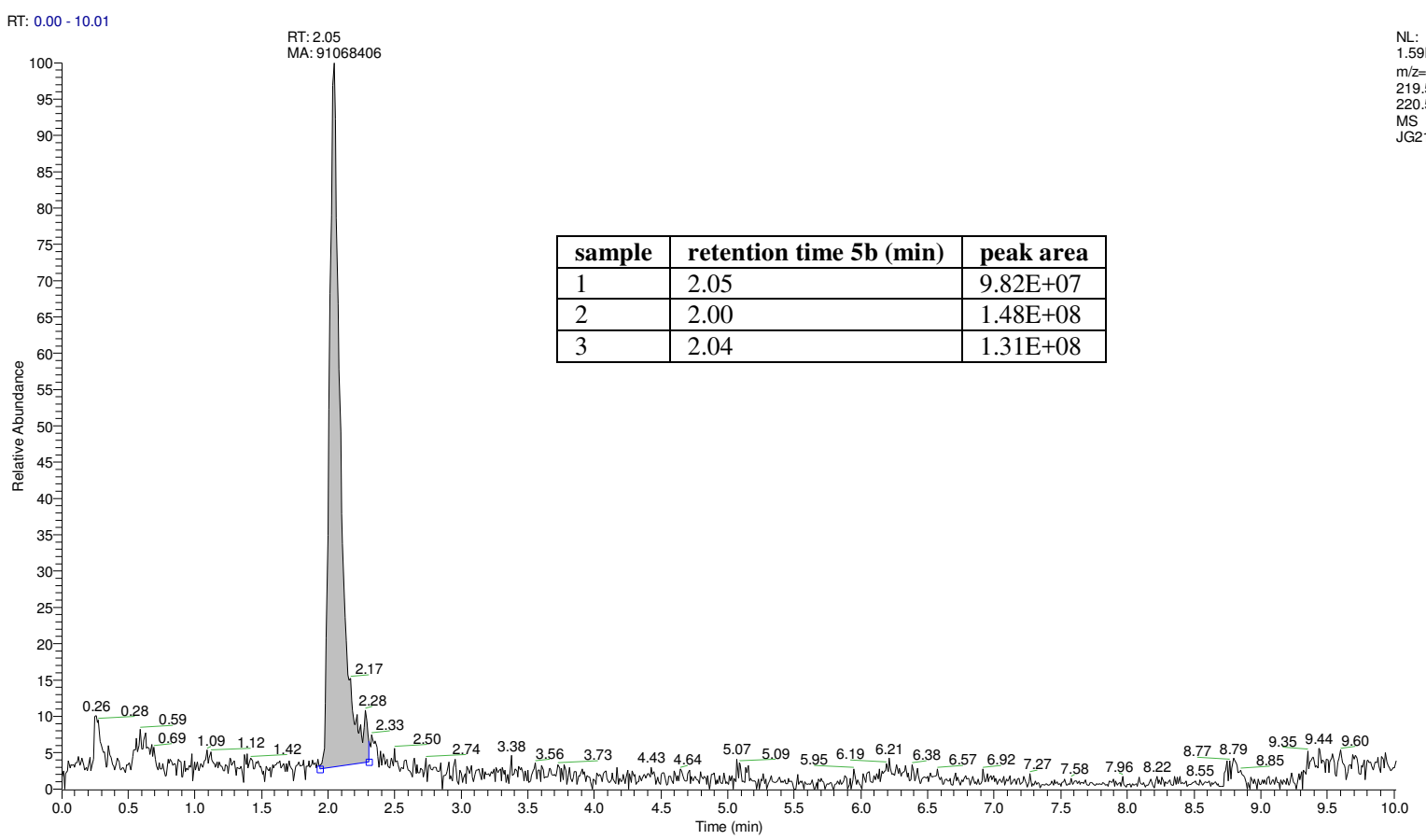

Table 1, Entry 3, Method B

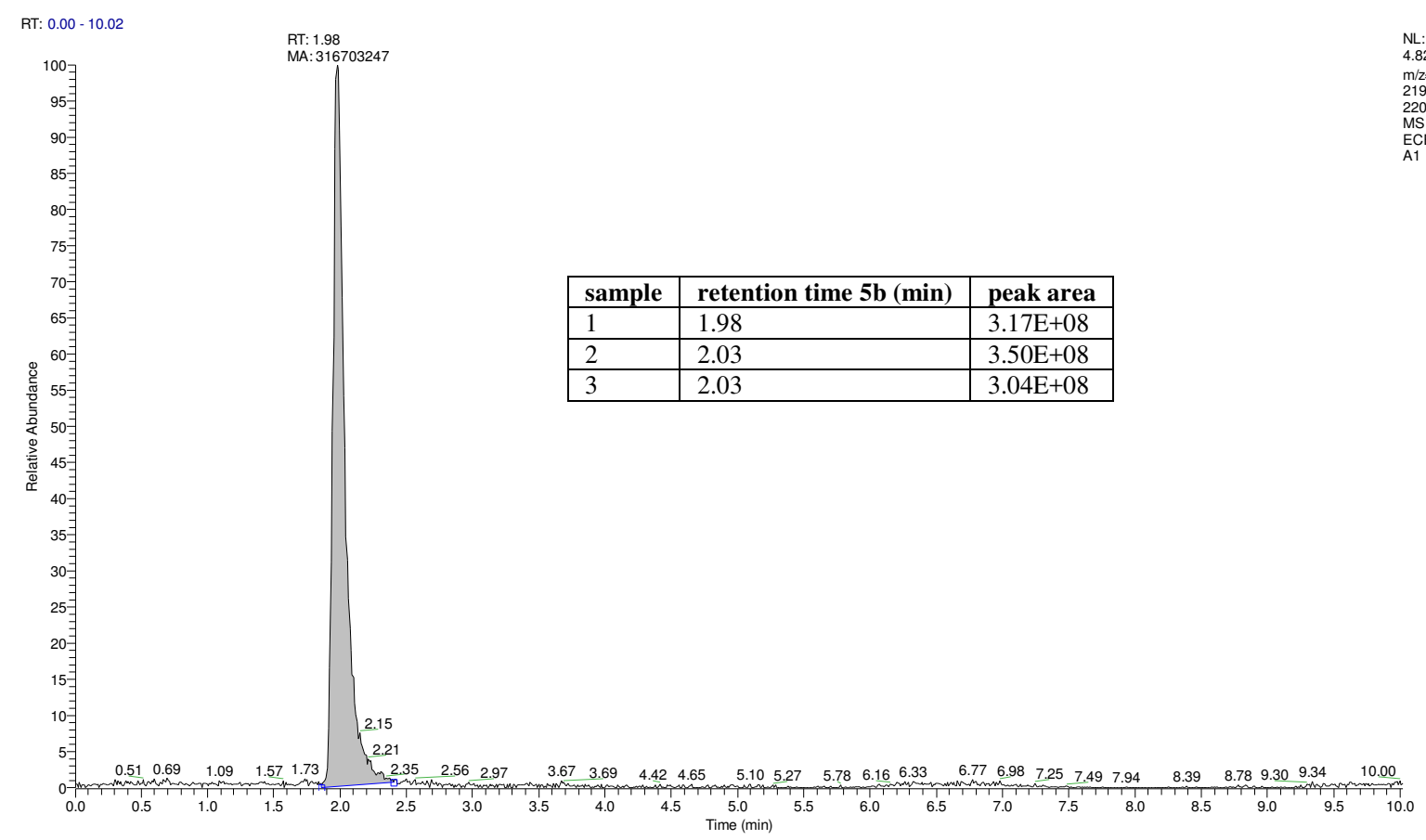


Table 1, Entry 3, Method C

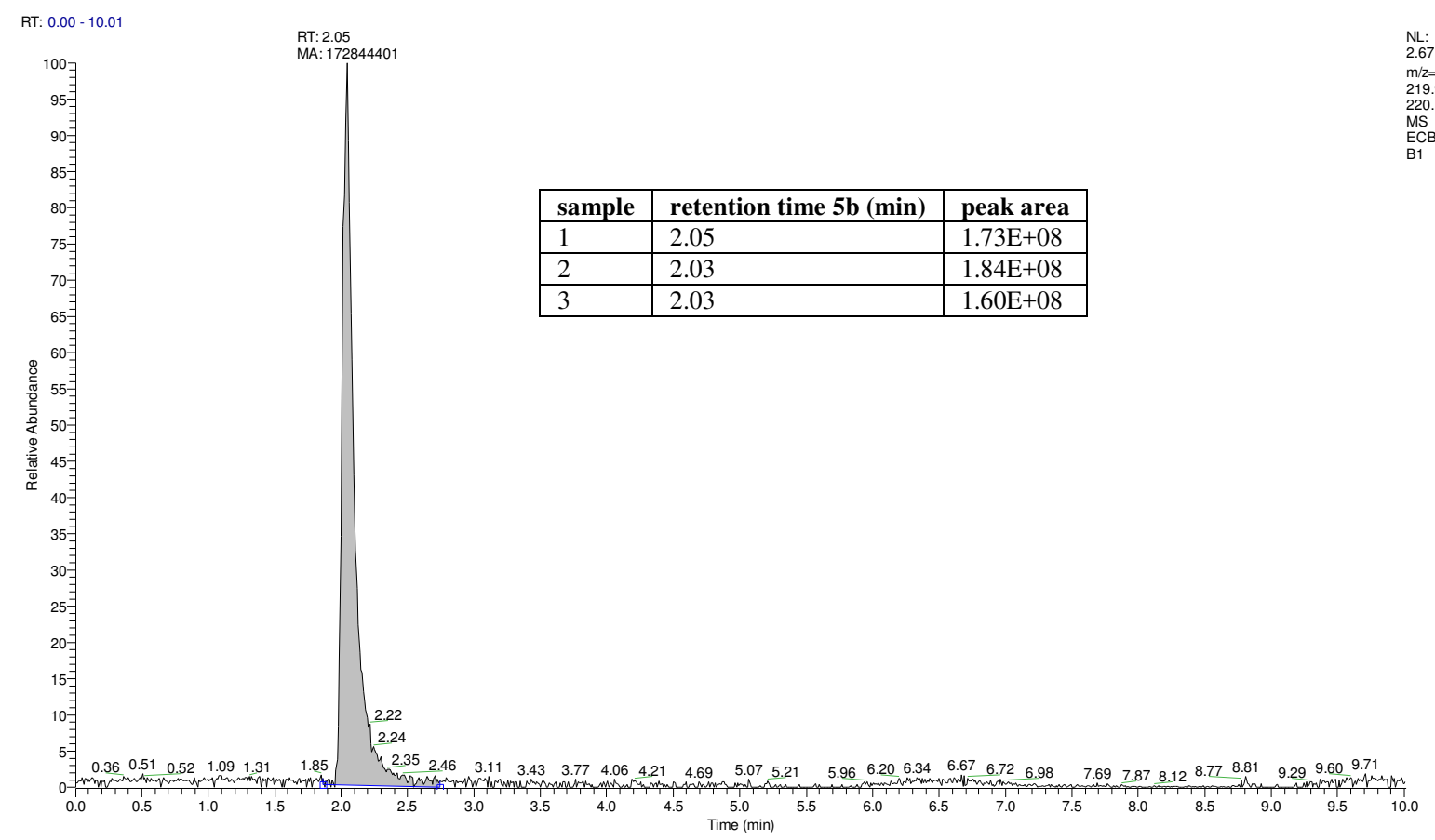


Table 1, Entry 4, Method A
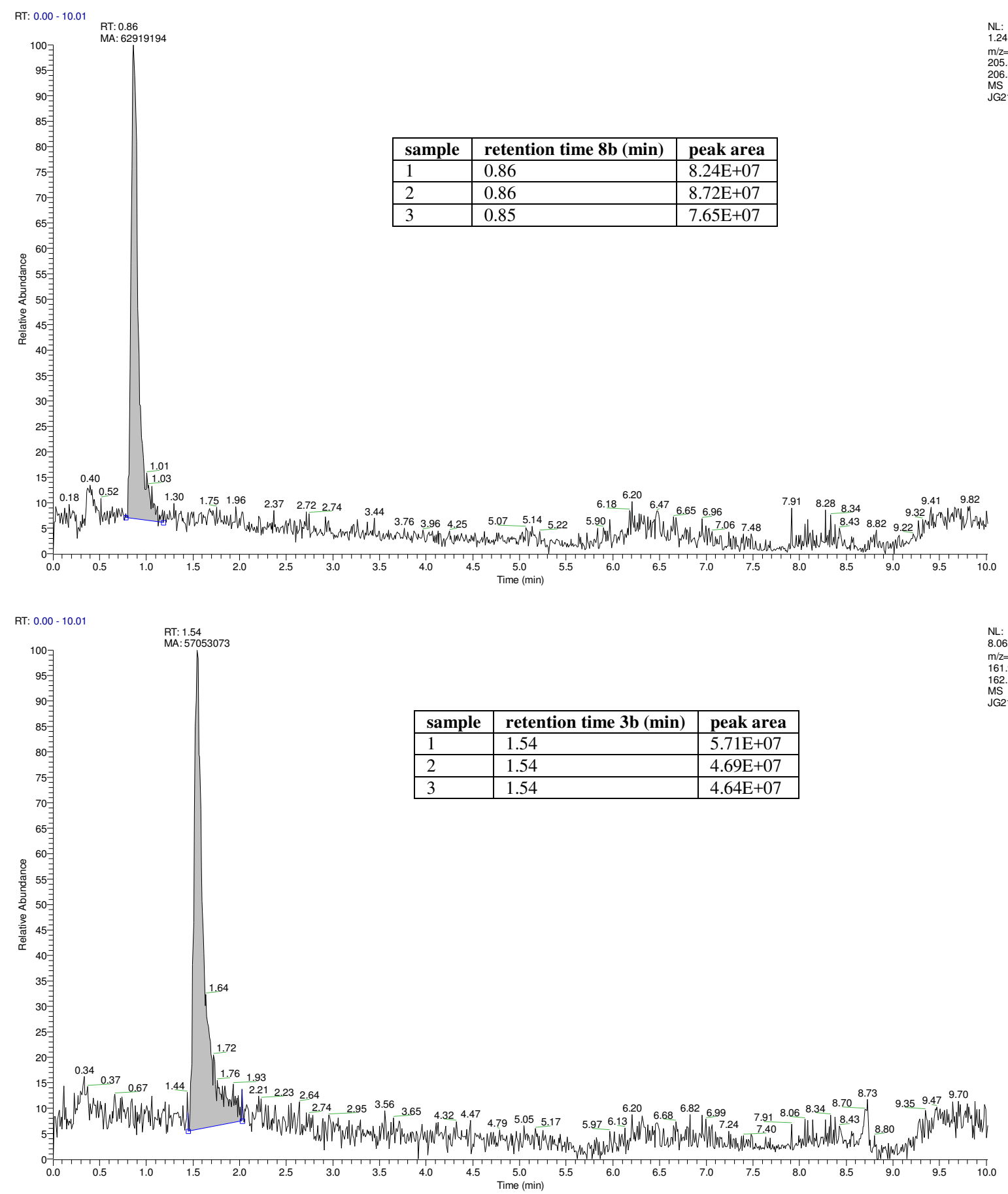


\section{Table 1, Entry 4, Method B}
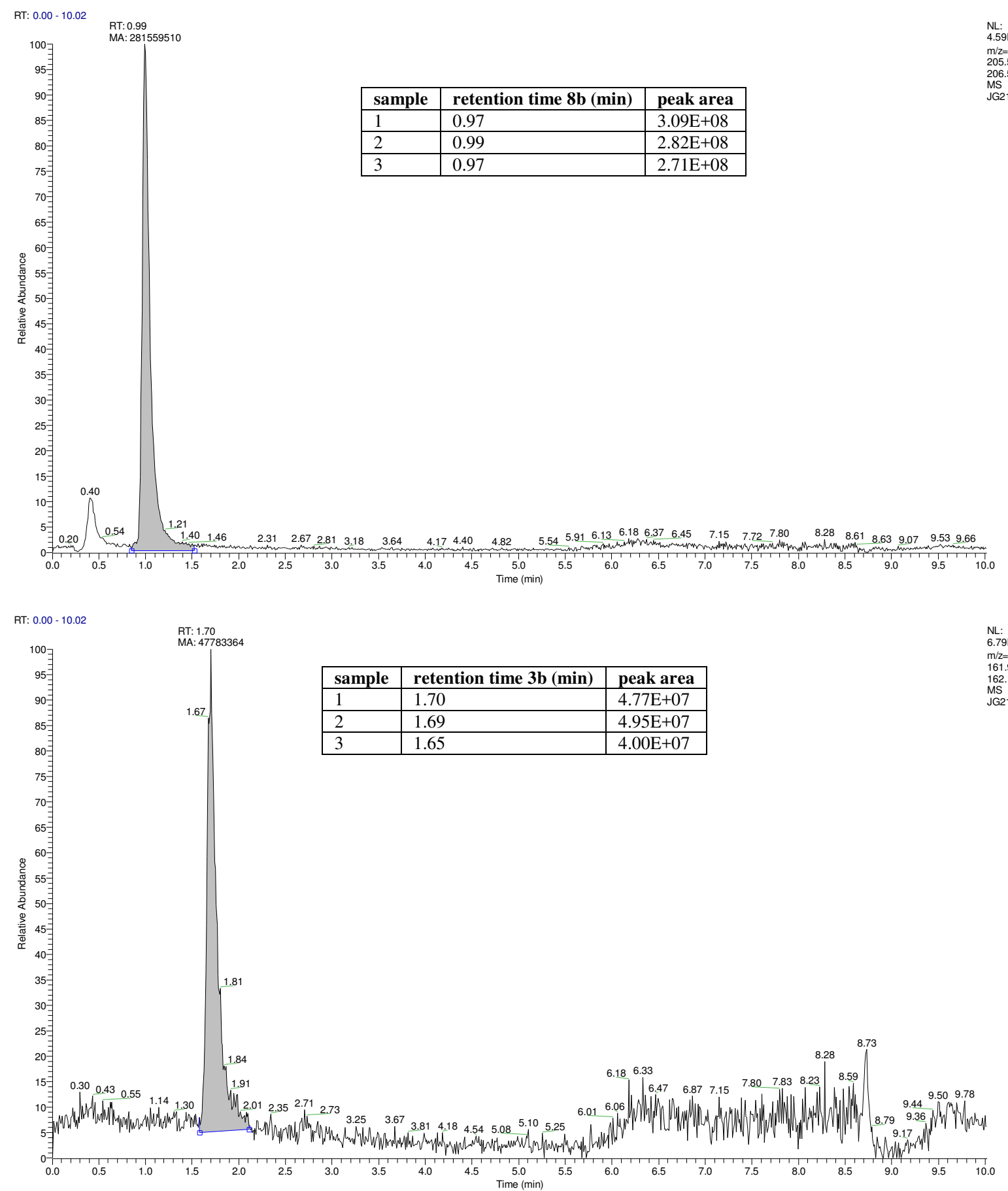
Table 1, Entry 4, Method C

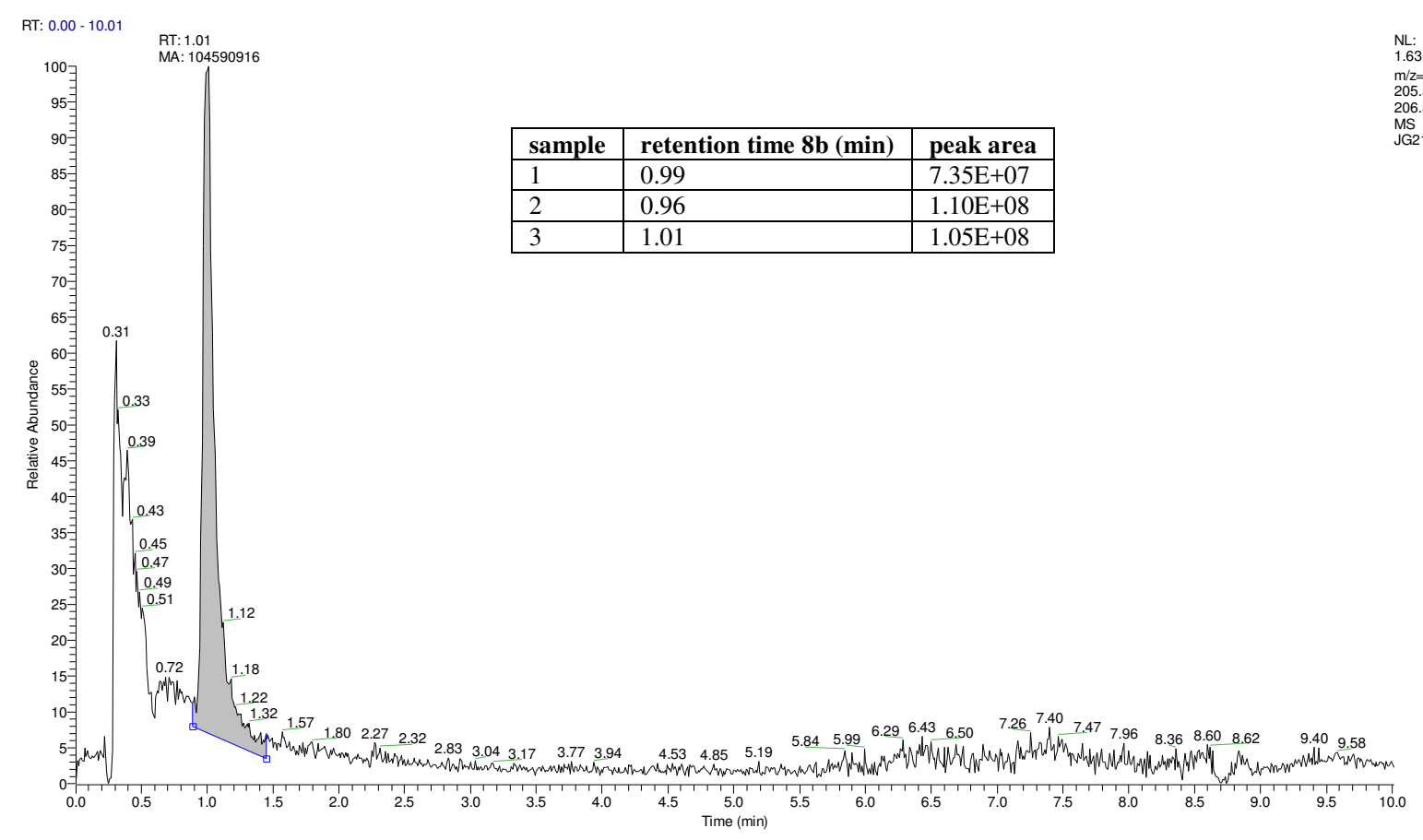

Table 1, Entry 5, Method A

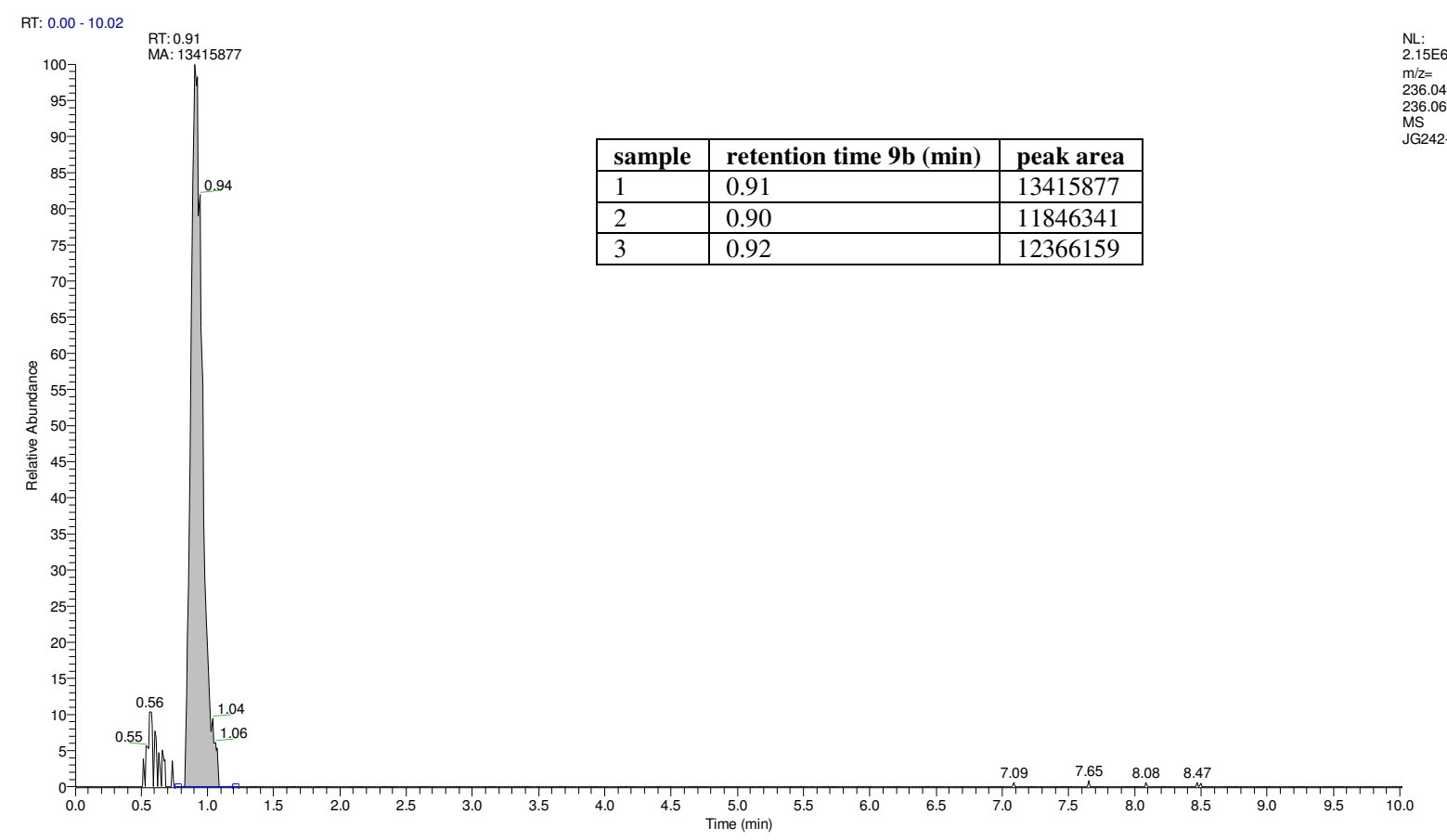


Table 1, Entry 5, Method B

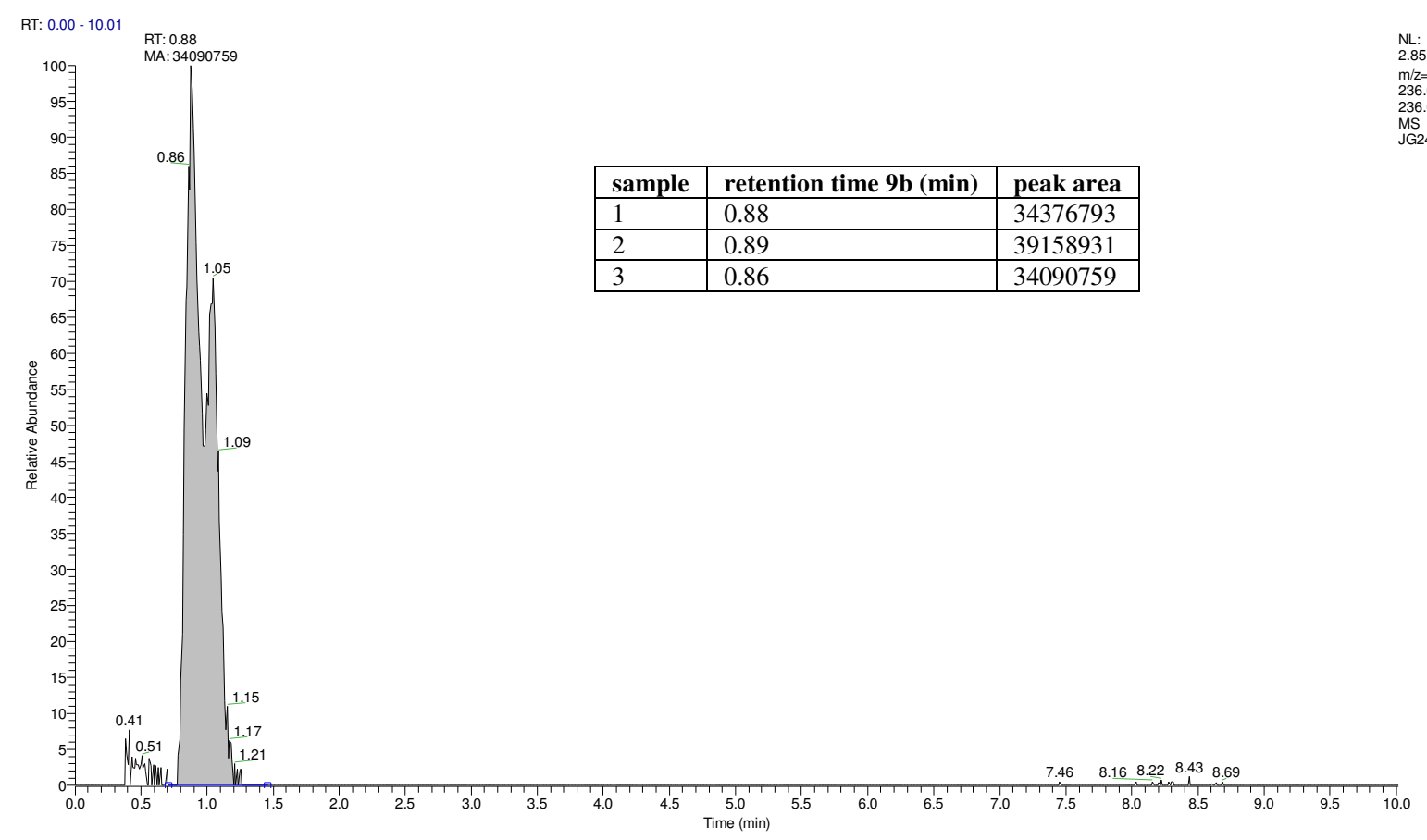

Table 1, Entry 5, Method C

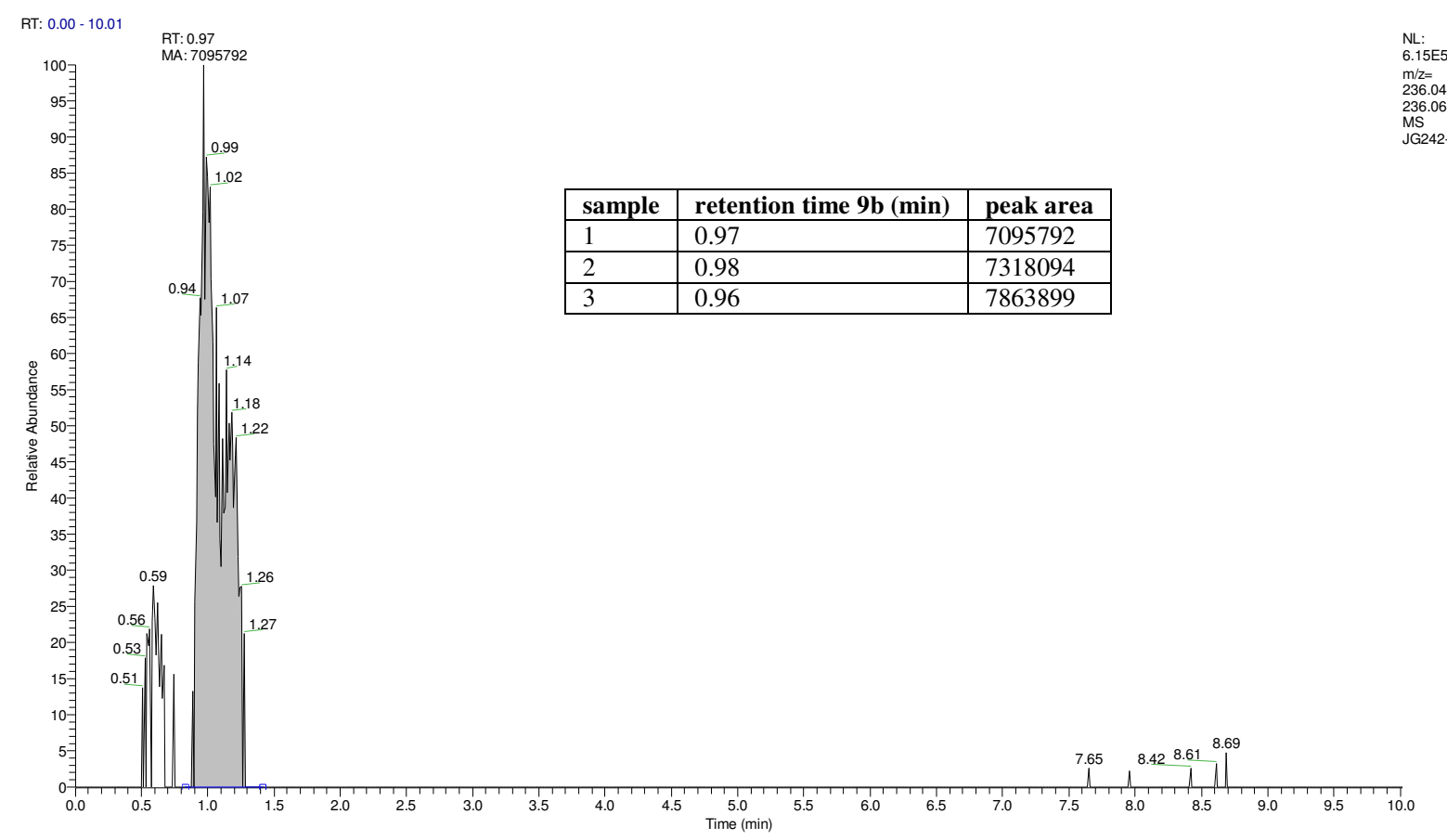




\subsection{LC-MS chromatograms of the network combined with thioester formation}

Table S-3, Entry 1
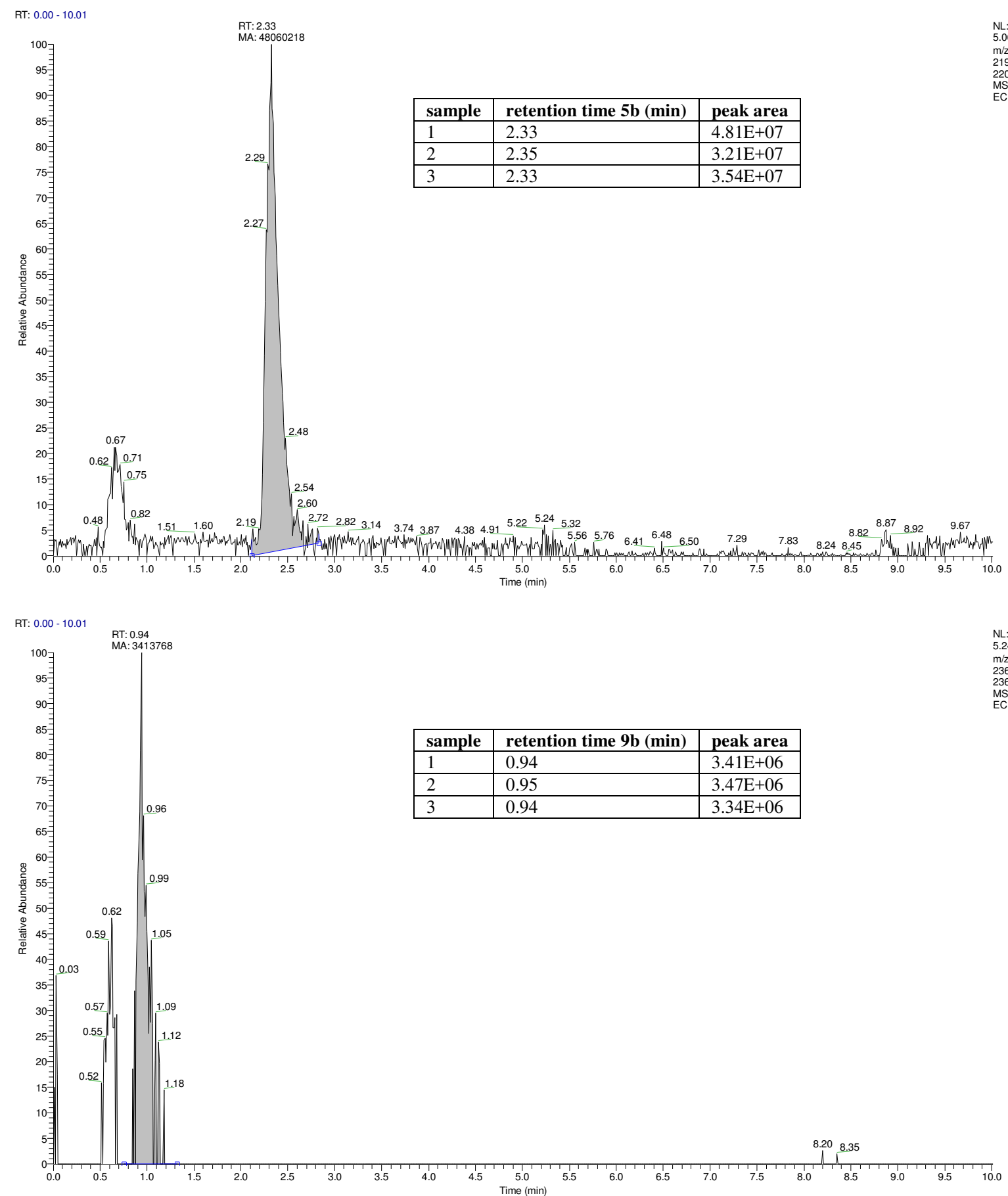
Table S-3, Entry 2
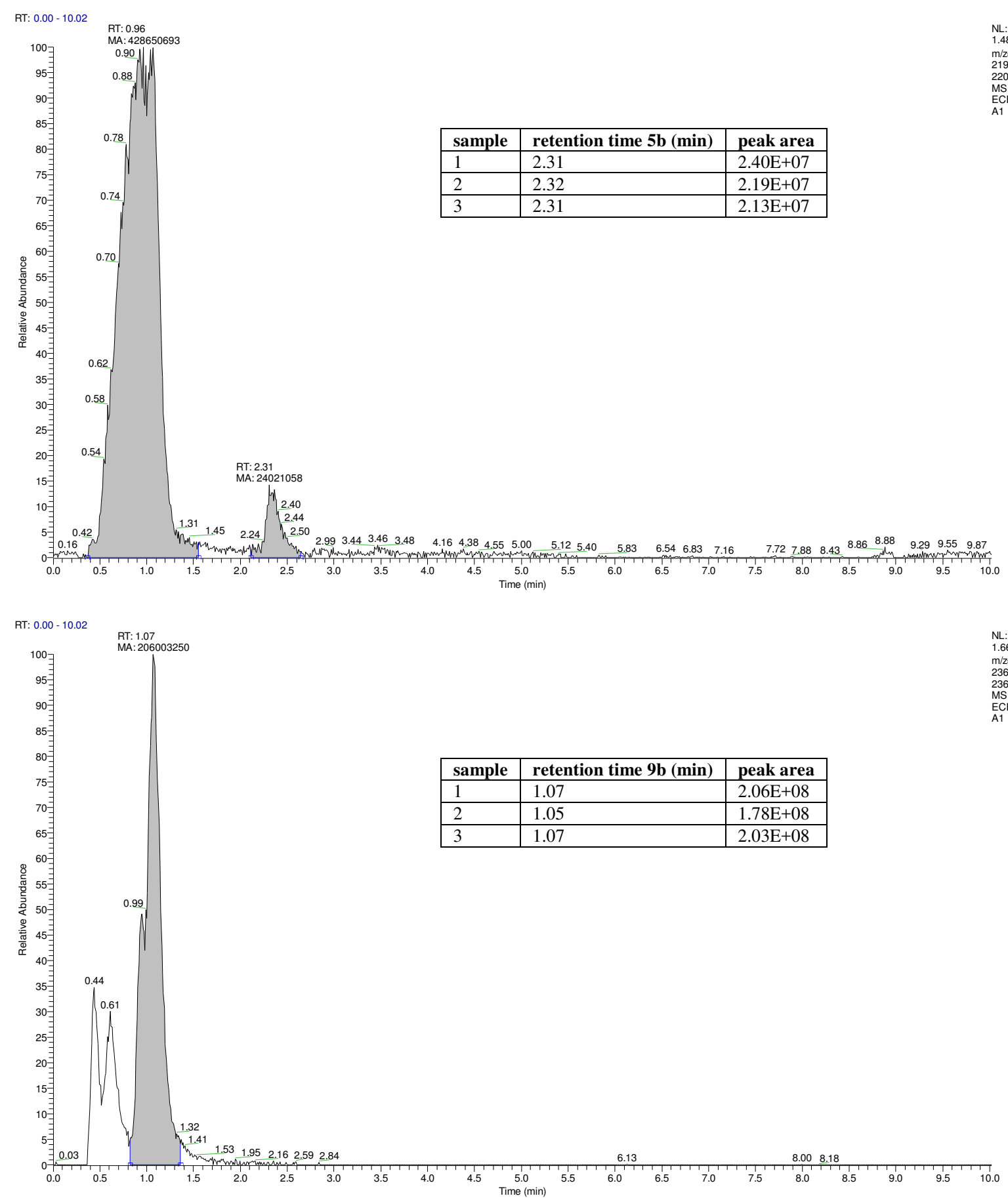
Table S-3, Entry 3
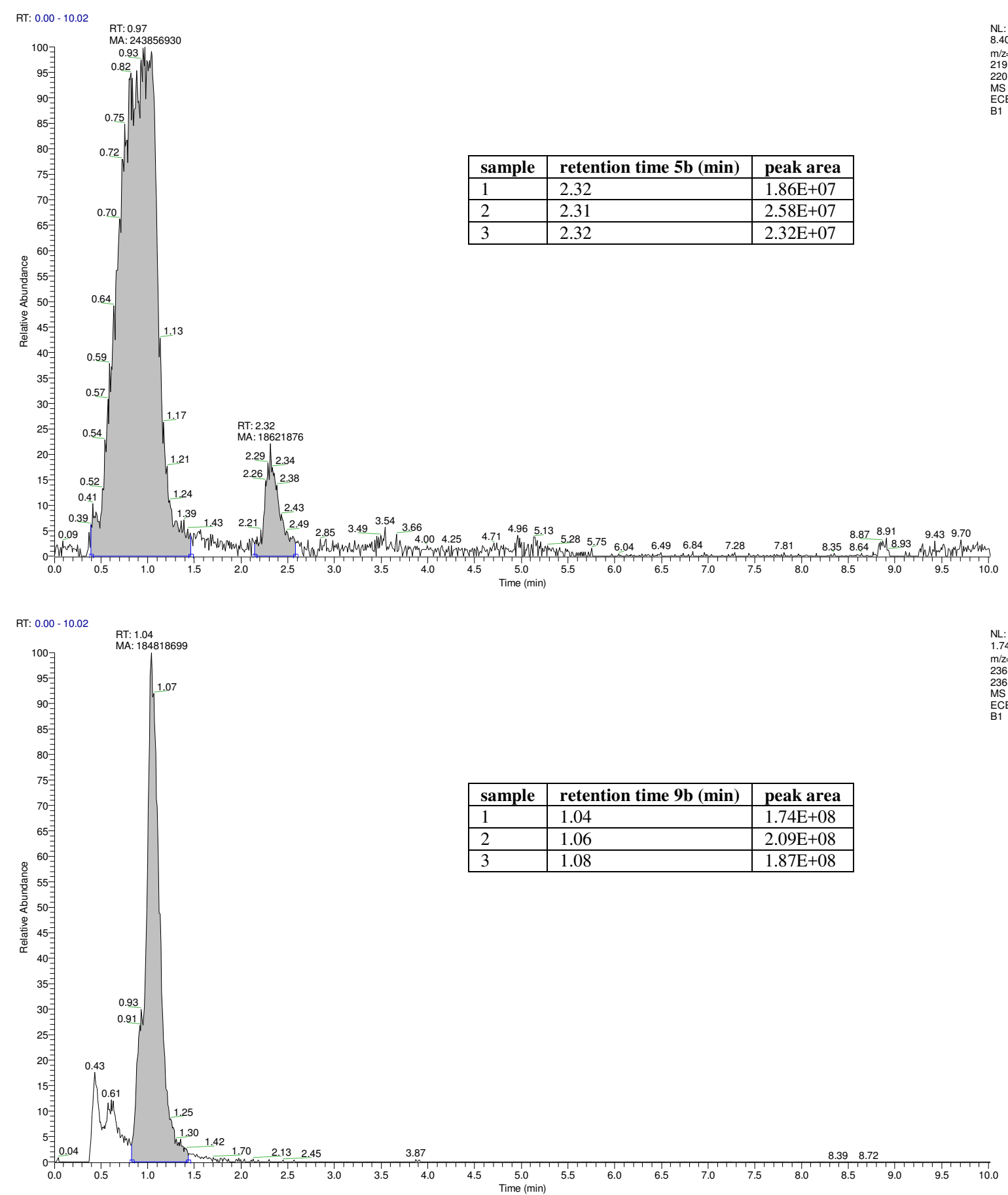


\subsection{GC-MS chromatograms of authentic samples}

\section{$N$-acetylcysteamine (1b)}
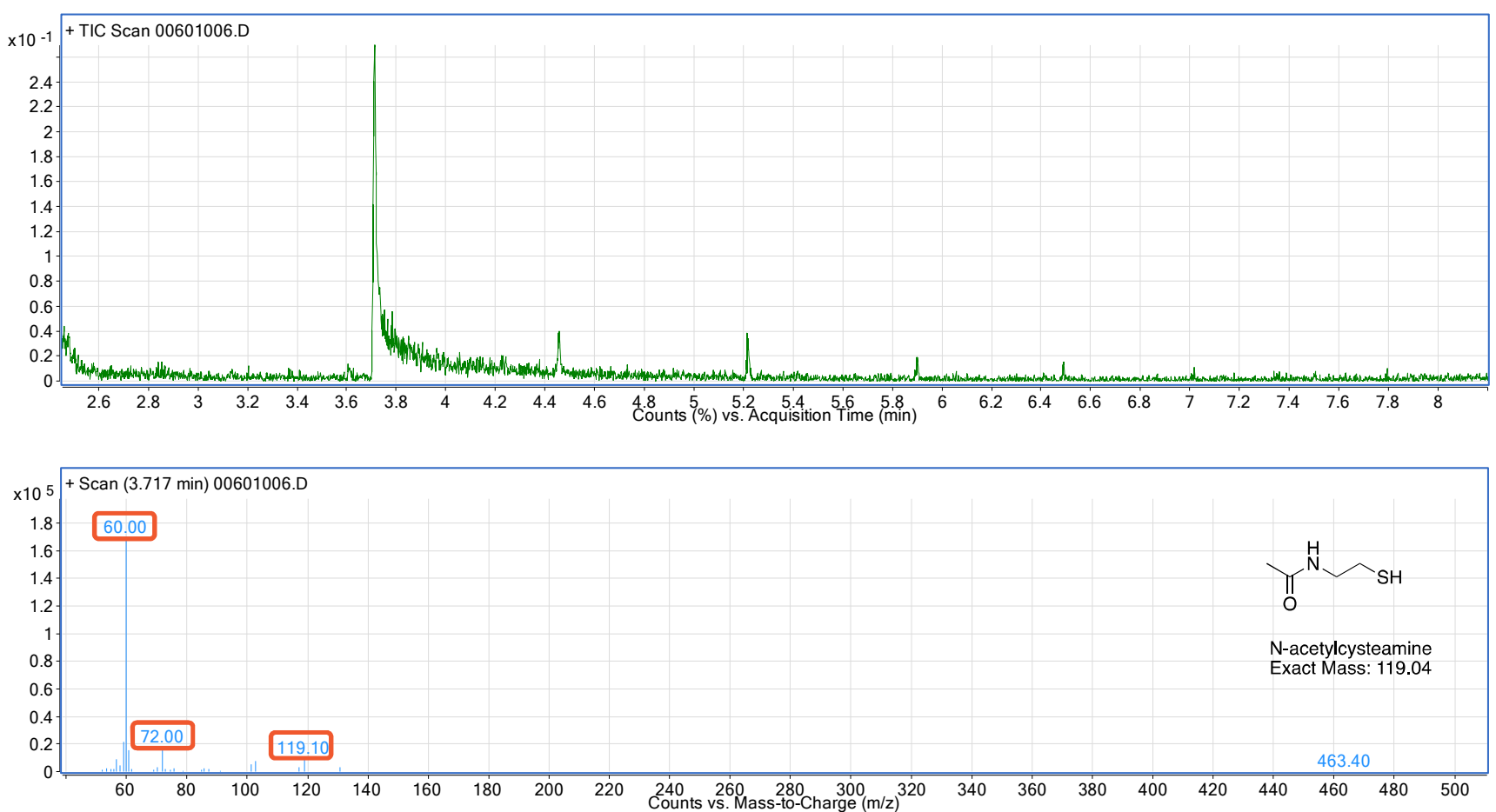

\section{$\mathrm{N}$-acetylcysteamine (1b) after derivatization}
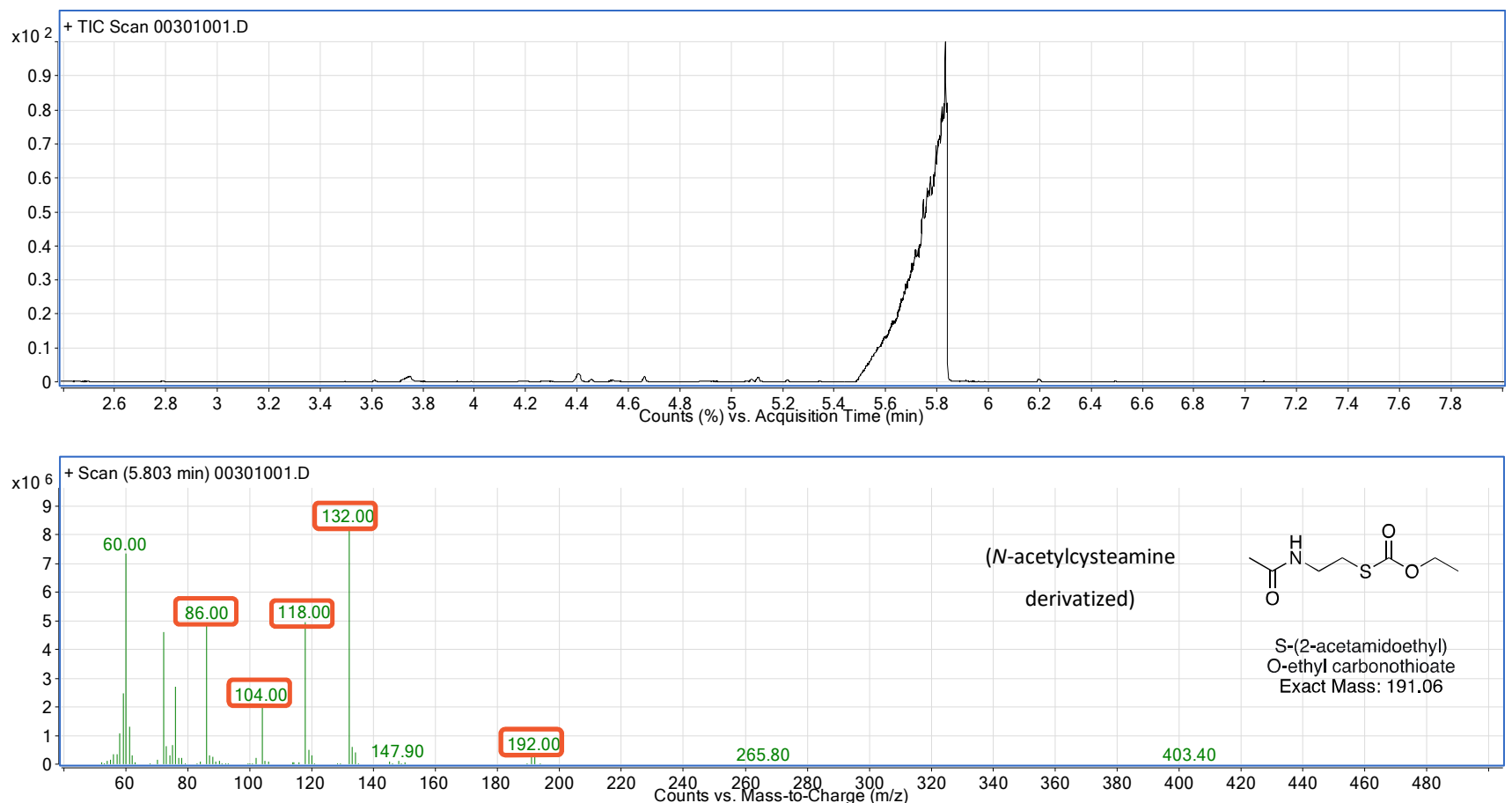


\subsection{GC-MS chromatograms of the network after thioester formation}

Table S-3, Entry 1
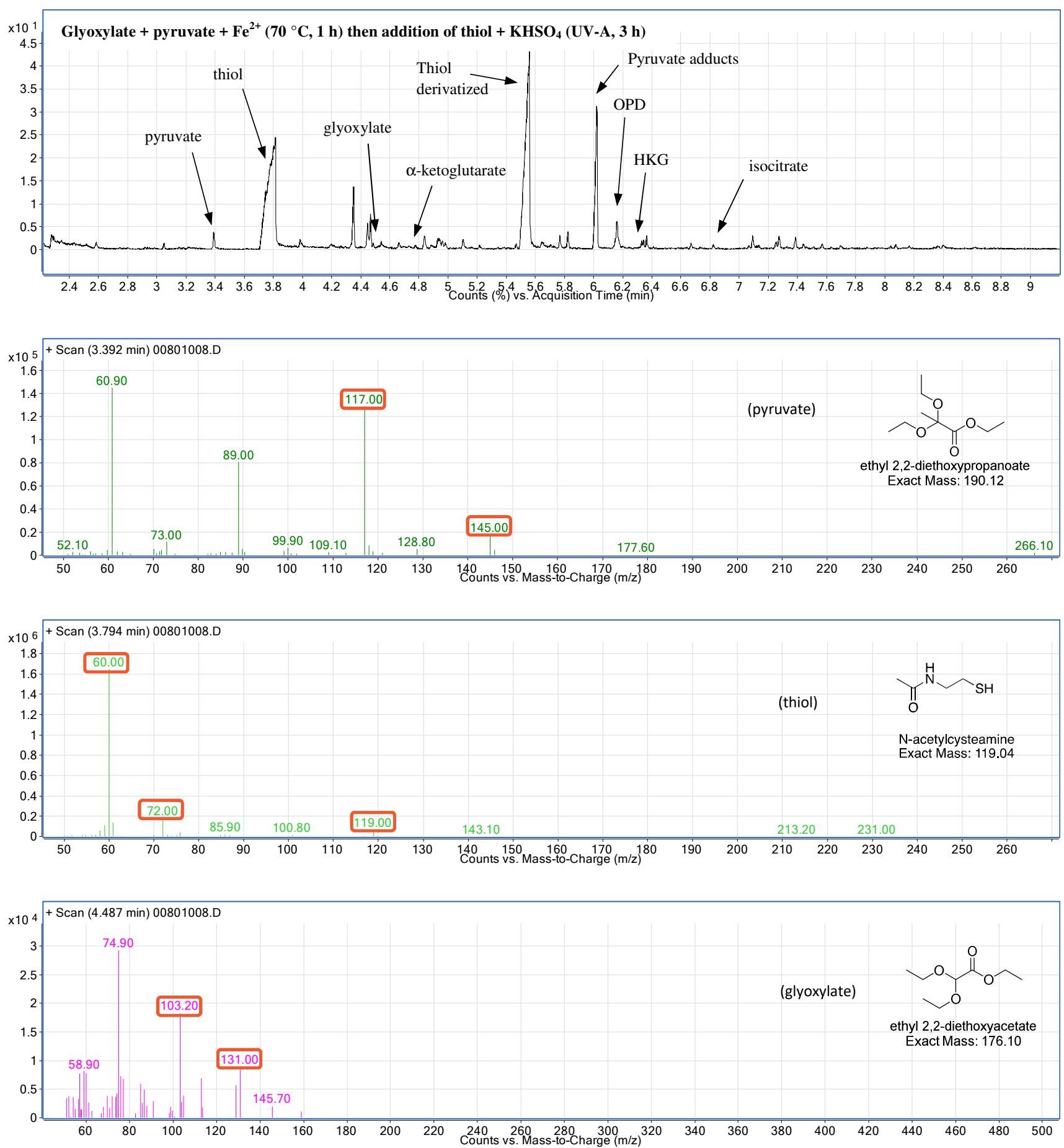

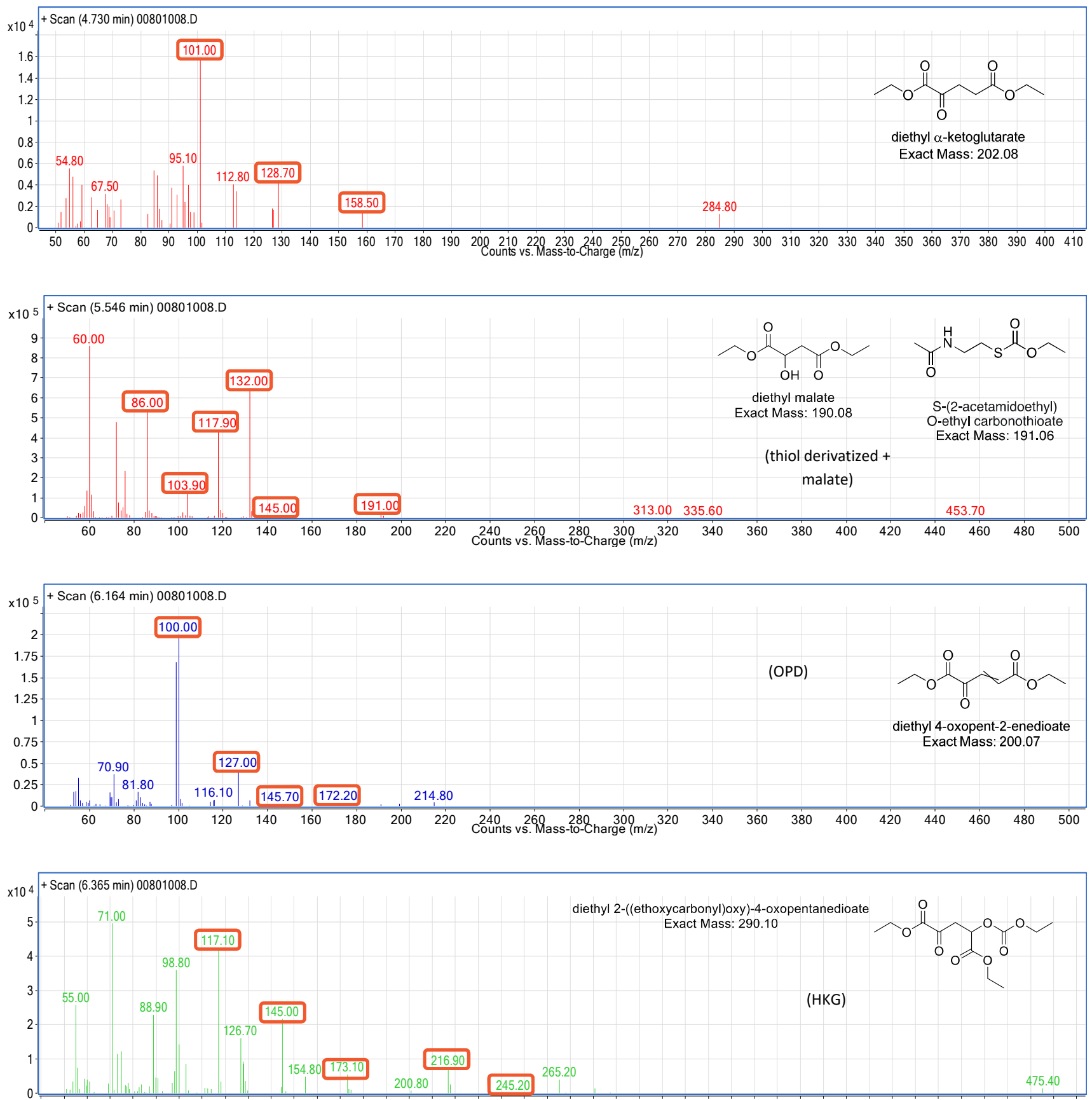

5060708090100110120130140150160170180190200210220230240250260270280290300310320330340350360370380390400410420430440450460470480

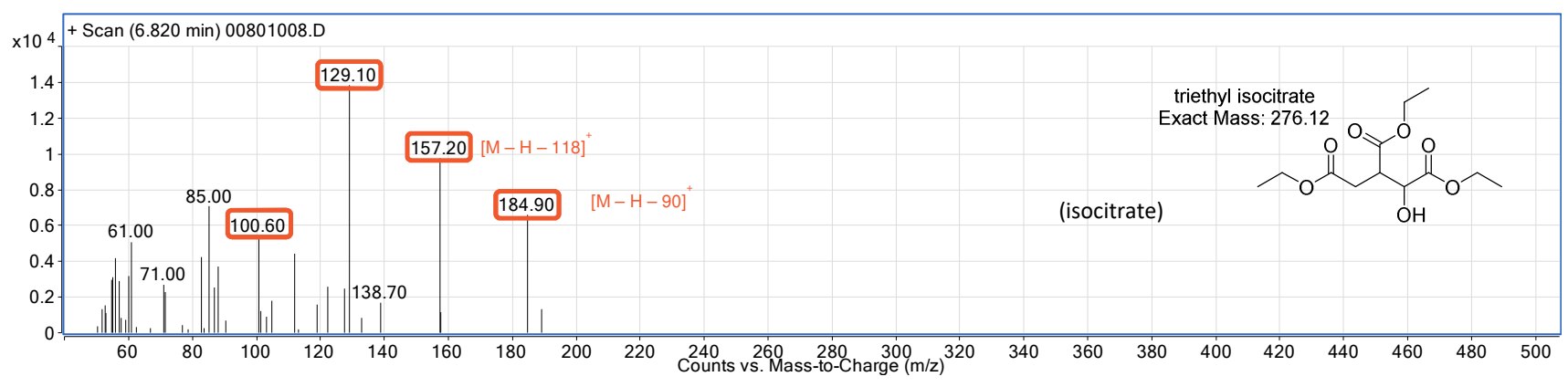


Table S-3, Entry 2
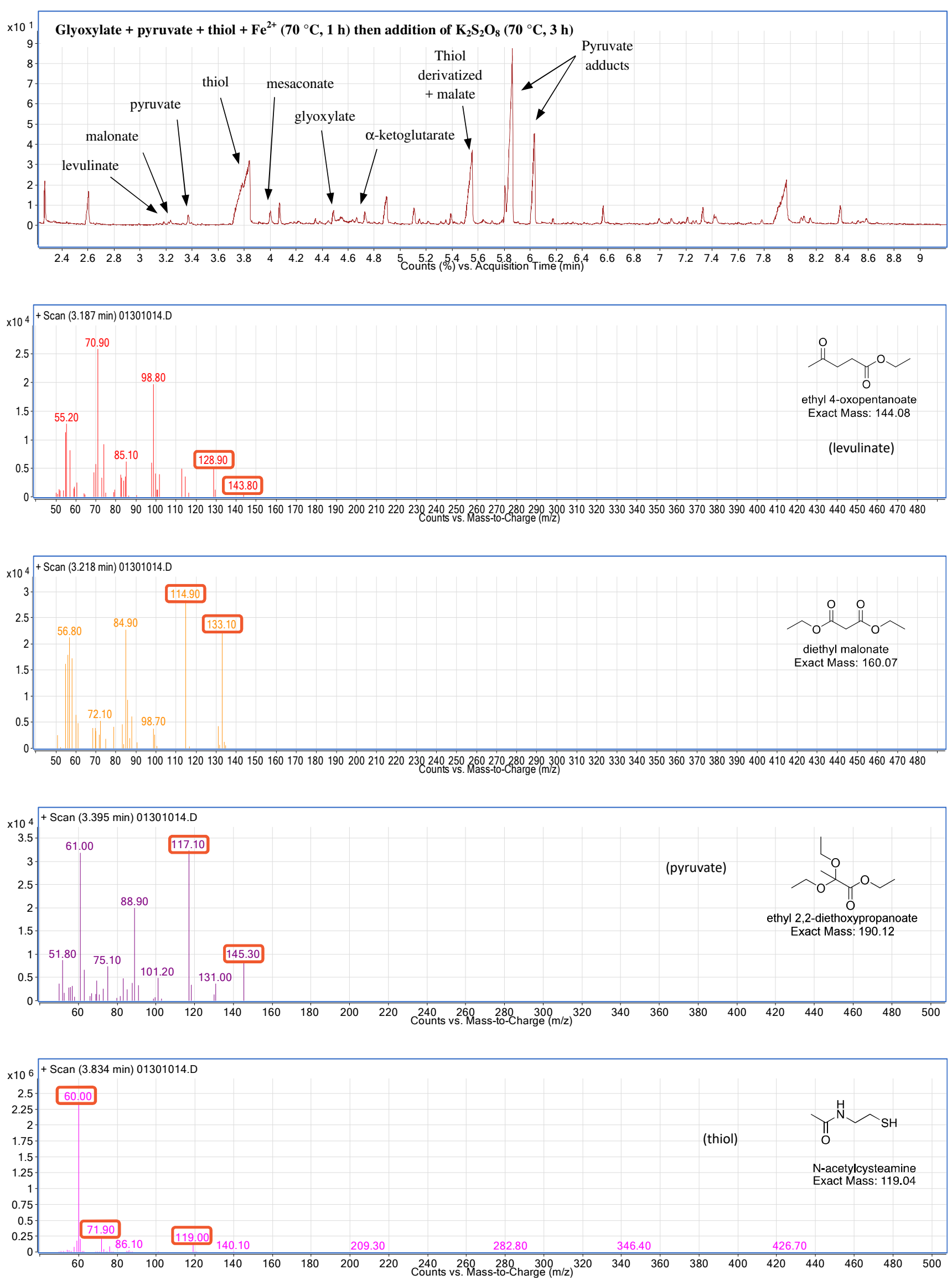


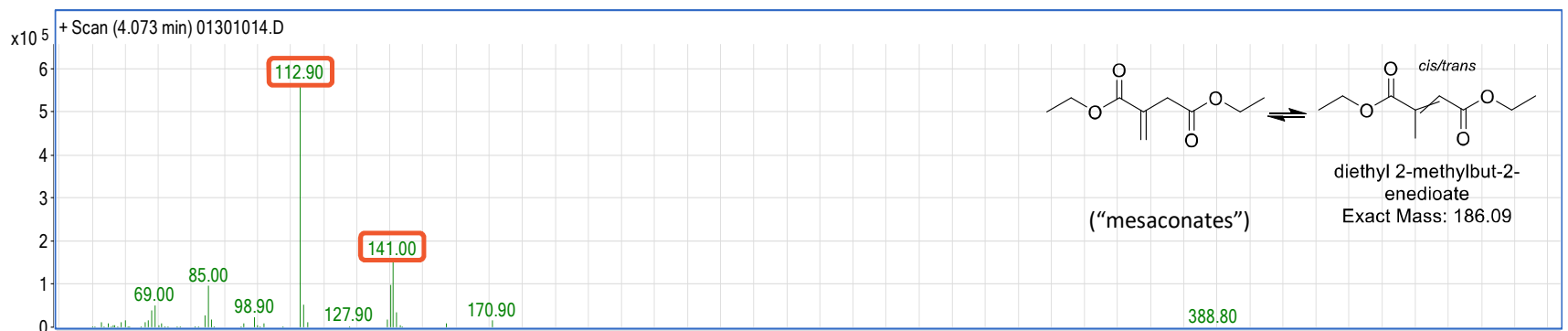

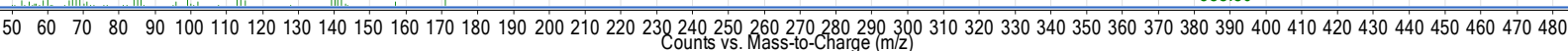
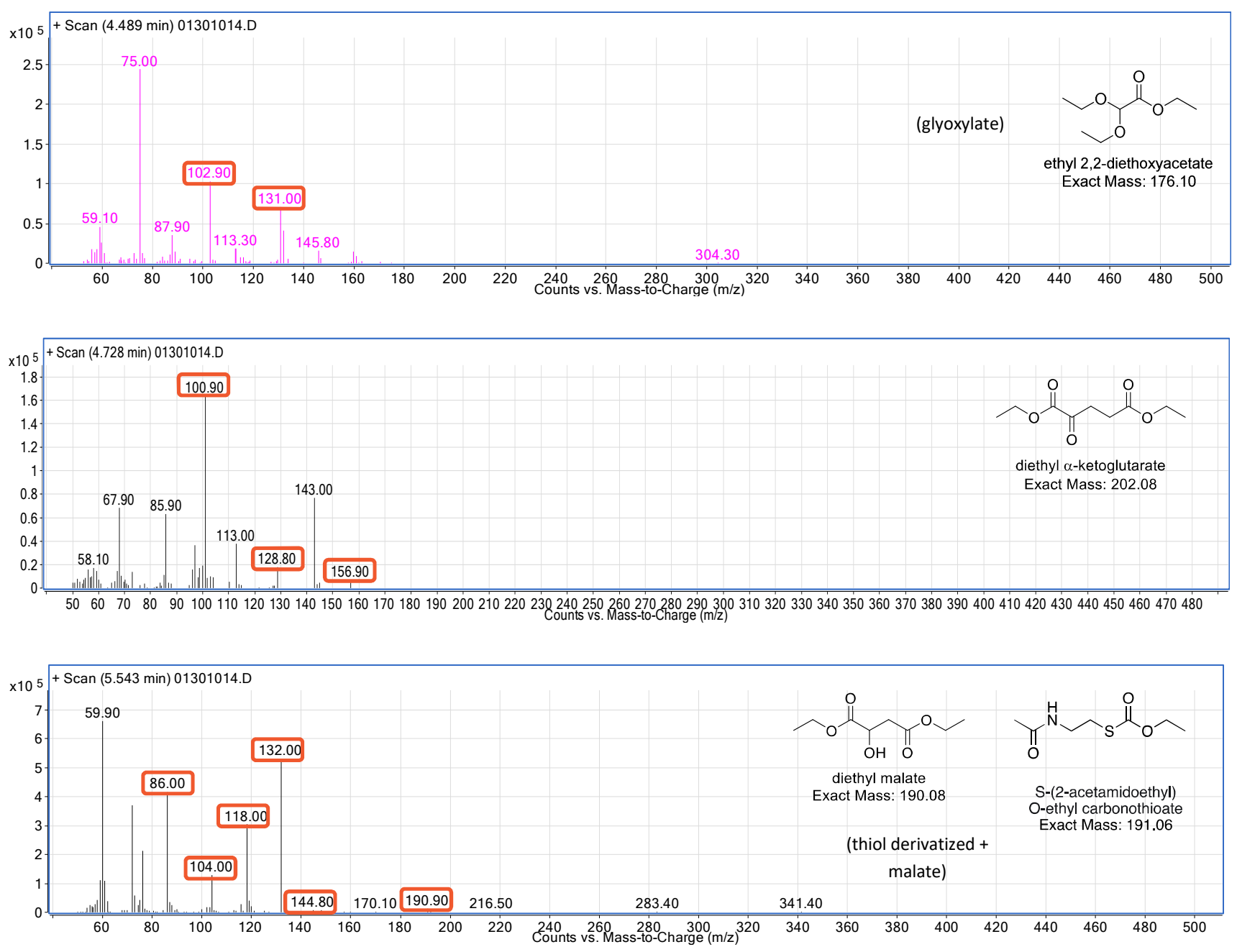
Table S-3, Entry 3
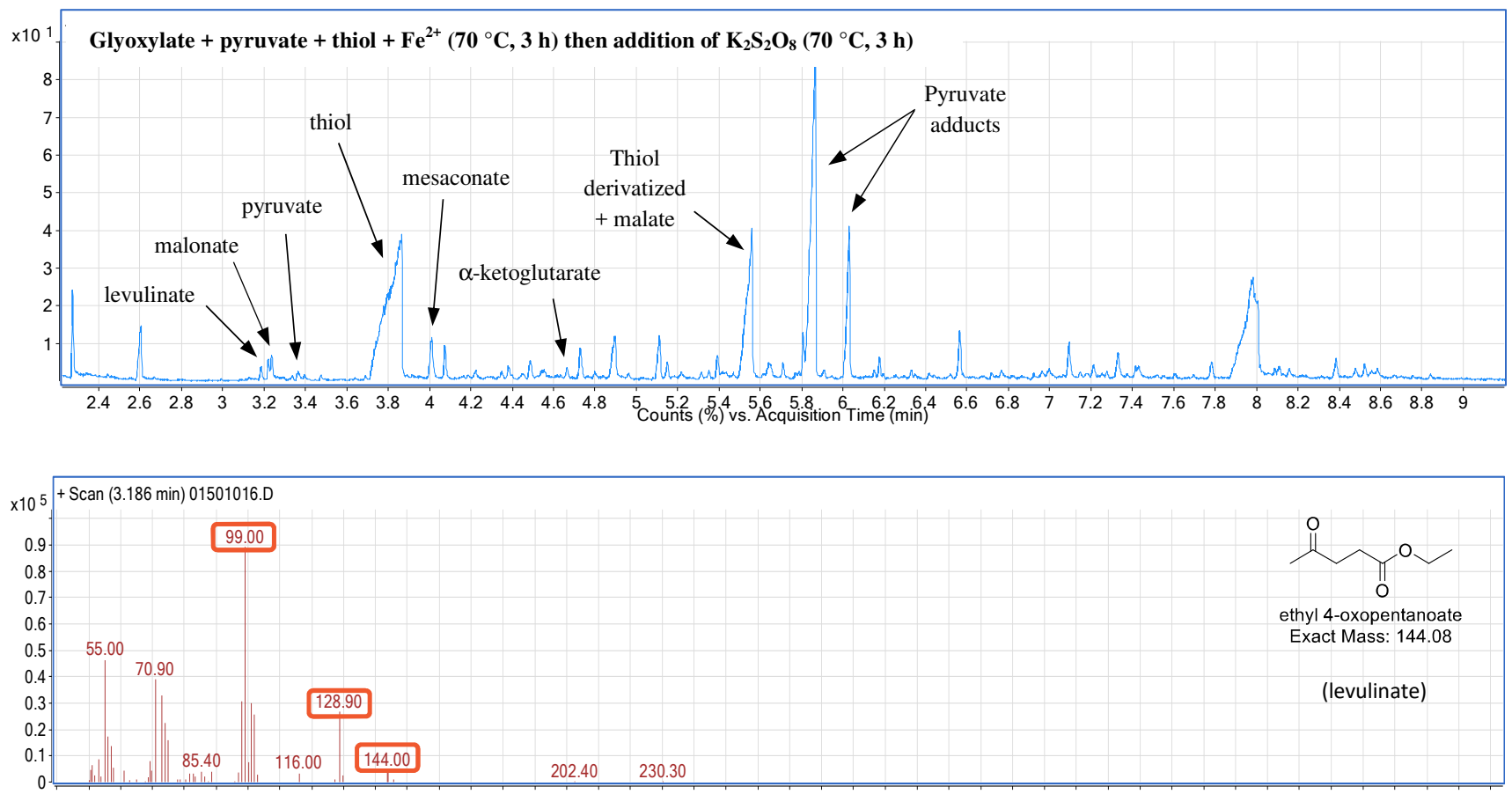

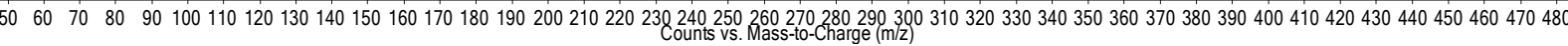

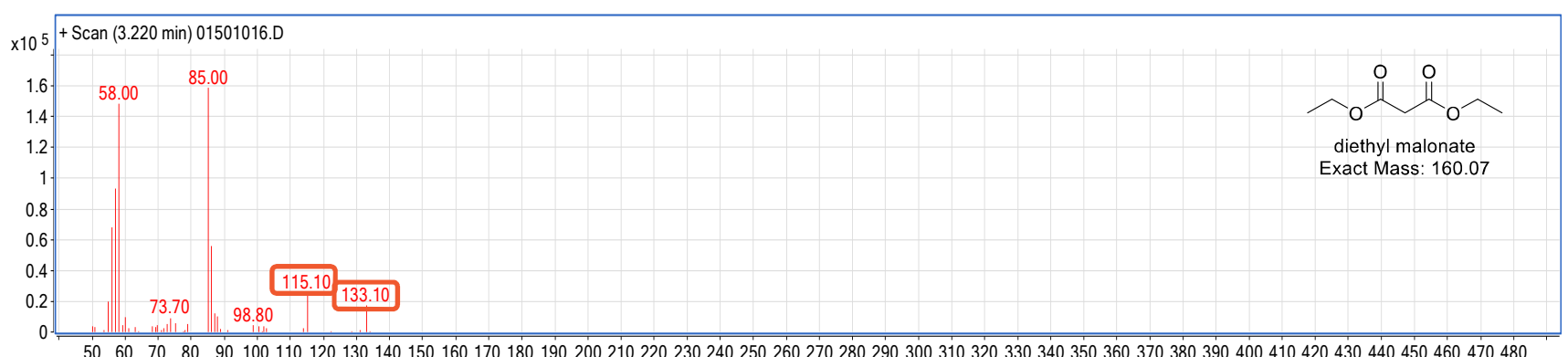

$5060708090100110120130140150160170180190200210220230240250 \begin{aligned} & 660270 \\ & \text { Counts vs. Wass-to-Charge } 2903300310320330340350360370380390400410420430440450460470480\end{aligned}$
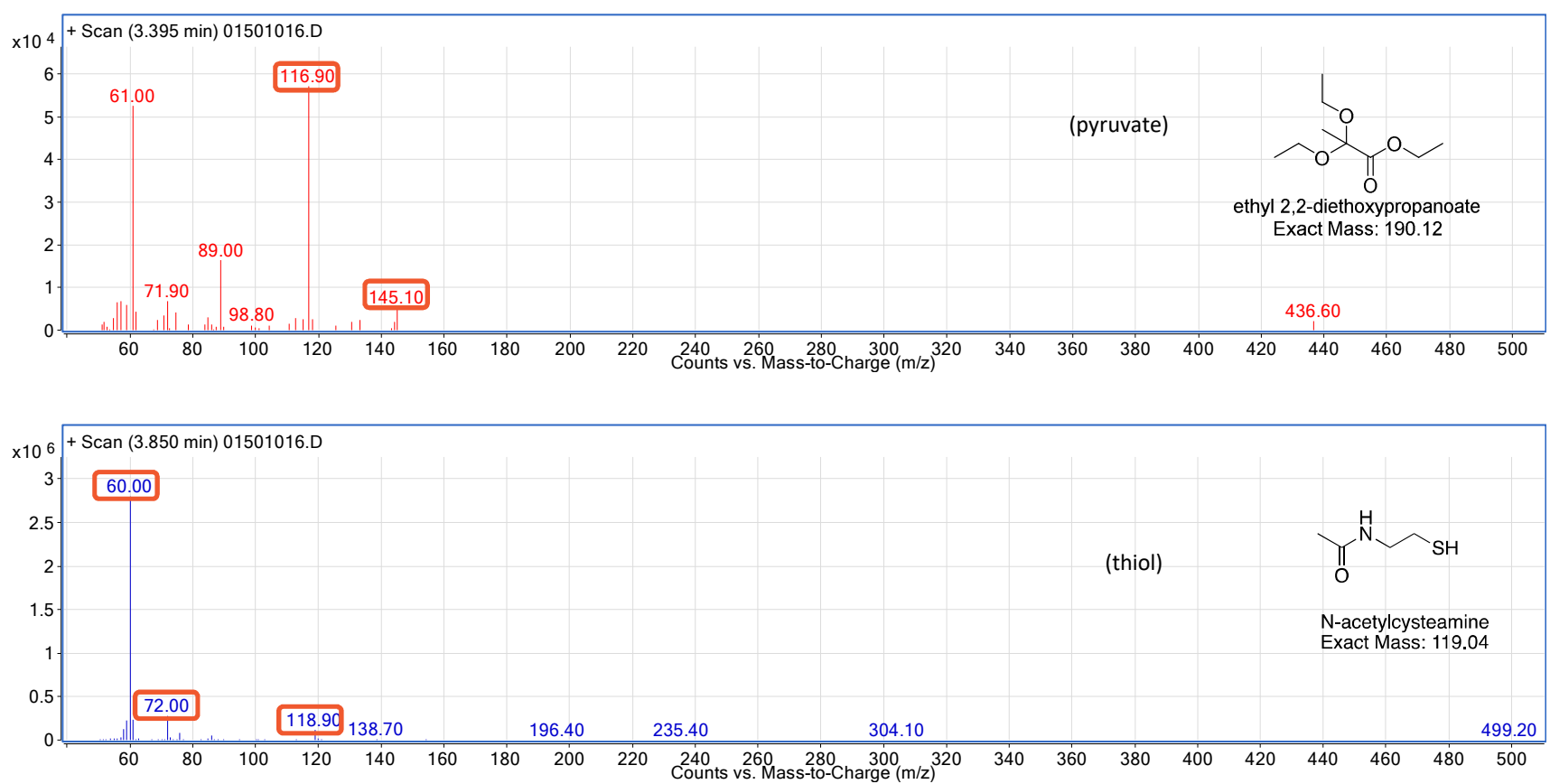


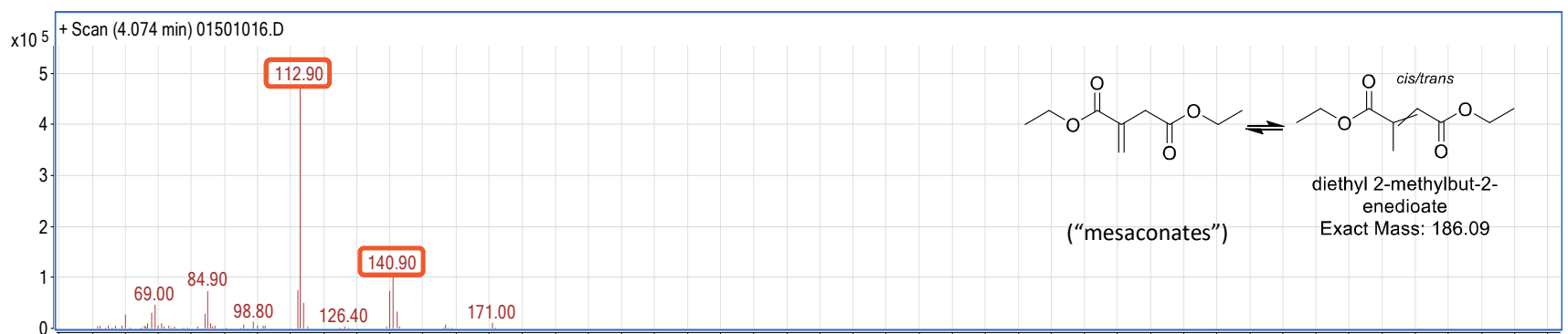

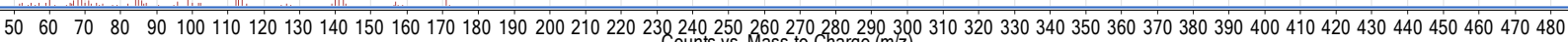

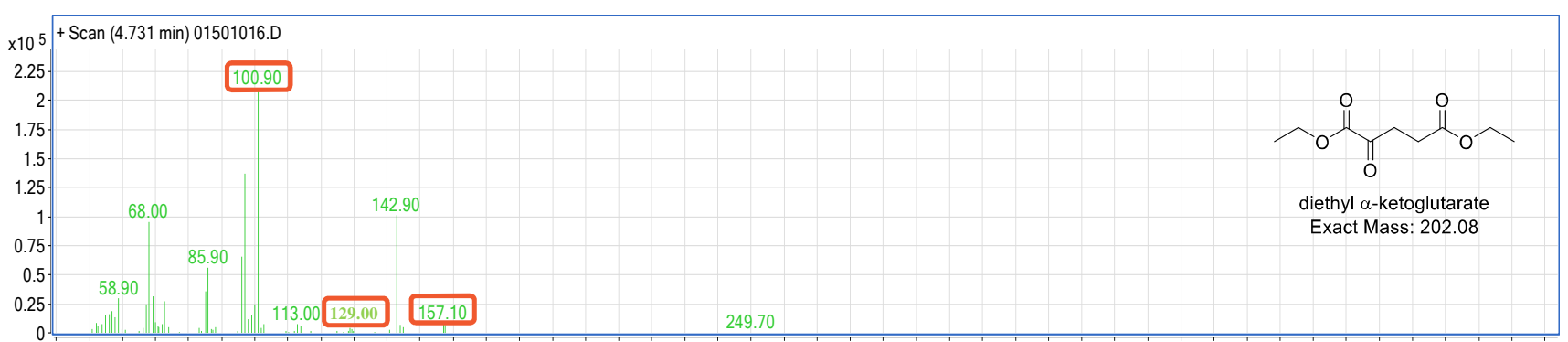

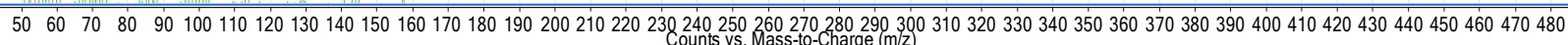

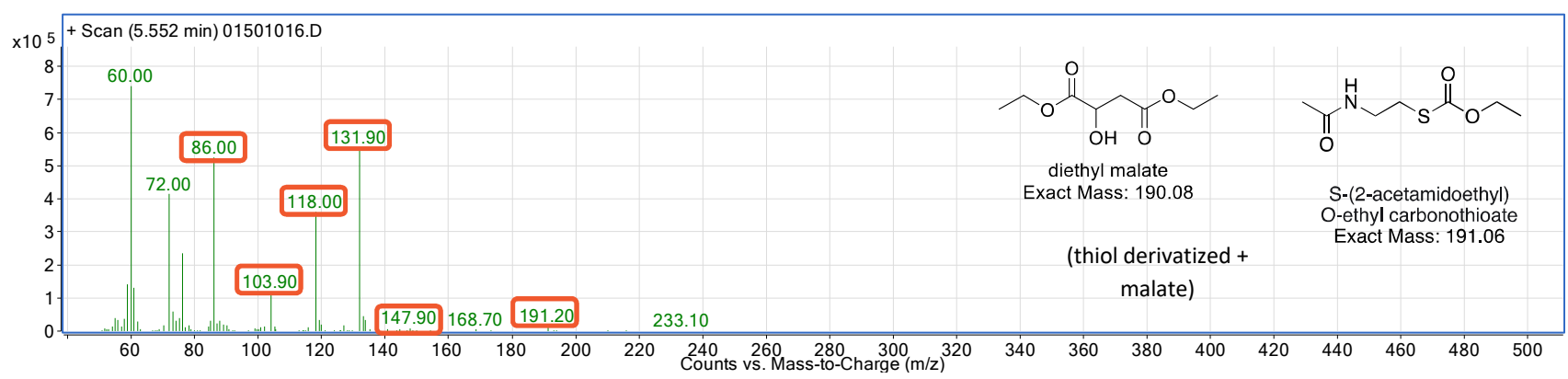




\section{Supporting references}

1. Muchowska, K. B. et al. Metals promote sequences of the reverse Krebs cycle. Nat. Ecol. Evol. 1, 1716-1721 (2017).

2. Varma, S. J., Muchowska, K. B., Chatelain, P. \& Moran, J. Native iron reduces CO2 to intermediates and end-products of the acetyl CoA pathway. Nat. Ecol. Evol. 2, 1019-1024 (2018).

3. Muchowska, K. B., Varma, S. J. \& Moran, J. Synthesis and breakdown of universal metabolic precursors promoted by iron. Nature 569, 104-107 (2019).

4. Shewring, J. R. et al. Multimodal Probes: Superresolution and Transmission Electron Microscopy Imaging of Mitochondria, and Oxygen Mapping of Cells, Using Small-Molecule Ir(III) Luminescent Complexes. Inorg. Chem. 56, 15259-15270 (2017).

5. Fujimoto, N., Nakahodo, T. \& Fujihara, H. Synthesis of Anionic Sulfonate-functionalized Conducting Polymer Nanotubes and Selective Confinement of Cationic Gold Nanoparticles in Their Inner Cavities via Electrostatic Interaction. Chem. Lett. 42, 1394-1396 (2013).

6. Field, L., Owen, T. C., Crenshaw, R. R. \& Bryan, A. W. Organic Disulfides and Related Substances. IV. Thiolsulfonates and Disulfides Containing 2-Aminoethyl Moieties. J. Am. Chem. Soc. 83, 4414-4417 (1961).

7. Guntaka, N. S., Healy, A. R., Crawford, J. M., Herzon, S. B. \& Bruner, S. D. Structure and Functional Analysis of $\mathrm{ClbQ}$, an Unusual Intermediate-Releasing Thioesterase from the Colibactin Biosynthetic Pathway. ACS Chem. Biol. 12, 2598-2608 (2017).

8. Keddie, D. J., Grande, J. B., Gonzaga, F., Brook, M. A. \& Dargaville, T. R. Amphiphilic silicone architectures via anaerobic Thiol-Ene chemistry. Org. Lett. 13, 6006-6009 (2011).

9. Hagen, A., Poust, S., Katz, L. \& Keasling, J. D. Producing adipic acid and related compounds using hybrid polyketide synthases. 1-53 (2017).

10. Lowell, A. N. et al. Chemoenzymatic Total Synthesis and Structural Diversification of Tylactone-Based Macrolide Antibiotics through Late-Stage Polyketide Assembly, Tailoring, and C-H Functionalization. J. Am. Chem. Soc. 139, 7913-7920 (2017).

11. Palyam, N. \& Majewski, M. Organocatalytic syn-Aldol Reactions of Dioxanones with (S)Isoserinal Hydrate: Synthesis of L-Deoxymannojirimycin and L-Deoxyidonojirimycin. J. Org. Chem. 74, 4390-4392 (2009). 
12. Blaquiere, N., Shore, D. G., Rousseaux, S. \& Fagnou, K. Decarboxylative ketone aldol reactions: Development and mechanistic evaluation under metal-free conditions. J. Org. Chem. 74, 6190-6198 (2009). 
